Universidade de São Paulo

Instituto de Astronomia, Geofísica e Ciências Atmosféricas - IAG

Departamento de Geofísica

Dissertação de Mestrado

\title{
ANÁLISE COMPARATIVA DE APROXIMAÇÕES NÃO- HIPERBÓLICAS DOS TEMPOS DE TRÂNSITO DE DADOS SÍSMICOS MULTICOMPONENTE UTILIZANDO TECNOLOGIA OBN
}

\author{
Aluno \\ Nelson Ricardo Coelho Flores Zuniga \\ Orientador \\ Prof. Dr. Eder Cassola Molina \\ Coorientador \\ Prof. Dr. Renato Luiz Prado
}

São Paulo

2017 

Nelson Ricardo Coelho Flores Zuniga

\title{
ANÁLISE COMPARATIVA DE APROXIMAÇÕES NÃO- HIPERBÓLICAS DOS TEMPOS DE TRÂNSITO DE DADOS SÍSMICOS MULTICOMPONENTE UTILIZANDO TECNOLOGIA OBN
}

\author{
Dissertação apresentada ao Instituto de \\ Astronomia, Geofísica e Ciências \\ Atmosféricas da Universidade de São \\ Paulo como parte dos requisitos para \\ obtenção do título de Mestre em \\ Ciências na área de Geofísica.
}

"Versão Corrigida. O original encontra-se disponível na Unidade."

São Paulo 



\section{SUMÁRIO}

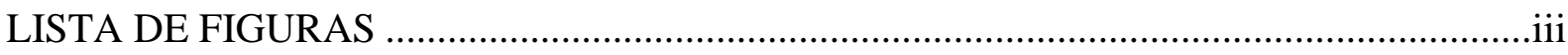

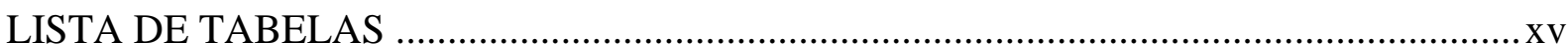

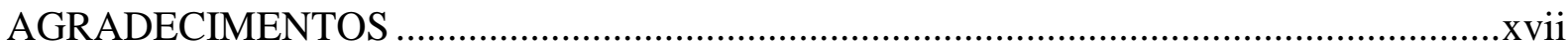

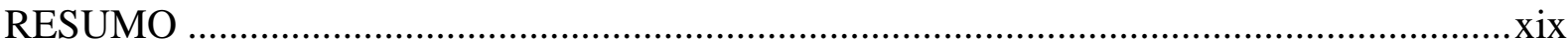

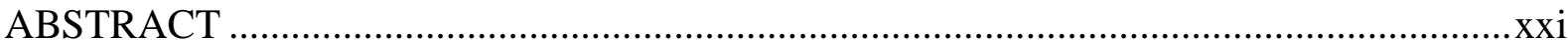

1 INTRODUÇÃ

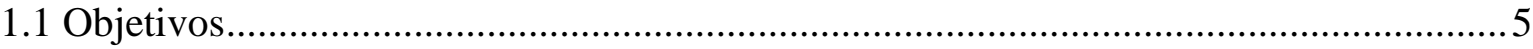

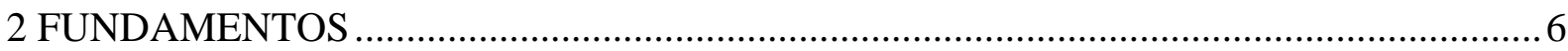

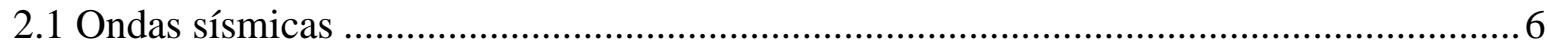

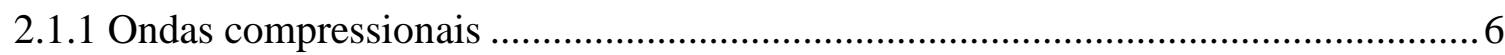

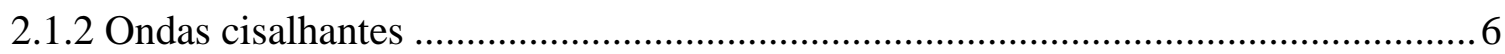

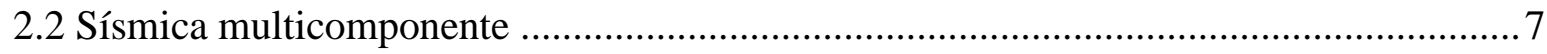

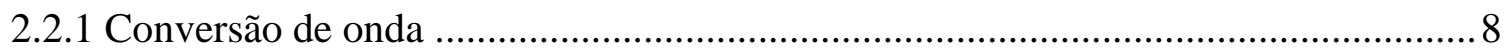

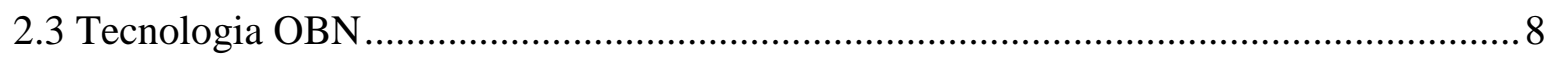

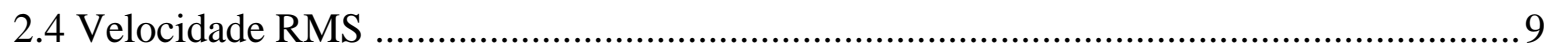

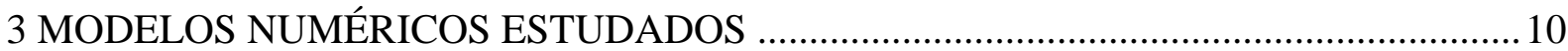

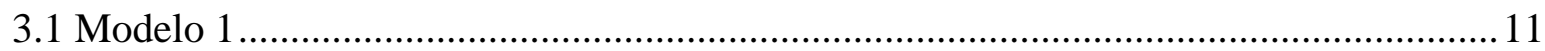

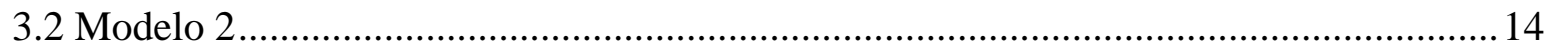

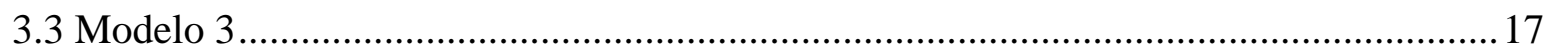

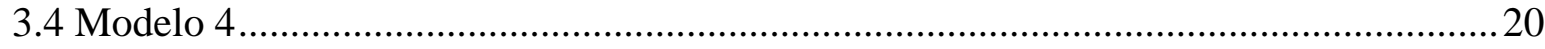

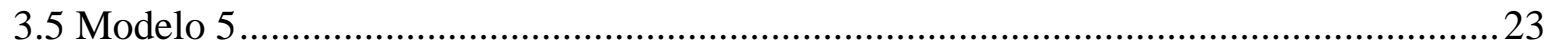

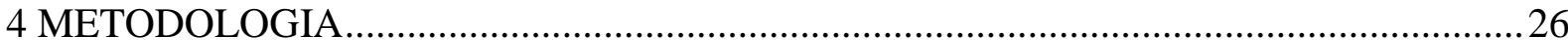

4.1 Expressões não-hiperbólicas para análise de velocidades ..........................................26

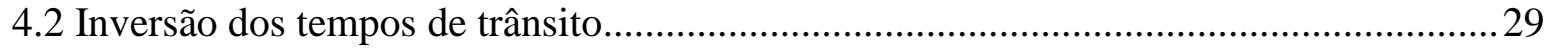

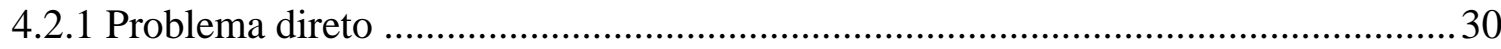


4.2.2 Análise de função objetivo .....

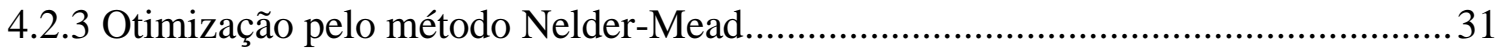

4.3 Análise do residual das curvas de tempos de trânsito .................................................... 32

4.4 Análise da eficiência das expressões não-hiperbólicas ................................................. 33

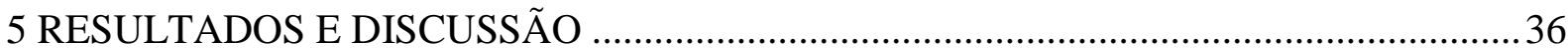

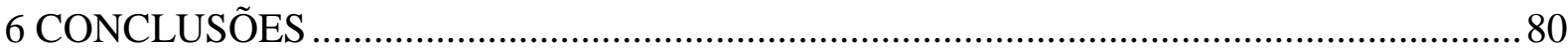

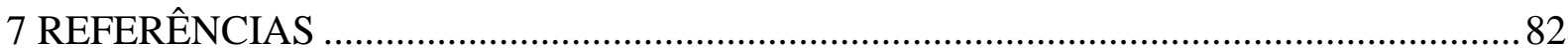




\section{LISTA DE FIGURAS}

Figura 1: Deformação elástica e movimentação de partículas associada à passagem de ondas P. (Kearey, Brooks e Hill, 2002).

Figura 2: Deformação elástica e movimentação de partículas associada à passagem de ondas S. (Kearey, Brooks e Hill, 2002).

Figura 3: Representação das componentes registradas em um sistema de coordenadas cartesianas (XYZ). A estrela vermelha representa as fontes e o triângulo azul representa os receptores.

Figura 4: (a) Reflexão de onda no ponto médio comum (CMP); (b) Reflexão de onda PSv no ponto de conversão comum (CCP)

Figura 5: Reflexão de onda PP e de onda PS com a utilização de tecnologia OBN.

Figura 6: Esquematização demonstrando como a velocidade de NMO e a de RMS diferem-se mais com o aumento do afastamento. Linhas sólidas representam as velocidades intervalares e as pontilhadas representam as velocidades RMS.

Figura 7: Perfis de velocidade de onda $\mathrm{P}$, velocidade de onda $\mathrm{S}$ e razão $\mathrm{Vp} / \mathrm{Vs}$ com relação à profundidade do Modelo 1.

Figura 8: Esquematização de traçado de raios do evento de reflexão PP do Modelo 1........... 12

Figura 9: Esquematização de traçado de raios do evento de reflexão PS do Modelo 1........... 12

Figura 10: Curva de tempos de trânsito do evento de reflexão PP do Modelo 1..................... 13

Figura 11: Curva de tempos de trânsito do evento de reflexão PS do Modelo 1..................... 13

Figura 12: Perfis de velocidade de onda $\mathrm{P}$, velocidade de onda $\mathrm{S}$ e razão $\mathrm{Vp} / \mathrm{Vs}$ com relação à

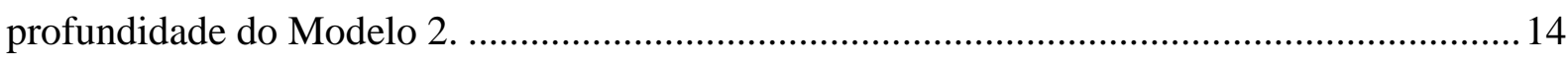

Figura 13: Esquematização de traçado de raios do evento de reflexão PP do Modelo 2......... 15

Figura 14: Esquematização de traçado de raios do evento de reflexão PS do Modelo 2......... 15

Figura 15: Curva de tempos de trânsito do evento de reflexão PP do Modelo 2. .................... 16

Figura 16: Curva de tempos de trânsito do evento de reflexão PS do Modelo 2. ..................... 16

Figura 17: Perfis de velocidade de onda $\mathrm{P}$, velocidade de onda $\mathrm{S}$ e razão $\mathrm{Vp} / \mathrm{Vs}$ com relação à profundidade do Modelo 3. 
Figura 18: Esquematização de traçado de raios do evento de reflexão PP do Modelo 3......... 18

Figura 19: Esquematização de traçado de raios do evento de reflexão PS do Modelo 3......... 18

Figura 20: Curva de tempos de trânsito do evento de reflexão PP do Modelo 3..................... 19

Figura 21: Curva de tempos de trânsito do evento de reflexão PS do Modelo 3.

Figura 22: Perfis de velocidade de onda $\mathrm{P}$, velocidade de onda $\mathrm{S}$ e razão $\mathrm{Vp} / \mathrm{Vs}$ com relação à profundidade do Modelo 4.

Figura 23: Esquematização de traçado de raios do evento de reflexão PP do Modelo 4.........21

Figura 24: Esquematização de traçado de raios do evento de reflexão PS do Modelo 4.........21

Figura 25: Curva de tempos de trânsito do evento de reflexão PP do Modelo 4. .....................22

Figura 26: Curva de tempos de trânsito do evento de reflexão PS do Modelo 4.

Figura 27: Perfis de velocidade de onda $\mathrm{P}$, velocidade de onda $\mathrm{S}$ e razão $\mathrm{Vp} / \mathrm{Vs}$ com relação à profundidade do Modelo 5.

Figura 28: Esquematização de traçado de raios do evento de reflexão PP do Modelo 5......... 24

Figura 29: Esquematização de traçado de raios do evento de reflexão PS do Modelo 5......... 24

Figura 30: Curva de tempos de trânsito do evento de reflexão PP do Modelo 5. ....................25

Figura 31: Curva de tempos de trânsito do evento de reflexão PS do Modelo 5. 25

Figura 32: Mapas de dispersão sobrepostos ao mapa residual de função objetivo mostrando a complexidade da aproximação multiparamétrica de Malovichko (1978) para um evento de reflexão de onda PP do Modelo 1. As dispersões em vermelho representam a região de mínimo global da função. 38

Figura 33: Mapas de dispersão sobrepostos ao mapa residual de função objetivo mostrando a complexidade da aproximação multiparamétrica de Malovichko (1978) para um evento de reflexão de onda PS do Modelo 1. As dispersões em vermelho representam a região de mínimo global da função. 38

Figura 34: Mapas de dispersão sobrepostos ao mapa residual de função objetivo mostrando a complexidade da aproximação multiparamétrica de Alkhalifah e Tsvankin (1995) para um evento de reflexão de onda PP do Modelo 1. As dispersões em vermelho representam a região de mínimo global da função. 
Figura 35: Mapas de dispersão sobrepostos ao mapa residual de função objetivo mostrando a complexidade da aproximação multiparamétrica de Alkhalifah e Tsvankin (1995) para um evento de reflexão de onda PS do Modelo 1. As dispersões em vermelho representam a região de mínimo global da função.

Figura 36: Mapas de dispersão sobrepostos ao mapa residual de função objetivo mostrando a complexidade da aproximação multiparamétrica de Ursin e Stovas (2006) para um evento de reflexão de onda PP do Modelo 1. As dispersões em vermelho representam a região de mínimo global da função.

Figura 37: Mapas de dispersão sobrepostos ao mapa residual de função objetivo mostrando a complexidade da aproximação multiparamétrica de Ursin e Stovas (2006) para um evento de reflexão de onda PS do Modelo 1. As dispersões em vermelho representam a região de mínimo global da função.

Figura 38: Mapas de dispersão sobrepostos ao mapa residual de função objetivo mostrando a complexidade da aproximação multiparamétrica de Blias (2009) para um evento de reflexão de onda PP do Modelo 1. As dispersões em vermelho representam a região de mínimo global da função.

Figura 39: Mapas de dispersão sobrepostos ao mapa residual de função objetivo mostrando a complexidade da aproximação multiparamétrica de Blias (2009) para um evento de reflexão de onda PS do Modelo 1. As dispersões em vermelho representam a região de mínimo global da função.

Figura 40: Mapas de dispersão sobrepostos ao mapa residual de função objetivo mostrando a complexidade da aproximação multiparamétrica de Muir e Dellinger (1985) para um evento de reflexão de onda PP do Modelo 1. As dispersões em vermelho representam a região de mínimo global da função e as dispersões em azul representam a região de mínimo local. ..... 42 Figura 41: Mapas de dispersão sobrepostos ao mapa residual de função objetivo mostrando a complexidade da aproximação multiparamétrica de Muir e Dellinger (1985) para um evento de reflexão de onda PS do Modelo 1. As dispersões em vermelho representam a região de mínimo global da função e as dispersões em azul representam a região de mínimo local. ..... 42 Figura 42: Mapas de dispersão sobrepostos ao mapa residual de função objetivo mostrando a complexidade da aproximação multiparamétrica de Li (2001) para um evento de reflexão de 
onda PP do Modelo 1. As dispersões em vermelho representam a região de mínimo global da função e as dispersões em azul representam a região de mínimo local

Figura 43: Mapas de dispersão sobrepostos ao mapa residual de função objetivo mostrando a complexidade da aproximação multiparamétrica de Li (2001) para um evento de reflexão de onda PS do Modelo 1. As dispersões em vermelho representam a região de mínimo global da função e as dispersões em azul representam a região de mínimo local.

Figura 44: Mapas de dispersão sobrepostos ao mapa residual de função objetivo mostrando a complexidade da aproximação multiparamétrica de Malovichko (1978) para um evento de reflexão de onda PP do Modelo 2. As dispersões em vermelho representam a região de mínimo global da função.

Figura 45: Mapas de dispersão sobrepostos ao mapa residual de função objetivo mostrando a complexidade da aproximação multiparamétrica de Malovichko (1978) para um evento de reflexão de onda PS do Modelo 2. As dispersões em vermelho representam a região de mínimo global da função.

Figura 46: Mapas de dispersão sobrepostos ao mapa residual de função objetivo mostrando a complexidade da aproximação multiparamétrica de Alkhalifah e Tsvankin (1995) para um evento de reflexão de onda PP do Modelo 2. As dispersões em vermelho representam a região de mínimo global da função.

Figura 47: Mapas de dispersão sobrepostos ao mapa residual de função objetivo mostrando a complexidade da aproximação multiparamétrica de Alkhalifah e Tsvankin (1995) para um evento de reflexão de onda PS do Modelo 2. As dispersões em vermelho representam a região de mínimo global da função.

Figura 48: Mapas de dispersão sobrepostos ao mapa residual de função objetivo mostrando a complexidade da aproximação multiparamétrica de Ursin e Stovas (2006) para um evento de reflexão de onda PP do Modelo 2. As dispersões em vermelho representam a região de mínimo global da função.

Figura 49: Mapas de dispersão sobrepostos ao mapa residual de função objetivo mostrando a complexidade da aproximação multiparamétrica de Ursin e Stovas (2006) para um evento de reflexão de onda PS do Modelo 2. As dispersões em vermelho representam a região de mínimo global da função. 46 
Figura 50: Mapas de dispersão sobrepostos ao mapa residual de função objetivo mostrando a complexidade da aproximação multiparamétrica de Blias (2009) para um evento de reflexão de onda PP do Modelo 2. As dispersões em vermelho representam a região de mínimo global da função.

Figura 51: Mapas de dispersão sobrepostos ao mapa residual de função objetivo mostrando a complexidade da aproximação multiparamétrica de Blias (2009) para um evento de reflexão de onda PS do Modelo 2. As dispersões em vermelho representam a região de mínimo global da função. 47

Figura 52: Mapas de dispersão sobrepostos ao mapa residual de função objetivo mostrando a complexidade da aproximação multiparamétrica de Muir e Dellinger (1985) para um evento de reflexão de onda PP do Modelo 2. As dispersões em vermelho representam a região de mínimo global da função e as dispersões em azul representam a região de mínimo local. ......48

Figura 53: Mapas de dispersão sobrepostos ao mapa residual de função objetivo mostrando a complexidade da aproximação multiparamétrica de Muir e Dellinger (1985) para um evento de reflexão de onda PS do Modelo 2. As dispersões em vermelho representam a região de mínimo global da função e as dispersões em azul representam a região de mínimo local. .....48

Figura 54: Mapas de dispersão sobrepostos ao mapa residual de função objetivo mostrando a complexidade da aproximação multiparamétrica de Li (2001) para um evento de reflexão de onda PP do Modelo 2. As dispersões em vermelho representam a região de mínimo global da função e as dispersões em azul representam a região de mínimo local.

Figura 55: Mapas de dispersão sobrepostos ao mapa residual de função objetivo mostrando a complexidade da aproximação multiparamétrica de Li (2001) para um evento de reflexão de onda PS do Modelo 2. As dispersões em vermelho representam a região de mínimo global da função e as dispersões em azul representam a região de mínimo local.

Figura 56: Mapas de dispersão sobrepostos ao mapa residual de função objetivo mostrando a complexidade da aproximação multiparamétrica de Malovichko (1978) para um evento de reflexão de onda PP do Modelo 3. As dispersões em vermelho representam a região de mínimo global da função.

Figura 57: Mapas de dispersão sobrepostos ao mapa residual de função objetivo mostrando a complexidade da aproximação multiparamétrica de Malovichko (1978) para um evento de 
reflexão de onda PS do Modelo 3. As dispersões em vermelho representam a região de mínimo global da função.

Figura 58: Mapas de dispersão sobrepostos ao mapa residual de função objetivo mostrando a complexidade da aproximação multiparamétrica de Alkhalifah e Tsvankin (1995) para um evento de reflexão de onda PP do Modelo 3. As dispersões em vermelho representam a região de mínimo global da função.

Figura 59: Mapas de dispersão sobrepostos ao mapa residual de função objetivo mostrando a complexidade da aproximação multiparamétrica de Alkhalifah e Tsvankin (1995) para um evento de reflexão de onda PS do Modelo 3. As dispersões em vermelho representam a região de mínimo global da função.

Figura 60: Mapas de dispersão sobrepostos ao mapa residual de função objetivo mostrando a complexidade da aproximação multiparamétrica de Ursin e Stovas (2006) para um evento de reflexão de onda PP do Modelo 3. As dispersões em vermelho representam a região de mínimo global da função.

Figura 61: Mapas de dispersão sobrepostos ao mapa residual de função objetivo mostrando a complexidade da aproximação multiparamétrica de Ursin e Stovas (2006) para um evento de reflexão de onda PS do Modelo 3. As dispersões em vermelho representam a região de mínimo global da função. 52

Figura 62: Mapas de dispersão sobrepostos ao mapa residual de função objetivo mostrando a complexidade da aproximação multiparamétrica de Blias (2009) para um evento de reflexão de onda PP do Modelo 3. As dispersões em vermelho representam a região de mínimo global da função

Figura 63: Mapas de dispersão sobrepostos ao mapa residual de função objetivo mostrando a complexidade da aproximação multiparamétrica de Blias (2009) para um evento de reflexão de onda PS do Modelo 3. As dispersões em vermelho representam a região de mínimo global da função.

Figura 64: Mapas de dispersão sobrepostos ao mapa residual de função objetivo mostrando a complexidade da aproximação multiparamétrica de Muir e Dellinger (1985) para um evento de reflexão de onda PP do Modelo 3. As dispersões em vermelho representam a região de mínimo global da função e as dispersões em azul representam a região de mínimo local. .....54 
Figura 65: Mapas de dispersão sobrepostos ao mapa residual de função objetivo mostrando a complexidade da aproximação multiparamétrica de Muir e Dellinger (1985) para um evento de reflexão de onda PS do Modelo 3. As dispersões em vermelho representam a região de mínimo global da função e as dispersões em azul representam a região de mínimo local. .....54 Figura 66: Mapas de dispersão sobrepostos ao mapa residual de função objetivo mostrando a complexidade da aproximação multiparamétrica de Li (2001) para um evento de reflexão de onda PP do Modelo 3. As dispersões em vermelho representam a região de mínimo global da função e as dispersões em azul representam a região de mínimo local. 55

Figura 67: Mapas de dispersão sobrepostos ao mapa residual de função objetivo mostrando a complexidade da aproximação multiparamétrica de Li (2001) para um evento de reflexão de onda PS do Modelo 3. As dispersões em vermelho representam a região de mínimo global da função e as dispersões em azul representam a região de mínimo local. 55 Figura 68: Mapas de dispersão sobrepostos ao mapa residual de função objetivo mostrando a complexidade da aproximação multiparamétrica de Malovichko (1978) para um evento de reflexão de onda PP do Modelo 4. As dispersões em vermelho representam a região de mínimo global da função. 56

Figura 69: Mapas de dispersão sobrepostos ao mapa residual de função objetivo mostrando a complexidade da aproximação multiparamétrica de Malovichko (1978) para um evento de reflexão de onda PS do Modelo 4. As dispersões em vermelho representam a região de mínimo global da função 56

Figura 70: Mapas de dispersão sobrepostos ao mapa residual de função objetivo mostrando a complexidade da aproximação multiparamétrica de Alkhalifah e Tsvankin (1995) para um evento de reflexão de onda PP do Modelo 4. As dispersões em vermelho representam a região de mínimo global da função.

Figura 71: Mapas de dispersão sobrepostos ao mapa residual de função objetivo mostrando a complexidade da aproximação multiparamétrica de Alkhalifah e Tsvankin (1995) para um evento de reflexão de onda PS do Modelo 4. As dispersões em vermelho representam a região de mínimo global da função.

Figura 72: Mapas de dispersão sobrepostos ao mapa residual de função objetivo mostrando a complexidade da aproximação multiparamétrica de Ursin e Stovas (2006) para um evento de 
reflexão de onda PP do Modelo 4. As dispersões em vermelho representam a região de mínimo global da função.

Figura 73: Mapas de dispersão sobrepostos ao mapa residual de função objetivo mostrando a complexidade da aproximação multiparamétrica de Ursin e Stovas (2006) para um evento de reflexão de onda PS do Modelo 4. As dispersões em vermelho representam a região de mínimo global da função. 58

Figura 74: Mapas de dispersão sobrepostos ao mapa residual de função objetivo mostrando a complexidade da aproximação multiparamétrica de Blias (2009) para um evento de reflexão de onda PP do Modelo 4. As dispersões em vermelho representam a região de mínimo global da função.

Figura 75: Mapas de dispersão sobrepostos ao mapa residual de função objetivo mostrando a complexidade da aproximação multiparamétrica de Blias (2009) para um evento de reflexão de onda PS do Modelo 4. As dispersões em vermelho representam a região de mínimo global da função. 59

Figura 76: Mapas de dispersão sobrepostos ao mapa residual de função objetivo mostrando a complexidade da aproximação multiparamétrica de Muir e Dellinger (1985) para um evento de reflexão de onda PP do Modelo 4. As dispersões em vermelho representam a região de mínimo global da função e as dispersões em azul representam a região de mínimo local.

Figura 77: Mapas de dispersão sobrepostos ao mapa residual de função objetivo mostrando a complexidade da aproximação multiparamétrica de Muir e Dellinger (1985) para um evento de reflexão de onda PS do Modelo 4. As dispersões em vermelho representam a região de mínimo global da função e as dispersões em azul representam a região de mínimo local. .....60

Figura 78: Mapas de dispersão sobrepostos ao mapa residual de função objetivo mostrando a complexidade da aproximação multiparamétrica de Li (2001) para um evento de reflexão de onda PP do Modelo 4. As dispersões em vermelho representam a região de mínimo global da função e as dispersões em azul representam a região de mínimo local

Figura 79: Mapas de dispersão sobrepostos ao mapa residual de função objetivo mostrando a complexidade da aproximação multiparamétrica de Li (2001) para um evento de reflexão de onda PS do Modelo 4. As dispersões em vermelho representam a região de mínimo global da função e as dispersões em azul representam a região de mínimo local. 61 
Figura 80: Mapas de dispersão sobrepostos ao mapa residual de função objetivo mostrando a complexidade da aproximação multiparamétrica de Malovichko (1978) para um evento de reflexão de onda PP do Modelo 5. As dispersões em vermelho representam a região de mínimo global da função

Figura 81: Mapas de dispersão sobrepostos ao mapa residual de função objetivo mostrando a complexidade da aproximação multiparamétrica de Malovichko (1978) para um evento de reflexão de onda PS do Modelo 5. As dispersões em vermelho representam a região de mínimo global da função.

Figura 82: Mapas de dispersão sobrepostos ao mapa residual de função objetivo mostrando a complexidade da aproximação multiparamétrica de Alkhalifah e Tsvankin (1995) para um evento de reflexão de onda PP do Modelo 5. As dispersões em vermelho representam a região de mínimo global da função.

Figura 83: Mapas de dispersão sobrepostos ao mapa residual de função objetivo mostrando a complexidade da aproximação multiparamétrica de Alkhalifah e Tsvankin (1995) para um evento de reflexão de onda PS do Modelo 5. As dispersões em vermelho representam a região de mínimo global da função.

Figura 84: Mapas de dispersão sobrepostos ao mapa residual de função objetivo mostrando a complexidade da aproximação multiparamétrica de Ursin e Stovas (2006) para um evento de reflexão de onda PP do Modelo 5. As dispersões em vermelho representam a região de mínimo global da função

Figura 85: Mapas de dispersão sobrepostos ao mapa residual de função objetivo mostrando a complexidade da aproximação multiparamétrica de Ursin e Stovas (2006) para um evento de reflexão de onda PS do Modelo 5. As dispersões em vermelho representam a região de mínimo global da função

Figura 86: Mapas de dispersão sobrepostos ao mapa residual de função objetivo mostrando a complexidade da aproximação multiparamétrica de Blias (2009) para um evento de reflexão de onda PP do Modelo 5. As dispersões em vermelho representam a região de mínimo global da função.

Figura 87: Mapas de dispersão sobrepostos ao mapa residual de função objetivo mostrando a complexidade da aproximação multiparamétrica de Blias (2009) para um evento de reflexão 
de onda PS do Modelo 5. As dispersões em vermelho representam a região de mínimo global da função.

Figura 88: Mapas de dispersão sobrepostos ao mapa residual de função objetivo mostrando a complexidade da aproximação multiparamétrica de Muir e Dellinger (1985) para um evento de reflexão de onda PP do Modelo 5. As dispersões em vermelho representam a região de mínimo global da função e as dispersões em azul representam a região de mínimo local. ......66

Figura 89: Mapas de dispersão sobrepostos ao mapa residual de função objetivo mostrando a complexidade da aproximação multiparamétrica de Muir e Dellinger (1985) para um evento de reflexão de onda PS do Modelo 5. As dispersões em vermelho representam a região de mínimo global da função e as dispersões em azul representam a região de mínimo local.

Figura 90: Mapas de dispersão sobrepostos ao mapa residual de função objetivo mostrando a complexidade da aproximação multiparamétrica de Li (2001) para um evento de reflexão de onda PP do Modelo 5. As dispersões em vermelho representam a região de mínimo global da função e as dispersões em azul representam a região de mínimo local. 67

Figura 91: Mapas de dispersão sobrepostos ao mapa residual de função objetivo mostrando a complexidade da aproximação multiparamétrica de Li (2001) para um evento de reflexão de onda PS do Modelo 5. As dispersões em vermelho representam a região de mínimo global da função e as dispersões em azul representam a região de mínimo local

Figura 92: Diferença dos tempos de trânsito exatos e calculados pelas expressões utilizando os parâmetros que resultam da inversão dos tempos de trânsito de onda PP para o Modelo 1. ...71 Figura 93: Diferença dos tempos de trânsito exatos e calculados pelas expressões utilizando os parâmetros que resultam da inversão dos tempos de trânsito de onda PS para o Modelo 1....71 Figura 94: Diferença dos tempos de trânsito exatos e calculados pelas expressões utilizando os parâmetros que resultam da inversão dos tempos de trânsito de onda PP para o Modelo 2. ...72 Figura 95: Diferença dos tempos de trânsito exatos e calculados pelas expressões utilizando os parâmetros que resultam da inversão dos tempos de trânsito de onda PS para o Modelo 2...72 Figura 96: Diferença dos tempos de trânsito exatos e calculados pelas expressões utilizando os parâmetros que resultam da inversão dos tempos de trânsito de onda PP para o Modelo 3...73 Figura 97: Diferença dos tempos de trânsito exatos e calculados pelas expressões utilizando os parâmetros que resultam da inversão dos tempos de trânsito de onda PS para o Modelo 3...73 
Figura 98: Diferença dos tempos de trânsito exatos e calculados pelas expressões utilizando os parâmetros que resultam da inversão dos tempos de trânsito de onda PP para o Modelo 4...74 Figura 99: Diferença dos tempos de trânsito exatos e calculados pelas expressões utilizando os parâmetros que resultam da inversão dos tempos de trânsito de onda PS para o Modelo 4. ...74 Figura 100: Diferença dos tempos de trânsito exatos e calculados pelas expressões utilizando os parâmetros que resultam da inversão dos tempos de trânsito de onda PP para o Modelo 5. 75

Figura 101: Diferença dos tempos de trânsito exatos e calculados pelas expressões utilizando os parâmetros que resultam da inversão dos tempos de trânsito de onda PS para o Modelo 5. 


\section{LISTA DE TABELAS}

Tabela 1: Tempos absolutos necessários (em segundos) para executar as rotinas de inversão considerando as diferentes aproximações, eventos e modelos. Equação 1 - Dix (1955), Equação 2 - Malovichko (1978), Equação 3 - Slotboom et al. (1990), Equação 4 - Alkhalifah e Tsvankin (1995), Equação 5 - Ursin e Stovas (2006), Equação 6 - Blias (2009), Equação 7 - Muir e Dellinger (1985) e Equação 8 - Li (2001).

Tabela 2: Valores de mínimos globais obtidos considerando as diferentes aproximações, eventos e modelos. Equação 1 - Dix (1955), Equação 2 - Malovichko (1978), Equação 3 Slotboom et al. (1990), Equação 4 - Alkhalifah e Tsvankin (1995), Equação 5 - Ursin e Stovas (2006), Equação 6 - Blias (2009), Equação 7 - Muir e Dellinger (1985) e Equação 8 $\operatorname{Li}(2001)$. 78

Tabela 3: Números de eficiência (adimensional) obtido considerando as diferentes aproximações, eventos e modelos. Equação 1 - Dix (1955), Equação 2 - Malovichko (1978), Equação 3 - Slotboom et al. (1990), Equação 4 - Alkhalifah e Tsvankin (1995), Equação 5 Ursin e Stovas (2006), Equação 6 - Blias (2009), Equação 7 - Muir e Dellinger (1985) e Equação 8 - Li (2001). 78 


\section{AGRADECIMENTOS}

Às pessoas que foram fundamentais para que este trabalho fosse possível, meu orientador Prof. Dr. Eder Cassola Molina, e meu coorientador, Prof. Dr. Renato Luiz Prado.

Aos professores da pós-graduação, que foram fundamentais para minha formação.

Aos grandes professores que fizeram parte da minha formação como um todo, desde a formação básica até minha graduação.

À Universidade de São Paulo e ao Instituto de Astronomia, Geofísica e Ciências Atmosféricas pela oportunidade de alcançar este título.

À direção do Instituto e às comissões CCP e CPG pelas excelentes gestões, que enriqueceram ainda mais minha conquista.

À secretaria de pós-graduação e de Geofísica por sempre nos ajudar de forma eficiente.

À equipe de apoio que mantém as instalações sempre nas melhores condições para que possamos trabalhar.

À CAPES por todo o apoio financeiro.

Aos meus colegas por estarmos juntos ao longo desta caminhada sempre nos apoiando.

Aos meus amigos, minha namorada, meus pais e minhas irmãs por sempre me apoiarem, incentivarem e acreditarem que eu poderia melhorar cada vez mais. 
"If I can see much farther, it's because I am standing on the shoulders of giants"

-Isaac Newton 


\section{RESUMO}

A análise de velocidades é uma etapa fundamental para o processamento sísmico e é realizada ajustando a curva de tempos de trânsito calculada pela aproximação hiperbólica com a curva observada no registro sísmico. Entretanto, na sísmica de exploração são facilmente encontrados modelos que apresentam características que tornam um evento de tempos de trânsito não-hiperbólico, algo que é intensificado quando utilizados dados sísmicos multicomponente, os quais apresentam eventos de ondas convertidas. Outro fator importante é a utilização de tecnologia OBN que também torna o evento menos hiperbólico devido à geometria de aquisição. Dessa maneira é fundamental utilizar-se aproximações que consigam controlar essa não-hiperbolicidade para realizar a análise de velocidades.

O estudo numérico proposto no presente trabalho focou em analisar a complexidade das funções objetivo, e sua qualidade e eficiência no ajuste de curvas dos tempos de trânsito com diferentes aproximações. Os modelos estudados, originados de perfis de poços da Bacia de Santos, apresentam diferentes características que tornam as análises propostas mais complexas. Dessa forma, as aproximações utilizadas são de igual complexidade, e pelo fato de utilizarem três parâmetros, o estudo foi tratado como um problema de inversão seguindo um critério de otimização.

Com o conjunto de informações obtidas nos testes, foi determinado quão complexa é cada aproximação, e a qualidade e eficiência que ela apresenta para obter os resultados almejados. Sendo assim, foi possível identificar as aproximações mais indicadas para cada modelo estudado, para cada tipo de evento de reflexão e para todos os modelos de uma forma genérica. 


\section{ABSTRACT}

The velocity analysis is a fundamental tool in the seismic processing, and it is performed fitting the calculated travel-time curve to the curve recorded in the seismic record. However, in the seismic survey, there are many models that present characteristics which make a travel-time event nonhyperbolic. This is intensified with using multicomponent seismic data, which present converted wave events. Another important factor is the use of the OBN technology that makes an event less hyperbolic due to its geometry acquisition. Therefore, we must use approximations which could control this nonhyperbolicity to perform the velocity analysis.

The numerical study proposed here aimed to analyze the complexity of the objective functions and the quality and the efficiency of the travel-time curve fitting with different approximations. The models under study, elaborated from well logs data of the Santos Basin, shown different characteristics making the proposed analysis more complex. Thus, the approximations are of equal complexity, and due to the fact of the using three parameters, the study was treated as an inverse problem solved by an optimization criterion.

With the set of obtained informations, it was determined how complex each approximation is. The quality and the efficiency of each approximation were also studied. Thus, it was possible to identify the most appropriate approximations for each model tested, for each kind of reflection event, and for all situations studied here in a general form. 


\section{INTRODUÇÃO}

$\mathrm{Na}$ exploração geofísica, o método sísmico baseia-se na análise do retorno das ondas sísmicas geradas por fontes artificiais, comumente com o objetivo de obter-se o imageamento de estruturas geológicas. Essas ondas, se propagam pela subsuperfície até que sejam refletidas e/ou refratadas nas interfaces entre meios geológicos que contrastam por suas propriedades físicas, e então retornam à superfície.

Essas ondas sísmicas são registradas em diversos receptores posicionados em diferentes afastamentos da fonte. Tais receptores detectam as vibrações do solo (geofones) ou a variação da pressão no meio aquático (hidrofones). A geometria do arranjo de receptores utilizada depende do objetivo da aquisição sísmica (Sheriff e Geldart, 1995).

$\mathrm{Na}$ exploração de hidrocarbonetos, o método sísmico é normalmente utilizado para mapeamento de interfaces nas seções sísmicas visando a construção de um modelo geológico estrutural e estratigráfico, como também para estimativa de propriedades físicas e petrofísicas do meio analisado. Por tais motivos o método sísmico é amplamente utilizado na exploração de hidrocarbonetos e caracterização geológica (Kearey, Brooks e Hill, 2002).

Convencionalmente, a utilização do método sísmico visa o registro de ondas $\mathrm{P}$ (compressionais), sendo neste caso utilizados geofones verticais. Entretanto, quando se trata da sísmica multicomponente, objetiva-se o registro tanto de ondas $\mathrm{P}$ como de ondas $\mathrm{S}$ (cisalhantes). Com isso há a necessidade da utilização de geofones $3 \mathrm{C}$, ou seja, com três componentes, sendo um geofone vertical e dois horizontais em arranjo ortogonal.

A sísmica multicomponente permite o registro de um campo de onda mais completo do que o obtido com a sísmica convencional, o que proporciona uma caracterização mais detalhada da subsuperfície. Existem diversas vantagens em utilizar a sísmica multicomponente, dentre elas a possibilidade de determinar a razão Vp/Vs para mapear a variação litológica vertical e lateral (Pickett, 1963, Stewart et al., 2002, Agudelo et al., 2013), obter-se seções sísmicas de reflexão mesmo com refletividade fraca de onda P (Garrota, 1999, Stewart et al., 2002, 2003), a obtenção de uma melhor resolução dos dados sísmicos (Stewart et al., 2003; Meier et al., 2009, Ursenbach et al., 2013), melhorar o imageamento de falhas de alto ângulo (Purnell, 1992, Stewart et al., 2003, Wang et al., 2014), imagear através de 
nuvens de gás (Granli el al. 1995), discriminar fluidos como água e óleo em reservatórios fraturados (Qian et al., 2007), monitorar mais detalhadamente as mudanças em reservatórios de hidrocarboneto com a utilização de sísmica 4D (Spitz et al., 2000), dentre vários outros benefícios.

No início dos anos 2000, acreditava-se que a sísmica multicomponente seria unanimidade nos levantamentos sísmicos, tanto onshore como offshore (Davis, 2001; Hardage et al., 2011). Isso vem se tornando realidade devido ao fato de que muitos trabalhos relatam que o uso da sísmica multicomponente tem a capacidade de suprir as deficiências da sísmica convencional, e mesmo que em algumas situações não sejam apresentadas diferenças significativas nos resultados obtidos, há uma considerável diminuição da incerteza desses resultados devido à maior variedade de informações. Com isso há um significativo reconhecimento da sísmica multicomponente tanto a nível científico como industrial, mesmo que os grandes avanços dessa área não tenham muito mais de uma década (Kendall, 2006; Davis, 2001).

O processamento adequado de dados provenientes de aquisições multicomponente é um dos grandes desafios para o aumento de sua implementação, pois o processamento desse tipo de dado é consideravelmente mais complexo do que o processamento de dados sísmicos na forma convencional.

Nas aquisições offshore são utilizadas ondas PP (incidência P - reflexão P) e PSv (incidência $\mathrm{P}$ - reflexão Sv). O processamento de dados de ondas convertidas (PSv ou SvP) é mais complexo devido ao fato da onda incidente se propagar pelo meio com uma velocidade diferente da onda refletida. A diferença entre essas velocidades produz uma assimetria na trajetória do raio sísmico incidente e refletido.

A assimetria de raio em razão da conversão de onda gera um evento de tempos de trânsito não-hiperbólicos, o que exige a utilização de aproximações não-hiperbólicas multiparamétricas dos tempos de trânsito para que possa ser apropriadamente executada a análise de velocidades e a correção do sobretempo (NMO - Normal Move Out). Entretanto, não só a conversão de onda gera a não-hiperbolicidade de um evento de reflexão. Existem outros fatores que também contribuem como a heterogeneidade vertical do meio geológico associada a longos afastamentos fonte-receptor, pois existe um erro associado à discrepância entre as velocidades intervalar e de RMS (Root Mean Square) nas condições de afastamento 
fonte-receptor, sendo esse erro crescente com o aumento do afastamento. Também a diferença de datum entre fonte (posicionada na superfície do mar) e receptor (posicionado no leito marinho), proveniente da utilização da tecnologia OBN (Ocean Bottom Nodes) gera uma assimetria de raio sísmico.

A tecnologia OBN permite que seja feita a aquisição de dados sísmicos multicomponente em levantamentos offshore. Isso não seria possível com a tecnologia convencional (streamer), onde os receptores são posicionados na superfície do mar, pois as ondas $S$ não se propagam pela água.

As variadas características do comportamento não-hiperbólico dos eventos de reflexão de ondas sísmicas, de forma geral, vêm sendo estudadas nas últimas décadas em diversos trabalhos (Malovichko, 1978; Blias, 1983 e 2009; Muir e Dellinger, 1985; Castle, 1988 e 1994; Slotboom et al., 1990; Tsvankin e Thomsen, 1994; Alkhalifah e Tsvankin, 1995; Li, 2003; Li e Yuan, 1999, 2001, 2002 e 2003; Cheret, Bale e Leaney, 2000; Causse, Haugen e Rommel, 2000; Tsvankin e Grechka, 2000a,b; Fomel e Grechka, 2000 e 2001; Tsvankin, 2001; Leiderman et al., 2003; Silva et al., 2003; Ursin e Stovas, 2006). Esses trabalhos tinham, em sua maioria, o foco de desenvolver aproximações não-hiperbólicas para meios com simetria transversalmente isotrópica em relação ao eixo vertical (VTI - Vertical Transversal Isotropy), para meios verticalmente heterogêneos, e para assimetria de raio devido à conversão de onda.

Nas últimas décadas foram publicados diversos trabalhos onde há a comparação do desempenho das aproximações não-hiperbólicas, porém, na grande maioria, os autores comparam uma quantidade limitada de aproximações já existentes com a sua própria. Poucos trabalhos relatam as comparações entre aproximações de uma maneira independente (onde não há comparação com a aproximação desenvolvida pelo próprio autor), a exemplo de Aleixo e Schleicher (2010) e Golikov e Stovas (2012) que compararam o desempenho de aproximações em meios VTI para eventos de reflexão $\mathrm{qP}$ (quasi-P), nos quais em meios anisotrópicos a onda compressional não é puramente longitudinal.

É possível dizer que dentre as aproximações desenvolvidas e testadas em modelos teóricos e reais, até então não há nenhuma que seja capaz de se ajustar igualmente bem para todos os modelos. Dessa maneira, para determinado modelo devem ser testadas várias aproximações para identificar a mais apropriada. 
O interesse do presente trabalho é efetuar a análise de velocidades de eventos de reflexão de ondas P e de ondas convertidas PS no contexto da utilização da tecnologia OBN para modelos multicamadas em águas ultra-profundas com longos afastamentos.

Para o desenvolvimento do presente projeto foram implementados algoritmos de inversão para efetuar as análises de velocidades, as análises da complexidade de função objetivo e as análises de eficiência das aproximações

Este estudo visa contribuir para melhor conhecimento de modelos que refletem as situações encontradas no cenário atual de exploração de hidrocarbonetos, uma vez que inexistem estudos que analisam e comparam de forma independente aproximações nãohiperbólicas que consideram as características desses modelos.

\subsection{Objetivos}

O presente trabalho tem como objetivos a análise de velocidades de dados sintéticos, estudando a complexidade das funções objetivo visando investigar o comportamento de cada uma delas no processo de inversão. Também foi realizada a análise qualitativa das curvas de tempos de trânsito, observando a qualidade do ajuste das curvas calculadas em relação à observada. Adicionalmente foi proposta uma metodologia quantitativa de análise de eficiência de cada aproximação utilizada com o objetivo de relacionar a capacidade de ajuste e o tempo de processamento de cada aproximação não-hiperbólica. 


\section{FUNDAMENTOS}

Neste capítulo são apresentados os fundamentos necessários para a melhor compreensão das temáticas abordadas no presente trabalho.

\subsection{Ondas sísmicas}

As ondas sísmicas são ondas de energia que se propagam pela Terra e são originadas por sismos ou fontes artificiais. As ondas de corpo se propagam por meios materiais e podem ser refletidas ou refratadas em interfaces entre camadas ou estruturas geológicas a depender dos contrastes de propriedade físicas presentes (Kearey, Brooks e Hill, 2002).

\subsubsection{Ondas compressionais}

As ondas compressionais, também chamadas de ondas $\mathrm{P}$, se propagam de maneira longitudinal (mesma direção da vibração das partículas e da propagação da onda), comprimindo e distendendo o meio pelo qual viajam (Figura 1), e dessa forma, propagando-se mais rapidamente do que as demais ondas. As ondas $\mathrm{P}$ podem se propagar por qualquer tipo de matéria, seja sólido, líquido ou gás.

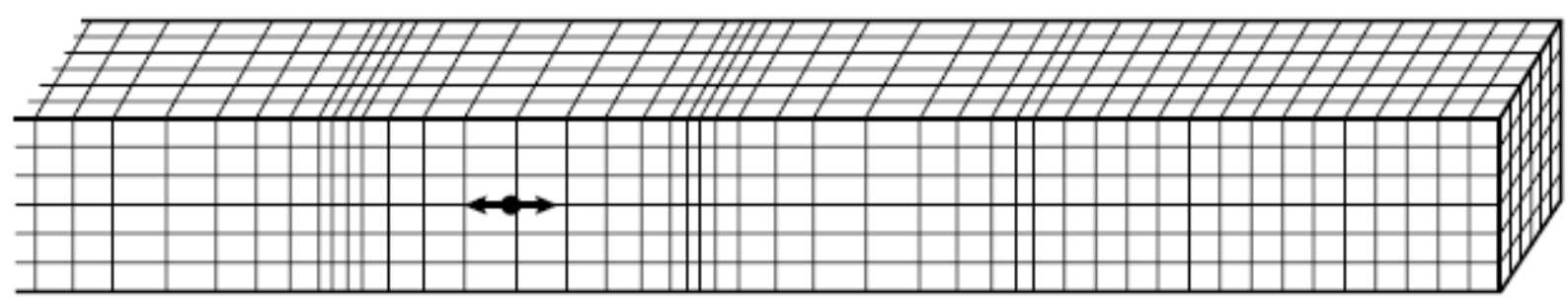

Figura 1: Deformação elástica e movimentação de partículas associada à passagem de ondas P. (Kearey, Brooks e Hill, 2002).

\subsubsection{Ondas cisalhantes}

As ondas cisalhantes (ondas $S$ ) são ondas que se propagam de forma transversal (com a direção de vibração das partículas perpendiculares à da propagação da onda), ou seja, a 
cisalhar o meio em que se propaga (Figura 2). Com isso a onda $S$ viaja pelo meio com velocidade inferior à da onda $\mathrm{P}$ e sendo incapaz de se propagar em meios líquidos e gasosos.

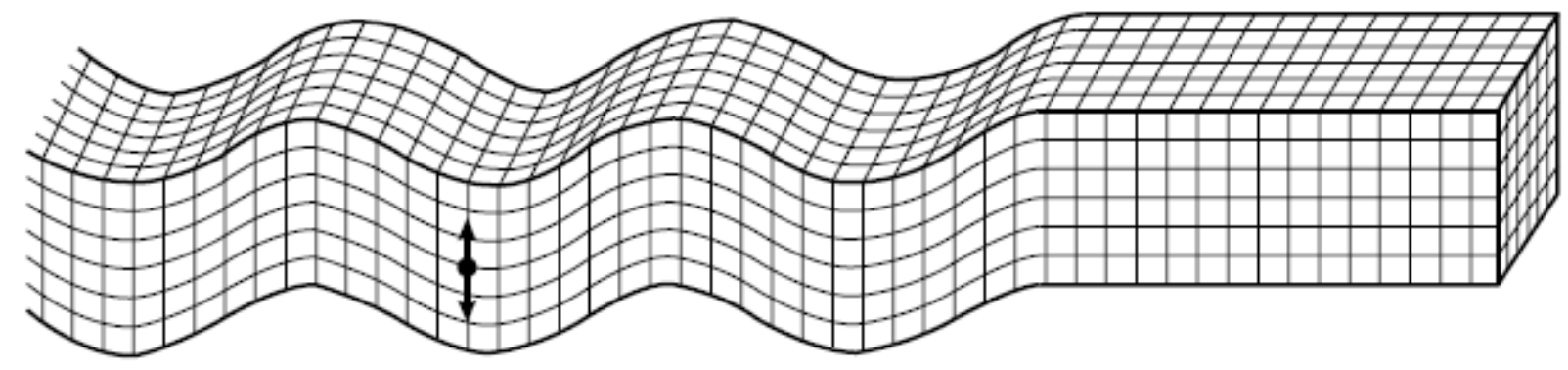

Figura 2: Deformação elástica e movimentação de partículas associada à passagem de ondas S. (Kearey, Brooks e Hill, 2002).

\subsection{Sísmica multicomponente}

A sísmica multicomponente destaca-se da sísmica convencional por utilizar não só o registro de ondas $\mathrm{P}$, mas também o de ondas $\mathrm{Sv}$ ( $\mathrm{S}$ vertical) e Sh (S horizontal), além de registrar ondas convertidas como PSv e SvP.

O processamento para o caso da sísmica multicomponente é mais complicado, pois são necessárias cinco sequências de processamento (Figura 3), uma para cada tipo de evento de reflexão citado, já que cada uma apresenta diferentes conteúdos de frequências e velocidades, além de apresentar diferentes magnitudes de ruídos aleatórios e coerentes.

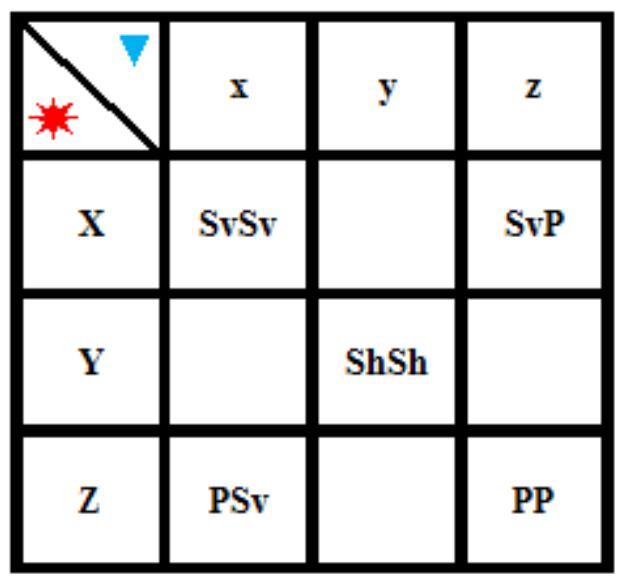

Figura 3: Representação das componentes registradas em um sistema de coordenadas cartesianas (XYZ). A estrela vermelha representa as fontes e o triângulo azul representa os receptores. 


\subsubsection{Conversão de onda}

Quando uma onda P incide em determinada interface entre camadas, ela pode refletir e refratar como onda S (e vice versa), gerando assim uma onda convertida. Dessa maneira, no caso de uma reflexão de onda convertida, a onda incide com uma velocidade e com um ângulo, mas emerge com outra velocidade e outro ângulo (Figura 4).

(a)

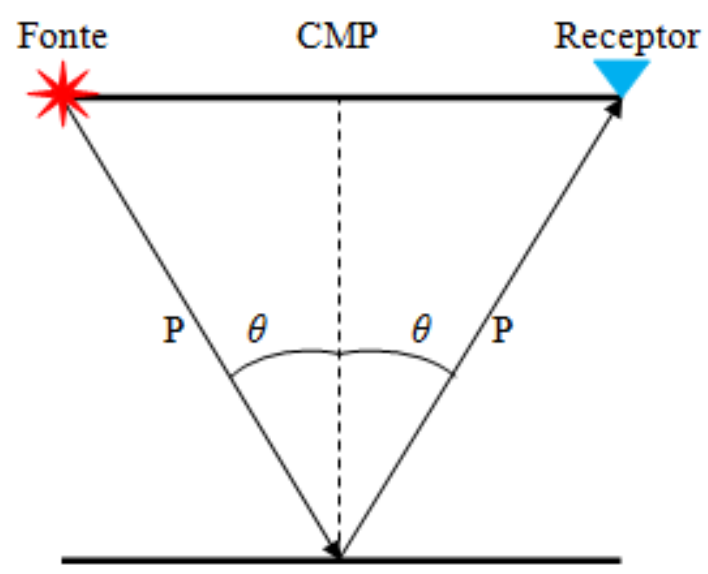

(b)

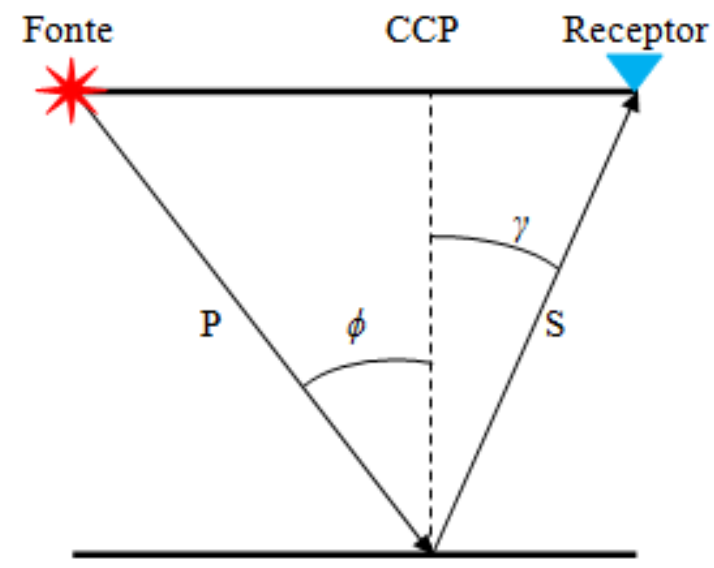

Figura 4: (a) Reflexão de onda no ponto médio comum (CMP); (b) Reflexão de onda PSv no ponto de conversão comum (CCP).

\subsection{Tecnologia OBN}

A tecnologia OBN (Ocean Bottom Nodes) utiliza a fonte na superfície enquanto os receptores são fixados no leito marinho (Figura 5). A tecnologia de aquisição offshore convencional (Streamer) é diferente justamente pelo fato de utilizar os receptores na superfície, o que impossibilita a aquisição multicomponente, pois não permite a aquisição de ondas S. Entretanto a utilização da tecnologia OBN gera uma assimetria de raio sísmico devido à diferença de datum entre fonte e receptor, o que dificulta o processamento. 


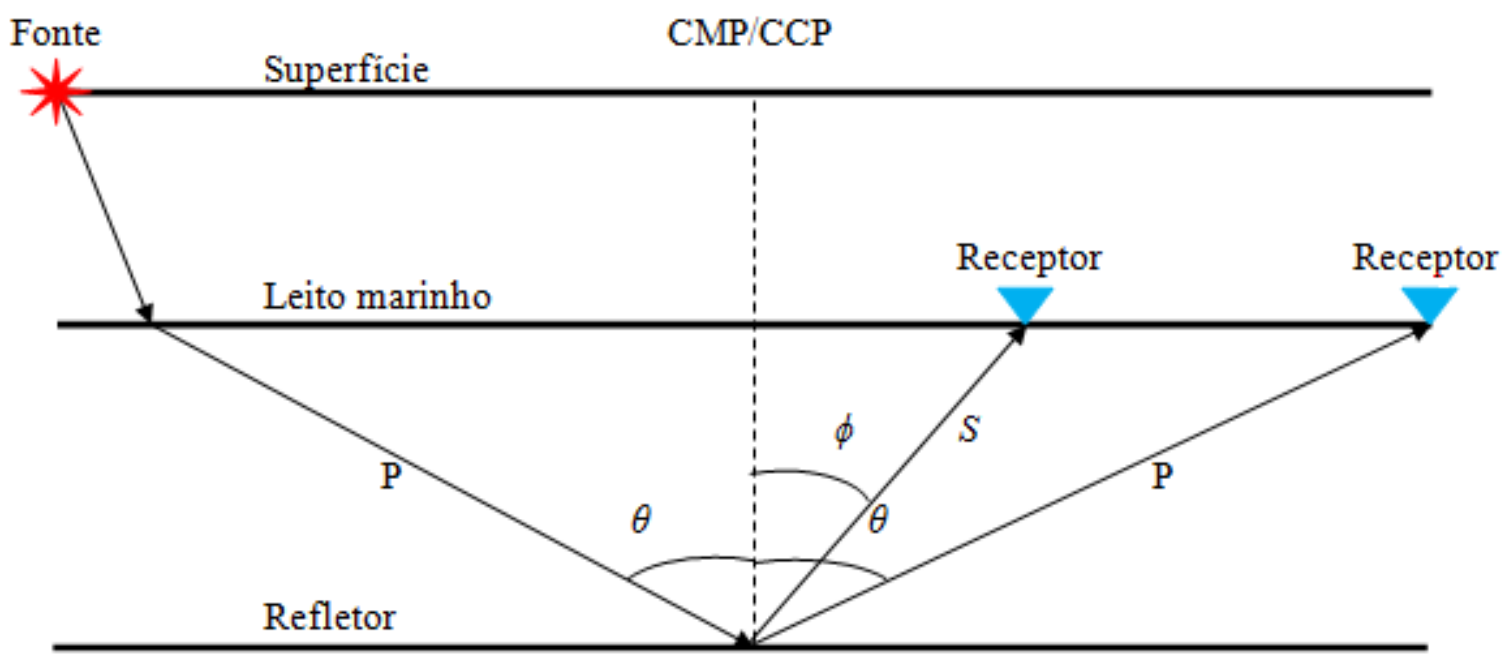

Figura 5: Reflexão de onda PP e de onda PS com a utilização de tecnologia OBN.

\subsection{Velocidade RMS}

A velocidade RMS (Root Mean Square) é a média quadrática das velocidades intervalares. Como durante o processamento utiliza-se a velocidade RMS é natural que haja um erro associado à discrepância entre a velocidade RMS e intervalar. Tal erro vai aumentando com o aumento do afastamento (Figura 6).

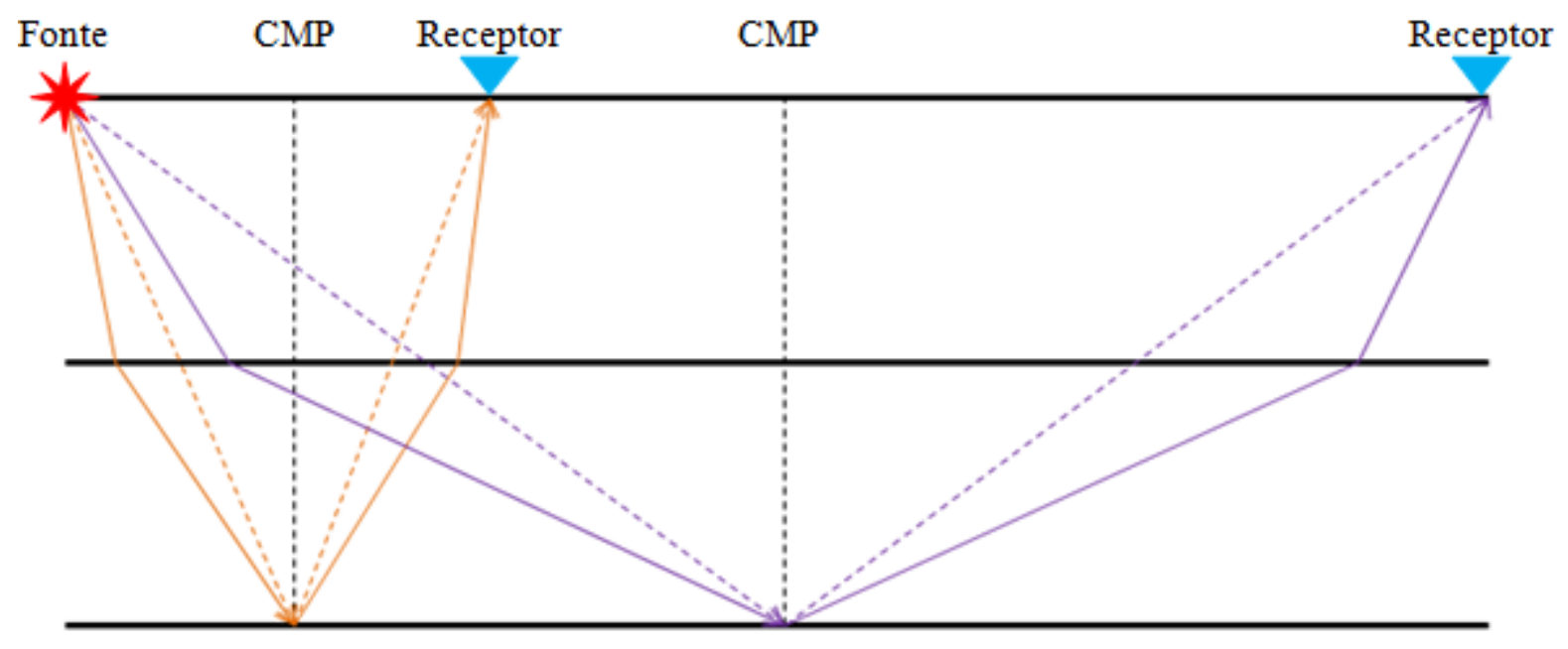

Figura 6: Esquematização demonstrando como a velocidade de NMO e a de RMS diferem-se mais com o aumento do afastamento. Linhas sólidas representam as velocidades intervalares e as pontilhadas representam as velocidades RMS. 


\section{MODELOS NUMÉRICOS ESTUDADOS}

No presente trabalho foram selecionados cinco modelos para serem estudados, com o objetivo de efetuar a análise de velocidades oriundas de eventos de reflexão de ondas PP e PS associados à interface entre a base da camada selante de sal e o reservatório carbonático.

Os modelos foram gerados a partir de informações obtidas de perfis de poços do présal da Bacia de Santos. Os perfis forneceram apenas as informações estratigráficas, necessárias para a definição do tipo de litologia presente em cada camada de cada modelo. Dessa maneira foi possível realizar a modelagem dos parâmetros físicos.

Para a análise proposta neste trabalho, são necessários parâmetros físicos que dependem dos parâmetros elásticos, como velocidade de onda $\mathrm{P}(\mathrm{Vp})$, velocidade de onda $\mathrm{S}$ (Vs) e razão entre velocidade de onda $\mathrm{P}$ e onda $\mathrm{S}(\mathrm{Vp} / \mathrm{Vs})$.

Os parâmetros físicos em questão foram obtidos da literatura e foram adaptados para diferentes profundidades e diferentes condições de pressão de forma independente para cada litologia, proporcionando, a cada camada, os valores de Vp, Vs e Vp/Vs, como é visto no cenário da exploração de hidrocarbonetos (Han, 1986; Lucet, 1989; Geertsma, 1961; Jizba, 1991; Strandenes, 1991; Blangy, 1992; Cadoret, 1993; Yale e Jameison, 1994; Mavko et al., 2009).

Tendo o perfil de velocidades em função da profundidade completo, é possível, por meio do método de traçado de raios, definir a forma com que os eventos de reflexão PP e PS se propagam por através das camadas, e dessa forma gerar as curvas de tempos de trânsito de cada evento para cada modelo (Margrave, 2000 e 2003).

Um fator crítico reside na geometria de aquisição quando se emprega a tecnologia OBN. Neste caso, há uma diferença de datum a entre fonte e o receptor. Esse tipo de característica ainda não pode ser simulada por pacotes convencionais do Seismic Unix. Este problema foi contornado com uso do software de modelagem 2D de campo de onda por diferenças finitas proposto por Thorbecke e Draganov (2012). 


\subsection{Modelo 1}

O primeiro modelo possui uma estrutura bem conhecida no pré-sal da Bacia de Santos, tendo uma camada de sal estratificado de mais de 2000 metros de espessura. Essa camada é composta por uma estrutura mais densa cercada por camadas menos densas. O perfil de velocidades, os traçados de raios e as curvas de tempos de trânsito, para este modelo, estão representadas nas figuras $7,8,9,10$ e 11 .

As informações de geometria do modelo e de geometria de aquisição são:

-Profundidade da fonte: 5 metros.

-Profundidade dos receptores (leito marinho): 2157 metros.

-Profundidade do topo da camada de sal: 2761 metros

-Profundidade do topo do reservatório (base da camada de sal): 5172 metros.

-Número de receptores: 100.

-Afastamento mínimo entre fonte e receptor: 150 metros.

-Afastamento entre receptores: 150 metros.
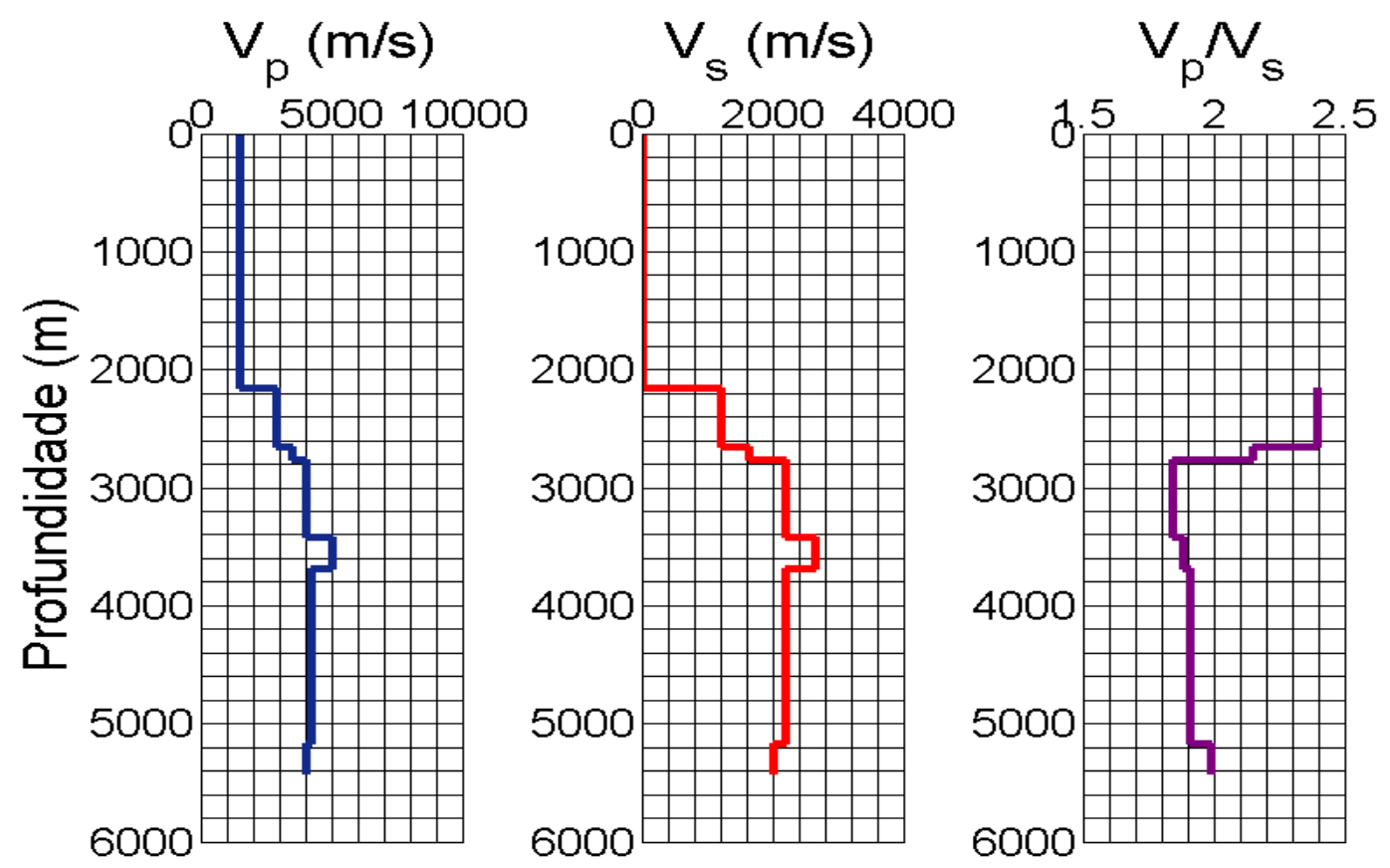

Figura 7: Perfis de velocidade de onda $\mathrm{P}$, velocidade de onda $\mathrm{S}$ e razão $\mathrm{Vp} / \mathrm{Vs}$ com relação à profundidade do Modelo 1. 


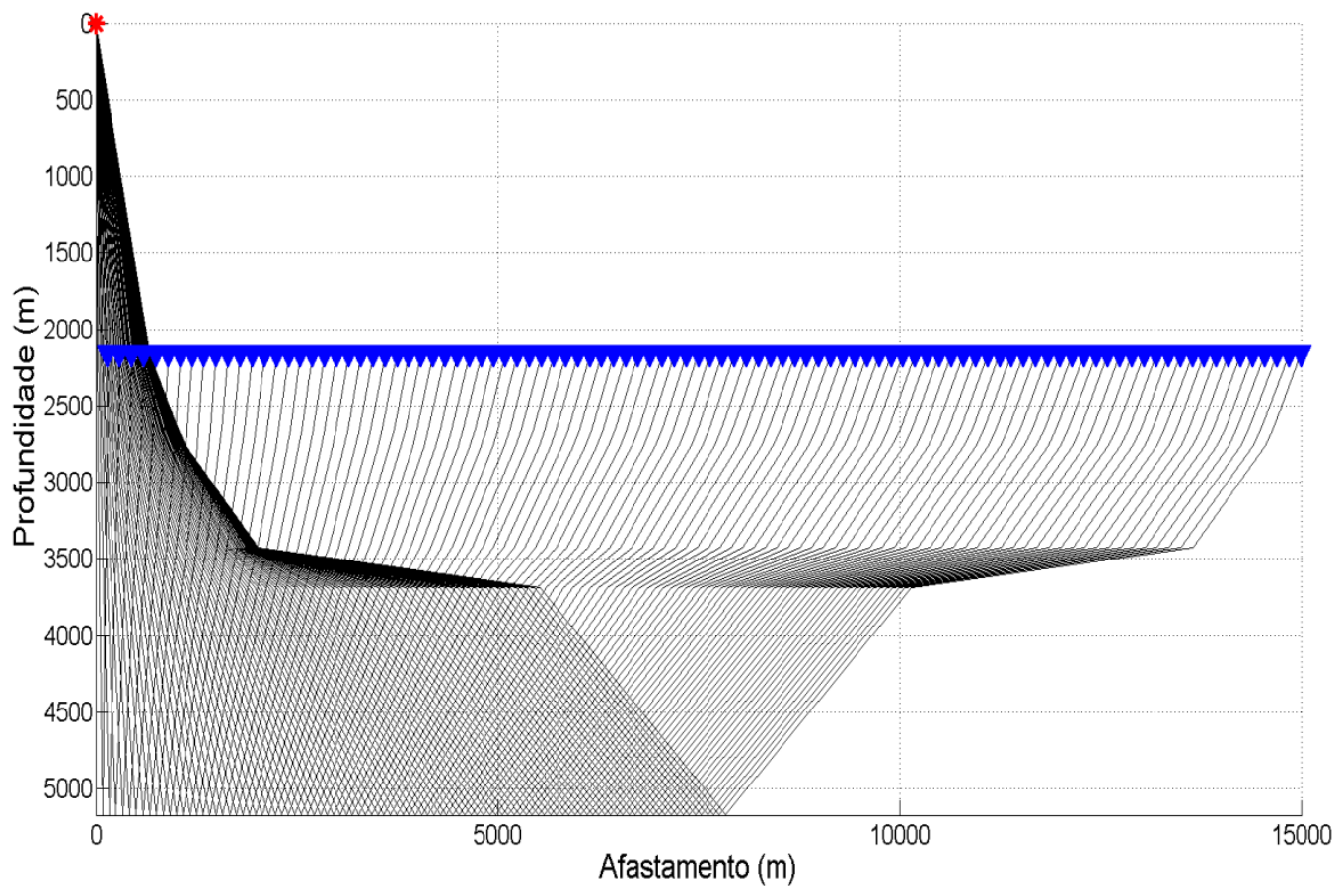

Figura 8: Esquematização de traçado de raios do evento de reflexão PP do Modelo 1.

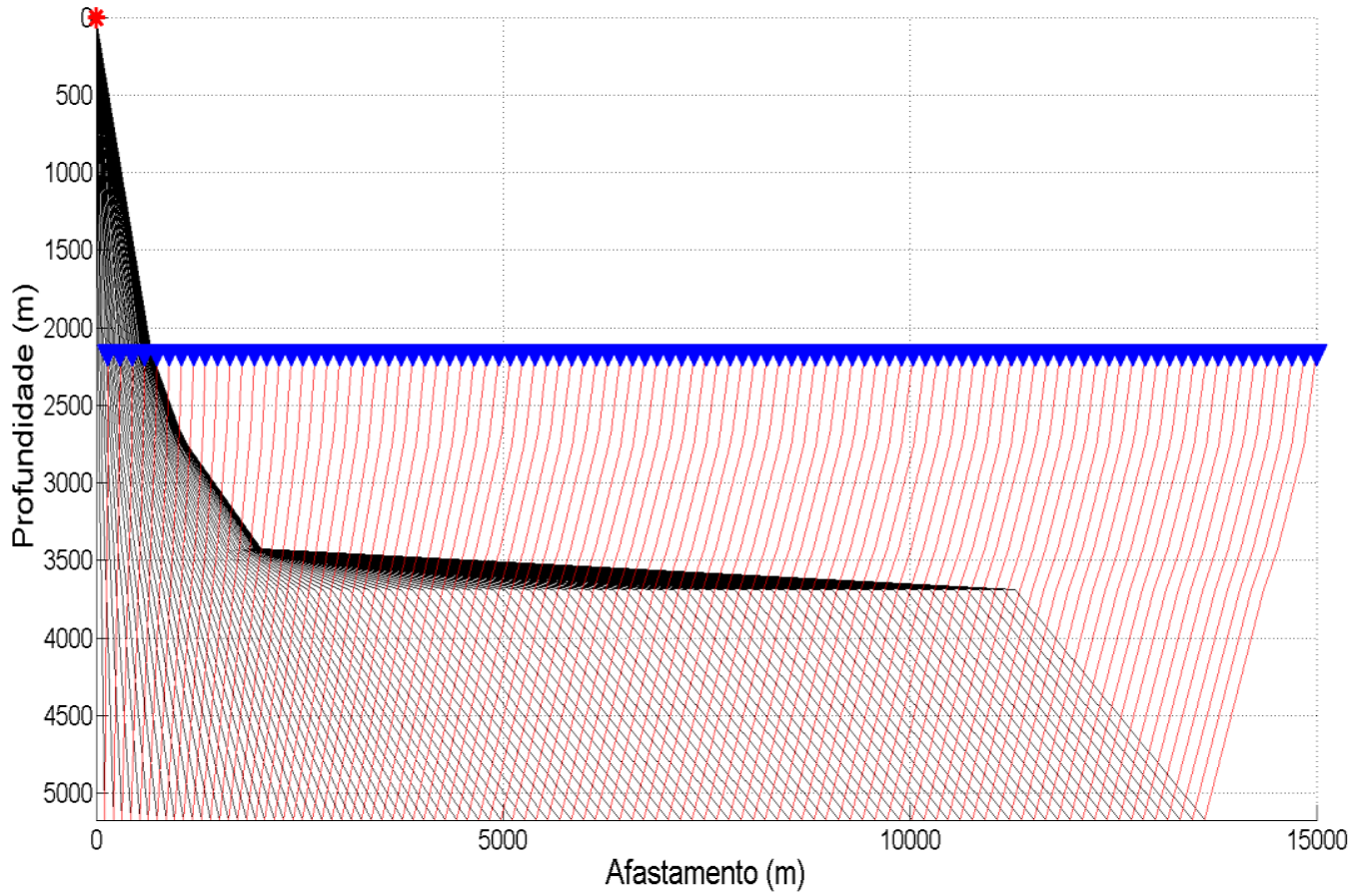

Figura 9: Esquematização de traçado de raios do evento de reflexão PS do Modelo 1. 


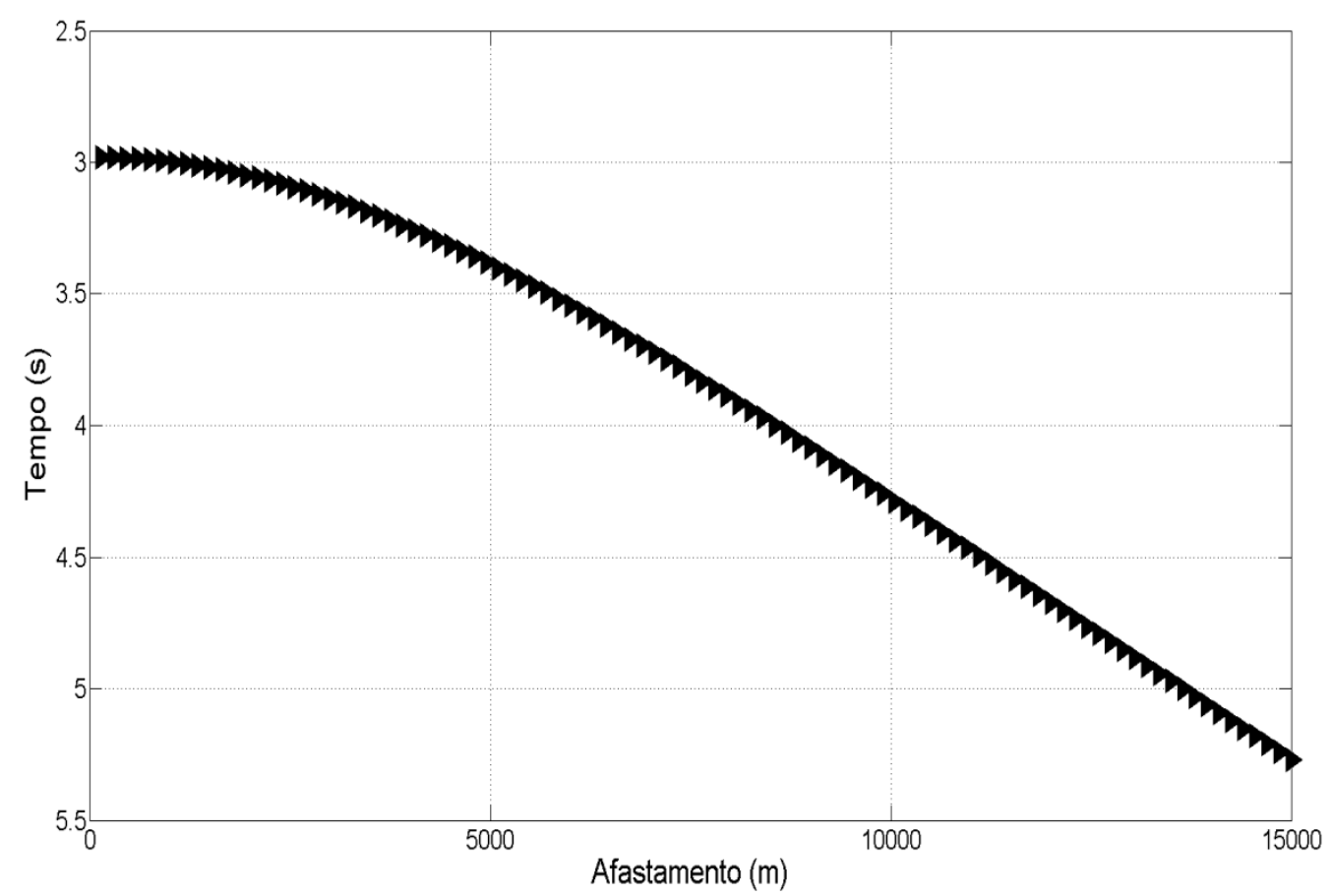

Figura 10: Curva de tempos de trânsito do evento de reflexão PP do Modelo 1.

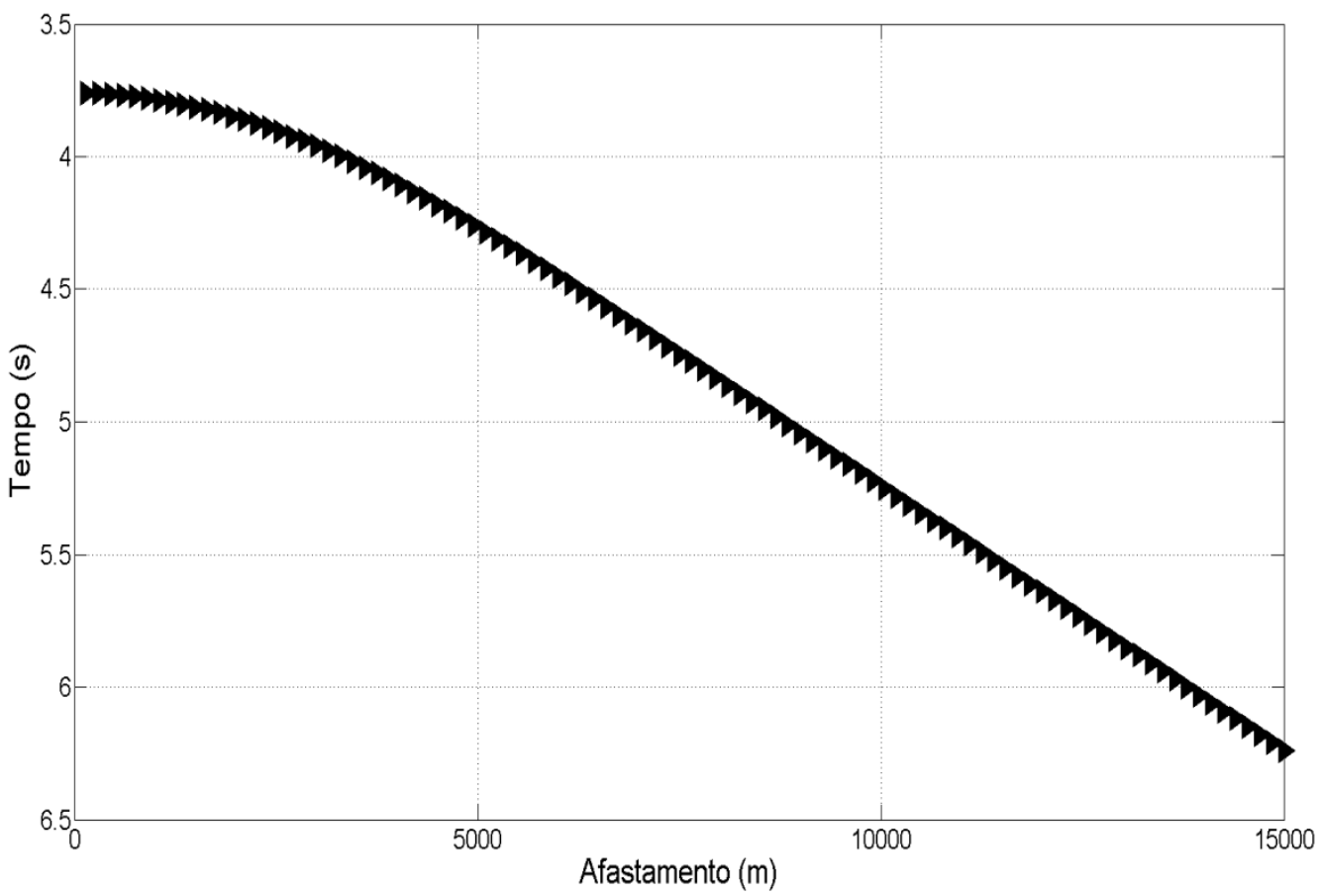

Figura 11: Curva de tempos de trânsito do evento de reflexão PS do Modelo 1. 


\subsection{Modelo 2}

De forma semelhante ao Modelo 1, este modelo apresenta uma camada de sal composta por uma estrutura mais densa cercada por duas estruturas menos densas, porém bem mais delgadas (menos de 1000 metros de espessura). O perfil de velocidades, os traçados de raios e as curvas de tempos de trânsito para este modelo estão representados nas figuras 12 , $13,14,15$ e 16.

As informações de geometria do modelo e de geometria de aquisição são:

-Profundidade da fonte: 5 metros.

-Profundidade dos receptores (leito marinho): 2356 metros

-Profundidade do topo da camada de sal: 3926 metros.

-Profundidade do topo do reservatório (base da camada de sal): 4721 metros.

-Número de receptores: 100.

-Afastamento mínimo entre fonte e receptor: 150 metros.

-Afastamento entre receptores: 150 metros.
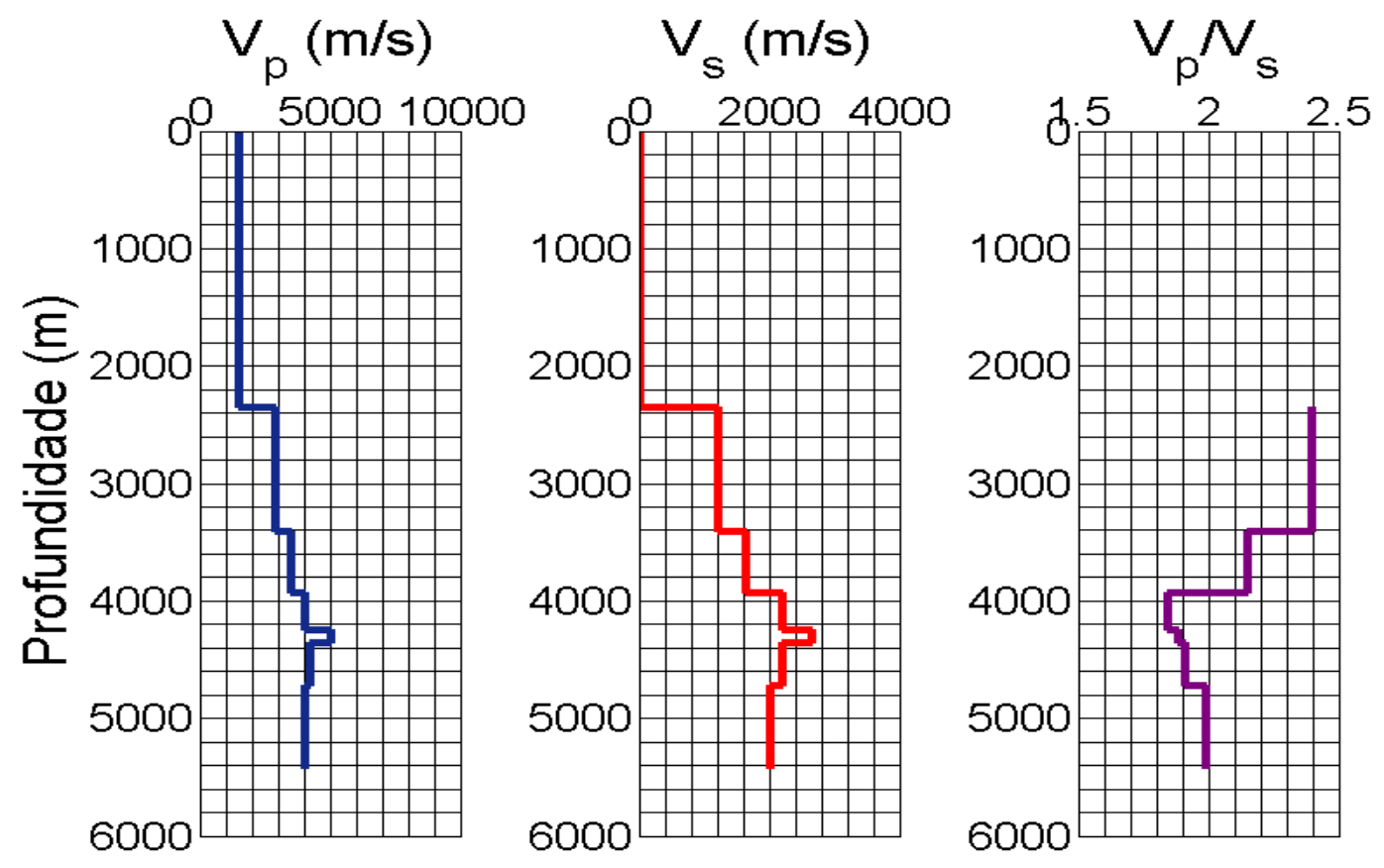

Figura 12: Perfis de velocidade de onda $\mathrm{P}$, velocidade de onda $\mathrm{S}$ e razão $\mathrm{Vp} / \mathrm{Vs}$ com relação à profundidade do Modelo 2. 


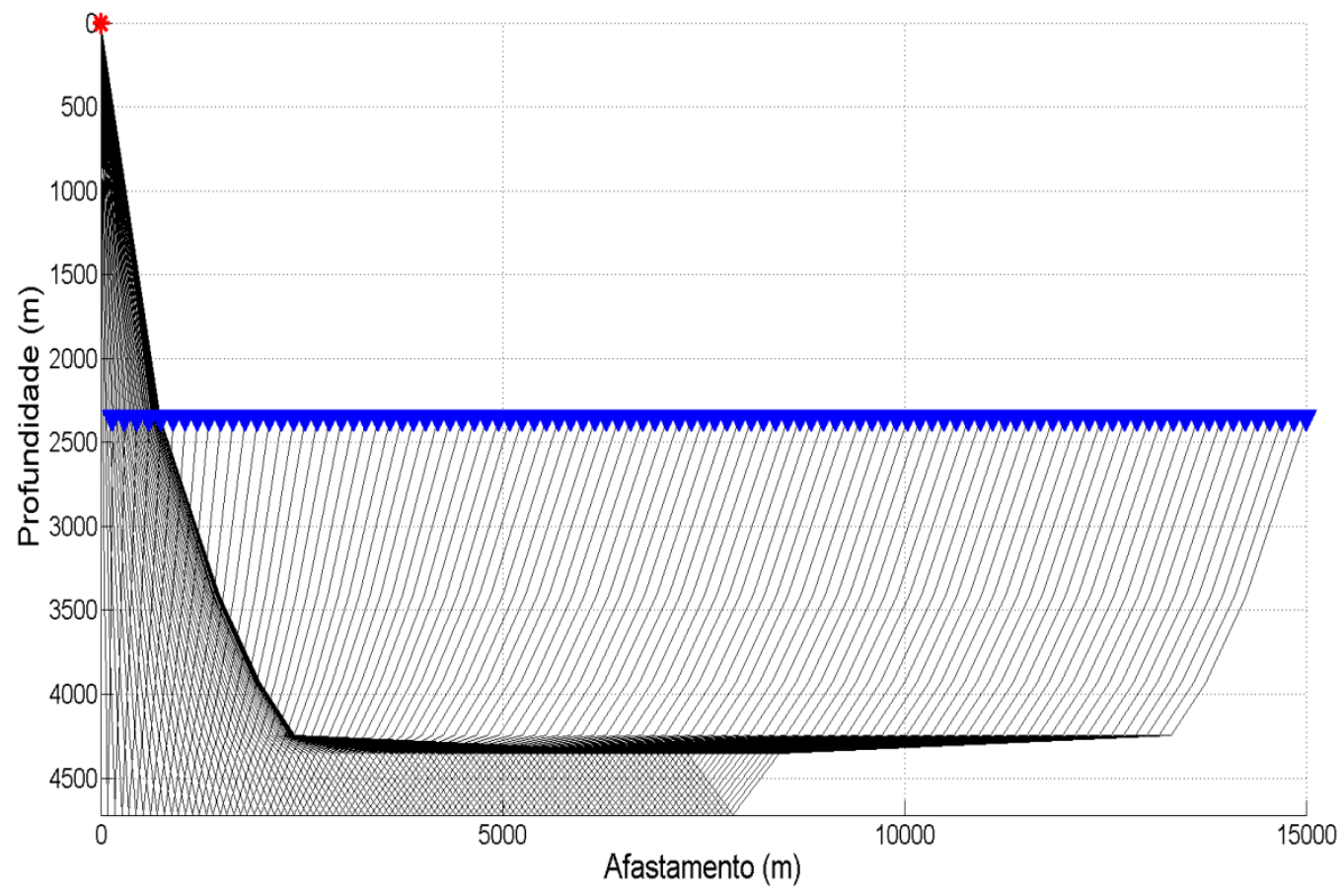

Figura 13: Esquematização de traçado de raios do evento de reflexão PP do Modelo 2.

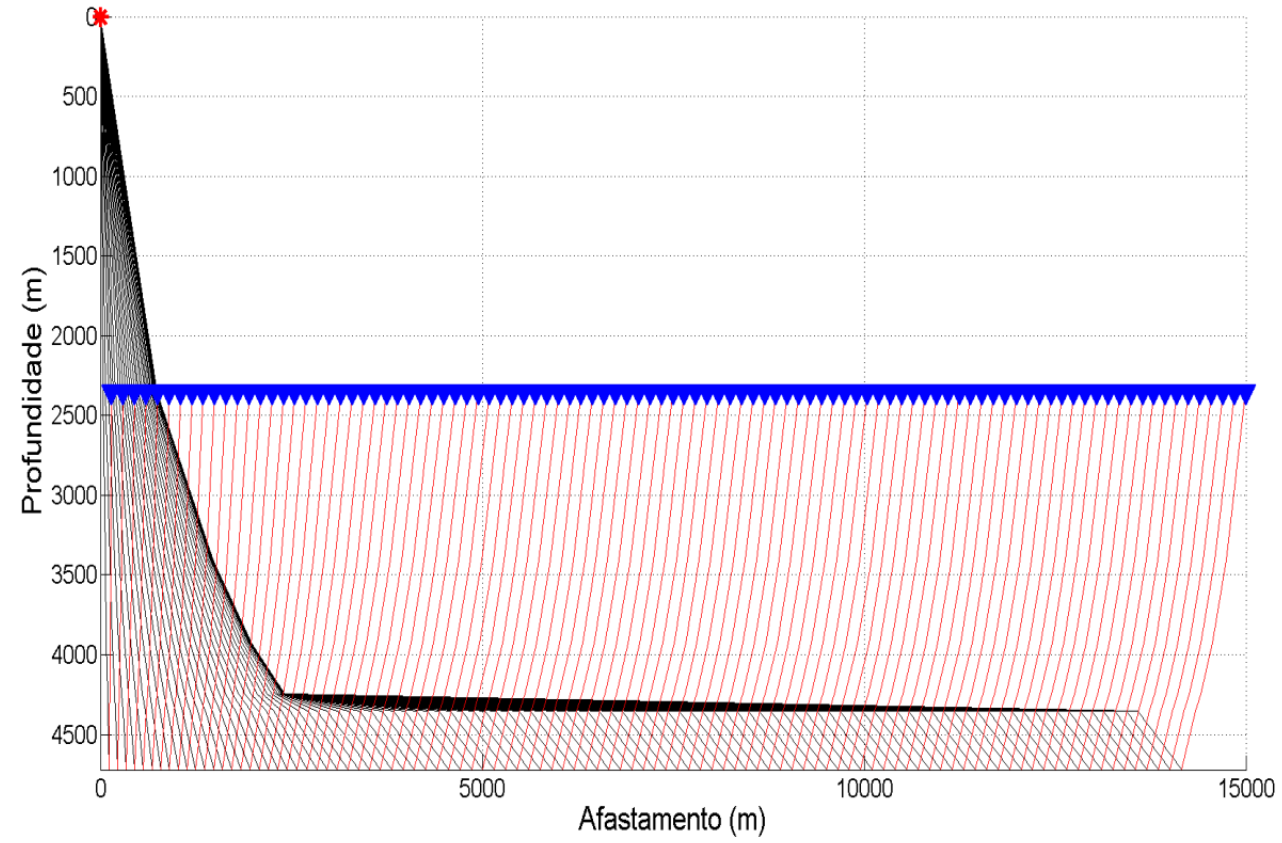

Figura 14: Esquematização de traçado de raios do evento de reflexão PS do Modelo 2. 


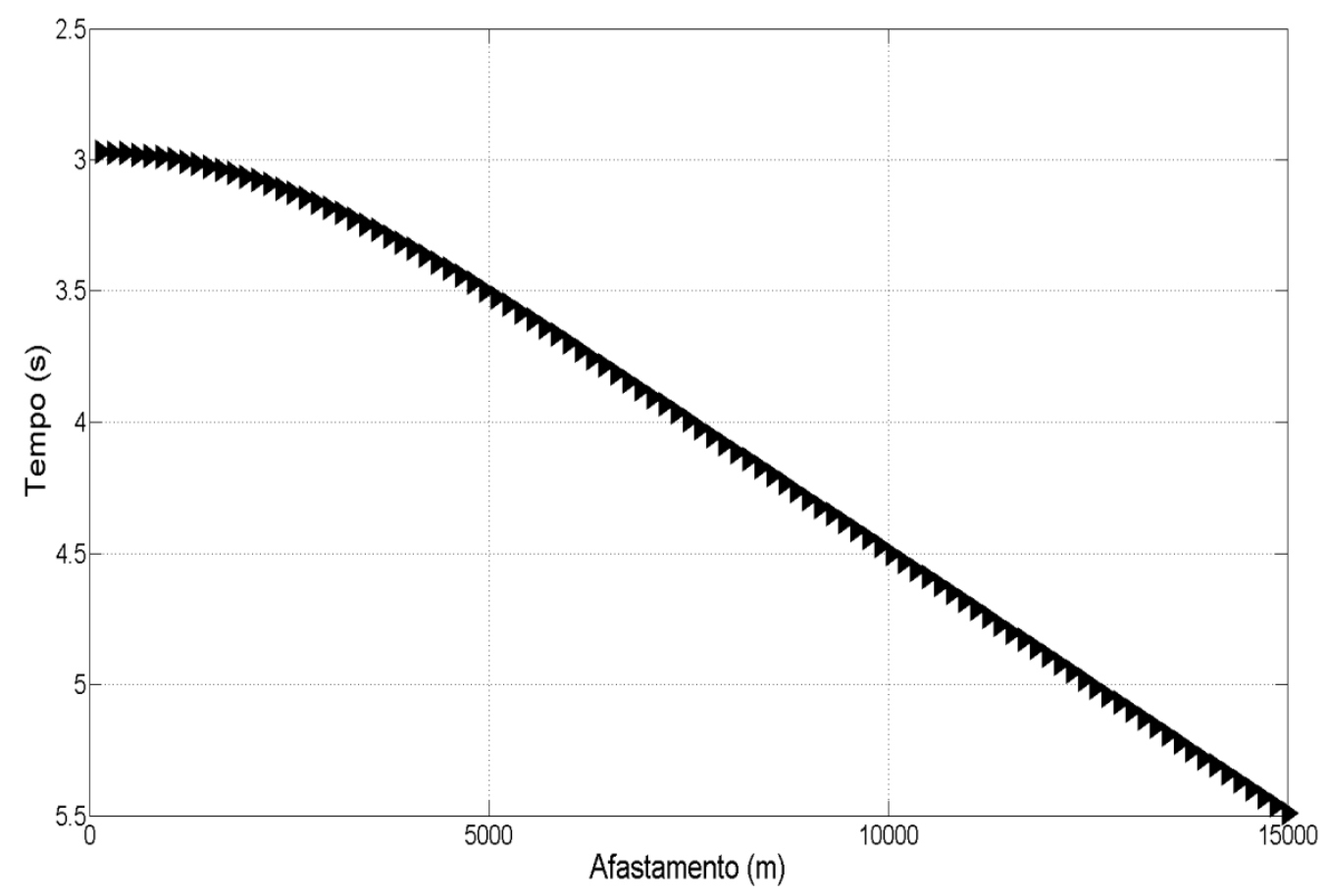

Figura 15: Curva de tempos de trânsito do evento de reflexão PP do Modelo 2.

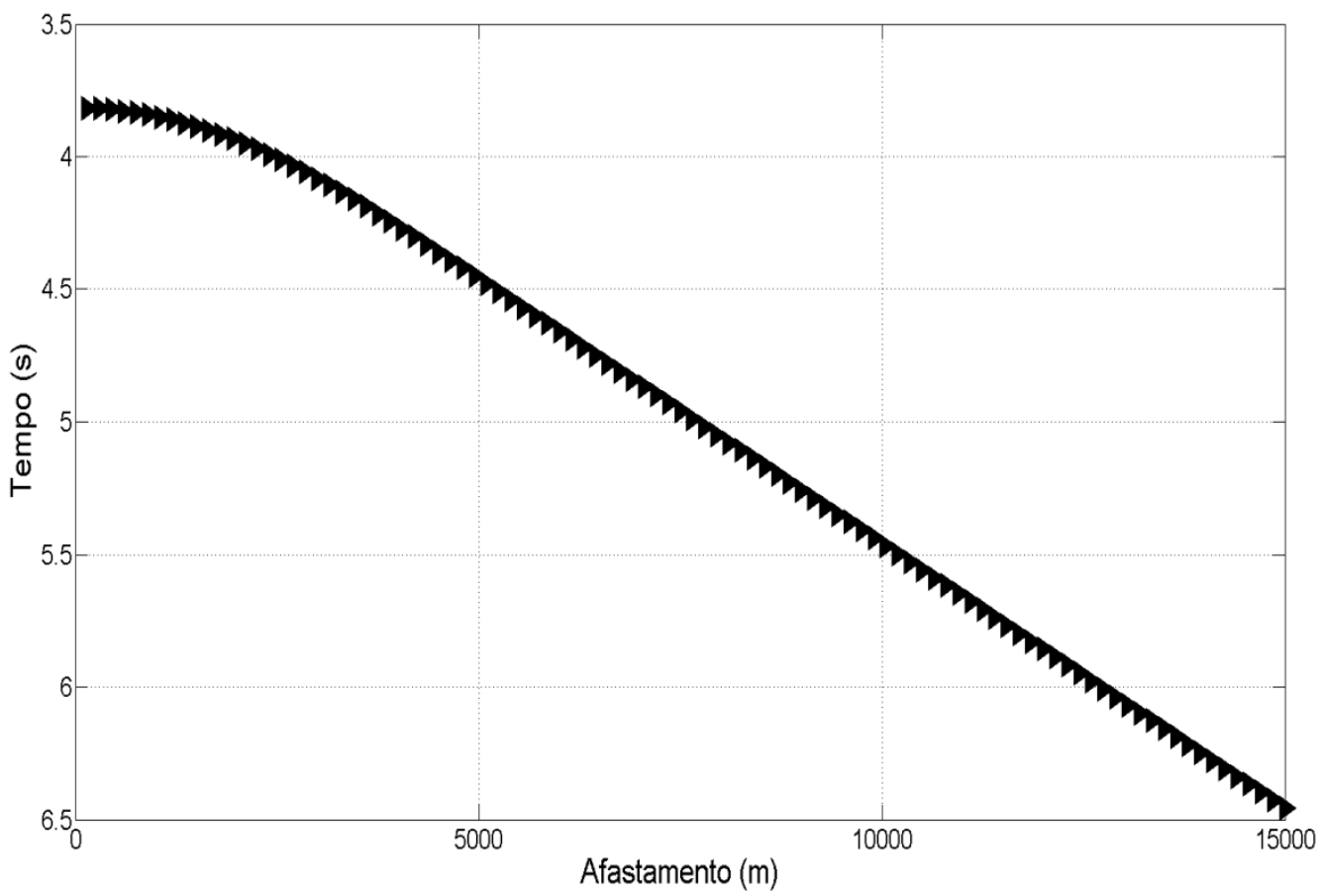

Figura 16: Curva de tempos de trânsito do evento de reflexão PS do Modelo 2. 


\subsection{Modelo 3}

O terceiro modelo apresenta uma estrutura salina semelhante à do Modelo 2, porém neste modelo a camada mais densa é consideravelmente mais espessa tendo aproximadamente 1000 metros. O perfil de velocidades, os traçados de raios e as curvas de tempos de trânsito para este modelo estão representados nas figuras 17, 18, 19, 20 e 21.

As informações de geometria do modelo e de geometria de aquisição são:

-Profundidade da fonte: 5 metros.

-Profundidade dos receptores (leito marinho): 2157 metros.

-Profundidade do topo da camada de sal: 3139 metros.

-Profundidade do topo do reservatório (base da camada de sal): 5005 metros.

-Número de receptores: 100.

-Afastamento mínimo entre fonte e receptor: 150 metros.

-Afastamento entre receptores: 150 metros.
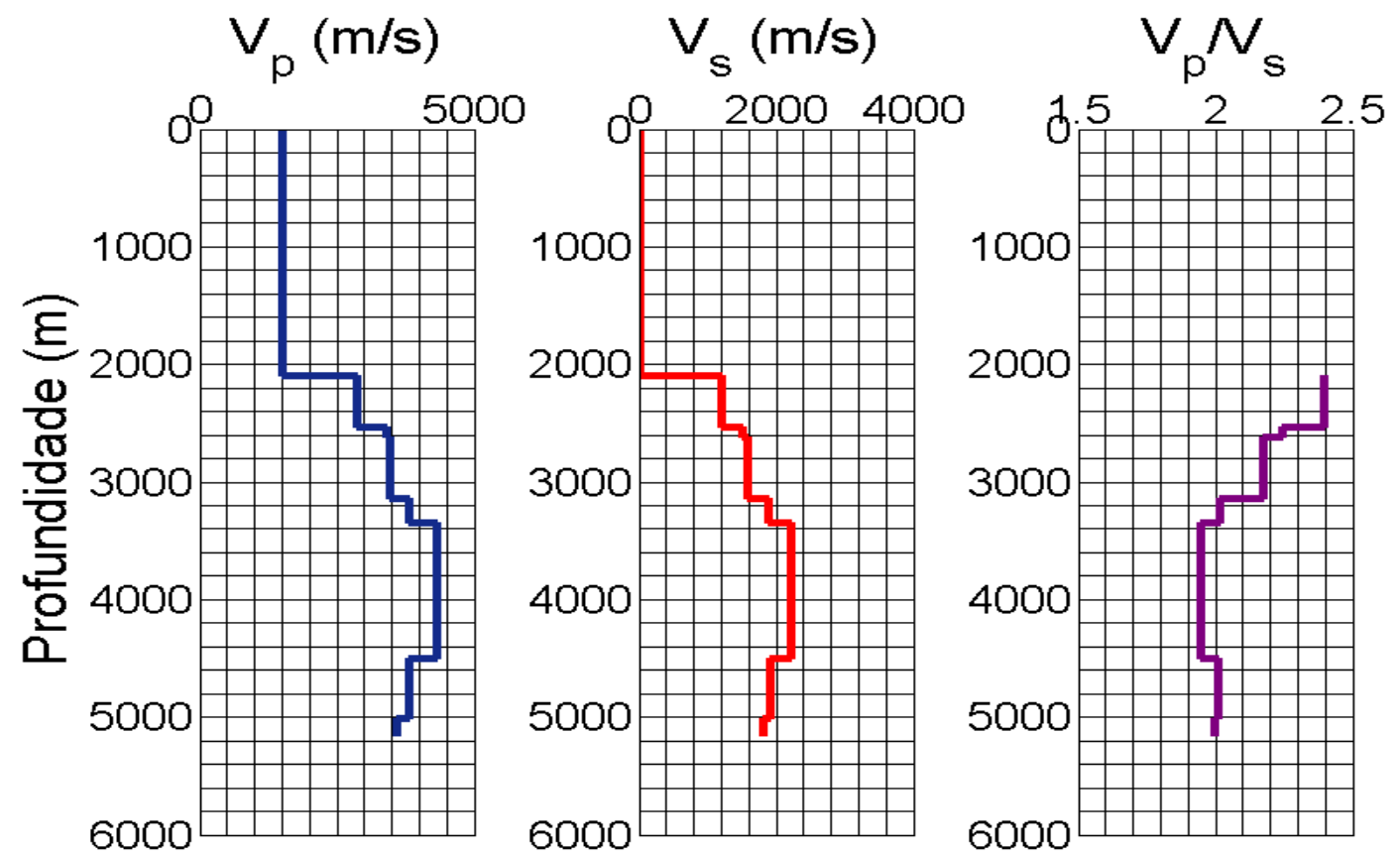

Figura 17: Perfis de velocidade de onda $\mathrm{P}$, velocidade de onda $\mathrm{S}$ e razão $\mathrm{Vp} / \mathrm{Vs}$ com relação à profundidade do Modelo 3. 


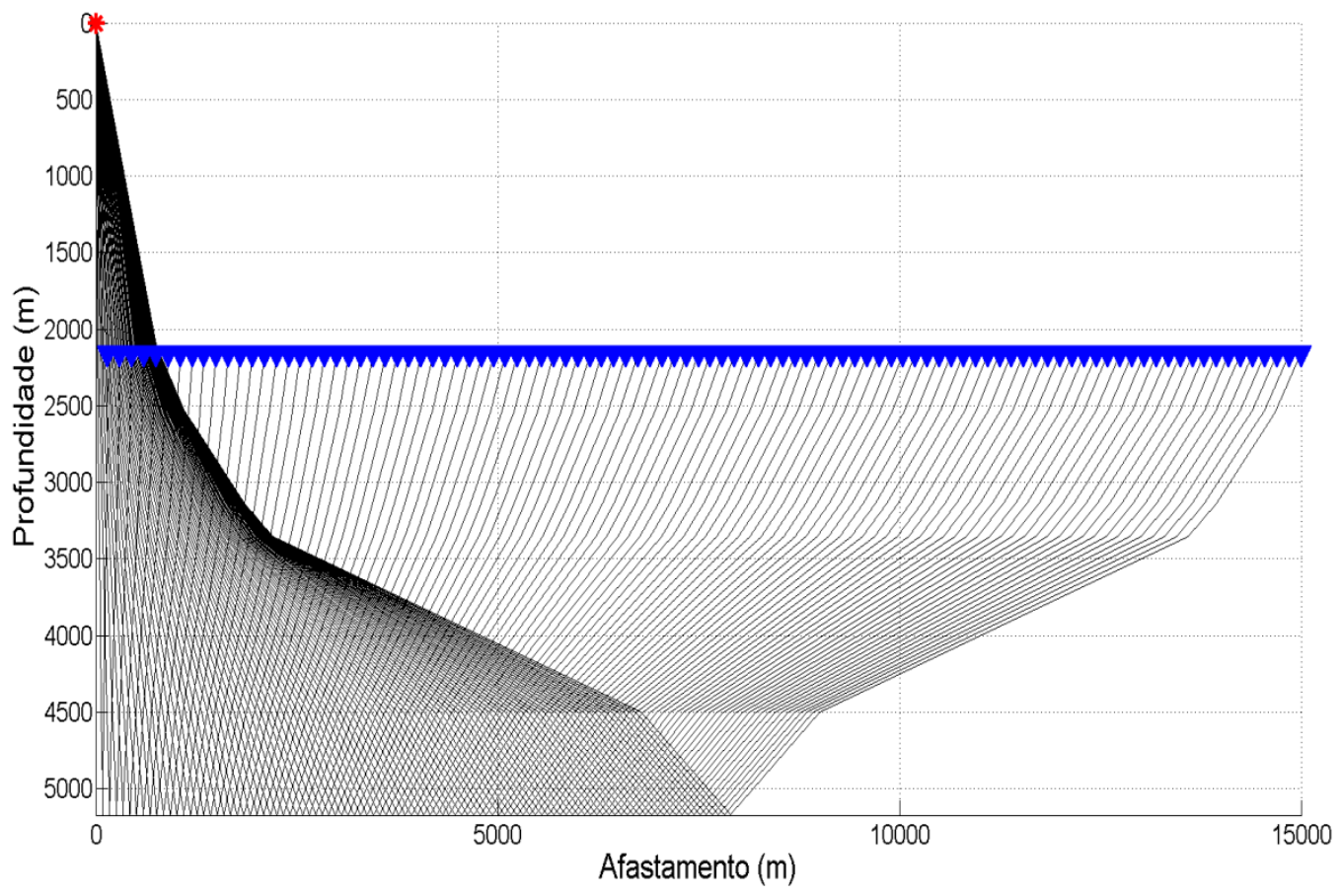

Figura 18: Esquematização de traçado de raios do evento de reflexão PP do Modelo 3.

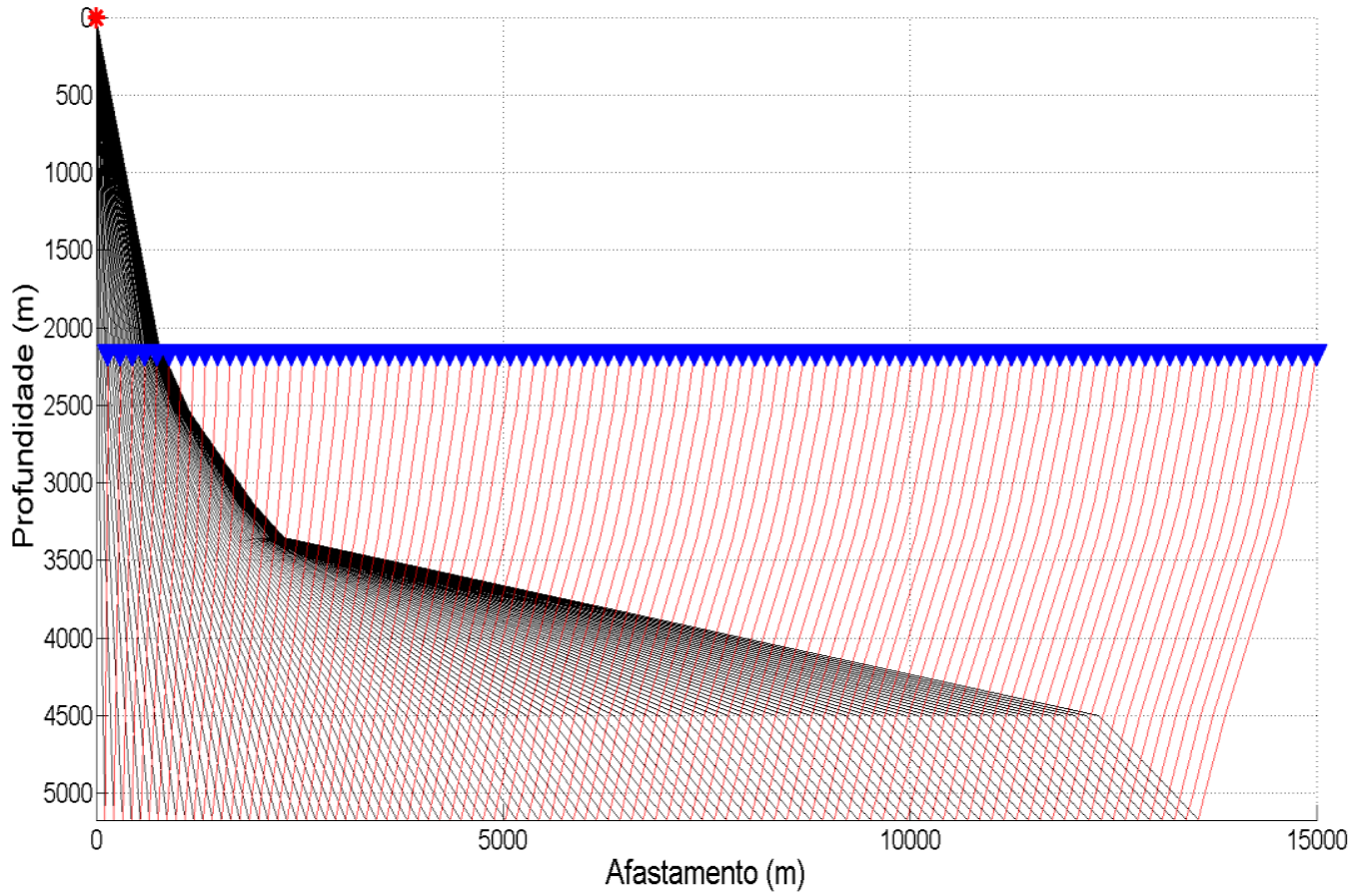

Figura 19: Esquematização de traçado de raios do evento de reflexão PS do Modelo 3. 


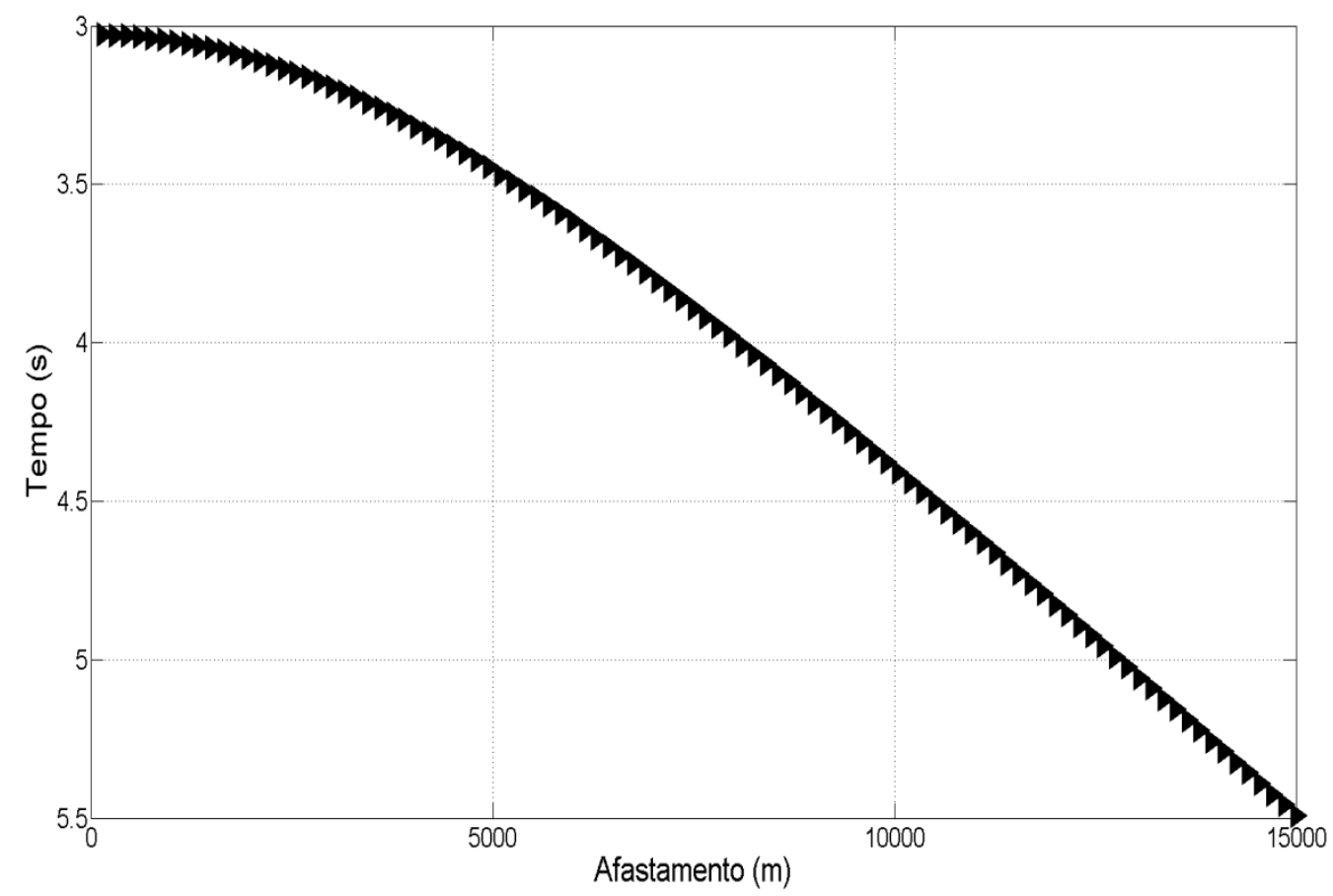

Figura 20: Curva de tempos de trânsito do evento de reflexão PP do Modelo 3.

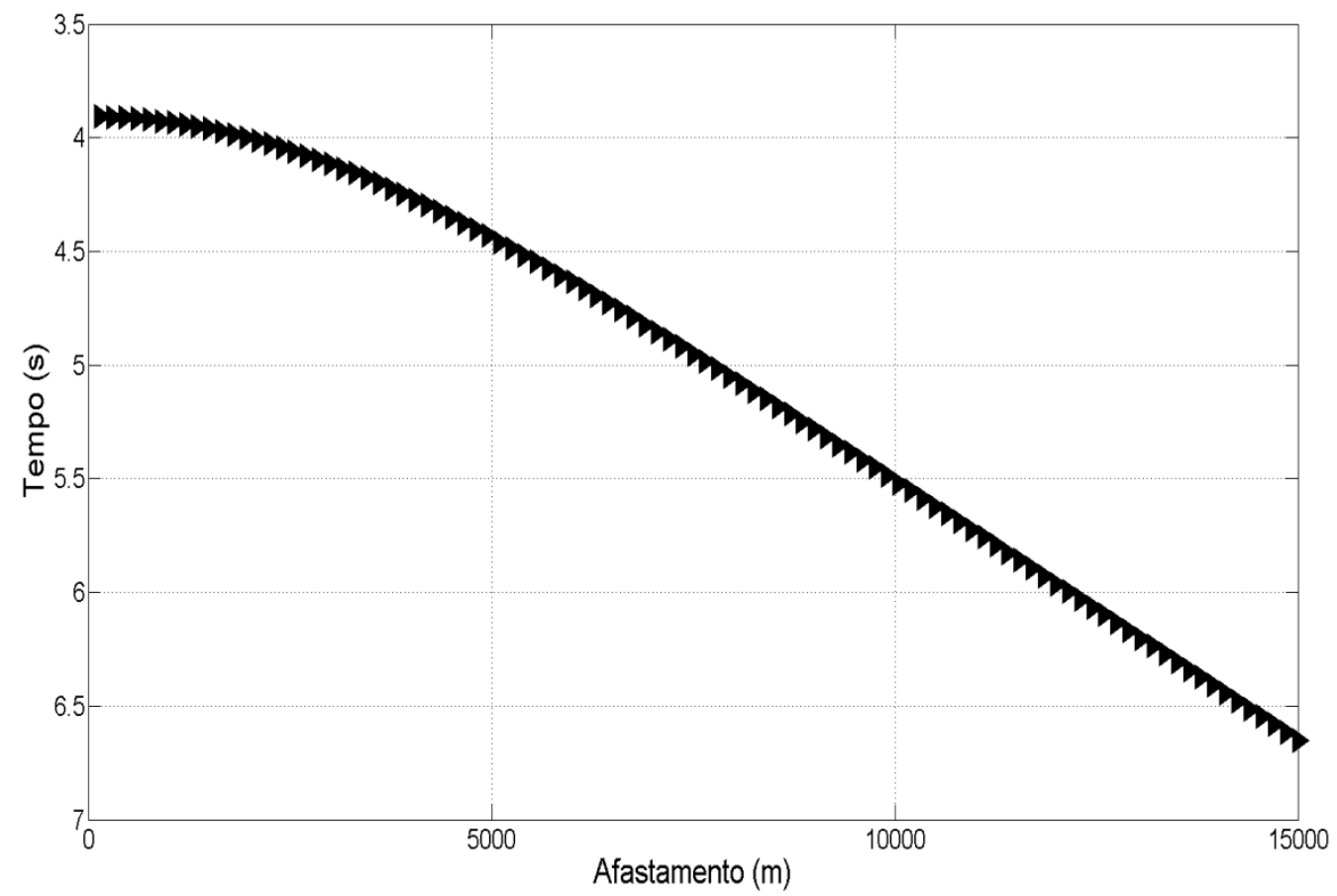

Figura 21: Curva de tempos de trânsito do evento de reflexão PS do Modelo 3. 


\subsection{Modelo 4}

O quarto modelo apresenta uma característica diferente dos demais, com a camada central da estrutura de sal sendo a menos densa, cercada por camadas mais densas, o que gera uma inversão de velocidades no trecho de sal. O perfil de velocidades, os traçados de raios e as curvas de tempos de trânsito para este modelo estão representados nas figuras 22, 23, 24, 25 e 26.

As informações de geometria do modelo e de geometria de aquisição são:

-Profundidade da fonte: 3 metros.

-Profundidade dos receptores (leito marinho): 2159 metros.

-Profundidade do topo da camada de sal: 3590 metros.

-Profundidade do topo do reservatório (base da camada de sal): 4949 metros.

-Número de receptores: 100.

-Afastamento mínimo entre fonte e receptor: 150 metros.

-Afastamento entre receptores: 150 metros.
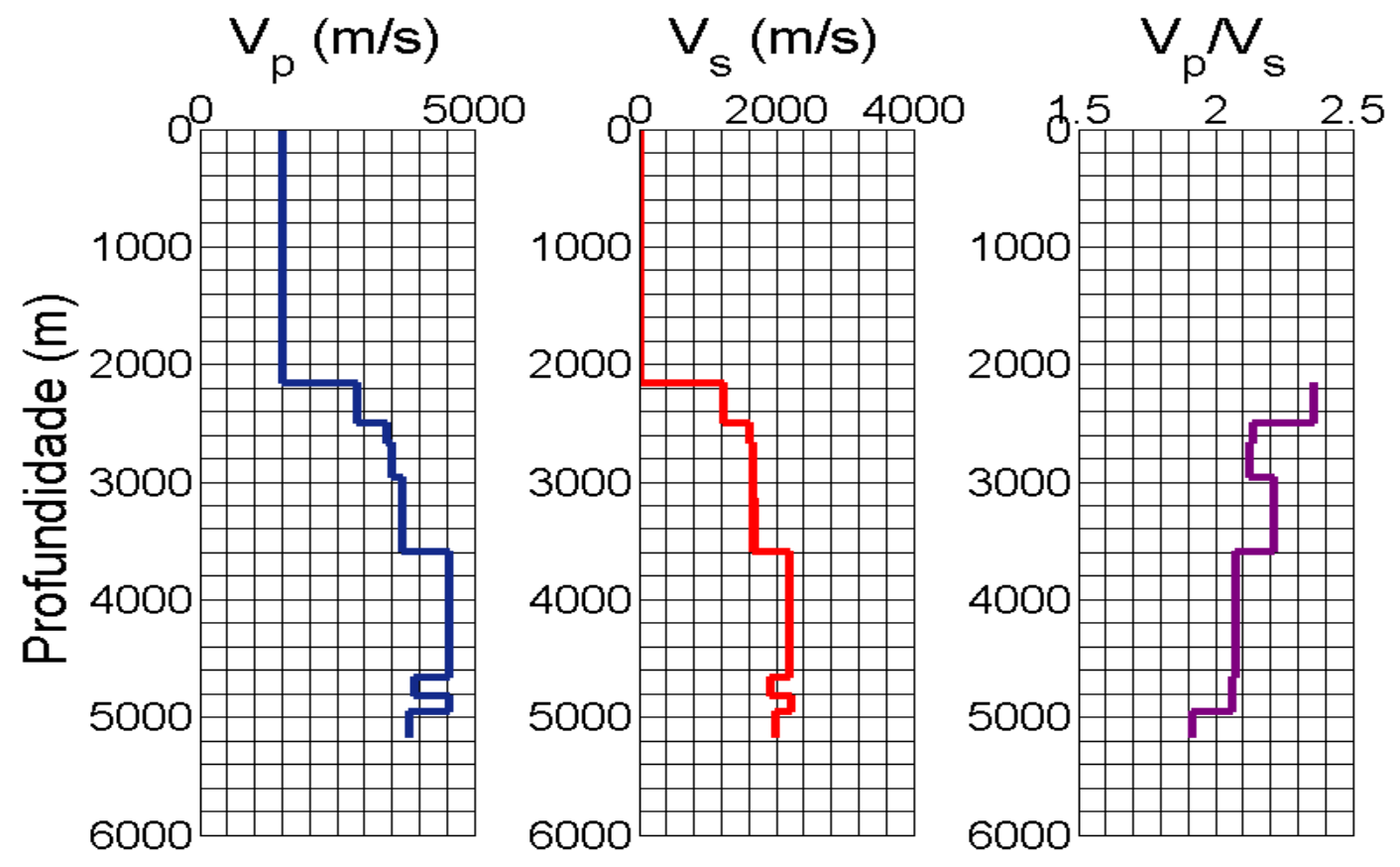

Figura 22: Perfis de velocidade de onda $\mathrm{P}$, velocidade de onda $\mathrm{S}$ e razão $\mathrm{Vp} / \mathrm{Vs}$ com relação à profundidade do Modelo 4. 


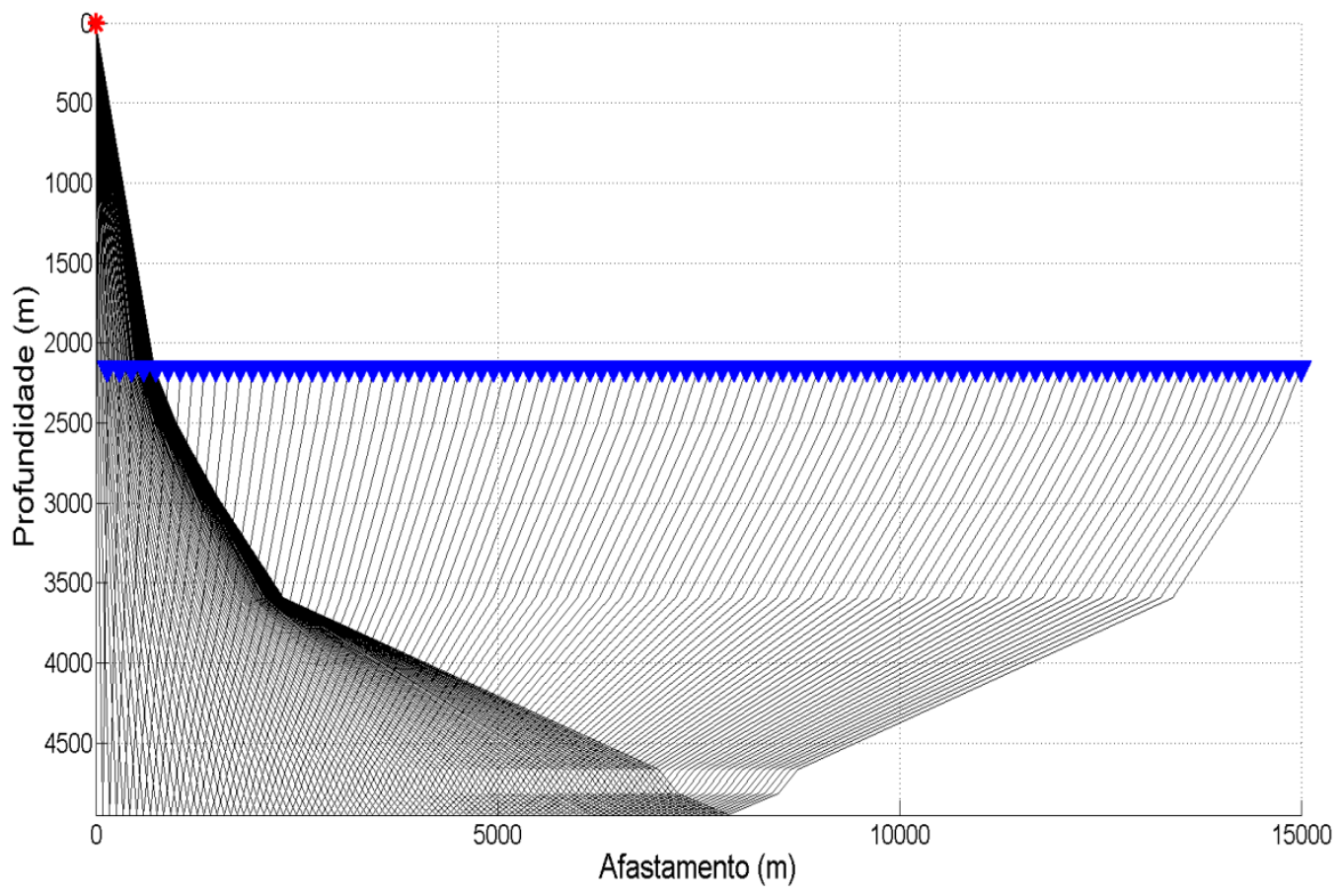

Figura 23: Esquematização de traçado de raios do evento de reflexão PP do Modelo 4.

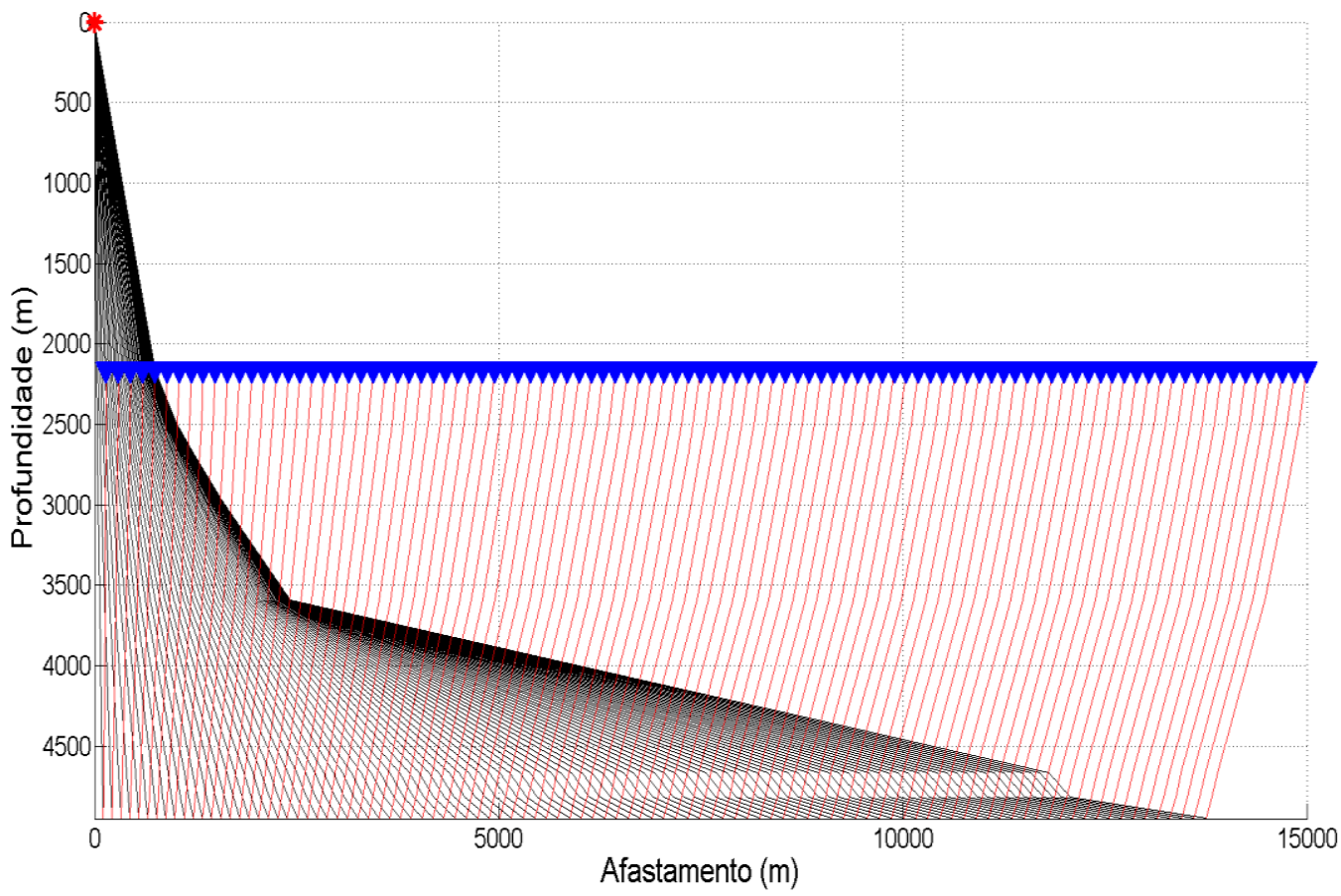

Figura 24: Esquematização de traçado de raios do evento de reflexão PS do Modelo 4. 


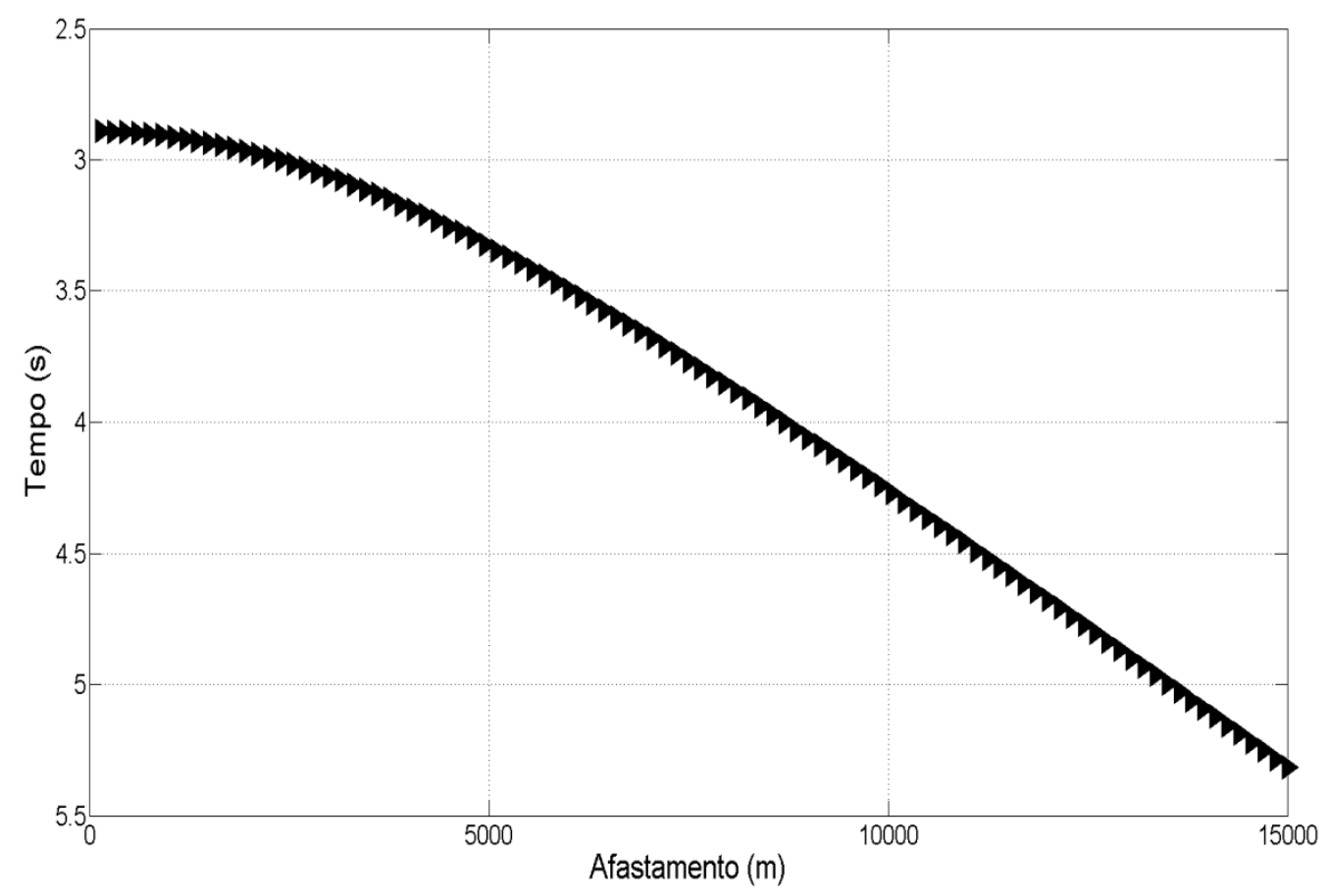

Figura 25: Curva de tempos de trânsito do evento de reflexão PP do Modelo 4.

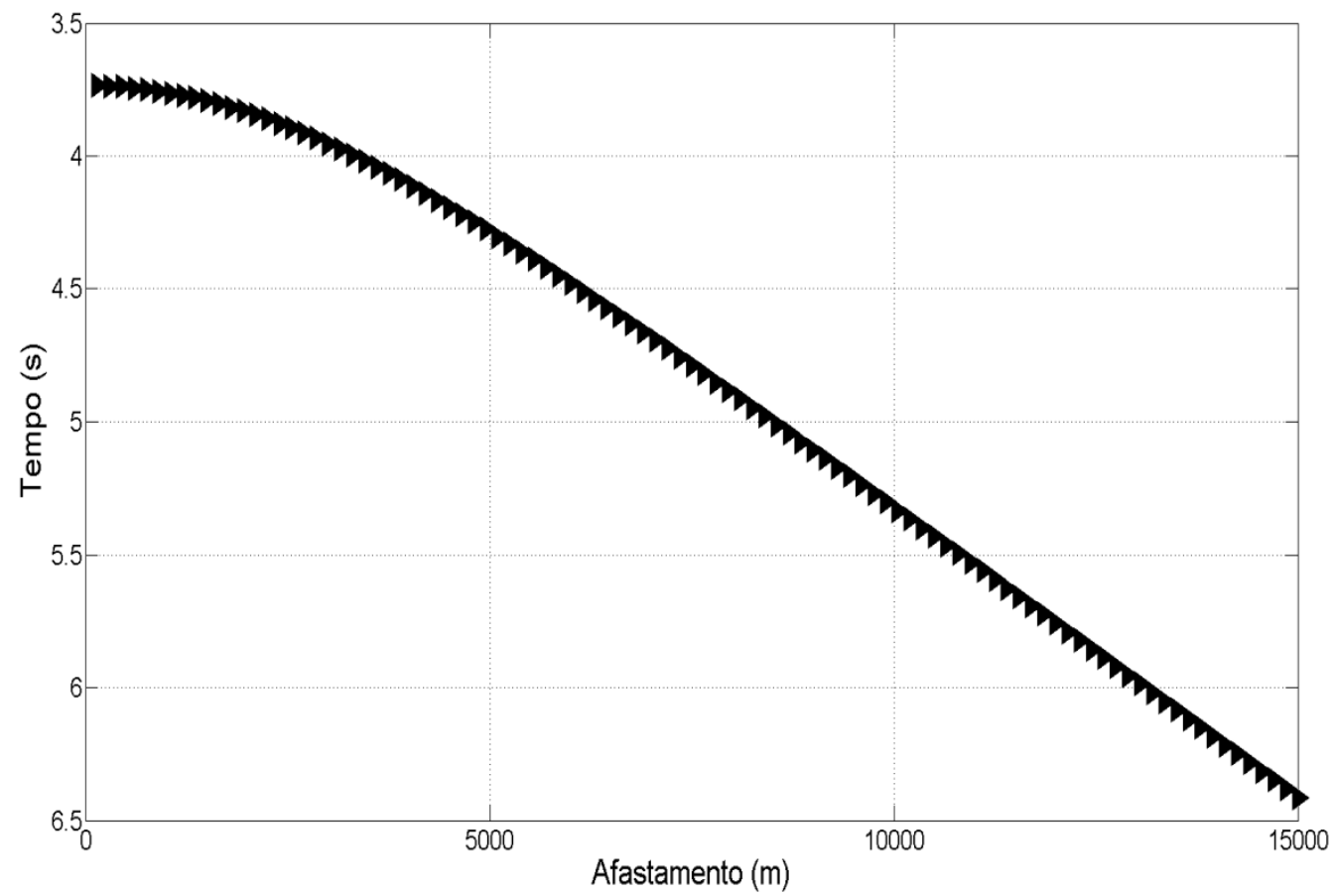

Figura 26: Curva de tempos de trânsito do evento de reflexão PS do Modelo 4. 


\subsection{Modelo 5}

O Modelo 5 é o mais complexo, tendo ao longo da estrutura salina de quase 2000 metros, diversas intercalações que geram inversões de velocidades abruptas. $\mathrm{O}$ perfil de velocidades, os traçados de raios e as curvas de tempos de trânsito para este modelo estão representados nas figuras $27,28,29,30$ e 31 .

As informações de geometria do modelo e de geometria de aquisição são:

-Profundidade da fonte: 3 metros.

-Profundidade dos receptores (leito marinho): 2257 metros.

-Profundidade do topo da camada de sal: 3251 metros.

-Profundidade do topo do reservatório (base da camada de sal): 4993 metros.

-Número de receptores: 100.

-Afastamento mínimo entre fonte e receptor: 150 metros.

-Afastamento entre receptores: 150 metros.
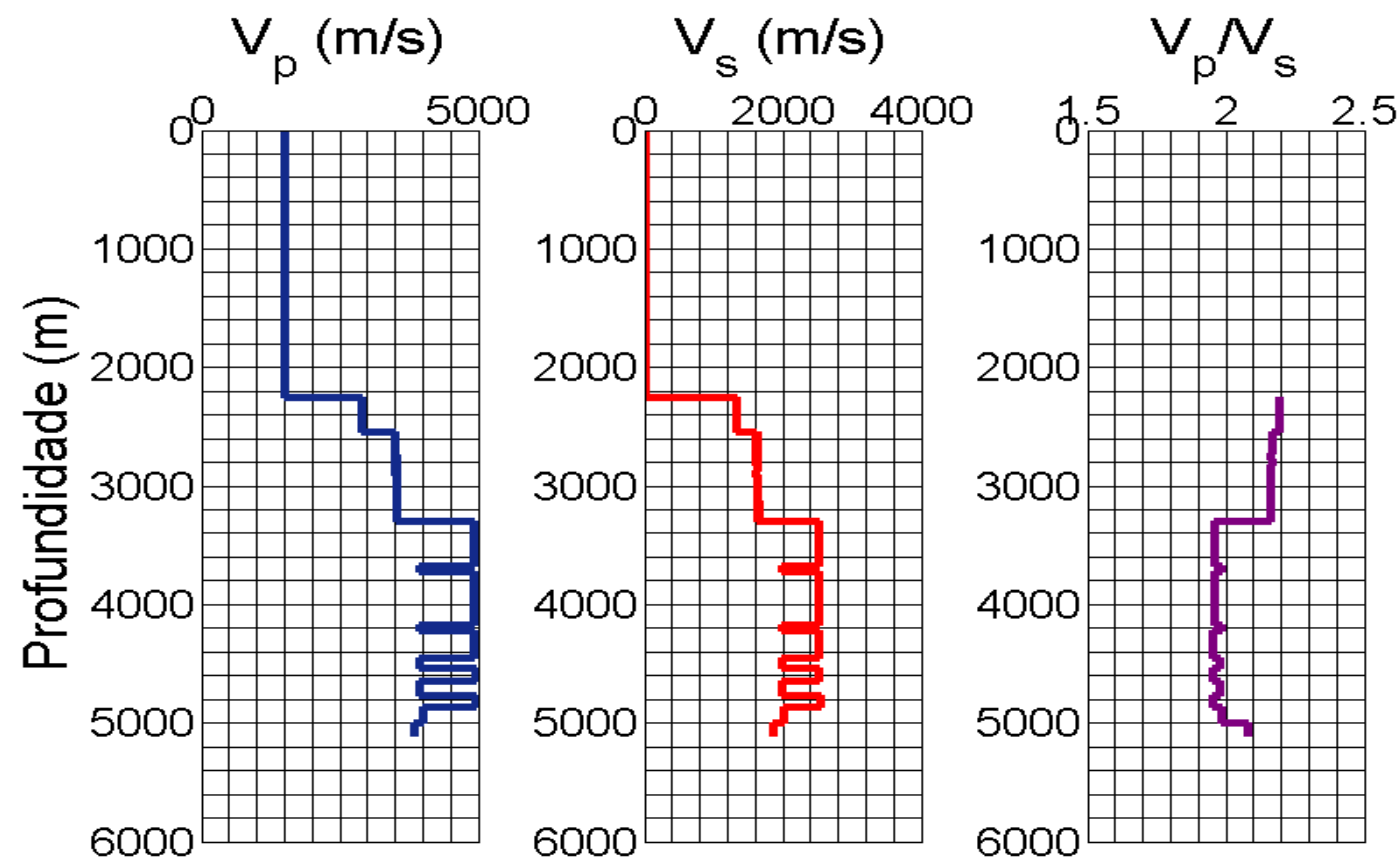

Figura 27: Perfis de velocidade de onda $\mathrm{P}$, velocidade de onda $\mathrm{S}$ e razão $\mathrm{Vp} / \mathrm{Vs}$ com relação à profundidade do Modelo 5. 


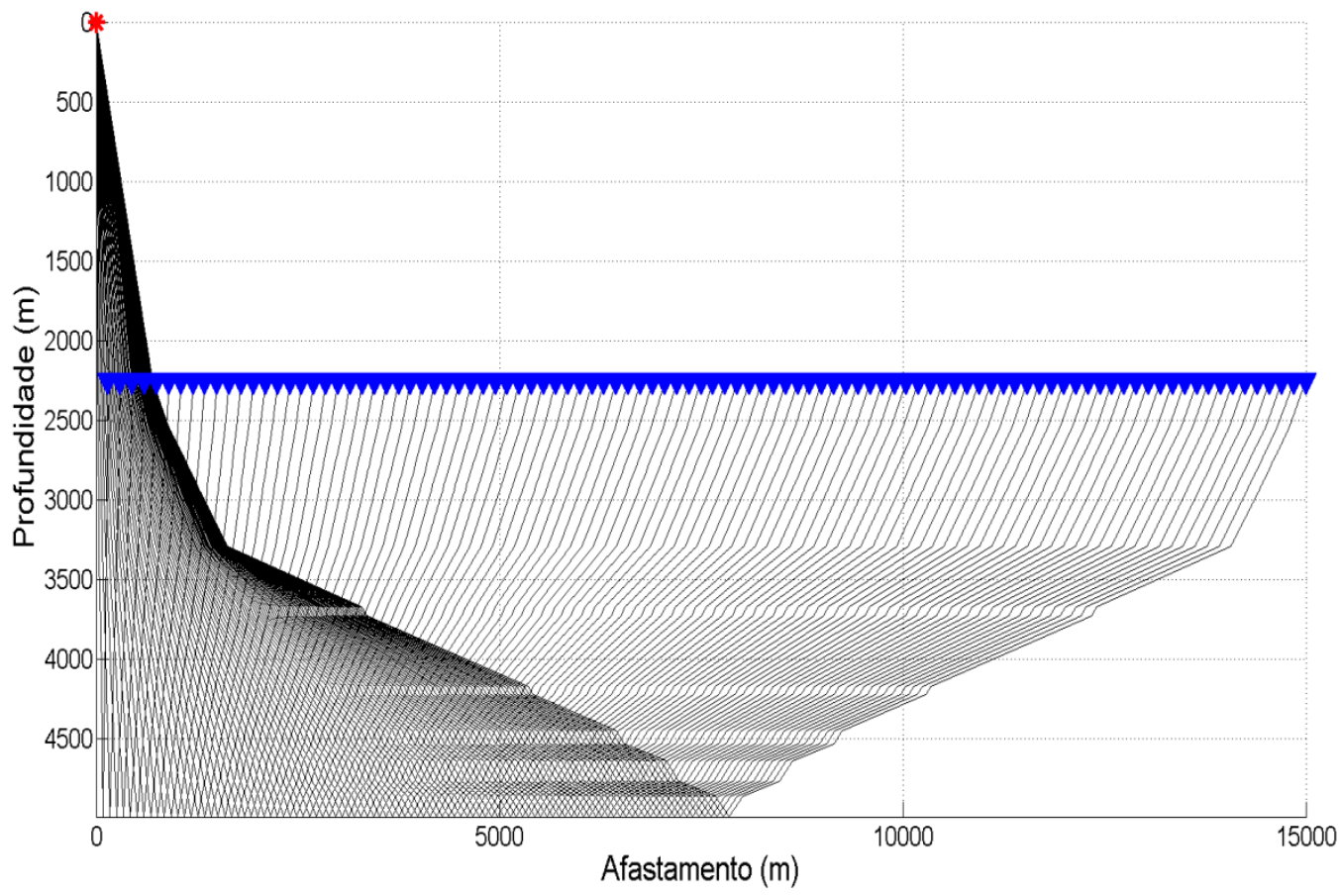

Figura 28: Esquematização de traçado de raios do evento de reflexão PP do Modelo 5.

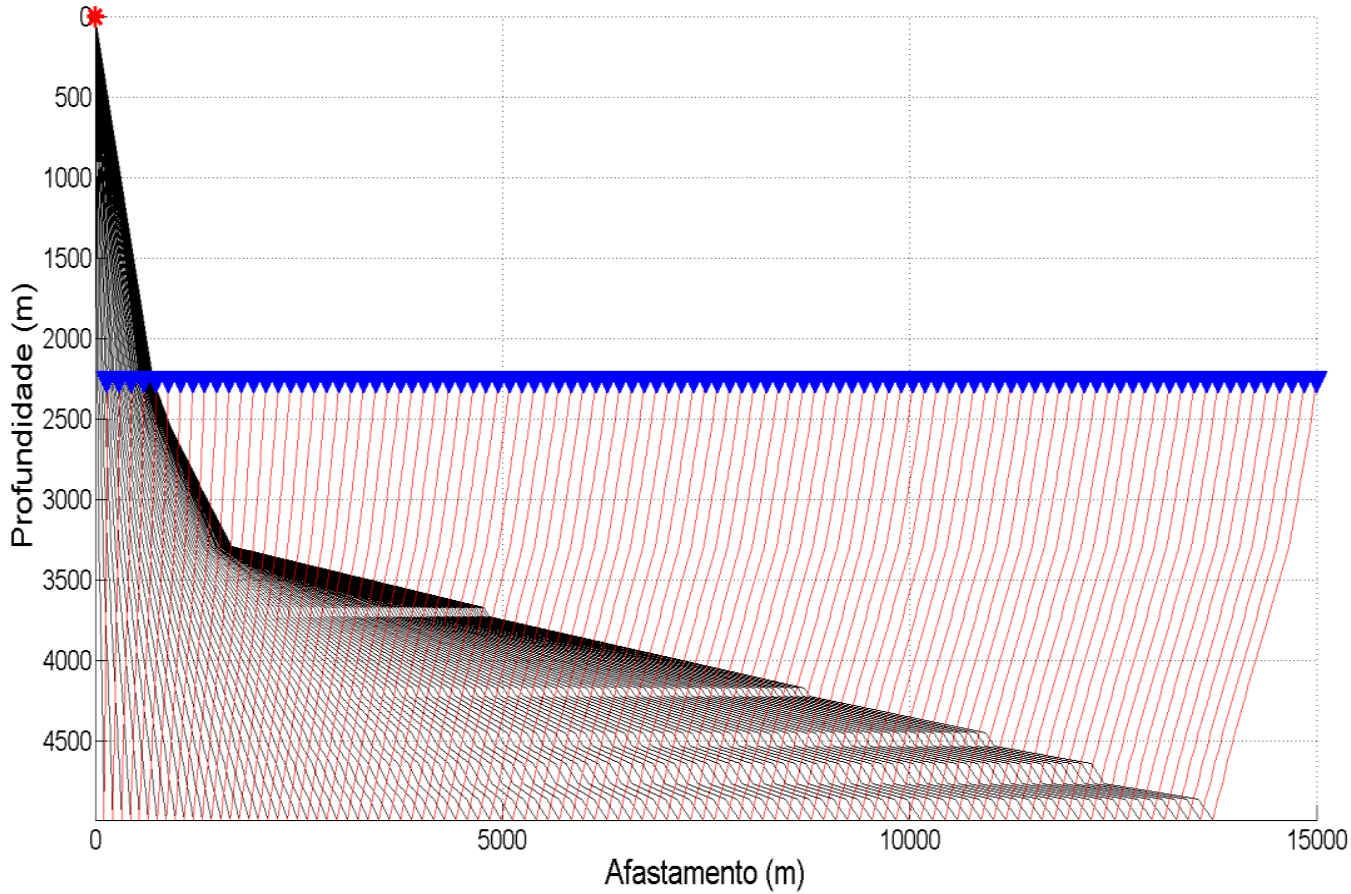

Figura 29: Esquematização de traçado de raios do evento de reflexão PS do Modelo 5. 


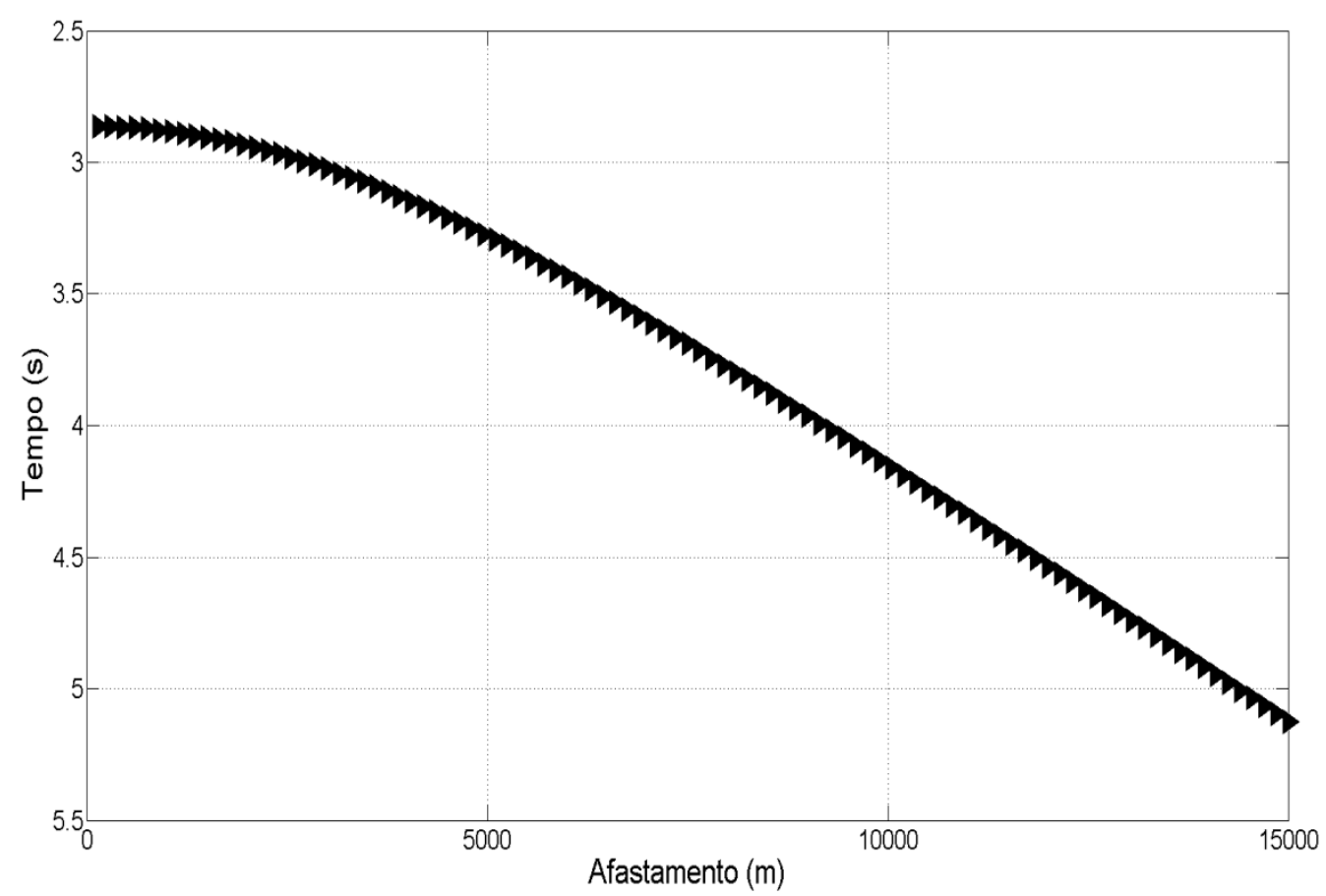

Figura 30: Curva de tempos de trânsito do evento de reflexão PP do Modelo 5.

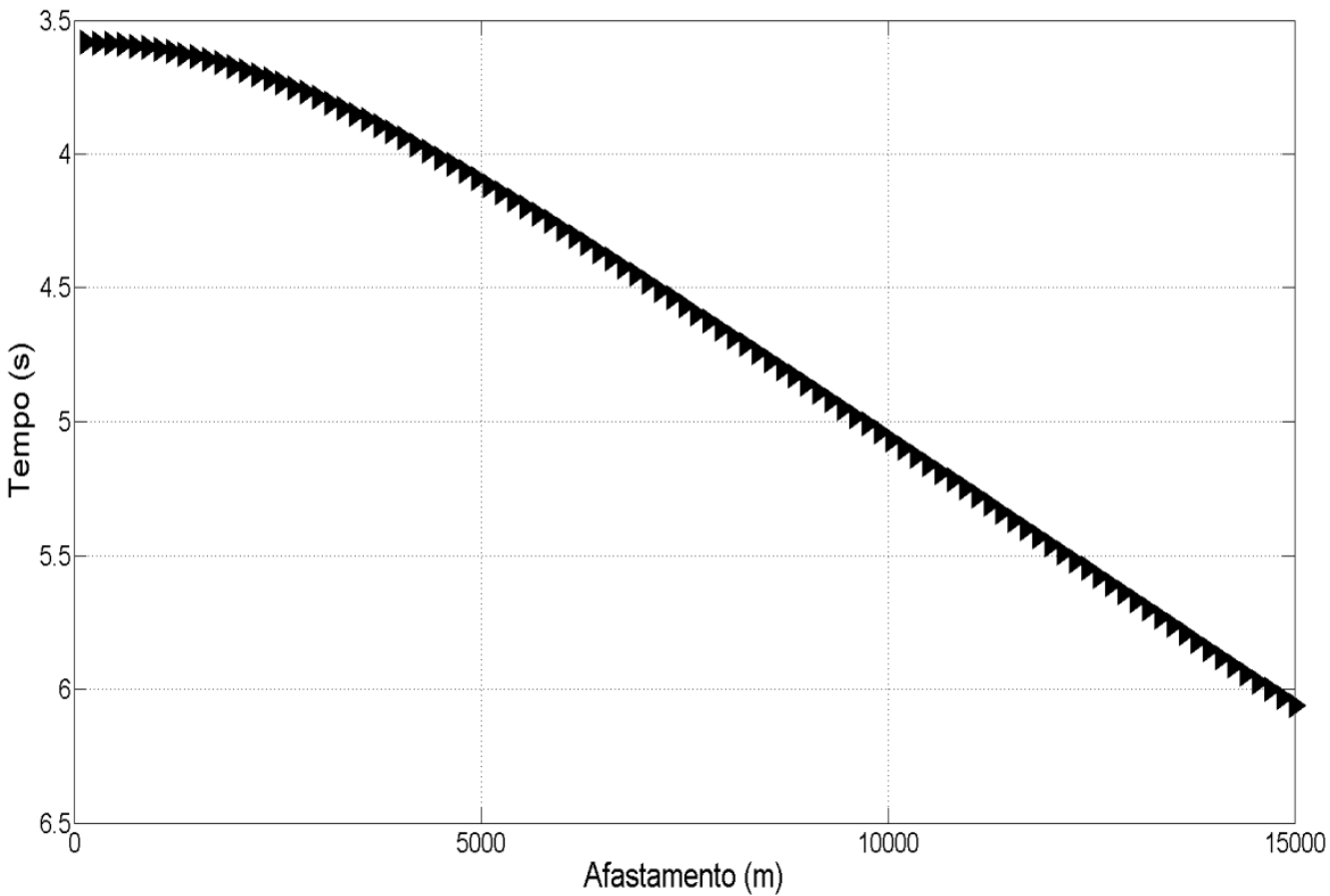

Figura 31: Curva de tempos de trânsito do evento de reflexão PS do Modelo 5. 


\section{METODOLOGIA}

\subsection{Expressões não-hiperbólicas para análise de velocidades}

Nas aproximações estudadas, $t$ é o tempo de trânsito duplo, $v$ é a velocidade de propagação da onda refletida, $t_{0}$ é o tempo para o afastamento nulo, e $x$ é o afastamento fontereceptor. Cada uma das aproximações utilizadas possui características próprias e, em geral, parâmetros adicionais que visam um melhor ajuste partindo de diferentes premissas.

A primeira aproximação é a própria equação da hipérbole (Equação 1), desenvolvida por Dix (1955), utilizada com o intuito de comparação com as às outras aproximações utilizadas.

$$
t=\sqrt{t_{0}^{2}+\frac{x^{2}}{v^{2}}}
$$

Malovichko (1978) desenvolveu uma aproximação chamada hipérbole deslocada (Equação 2), também estudada por Castle (1988 e 1994). Essa aproximação utiliza o parâmetro adicional $S$ (Equações 3 e 4) chamado de coeficiente de heterogeneidade, para a análise de velocidades em meios com heterogeneidade vertical em longos afastamentos.

$$
t=t_{0}^{2}\left(1-\frac{1}{S}\right)+\frac{1}{S} \sqrt{t_{0}^{2}+\frac{S x^{2}}{v^{2}}}
$$

Onde,

$$
S=\frac{\mu_{4}}{\mu_{2}^{2}}
$$

e

$$
\mu_{j=} \sum_{k=1}^{n} t_{k} v_{k}^{j} / \sum_{k=1}^{n} t_{k}
$$


Foi desenvolvida por Slotboom et al. (1990) uma equação visando a análise de velocidades para um comportamento não-hiperbólico proveniente da conversão de uma onda PP para PS. Essa equação é mais simples do que a maioria das equações não-hiperbólicas, pois ela não utiliza parâmetros adicionais, o que facilita sua implementação e proporciona um tempo de processamento menor (Equação 5).

$$
t=\frac{t_{0}}{2}+\sqrt{\frac{t_{0}^{2}}{2}+\frac{x^{2}}{2 v^{2}}}
$$

Alkhalifah e Tsvankin (1995) desenvolveram uma aproximação (Equação 6) para a análise de velocidades em meios com VTI (Vertical Transversal Isotropy), ou seja, simetria transversalmente isotrópica em relação ao eixo vertical. Tal aproximação se utiliza do parâmetro $\eta$ para quantificar a não-hiperbolicidade do evento. $\mathrm{O}$ parâmetro $\eta$ representa uma determinada anisotropia e é função dos parâmetros anisotrópicos de Thomsen (1986), $\varepsilon$ e $\delta$ (Equação 7).

$$
\begin{gathered}
t=\sqrt{t_{0}^{2}+\frac{x^{2}}{v^{2}}-\frac{2 \eta x^{4}}{v^{2}\left[t_{0}^{2} v^{2}+(1+2 \eta) x^{2}\right]}} \\
\eta=\frac{\varepsilon-\delta}{1+2 \delta}
\end{gathered}
$$

Sendo que $\varepsilon$ quantifica a diferença de velocidades para a propagação de onda ao longo do eixo de simetria e perpendicular ao eixo de simetria, e $\delta$ controla a propagação de onda $\mathrm{P}$ para ângulos próximos do eixo de simetria.

Ursin e Stovas (2006) desenvolveram uma aproximação fracional (Equação 8), com o parâmetro de heterogeneidade $S$ (Malovichko, 1978), também estudado por Fomel e Grechka (2001):

$$
t=\sqrt{t_{0}^{2}+\frac{x^{2}}{v^{2}}-\frac{(S-1) x^{4}}{4 v^{4}\left(t_{0}^{2}+\frac{(S-1)}{2} \frac{x^{2}}{v^{2}}\right)}}
$$


Foi proposta por Blias (2009) (Equação 9) uma expressão que também utiliza o parâmetro de heterogeneidade $S$, da mesma forma que a equação da hipérbole deslocada (Equação 2).

$$
t=\frac{1}{2} \sqrt{t_{0}^{2}+\frac{1-\sqrt{S-1}}{v^{2}}} x^{2}+\frac{1}{2} \sqrt{t_{0}^{2}+\frac{1+\sqrt{S-1}}{v^{2}}} x^{2}
$$

Muir e Dellinger (1985) propuseram uma equação que faz uso do parâmetro $f$, um parâmetro adimensional de anelipticidade (Equação 10), que descreve o quanto a frente de onda difere do formato esférico, fenômeno estudado também por Fomel e Grechka (2000).

$$
t=\sqrt{t_{0}^{2}+\frac{x^{2}}{v^{2}}-\frac{f(1-f) \mathrm{x}^{4}}{v^{2}\left(v^{2} t_{0}^{2}+f x^{2}\right)}}
$$

$\mathrm{Na}$ equação de Li (2001) (Equação 11), utiliza-se como terceiro parâmetro o $\gamma$ (Equação 12), e tal aproximação visa obter melhores informações sobre o CP (Converted Point).

$$
\begin{gathered}
t=\sqrt{t_{0}^{2}+\frac{x^{2}}{v^{2}}-\frac{(\gamma-1)}{\gamma v^{2}} \frac{(\gamma-1) x^{4}}{4 t_{0}^{2} v^{2}+(\gamma-1) x^{2}}} \\
\gamma=\gamma_{i s o}=\frac{v_{P 2}^{2}}{v_{C 2}^{2}}=\frac{\gamma_{e f f}\left(1+\gamma_{0}\right)}{\left(1+\gamma_{e f f}\right)}
\end{gathered}
$$

Sendo $\gamma_{i s o}$ é a razão entre os quadrados das velocidades de empilhamento de onda $\mathrm{P}$ e a de onda convertida, $v_{P 2}$ é a velocidade de empilhamento da onda $\mathrm{P}, v_{C 2}$ é a velocidade de empilhamento de onda convertida, $\gamma_{2}$ é a razão entre as velocidades de ondas $\mathrm{P}$ e $\mathrm{S}$ de empilhamento e $\gamma_{0}$ é a razão entre a velocidades de onda $\mathrm{P}$ e onda $\mathrm{S}$ que se propagam na componente normal. 
O parâmetro $\gamma_{e f f}$ é a razão entre o quadrado de $\gamma_{2}$ e $\gamma_{0}$ (Equação 13).

$$
\gamma_{e f f}=\frac{\gamma_{2}^{2}}{\gamma_{0}}
$$

Tal parâmetro foi utilizado por Yuan (2002) para razão entre afastamento e profundidade de até 1,5 $(x / z=1,5)$, trazendo ótimos resultados para tal condição. No entanto, de acordo com Yuan (2002) essa aproximação também é apropriada para valores de razão $x / z$ até 2.7 em meios isotrópicos homogêneos.

\subsection{Inversão dos tempos de trânsito}

O problema inverso baseia-se em determinar a causa a partir do efeito (Alifanov, 1995; Duarte, 2010; Aster, Borches e Thurber, 2012), sendo assim temos que os tempos de trânsito são o efeito e a partir dele poderemos determinar a causa, ou seja, caracterizar o modelo estudado. Para tal é fundamental conhecer a procedência dos dados para que não haja interferência na qualidade da análise do modelo (Tarantola, 2005).

A inversão proposta no presente trabalho é baseada no ajuste das curvas calculadas com cada uma das aproximações selecionadas com a curva correspondente observada no registro sísmico. Para a análise hiperbólica, é convencionalmente utilizada a aproximação hiperbólica, com o objetivo de ajustar a curva calculada à observada. Entretanto essa aproximação não é apropriada quando o evento não é hiperbólico (Malovichko, 1978; Castle, 1988 e 1994; Causse, Haugen e Rommel, 2000).

É proposto no presente trabalho que a inversão seja feita, para eventos de reflexão de ondas PP e PS, seguindo um critério de otimização utilizando aproximações não-hiperbólicas multiparamétricas, que serão comparadas à aproximação utilizada normalmente e entre si. Com isso, será possível identificar a aproximação mais adequada para a análise de velocidades e correção de NMO. 


\subsubsection{Problema direto}

O problema direto é intrinsecamente relacionado ao processo de inversão, pois nele é possível identificar o efeito a partir da causa (Duarte, 2010; Aster, Borches e Thurber, 2012).

Propõe-se que o problema direto parta da obtenção dos tempos de trânsito de um evento de reflexão de onda PP e PS, em função dos afastamentos fonte-receptor, por meio do método de traçado de raios. As modelagens foram feitas para meios multicamadas, com longos afastamentos fonte-receptor, em águas ultra-profundas (profundidades maiores de 1500 metros) e utilizando a tecnologia OBN para a obtenção dos tempos de trânsito de ondas convertidas.

\subsubsection{Análise de função objetivo}

A função objetivo é, na matemática, uma função que define a qualidade de uma solução em função de suas variáveis.

A metodologia utilizada, para que seja possível estimar os parâmetros das aproximações dos tempos de trânsito, baseia-se na implementação de um algoritmo com o objetivo de otimizar o ajuste das curvas para reflexões de ondas PP e PS.

O método dos mínimos quadrados é uma abordagem padrão para aproximação de soluções. Este método consiste em buscar o melhor ajuste para um conjunto de dados visando a minimização da soma dos quadrados das diferenças entre os valores estimados e observados (Stigler, 1981). No presente trabalho a função dos mínimos quadrados foi utilizada para a inversão visando mensurar o quão próximos são os tempos de trânsito estimados por meio das aproximações e os observados. Com o valor de mínimo da função, têm-se o ajuste ótimo, uma vez que a soma dos quadrados das diferenças entre os tempos de trânsito estimados e observados é a mínima possível.

Com isso é necessário efetuar a escolha do algoritmo de busca; entretanto, é fundamental analisar o quão complexo é o problema estudado. Essa análise é feita convencionalmente, observando os mapas residuais de função objetivo (Larsen, 1999, Kurt, 2007). É apropriado utilizar esse tipo de análise para os problemas que possuam duas incógnitas, mas nos casos de um problema inverso com mais de duas incógnitas não é possível ter informações confiáveis sobre a complexidade da função. Isso se dá pelo fato de 
que para a construção do mapa, dois parâmetros são variáveis (velocidade e o parâmetro adicional) e o terceiro (tempo normal) é fixado em seu valor associado ao valor de mínimo, ou seja, o valor mais próximo do correto.

Para suprir as limitações da metodologia tradicional foi adotada uma metodologia que consiste em analisar as dispersões dos resultados obtidos de diversas inversões. No presente trabalho propõe-se obter as dispersões a partir da utilização do algoritmo de busca NelderMead junto do procedimento Multi-start. Os resultados obtidos poderão ser plotados em forma de um mapa de três dimensões, onde no eixo vertical e horizontal estarão os parâmetros em questão, e a terceira dimensão está representada pelos valores dos mínimos da função objetivo (Bokhonok, 2010) discriminados com cores para diferentes faixas de valores da função. Analisando a dispersão nesse tipo de mapa, são facilmente diferenciados os mínimos locais do global.

\subsubsection{Otimização pelo método Nelder-Mead}

O objetivo principal da otimização é chegar a uma melhor opção dentre um determinado conjunto de alternativas, ou seja, maximizar ou minimizar uma função selecionando valores de entrada e os armazenando para então encontrar um valor de máximo ou mínimo (Horst, Pardalos e Thoai, 2000). Os processos de otimização, em sua maioria, gera uma melhoria a cada interação até que haja uma convergência no ponto de mínimo da função, porém vários modelos podem apresentar mais de uma solução, devido à sua nãolinearidade. Isso é muito comum durante a resolução de problemas inversos, onde o foco da inversão é obter a melhor aproximação possível dos parâmetros a serem estimados. Para resolver as inversões no presente trabalho foi utilizado o método Nelder-Mead com o intuito de minimizar a função objetivo.

Nelder e Mead (1965) foram responsáveis pelo desenvolvimento do método de otimização que leva o nome de seus criadores (método Nelder-Mead), baseado no trabalho de Spendley et al. (1962). O método em questão tem como base implementar um algoritmo que se utiliza de um simplex, um polítopo de $n+1$ vértices em $n$ dimensões, e com arestas de mesmo tamanho, apresentado de maneira mais detalhada por Lewis, Torczon e Trosset (2000). O objetivo desse método é, a partir do simplex, obter a melhor aproximação possível da direção do gradiente estudado, onde o gradiente crescente maximiza a função objetivo e o 
gradiente decrescente a minimiza. Esse processo baseia-se em substituir o pior vértice do simplex por um ponto refletido através do centróide da aresta oposta.

Como um polítopo com um número de dimensões igual ou maior do que quatro deve possuir cinco ou mais vértices, a representação gráfica mais adequada é por meio de projeções ortogonais em modelos bidimensionais ou tridimensionais (Coxeter, 1948).

O principal foco deste algoritmo era gerar uma convergência no menor tempo possível, fundamentada em diferentes formas de movimentação do simplex, a partir das quais eram substituídos os piores vértices por outros mais adequados. Dessa forma os novos simplex era originados a partir de um anterior. A interação do algoritmo é dividida em algumas etapas e parte de um ponto inicial aleatório.

Contudo, o método Nelder-Mead é um algoritmo de busca local, o que pode trazer estimativas erradas dos parâmetros caso seja executado apenas uma vez, pois alguns problemas de otimização podem ser multimodais, ou seja, há mais de uma solução. Por isso é fundamental a globalização de um algoritmo de busca local (Telraky e Sotirov, 2010 e 2013), que é feita usando o procedimento Multi-start, que consiste na utilização de algoritmos de busca repetidas vezes partindo de pontos iniciais aleatórios. Dessa forma a solução que determina o menor valor de mínimo para a função objetivo é a solução ótima para o problema (Kan e Timmer, 1978a, b).

O procedimento de globalização é essencial para a otimização de um dado, já que a partir de uma amostra única ou uma pequena amostragem pode-se não obter o valor de mínimo global da função. Com isso, o procedimento em questão mostra sua importância na resolução de problemas de inversão multimodais.

\subsection{Análise do residual das curvas de tempos de trânsito}

Após a curva calculada ser ajustada em relação à observada ainda há um erro residual existente entre as duas curvas que está associado ao valor da função objetivo (valor de mínimo). Esse valor de mínimo representa uma solução com um conjunto de parâmetros que melhor se adequa ao modelo observado. Com isso a curva calculada com os parâmetros associados ao valor de mínimo global apresenta a melhor solução possível dentre o conjunto de inversões. 
Muitas vezes é difícil comparar duas ou mais aproximações dentro da escala das curvas de tempos de percurso, em decorrência da qualidade do ajuste obtido. Por tal motivo é necessário efetuar a análise residual entre a curva calculada e a observada, que não é nada mais do que a diferença entre elas. Dessa maneira poderá ser analisada a diferença na qualidade do ajuste em uma escala bem menor, podendo-se observar com muito mais distinção as regiões da curva que se ajustaram melhor.

\subsection{Análise da eficiência das expressões não-hiperbólicas}

Cada expressão não-hiperbólica apresenta diferentes níveis de complexidade e parâmetros que diferem em suas premissas físicas. Essas diferenças interferem diretamente na qualidade do ajuste das curvas de tempos de trânsito, além de interferirem na quantidade de tempo tomada durante o procedimento de inversão. Dessa forma é difícil analisar de maneira qualitativa essa correlação entre qualidade do ajuste e o tempo que cada expressão leva para executá-lo. Com isso propõe-se uma análise quantitativa sobre essa correlação.

Como o tempo para que seja efetuado o ajuste de curvas depende tanto da complexidade de cada expressão como do número de inversões a serem executadas, é de grande interesse analisar o tempo relativo entre as expressões (Equação 15), já que dessa maneira ele independeria do número de inversões executadas, podendo-se analisar mais isoladamente o tempo de processamento de cada expressão.

$$
T_{R i}=\frac{T_{i}}{T_{n}}
$$

onde $T_{R i}$ é o tempo relativo de uma determinada expressão representado pelo quociente entre os tempos de execução do ajuste dessa determinada expressão $T_{i}$ e da que apresentar o maior tempo $T_{n}$ dentre as expressões testadas.

A outra parte dessa análise trata justamente da qualidade do ajuste, que está relacionada ao valor de mínimo global de cada aproximação $\left(M_{i}\right)$. Neste caso, o processo se baseia em encontrar o menor valor de mínimo dentre as expressões.

Dessa forma têm-se para cada expressão, o número de eficiência $\zeta_{i}$ (Equação 16), que representa a relação do produto entre o valor de mínimo global $\left(M_{i}\right)$ e o tempo relativo para 
executar o conjunto de inversões $\left(T_{R i}\right)$ para cada uma das expressões. Dessa forma quanto menor for o número de eficiência $\left(\zeta_{i}\right)$, mais eficiente será o processo.

$$
\zeta_{i}=M_{i} T_{R i}=M_{i} \frac{T_{i}}{T_{n}}
$$

É importante ressaltar que tais análises visam apenas expressões que demonstrem ser multimodais, pois são as expressões que demandarão múltiplas inversões para encontrar de maneira confiável o valor de mínimo global da função. 


\section{RESULTADOS E DISCUSSÃO}

A análise de complexidade de funções objetivo foi executada para cada uma das aproximações que possuem três parâmetros. Nesta etapa são apresentados os mapas de dispersão sobrepostos aos mapas residuais de função objetivo com o intuito de mostrar a complexidade de cada uma das aproximações não-hiperbólicas ao buscar as regiões de mínimo.

De modo geral foi observado nos mapas residuais de função objetivo que a equação em análise é responsável pela diferença em toda a estrutura da topografia da função sendo este fator o mais relevante para caracterizar a complexidade da função objetivo. O tipo de evento de reflexão (PP e PS) interfere de maneira menos significativa, mas ainda trazendo diferenças no deslocamento da topografia da função, como já era esperado. O fator de menor influência na estrutura da topografia da função é a complexidade do modelo, que por sua vez gera variações no comportamento das linhas de contorno em um nível localizado. Este último fator, apesar de pouco influenciar a topografia da função estruturalmente, pode trazer consequências como pequenas variações no comportamento das linhas de contorno, devido ao fato de equações como a de Ursin e Stovas (2006) e Blias (2009) passarem de uma condição de unimodalidade (apresentam apenas regiões de mínimos globais) para uma condição de multimodalidade (apresentam tanto regiões de mínimos globais e locais) em decorrência de variações na complexidade do modelo estudado, como pode ser visto nos resultados deste trabalho. Devido ao comportamento dessas equações deve-se ter cuidado ao usá-las, pois sem o pleno conhecimento de sua sensibilidade com relação ao modelo, há a possibilidade de utilizá-las erroneamente.

Com relação às equações de Dix (1955) e Slotboom et al. (1990), não houve a necessidade de análise de complexidade da função objetivo devido à característica da simplicidade destas equações que apresentam apenas dois parâmetros e são unimodais.

As equações de Malovichko (1978) e Alkhalifah e Tsvankin (1995) demonstraram ser as mais simples do conjunto de equações que apresentam três parâmetros. Entretanto mesmo possuindo três parâmetros, estas demostraram ser unimodais.

As equações de Muir e Dellinger (1985) e Li (2001) demonstraram ser multimodais em todas as situações experimentadas. 
Para melhor organização, as aproximações estão aqui definidas da seguinte maneira:

Equação 1 - Dix (1955)

Equação 2 - Malovichko (1978) - Representada pelas figuras 32 e 33 (para o Modelo 1), 44 e 45 (para o Modelo 2), 56 e 57 (para o Modelo 3), 68 e 69 (para o Modelo 4), 80 e 81 (para o Modelo 5).

Equação 3 - Slotboom et al. (1990)

Equação 4 - Alkhalifah e Tsvankin (1995) - Representada pelas figuras 34 e 35 (para o Modelo 1), 46 e 47 (para o Modelo 2), 58 e 59 (para o Modelo 3), 70 e 71 (para o Modelo 4), 82 e 83 (para o Modelo 5).

Equação 5 - Ursin e Stovas (2006) - Representada pelas figuras 36 e 37 (para o Modelo 1), 48 e 49 (para o Modelo 2), 60 e 61 (para o Modelo 3), 72 e 73 (para o Modelo 4), 84 e 85 (para o Modelo 5).

Equação 6 - Blias (2009) - Representada pelas figuras 38 e 39 (para o Modelo 1), 50 e 51 (para o Modelo 2), 62 e 63 (para o Modelo 3), 74 e 75 (para o Modelo 4), 86 e 87 (para o Modelo 5).

Equação 7 - Muir e Dellinger (1985) - Representada pelas figuras 40 e 41 (para o Modelo 1), 52 e 53 (para o Modelo 2), 64 e 65 (para o Modelo 3), 76 e 77 (para o Modelo 4), 88 e 89 (para o Modelo 5).

Equação 8 - Li (2001) - Representada pelas figuras 42 e 43 (para o Modelo 1), 54 e 55 (para o Modelo 2), 66 e 67 (para o Modelo 3), 78 e 79 (para o Modelo 4), 90 e 91 (para o Modelo 5). 


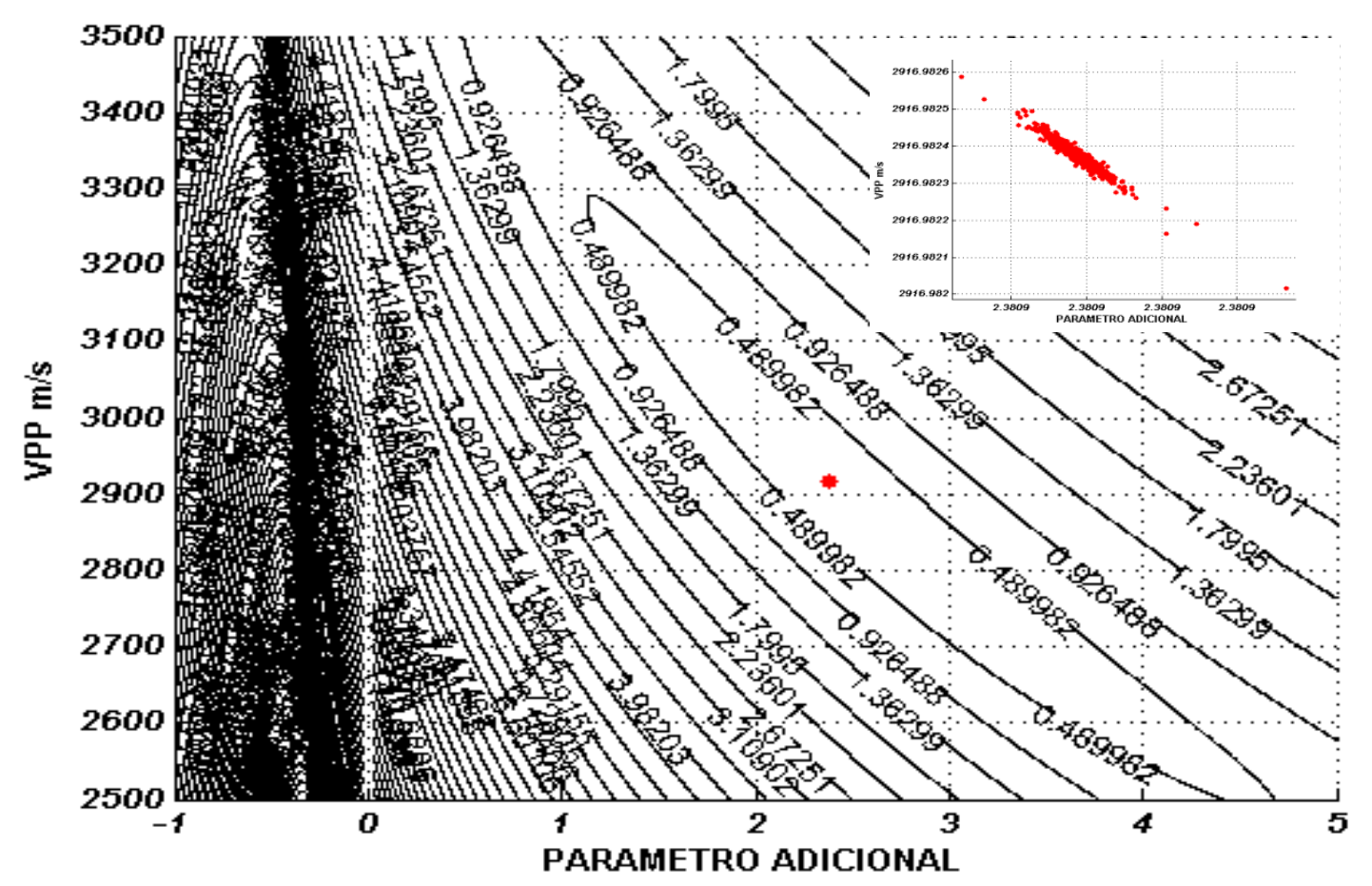

Figura 32: Mapas de dispersão sobrepostos ao mapa residual de função objetivo mostrando a complexidade da aproximação multiparamétrica de Malovichko (1978) para um evento de reflexão de onda PP do Modelo 1. As dispersões em vermelho representam a região de mínimo global da função.

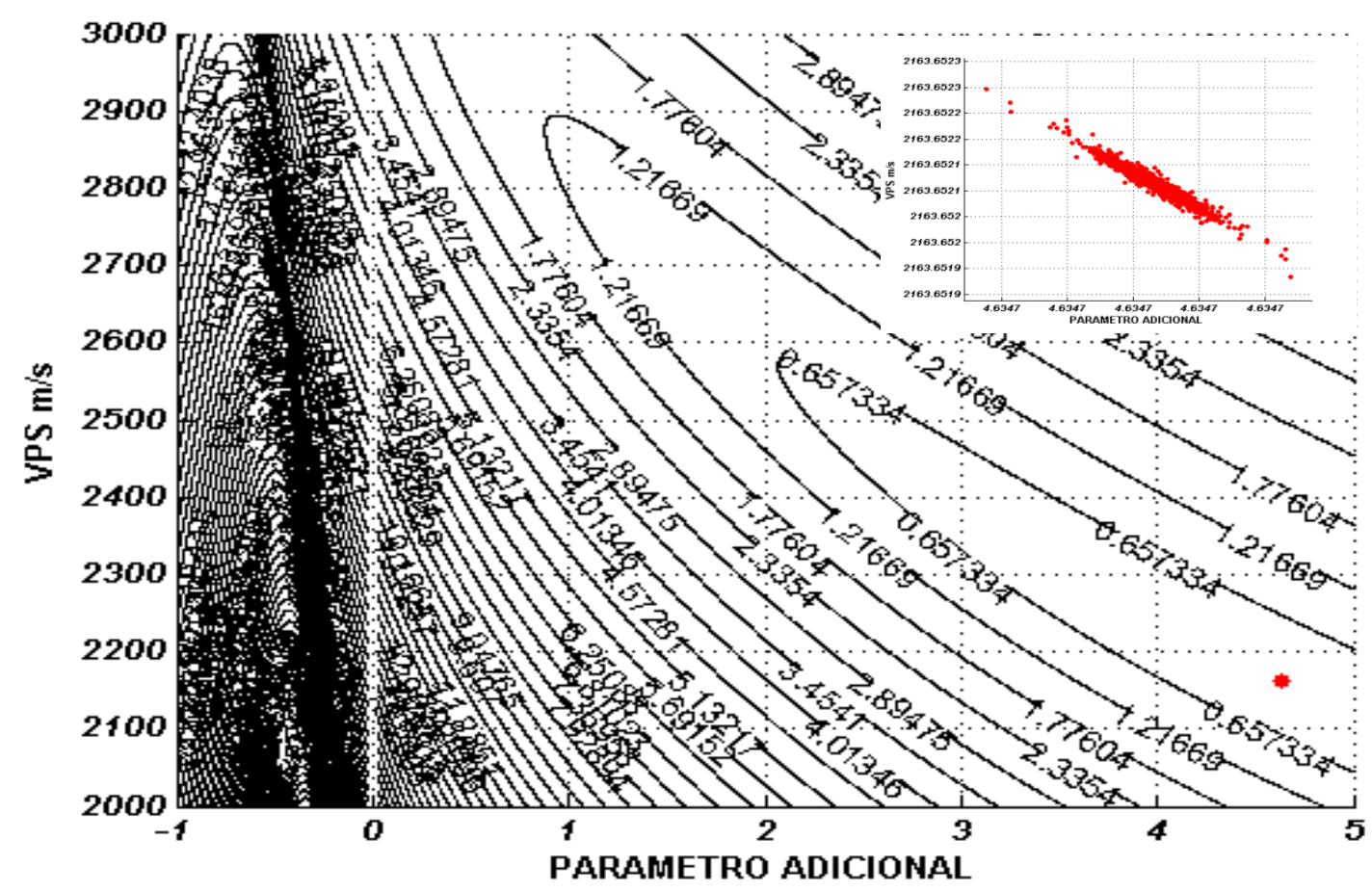

Figura 33: Mapas de dispersão sobrepostos ao mapa residual de função objetivo mostrando a complexidade da aproximação multiparamétrica de Malovichko (1978) para um evento de reflexão de onda PS do Modelo 1. As dispersões em vermelho representam a região de mínimo global da função. 


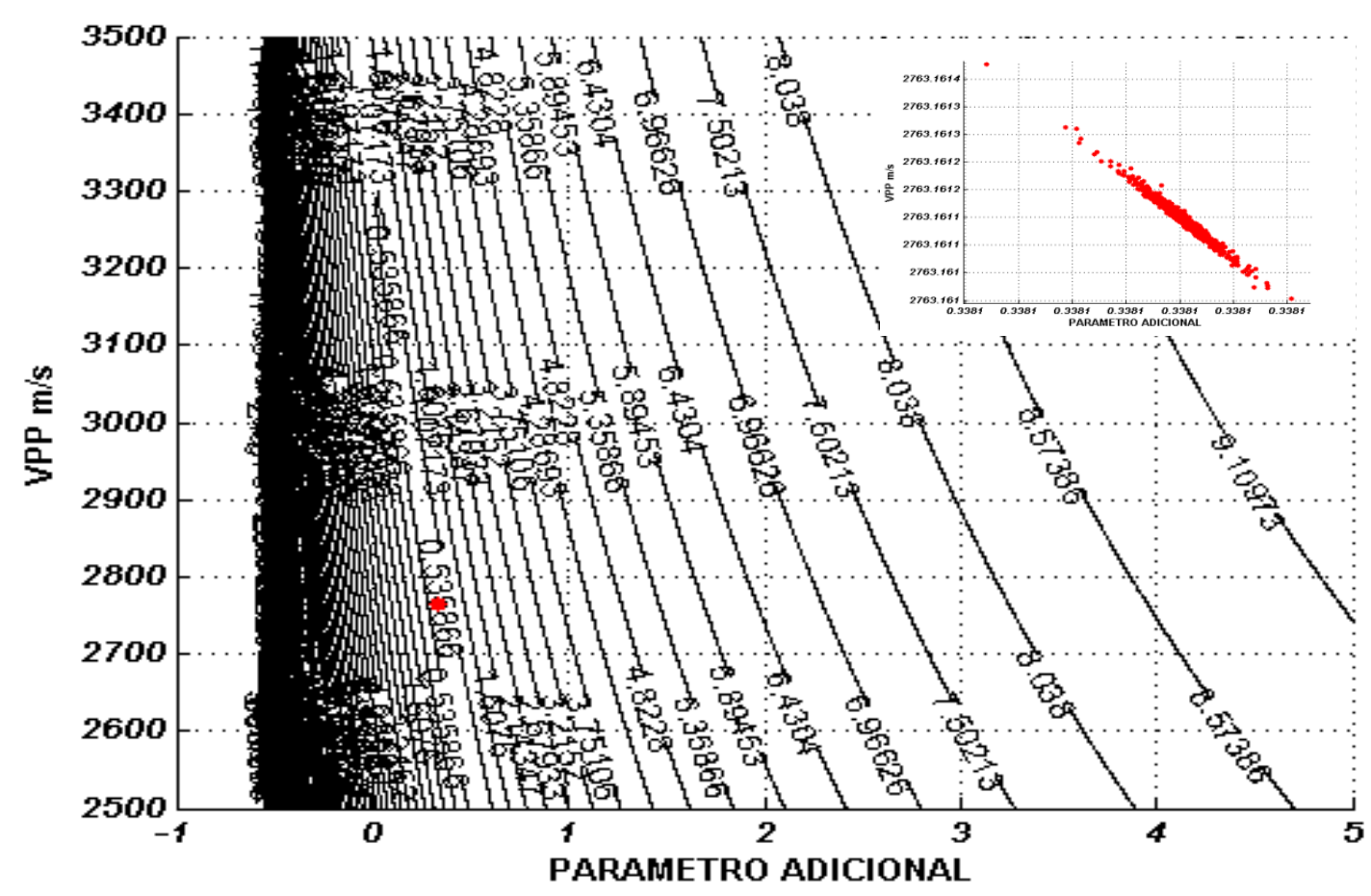

Figura 34: Mapas de dispersão sobrepostos ao mapa residual de função objetivo mostrando a complexidade da aproximação multiparamétrica de Alkhalifah e Tsvankin (1995) para um evento de reflexão de onda PP do Modelo 1. As dispersões em vermelho representam a região de mínimo global da função.

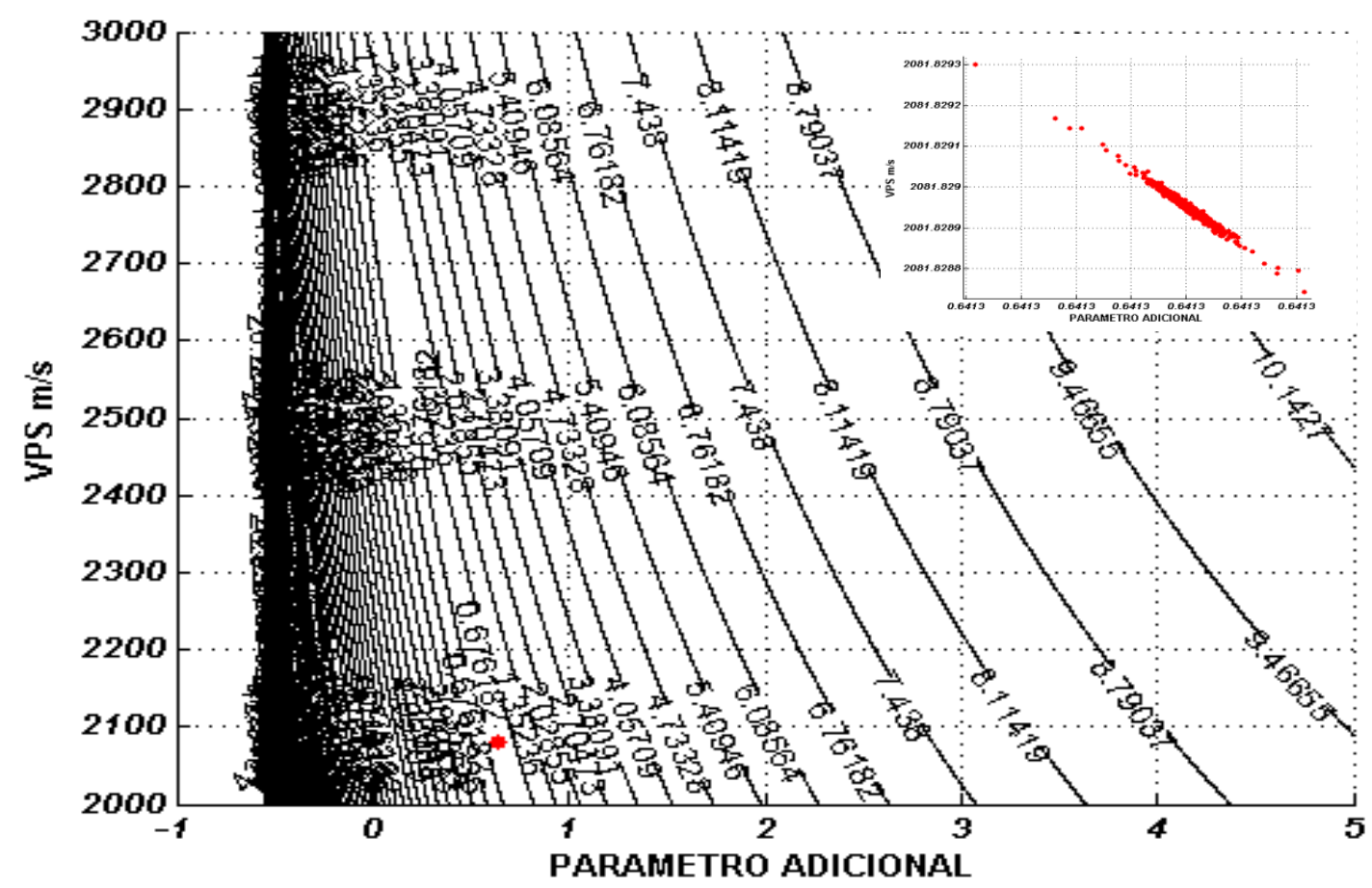

Figura 35: Mapas de dispersão sobrepostos ao mapa residual de função objetivo mostrando a complexidade da aproximação multiparamétrica de Alkhalifah e Tsvankin (1995) para um evento de reflexão de onda PS do Modelo 1. As dispersões em vermelho representam a região de mínimo global da função. 


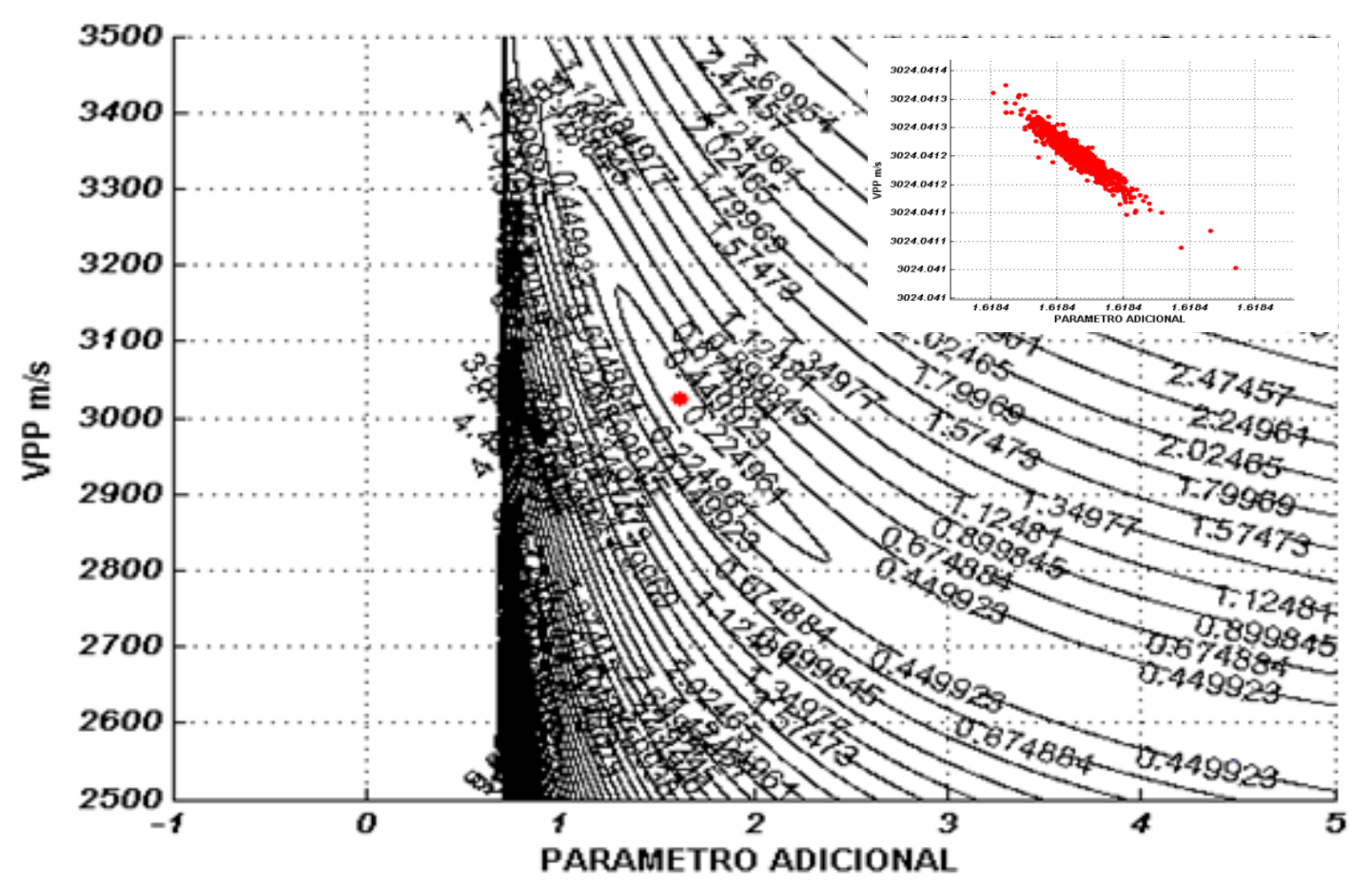

Figura 36: Mapas de dispersão sobrepostos ao mapa residual de função objetivo mostrando a complexidade da aproximação multiparamétrica de Ursin e Stovas (2006) para um evento de reflexão de onda PP do Modelo 1. As dispersões em vermelho representam a região de mínimo global da função.

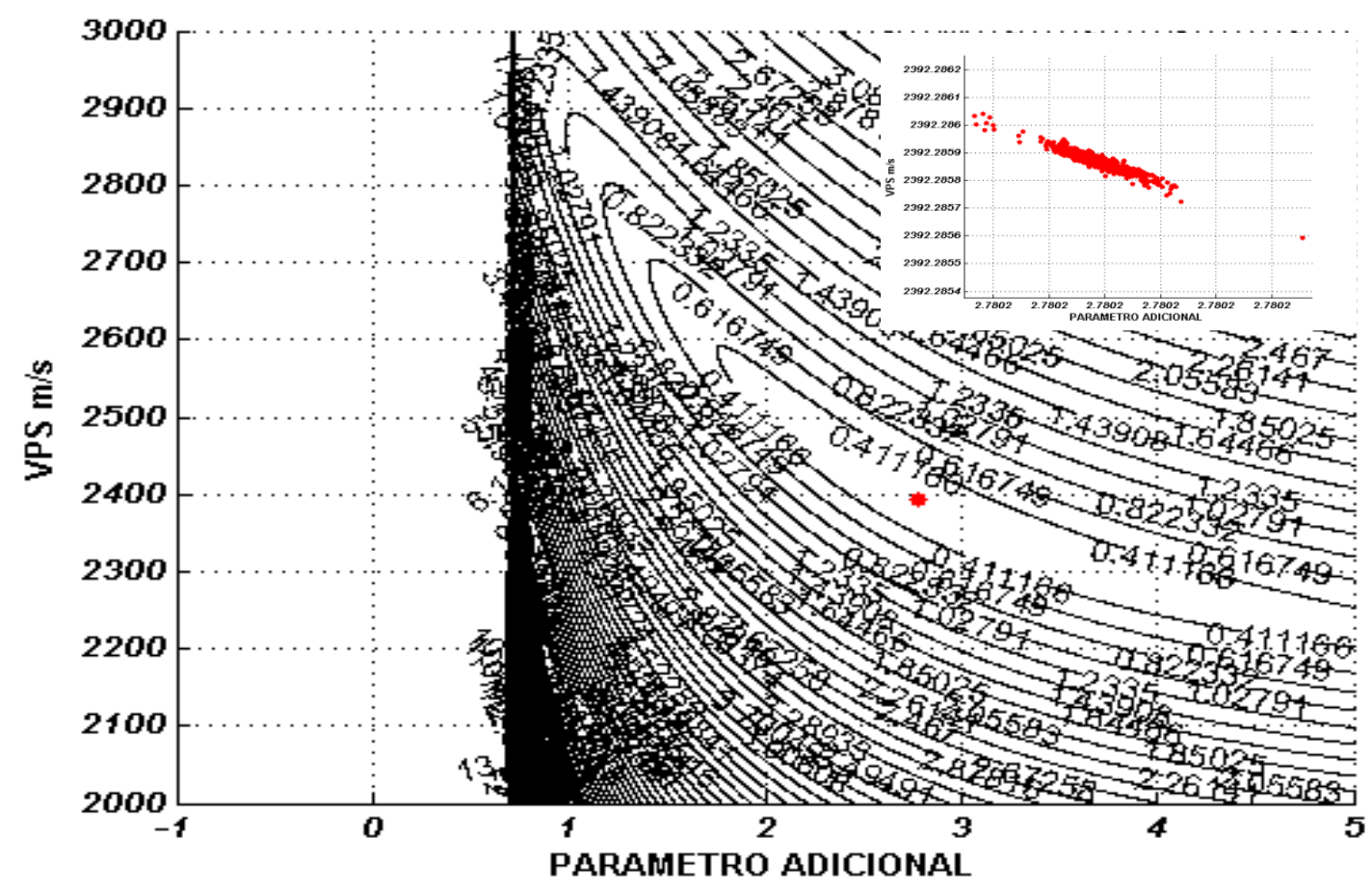

Figura 37: Mapas de dispersão sobrepostos ao mapa residual de função objetivo mostrando a complexidade da aproximação multiparamétrica de Ursin e Stovas (2006) para um evento de reflexão de onda PS do Modelo 1. As dispersões em vermelho representam a região de mínimo global da função. 


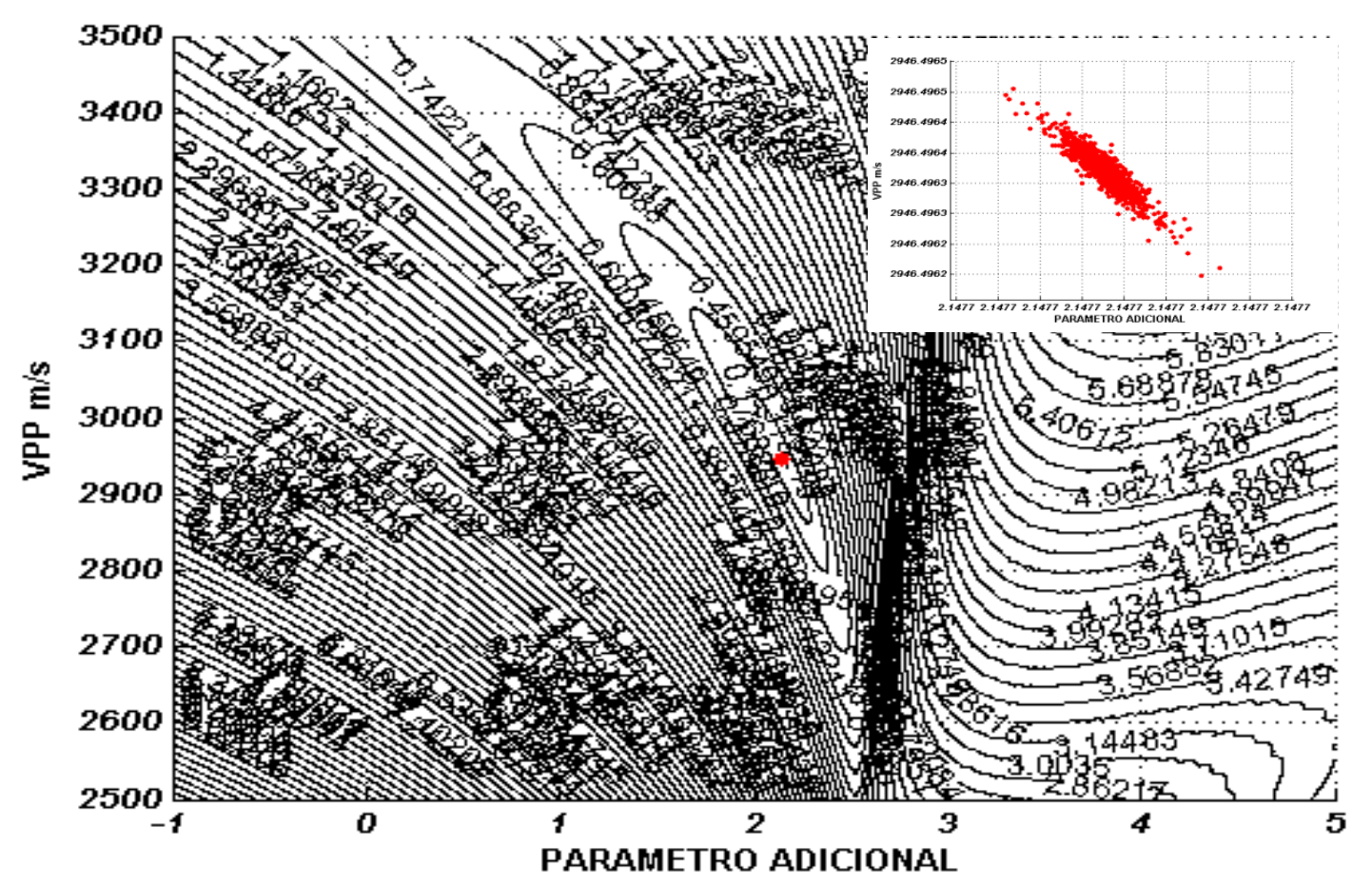

Figura 38: Mapas de dispersão sobrepostos ao mapa residual de função objetivo mostrando a complexidade da aproximação multiparamétrica de Blias (2009) para um evento de reflexão de onda PP do Modelo 1. As dispersões em vermelho representam a região de mínimo global da função.

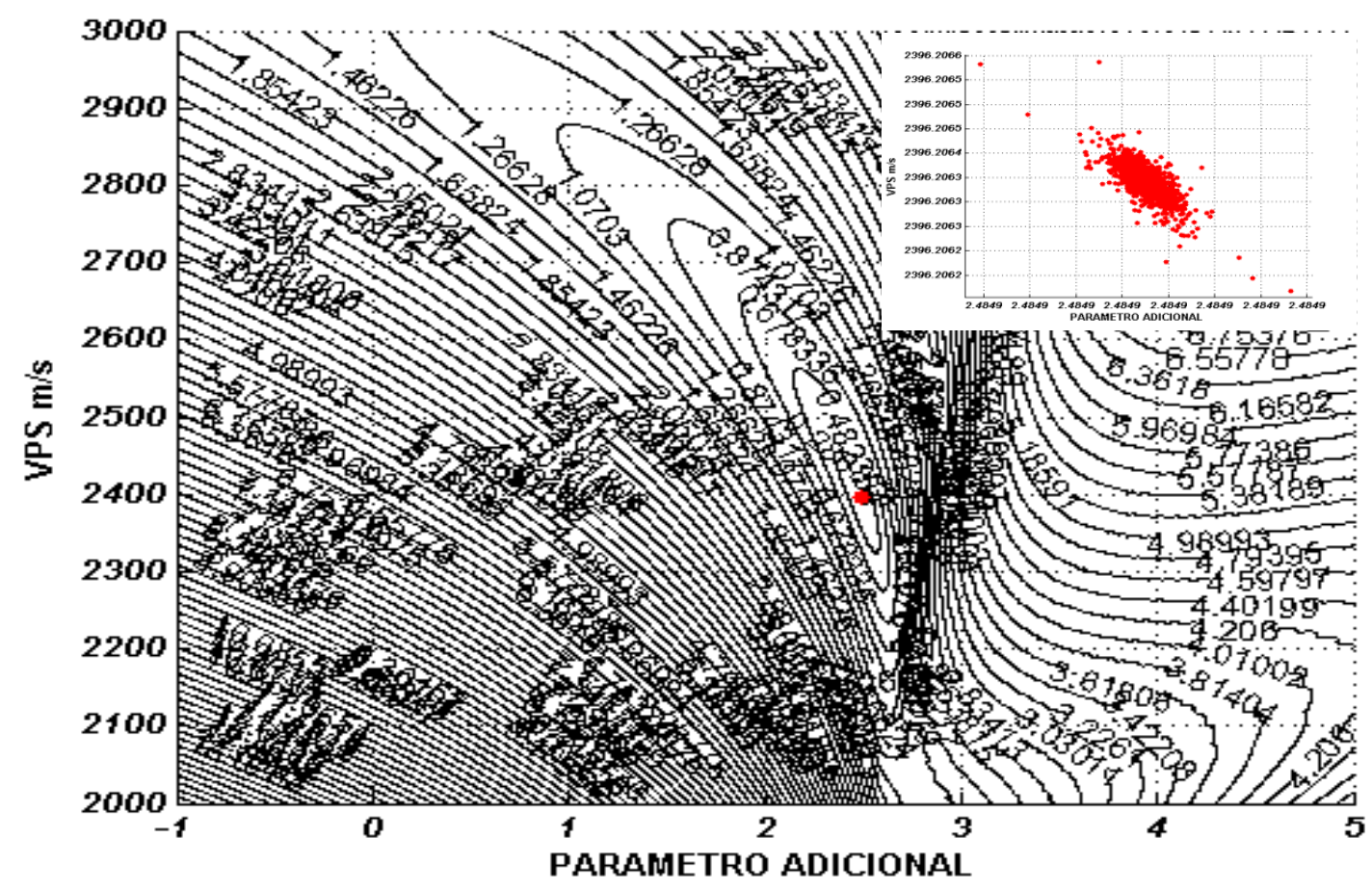

Figura 39: Mapas de dispersão sobrepostos ao mapa residual de função objetivo mostrando a complexidade da aproximação multiparamétrica de Blias (2009) para um evento de reflexão de onda PS do Modelo 1. As dispersões em vermelho representam a região de mínimo global da função. 


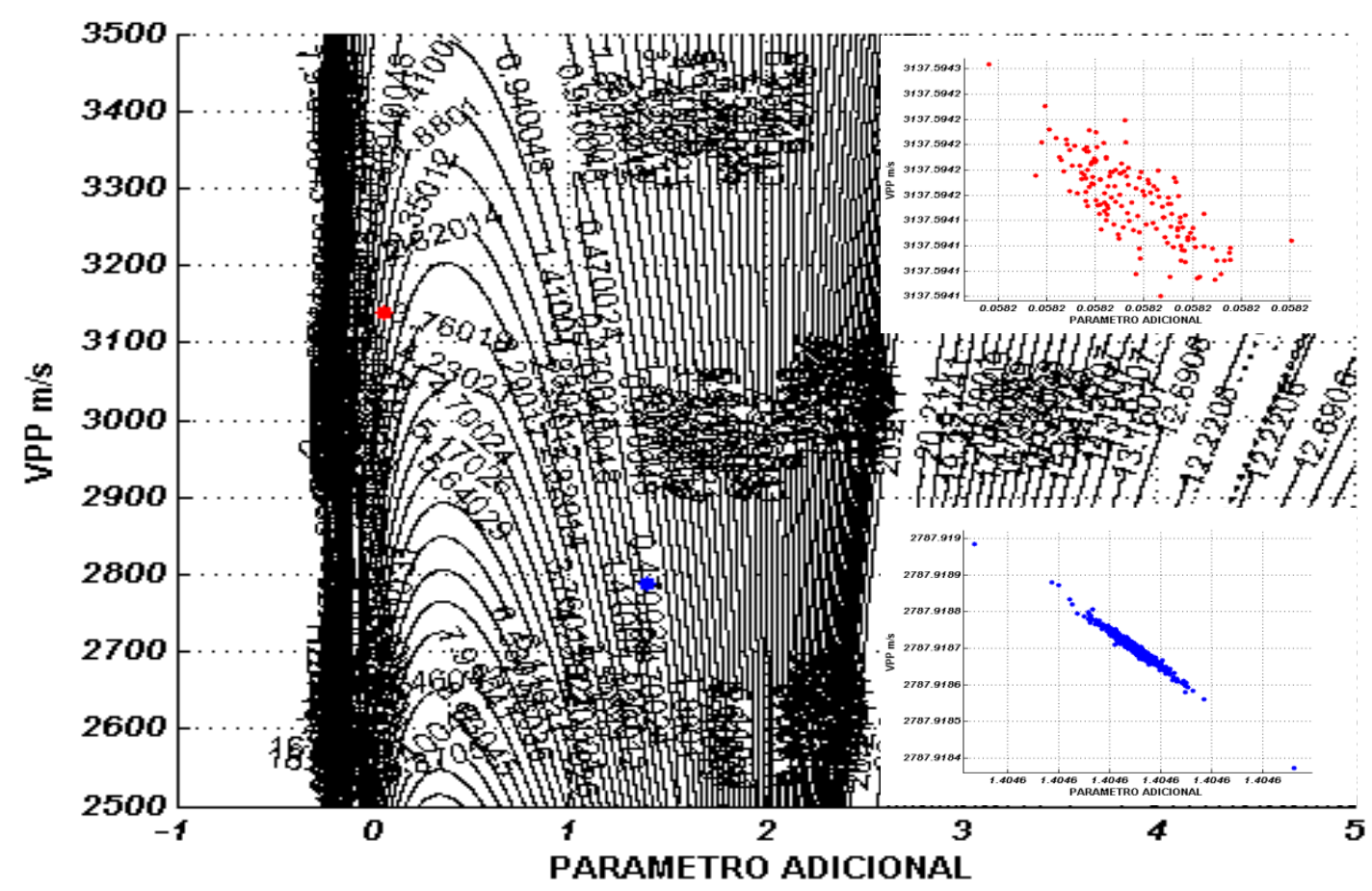

Figura 40: Mapas de dispersão sobrepostos ao mapa residual de função objetivo mostrando a complexidade da aproximação multiparamétrica de Muir e Dellinger (1985) para um evento de reflexão de onda PP do Modelo 1. As dispersões em vermelho representam a região de mínimo global da função e as dispersões em azul representam a região de mínimo local.

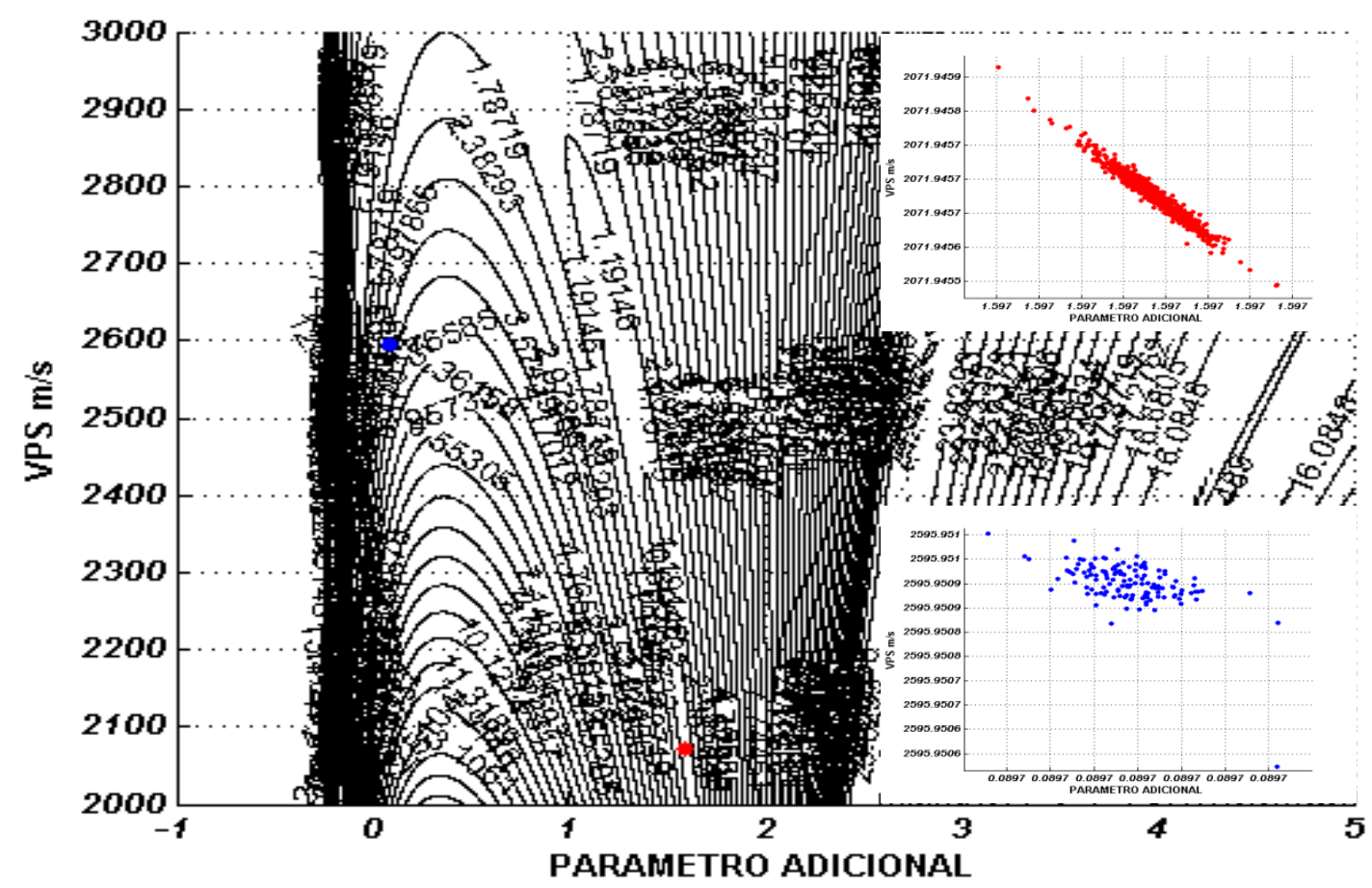

Figura 41: Mapas de dispersão sobrepostos ao mapa residual de função objetivo mostrando a complexidade da aproximação multiparamétrica de Muir e Dellinger (1985) para um evento de reflexão de onda PS do Modelo 1. As dispersões em vermelho representam a região de mínimo global da função e as dispersões em azul representam a região de mínimo local. 


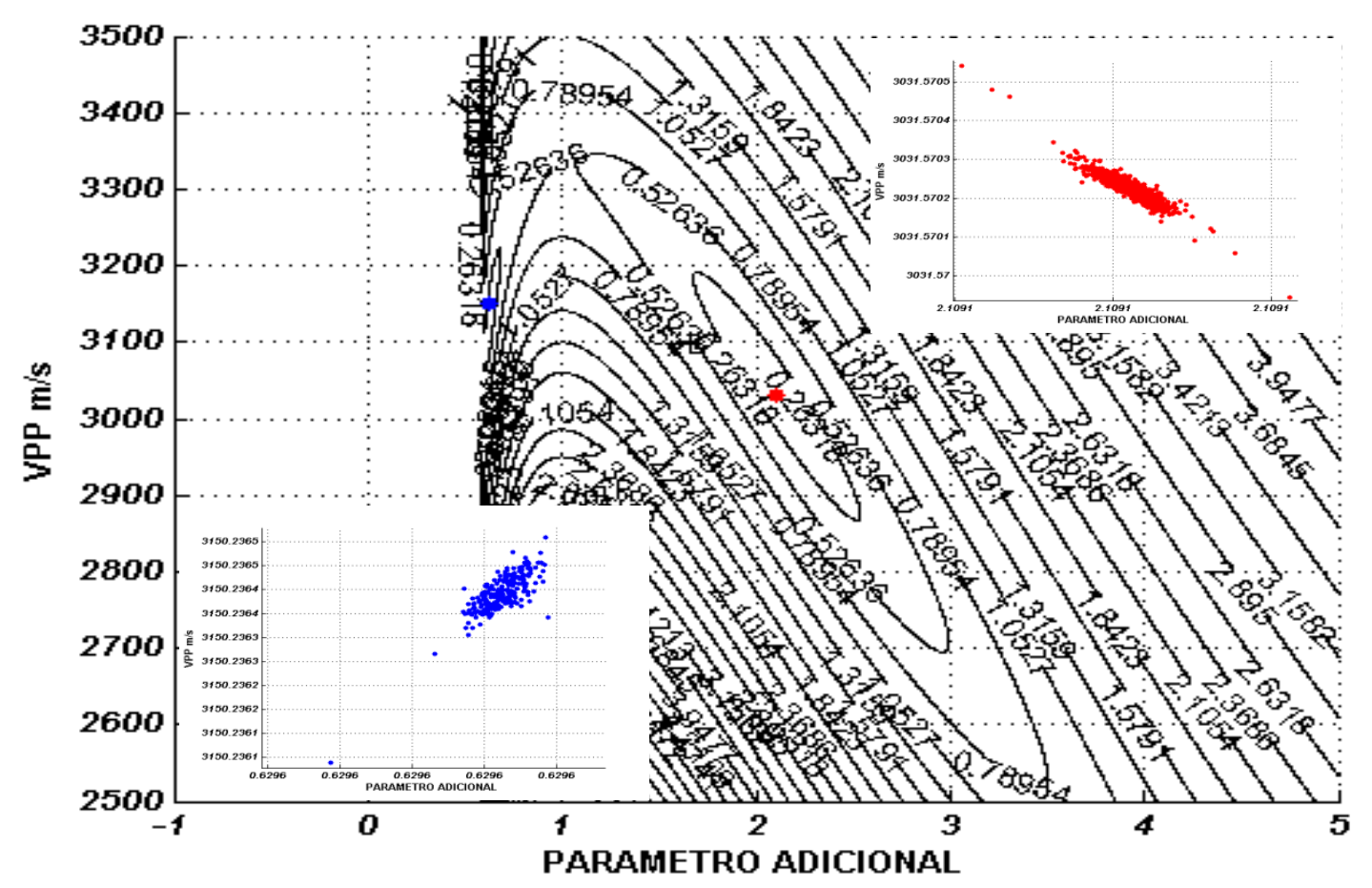

Figura 42: Mapas de dispersão sobrepostos ao mapa residual de função objetivo mostrando a complexidade da aproximação multiparamétrica de Li (2001) para um evento de reflexão de onda PP do Modelo 1. As dispersões em vermelho representam a região de mínimo global da função e as dispersões em azul representam a região de mínimo local.

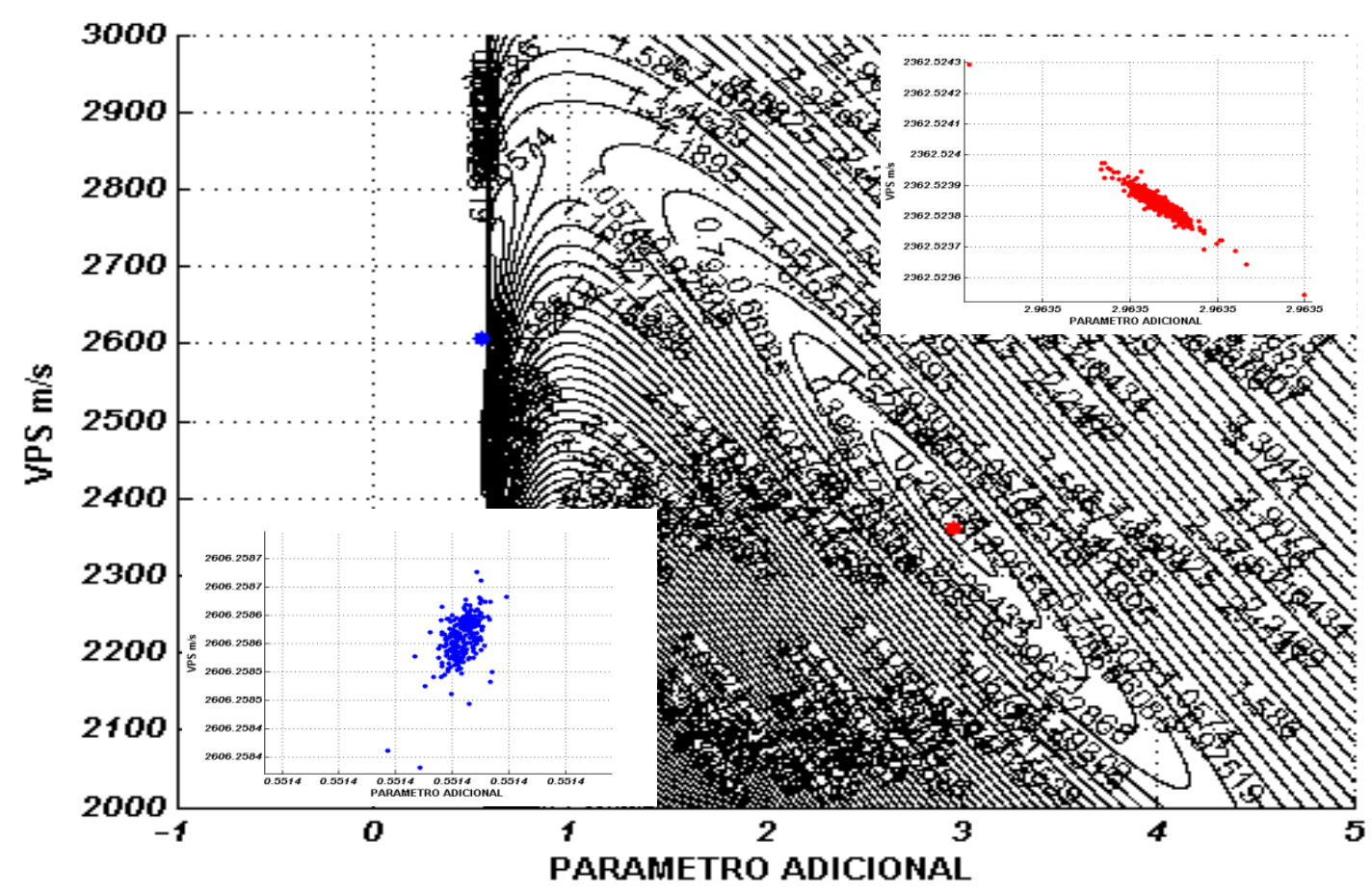

Figura 43: Mapas de dispersão sobrepostos ao mapa residual de função objetivo mostrando a complexidade da aproximação multiparamétrica de Li (2001) para um evento de reflexão de onda PS do Modelo 1. As dispersões em vermelho representam a região de mínimo global da função e as dispersões em azul representam a região de mínimo local. 


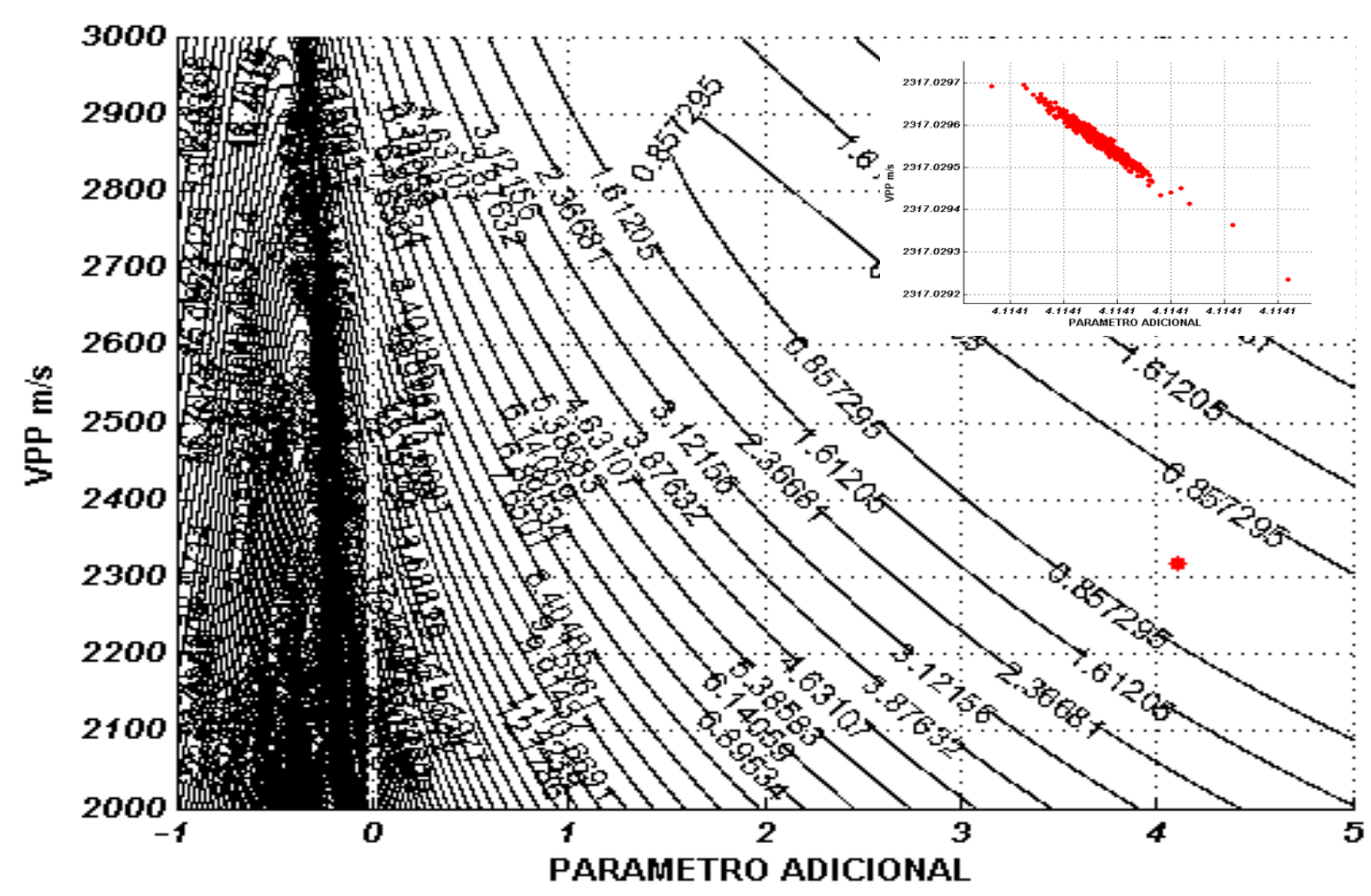

Figura 44: Mapas de dispersão sobrepostos ao mapa residual de função objetivo mostrando a complexidade da aproximação multiparamétrica de Malovichko (1978) para um evento de reflexão de onda PP do Modelo 2. As dispersões em vermelho representam a região de mínimo global da função.

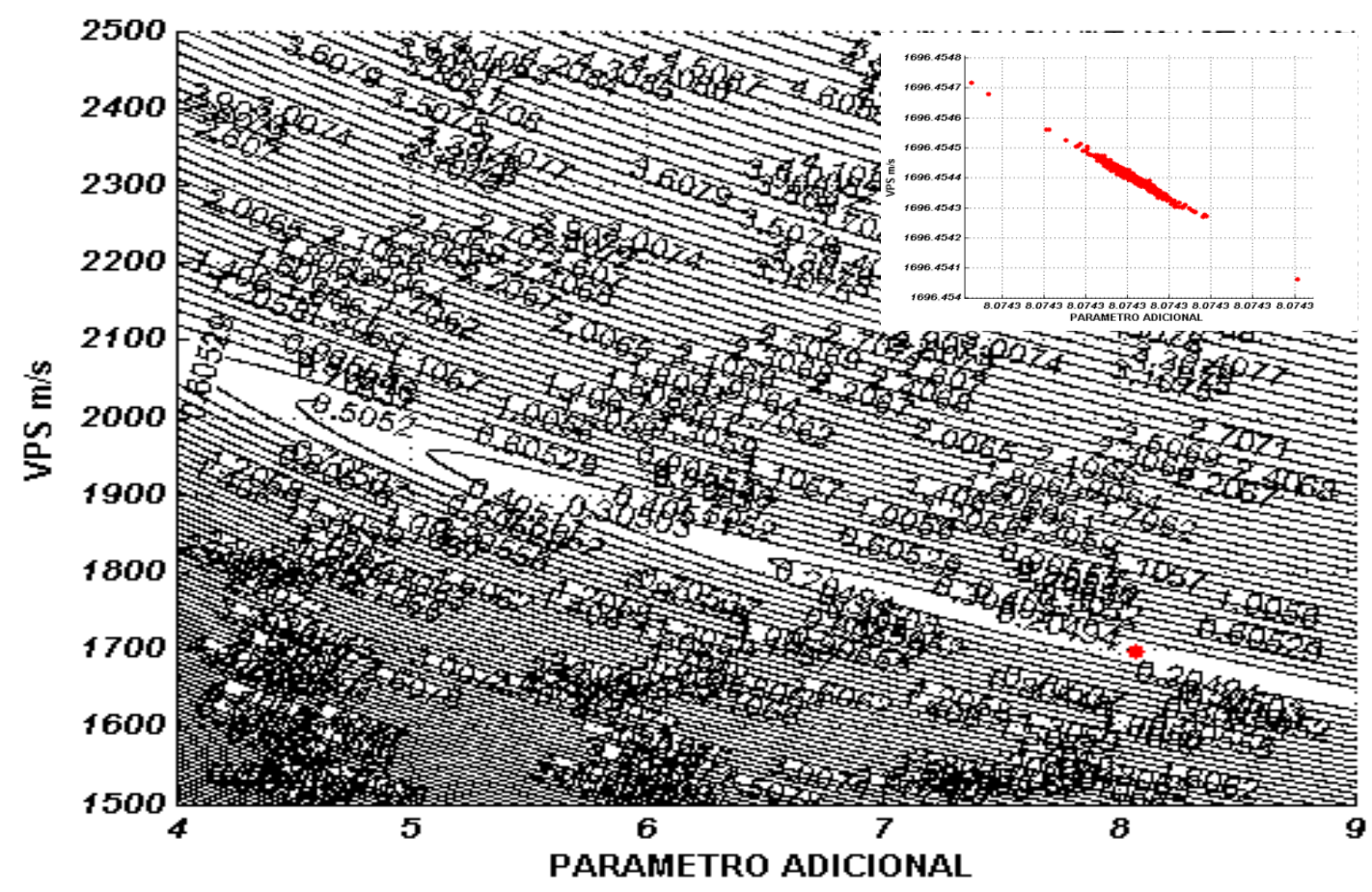

Figura 45: Mapas de dispersão sobrepostos ao mapa residual de função objetivo mostrando a complexidade da aproximação multiparamétrica de Malovichko (1978) para um evento de reflexão de onda PS do Modelo 2. As dispersões em vermelho representam a região de mínimo global da função. 


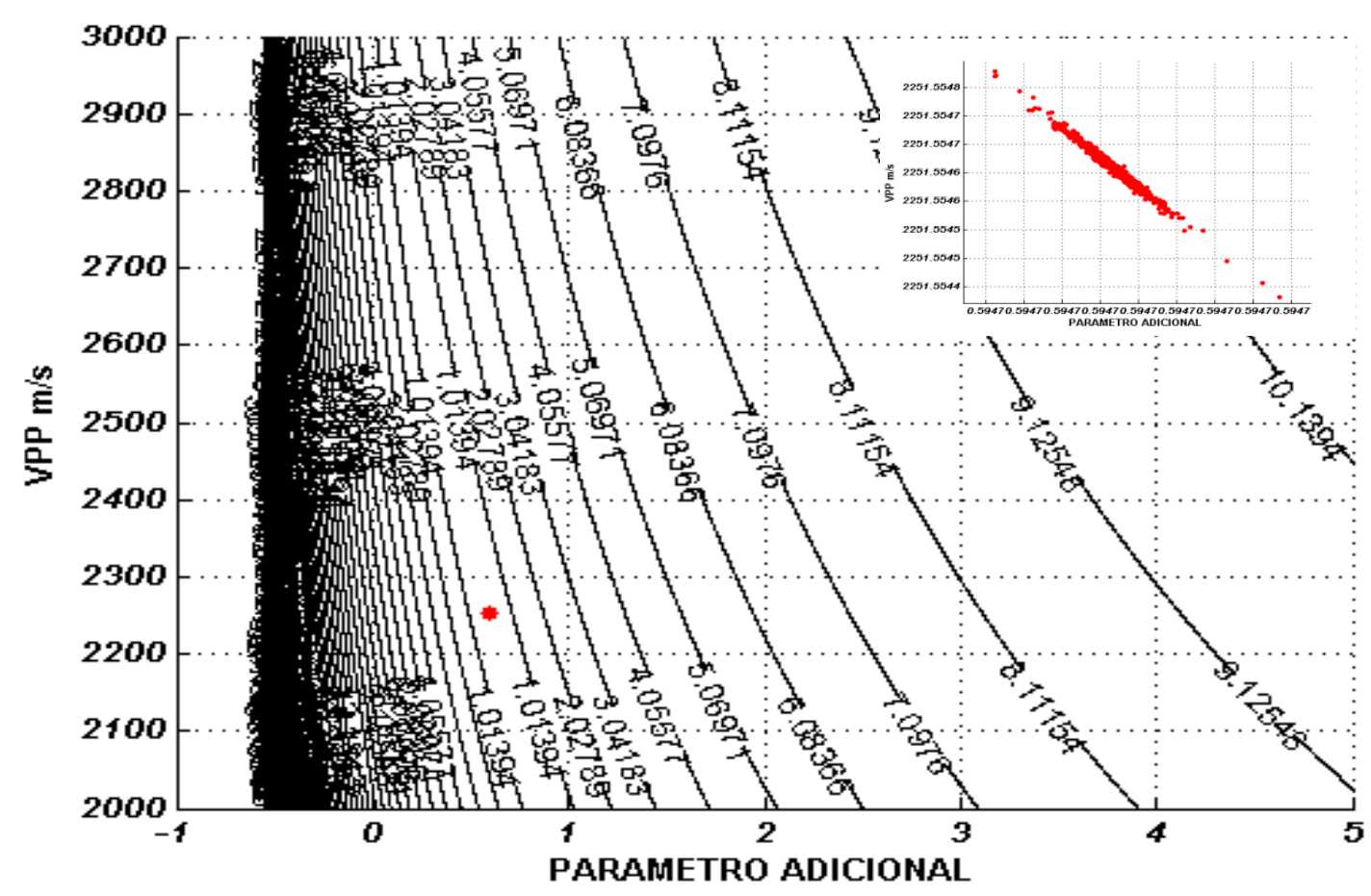

Figura 46: Mapas de dispersão sobrepostos ao mapa residual de função objetivo mostrando a complexidade da aproximação multiparamétrica de Alkhalifah e Tsvankin (1995) para um evento de reflexão de onda PP do Modelo 2. As dispersões em vermelho representam a região de mínimo global da função.

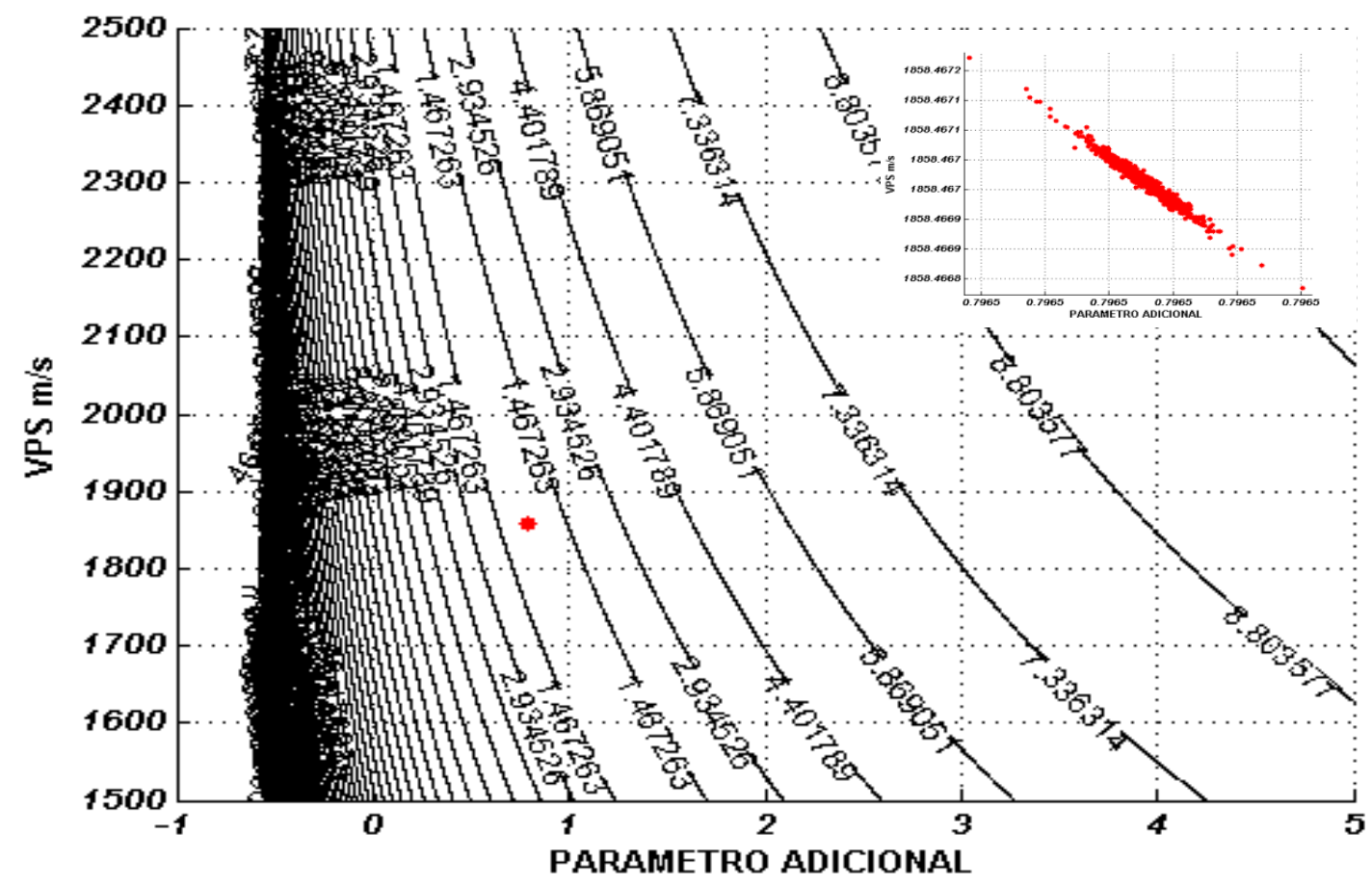

Figura 47: Mapas de dispersão sobrepostos ao mapa residual de função objetivo mostrando a complexidade da aproximação multiparamétrica de Alkhalifah e Tsvankin (1995) para um evento de reflexão de onda PS do Modelo 2. As dispersões em vermelho representam a região de mínimo global da função. 


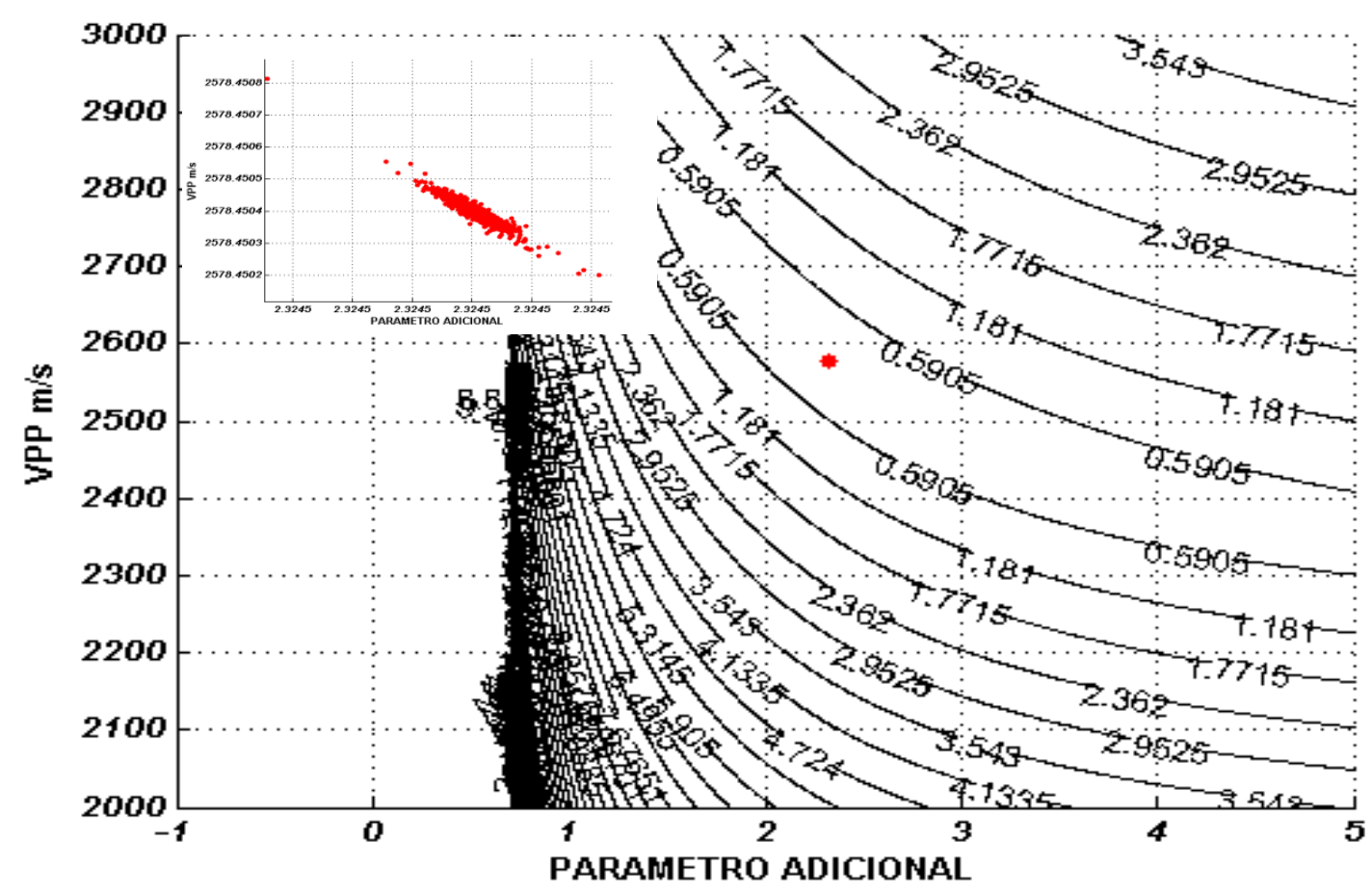

Figura 48: Mapas de dispersão sobrepostos ao mapa residual de função objetivo mostrando a complexidade da aproximação multiparamétrica de Ursin e Stovas (2006) para um evento de reflexão de onda PP do Modelo 2. As dispersões em vermelho representam a região de mínimo global da função.

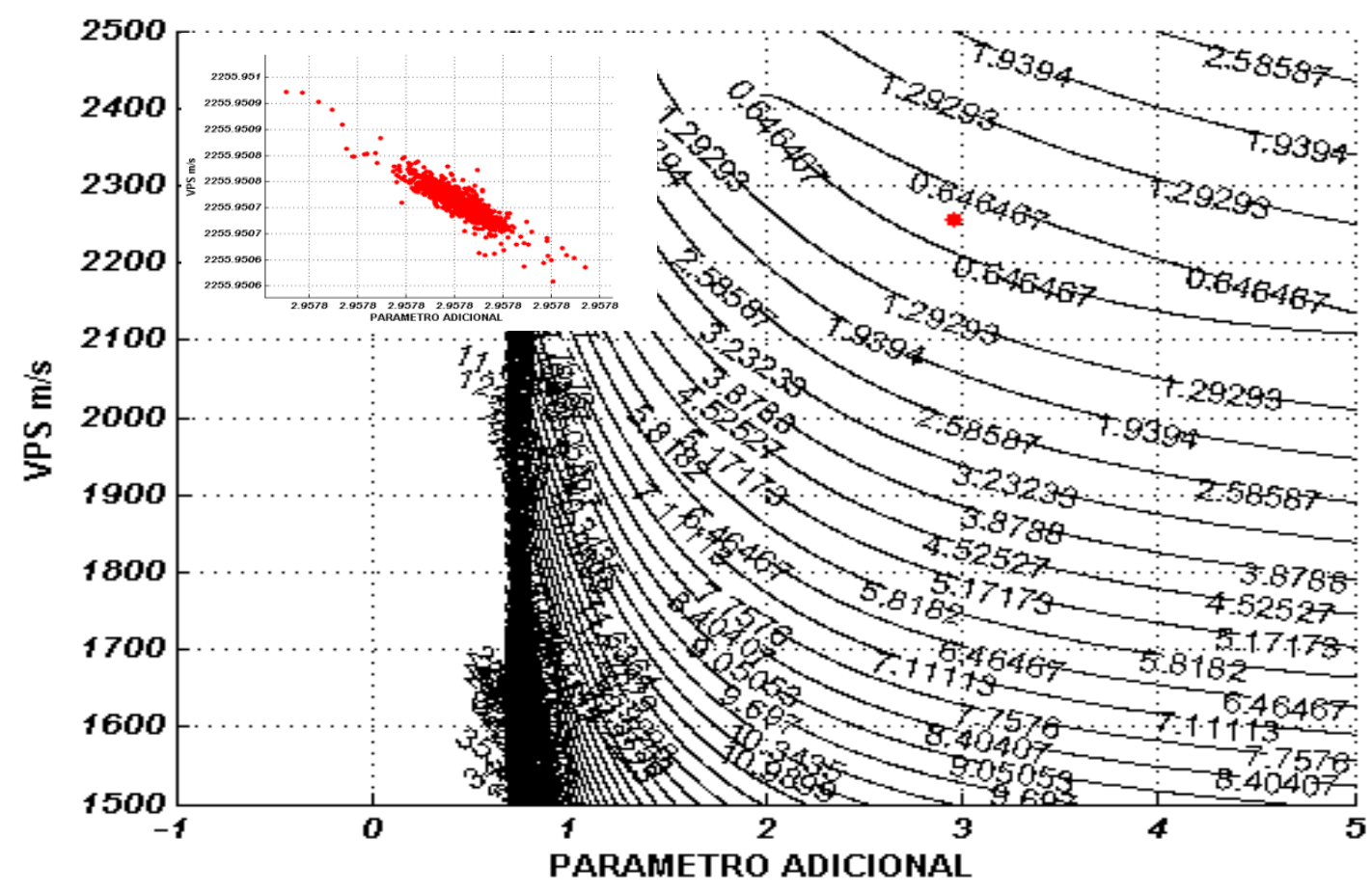

Figura 49: Mapas de dispersão sobrepostos ao mapa residual de função objetivo mostrando a complexidade da aproximação multiparamétrica de Ursin e Stovas (2006) para um evento de reflexão de onda PS do Modelo 2. As dispersões em vermelho representam a região de mínimo global da função. 


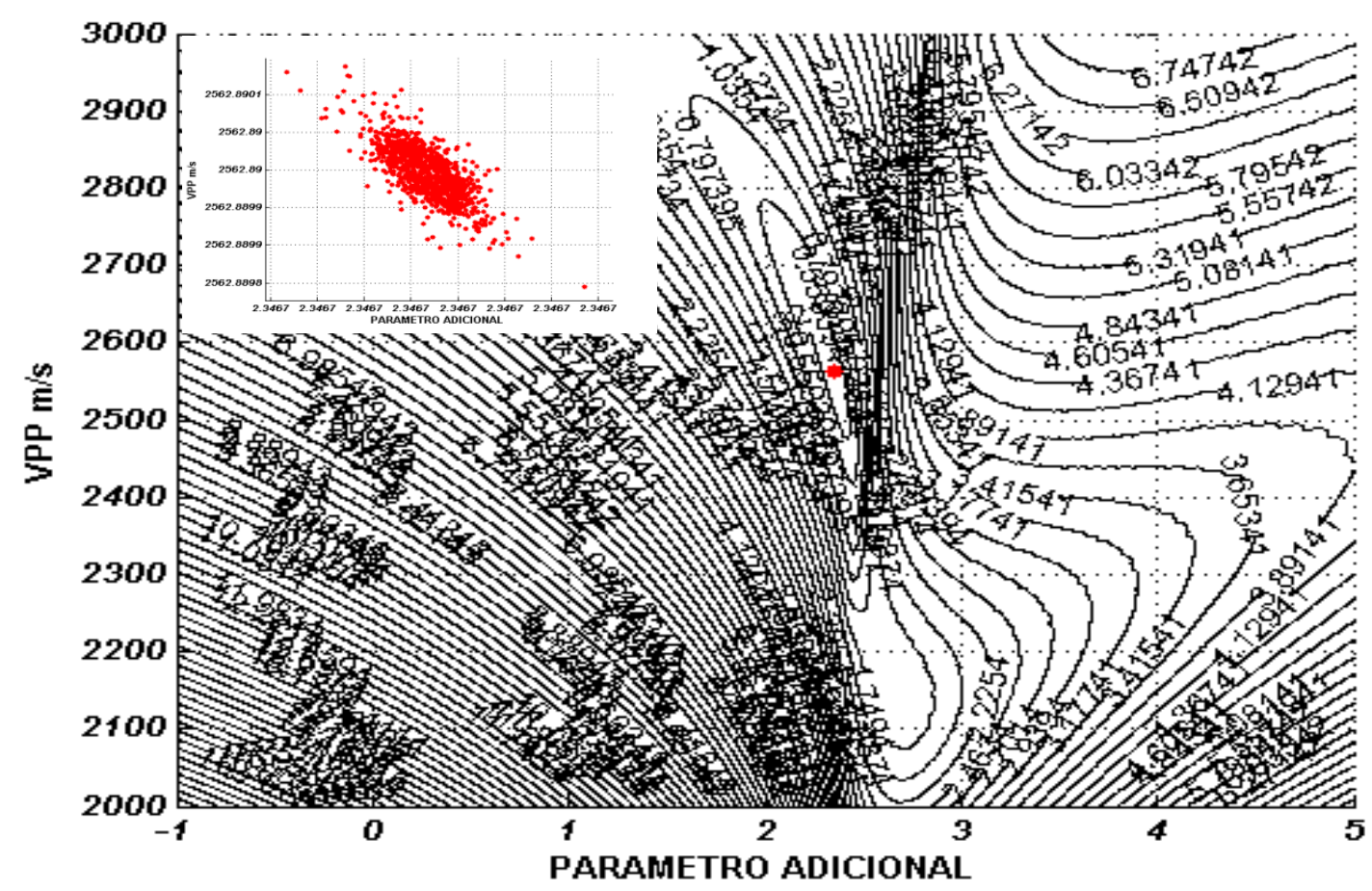

Figura 50: Mapas de dispersão sobrepostos ao mapa residual de função objetivo mostrando a complexidade da aproximação multiparamétrica de Blias (2009) para um evento de reflexão de onda PP do Modelo 2. As dispersões em vermelho representam a região de mínimo global da função.

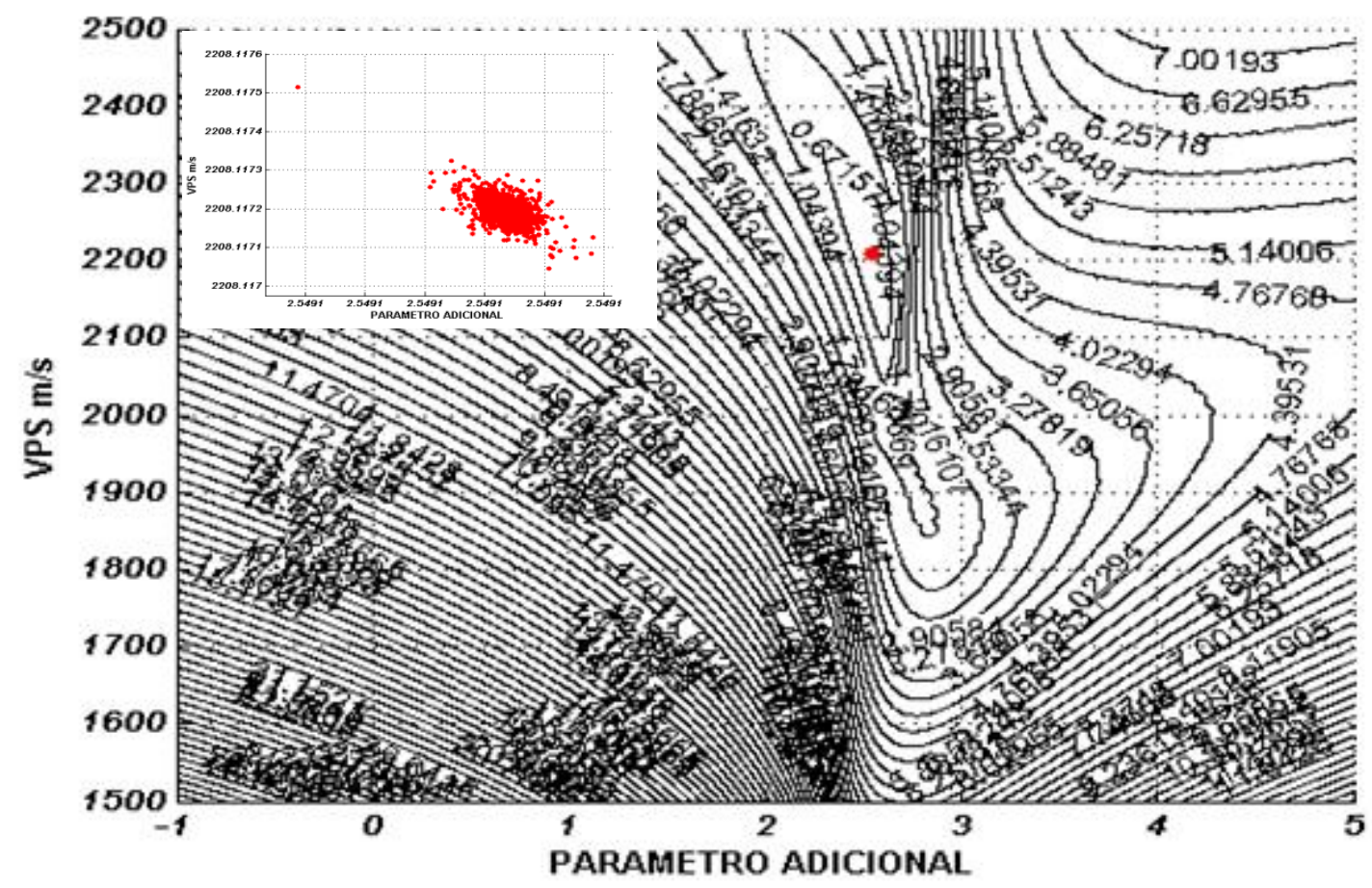

Figura 51: Mapas de dispersão sobrepostos ao mapa residual de função objetivo mostrando a complexidade da aproximação multiparamétrica de Blias (2009) para um evento de reflexão de onda PS do Modelo 2. As dispersões em vermelho representam a região de mínimo global da função. 


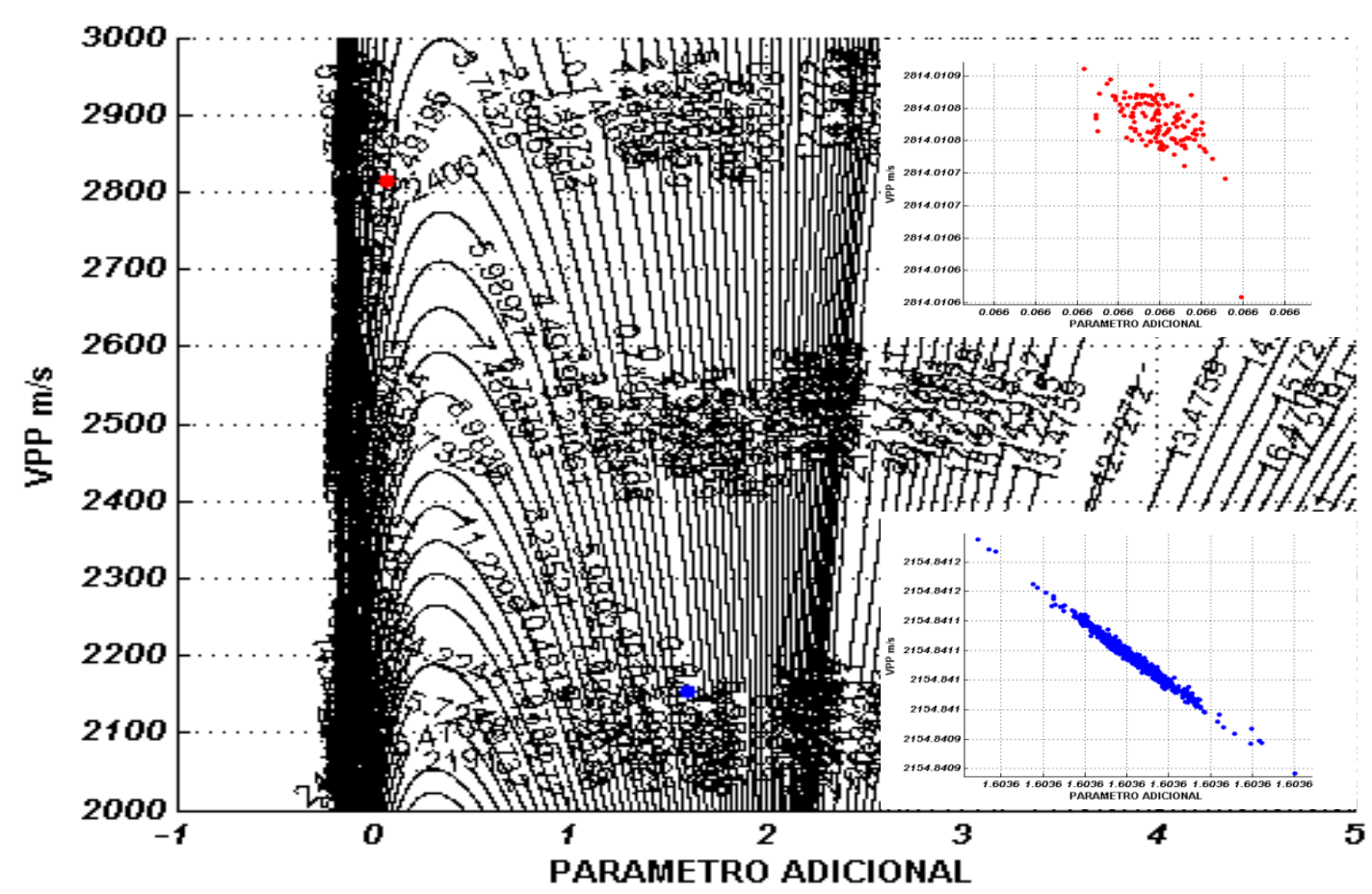

Figura 52: Mapas de dispersão sobrepostos ao mapa residual de função objetivo mostrando a complexidade da aproximação multiparamétrica de Muir e Dellinger (1985) para um evento de reflexão de onda PP do Modelo 2. As dispersões em vermelho representam a região de mínimo global da função e as dispersões em azul representam a região de mínimo local.

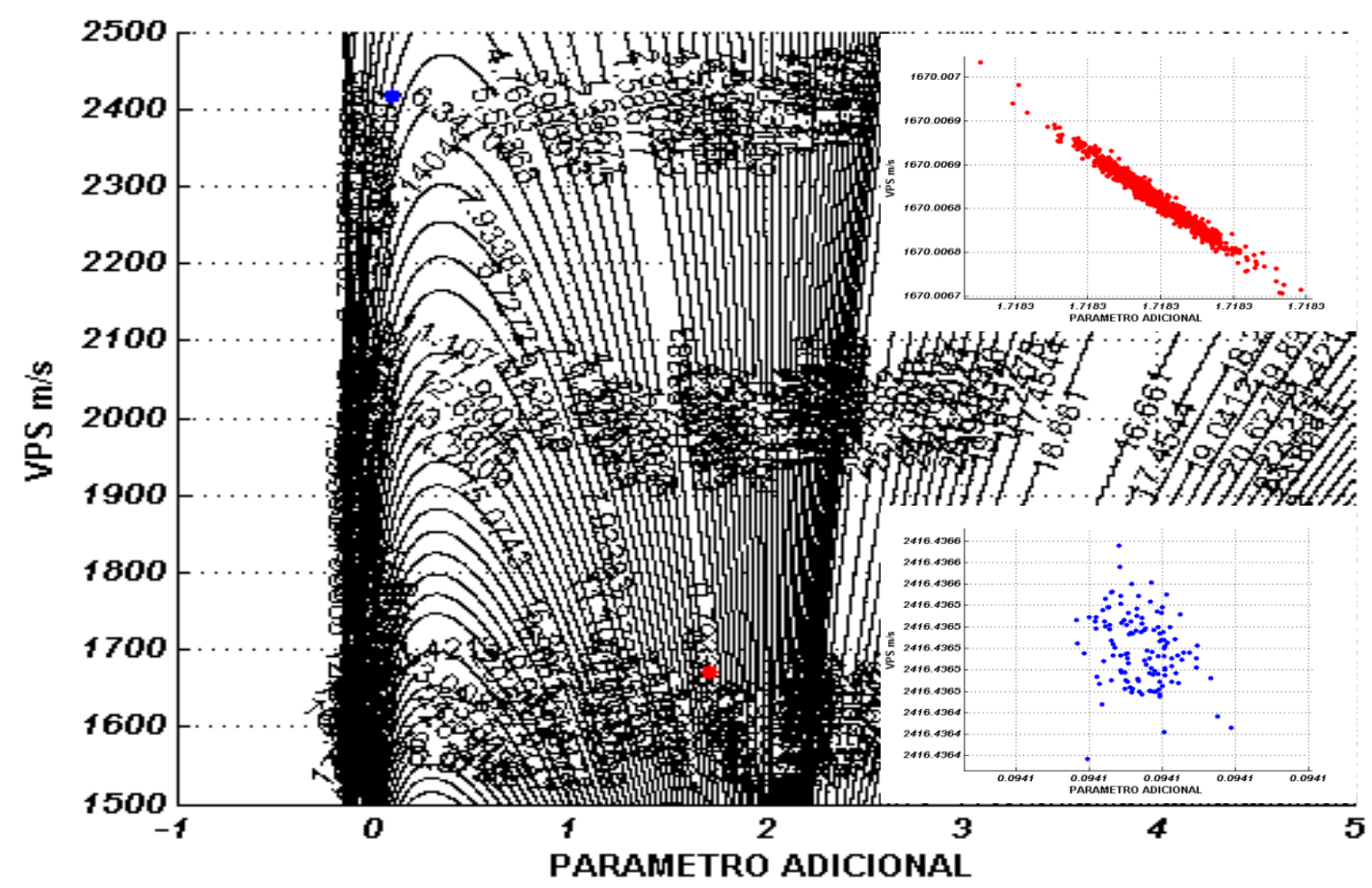

Figura 53: Mapas de dispersão sobrepostos ao mapa residual de função objetivo mostrando a complexidade da aproximação multiparamétrica de Muir e Dellinger (1985) para um evento de reflexão de onda PS do Modelo 2. As dispersões em vermelho representam a região de mínimo global da função e as dispersões em azul representam a região de mínimo local. 


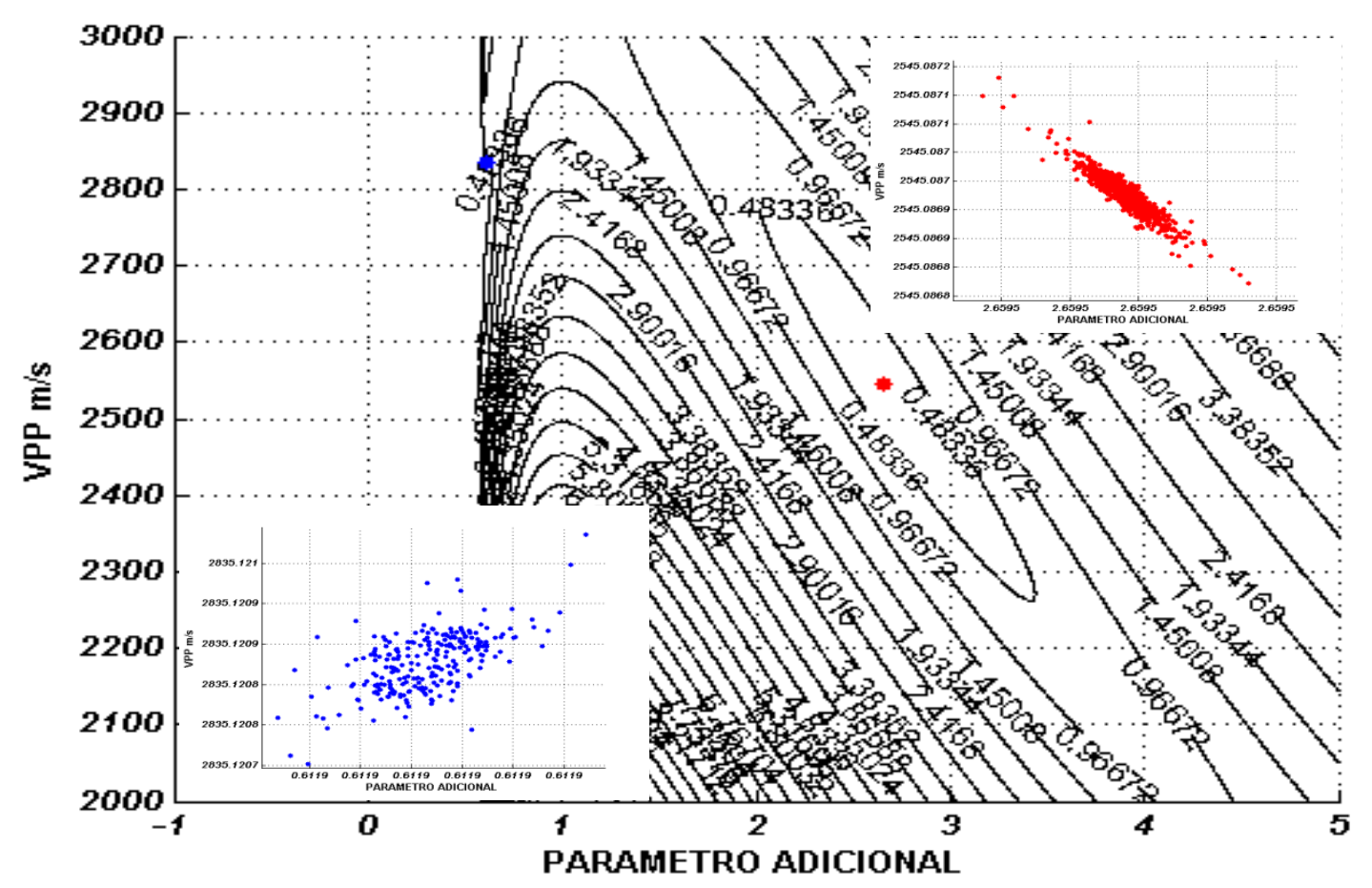

Figura 54: Mapas de dispersão sobrepostos ao mapa residual de função objetivo mostrando a complexidade da aproximação multiparamétrica de Li (2001) para um evento de reflexão de onda PP do Modelo 2. As dispersões em vermelho representam a região de mínimo global da função e as dispersões em azul representam a região de mínimo local.

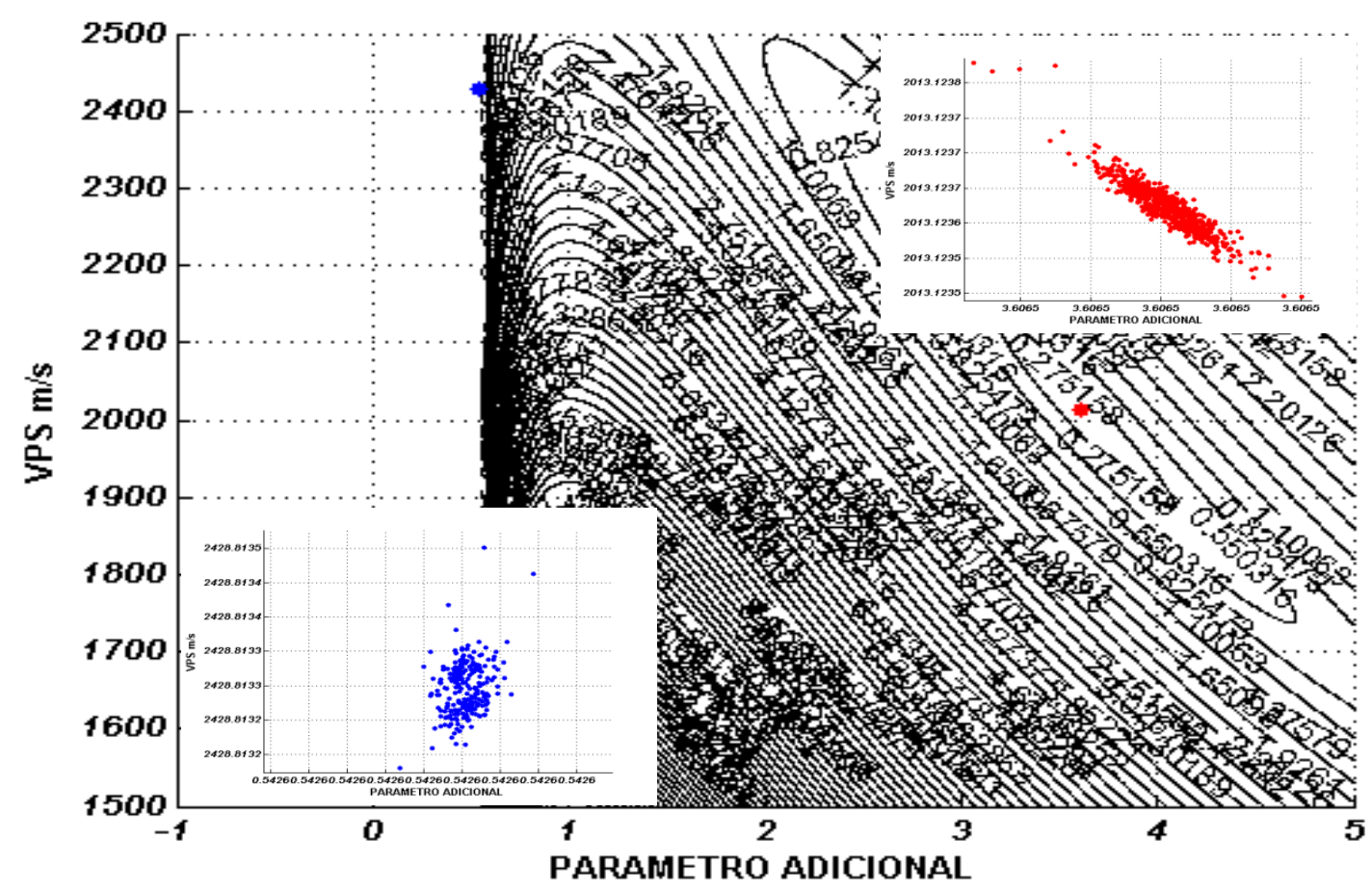

Figura 55: Mapas de dispersão sobrepostos ao mapa residual de função objetivo mostrando a complexidade da aproximação multiparamétrica de Li (2001) para um evento de reflexão de onda PS do Modelo 2. As dispersões em vermelho representam a região de mínimo global da função e as dispersões em azul representam a região de mínimo local. 


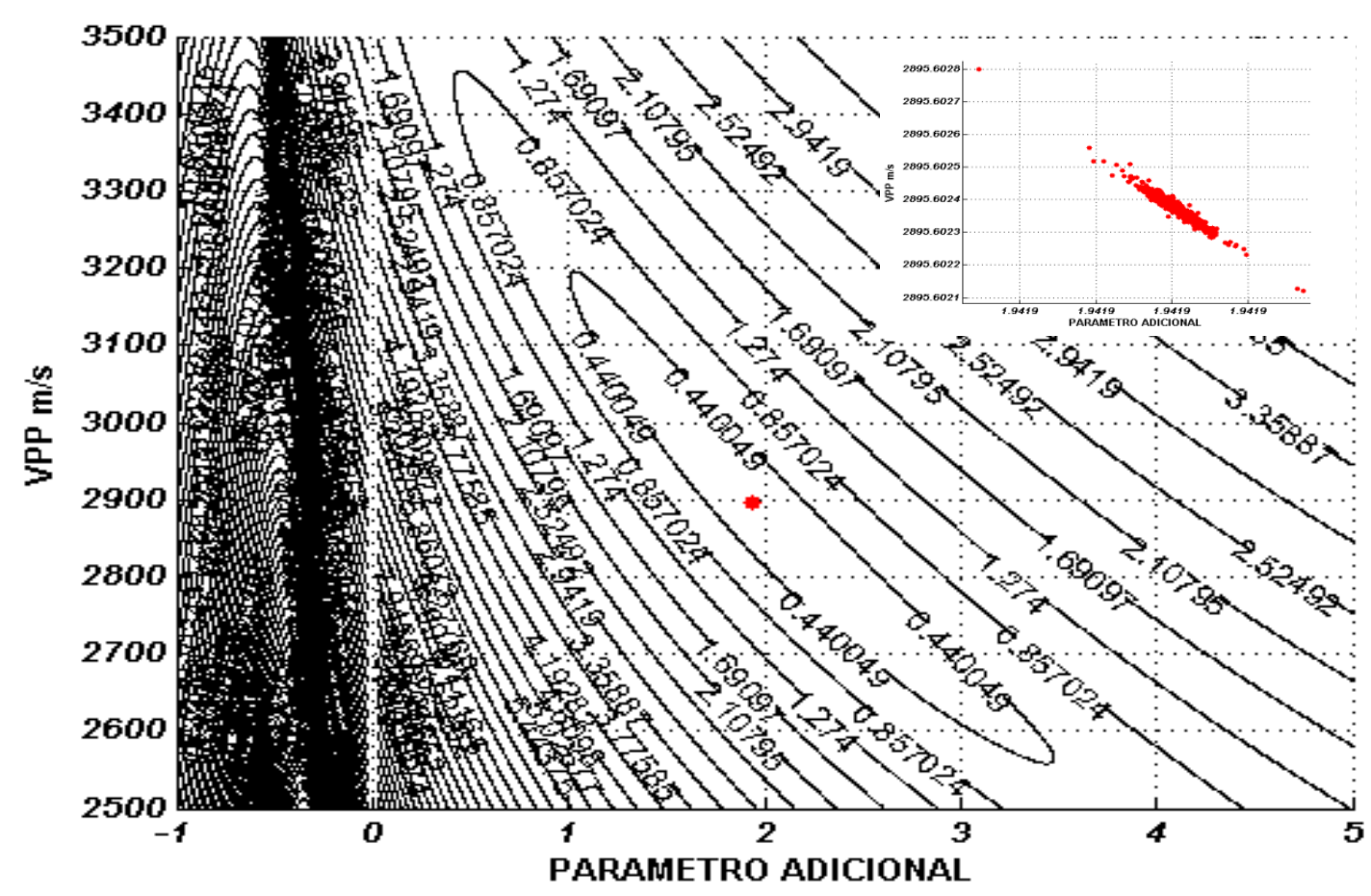

Figura 56: Mapas de dispersão sobrepostos ao mapa residual de função objetivo mostrando a complexidade da aproximação multiparamétrica de Malovichko (1978) para um evento de reflexão de onda PP do Modelo 3. As dispersões em vermelho representam a região de mínimo global da função.

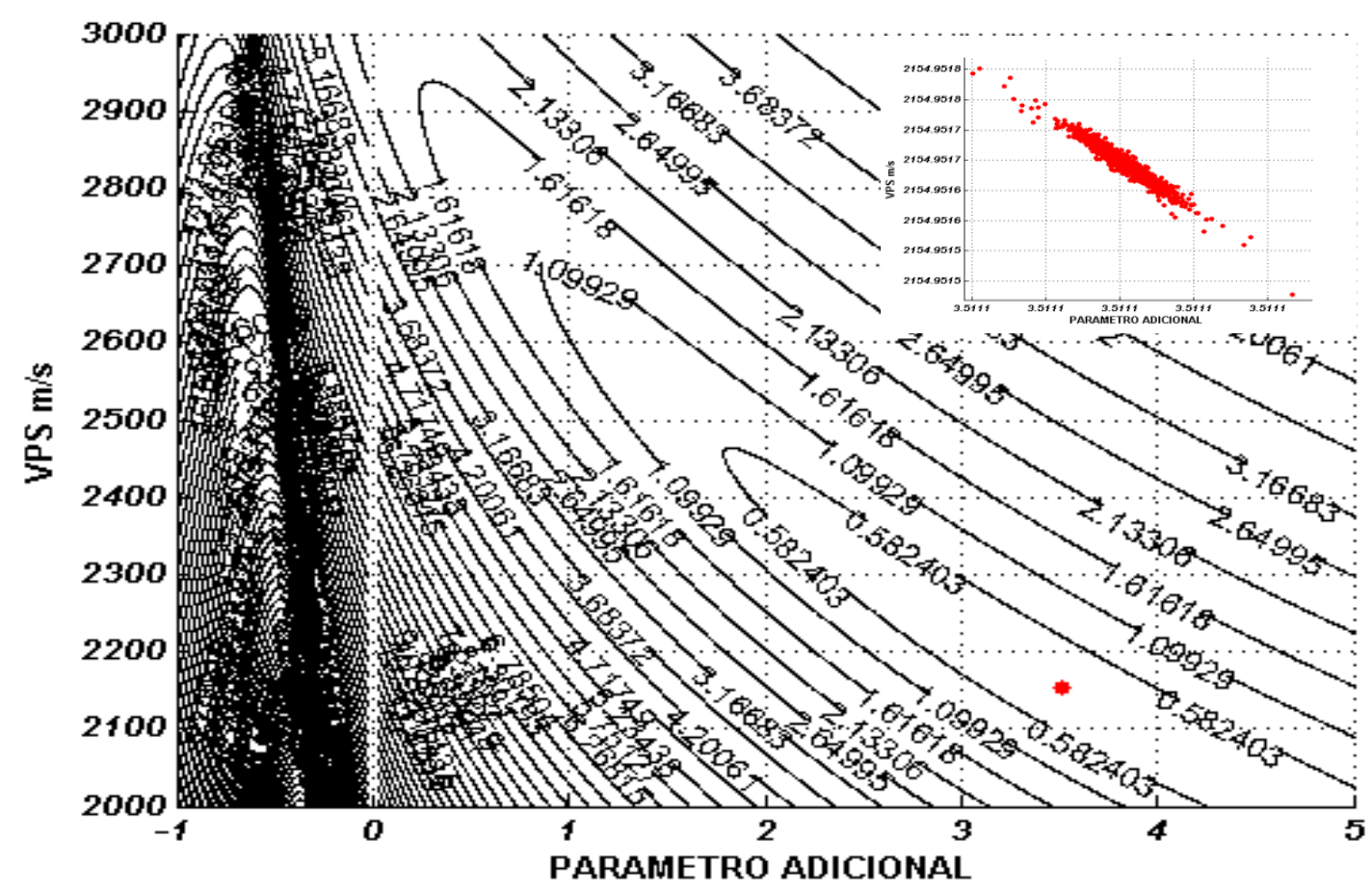

Figura 57: Mapas de dispersão sobrepostos ao mapa residual de função objetivo mostrando a complexidade da aproximação multiparamétrica de Malovichko (1978) para um evento de reflexão de onda PS do Modelo 3. As dispersões em vermelho representam a região de mínimo global da função. 


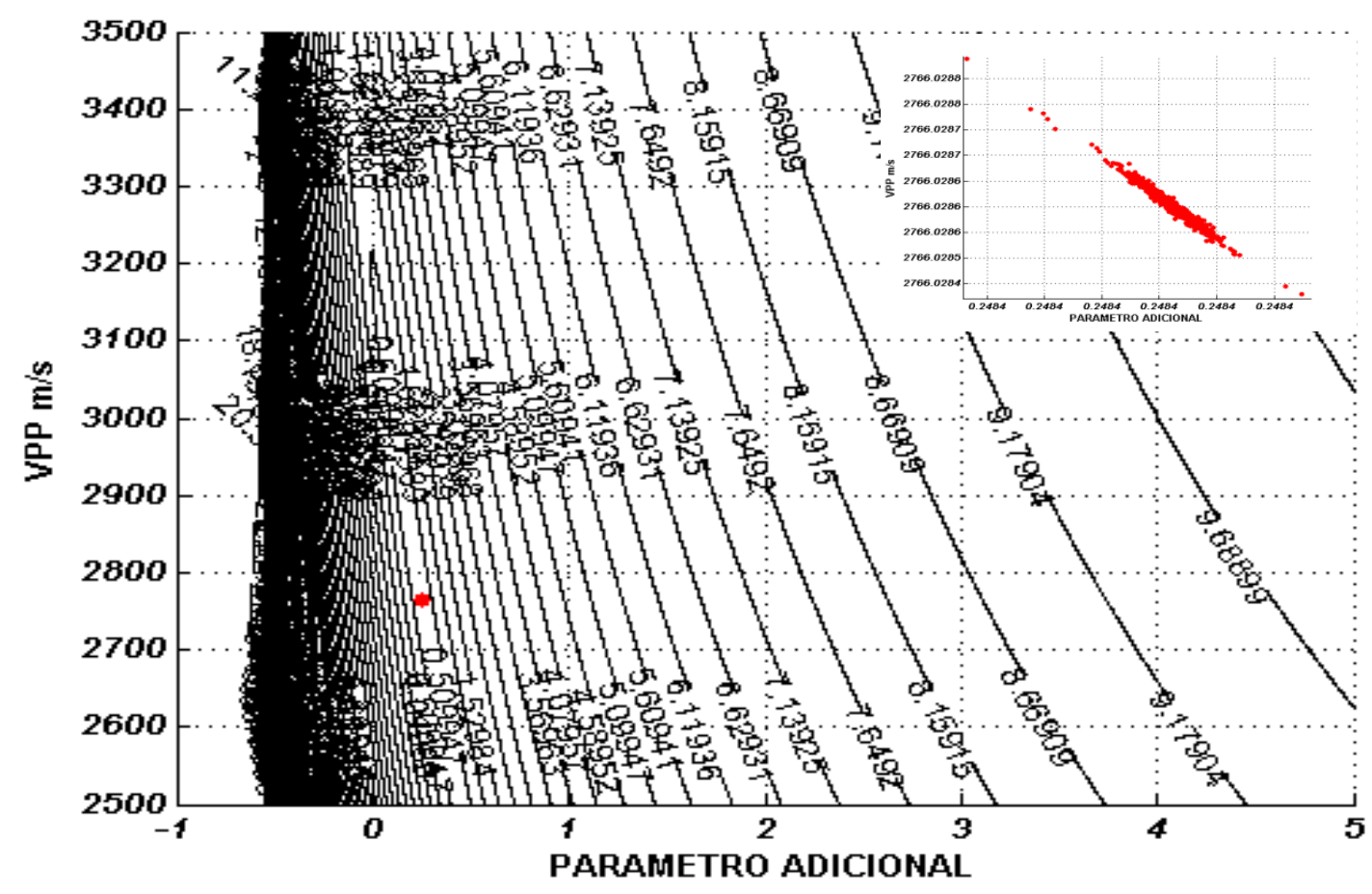

Figura 58: Mapas de dispersão sobrepostos ao mapa residual de função objetivo mostrando a complexidade da aproximação multiparamétrica de Alkhalifah e Tsvankin (1995) para um evento de reflexão de onda PP do Modelo 3. As dispersões em vermelho representam a região de mínimo global da função.

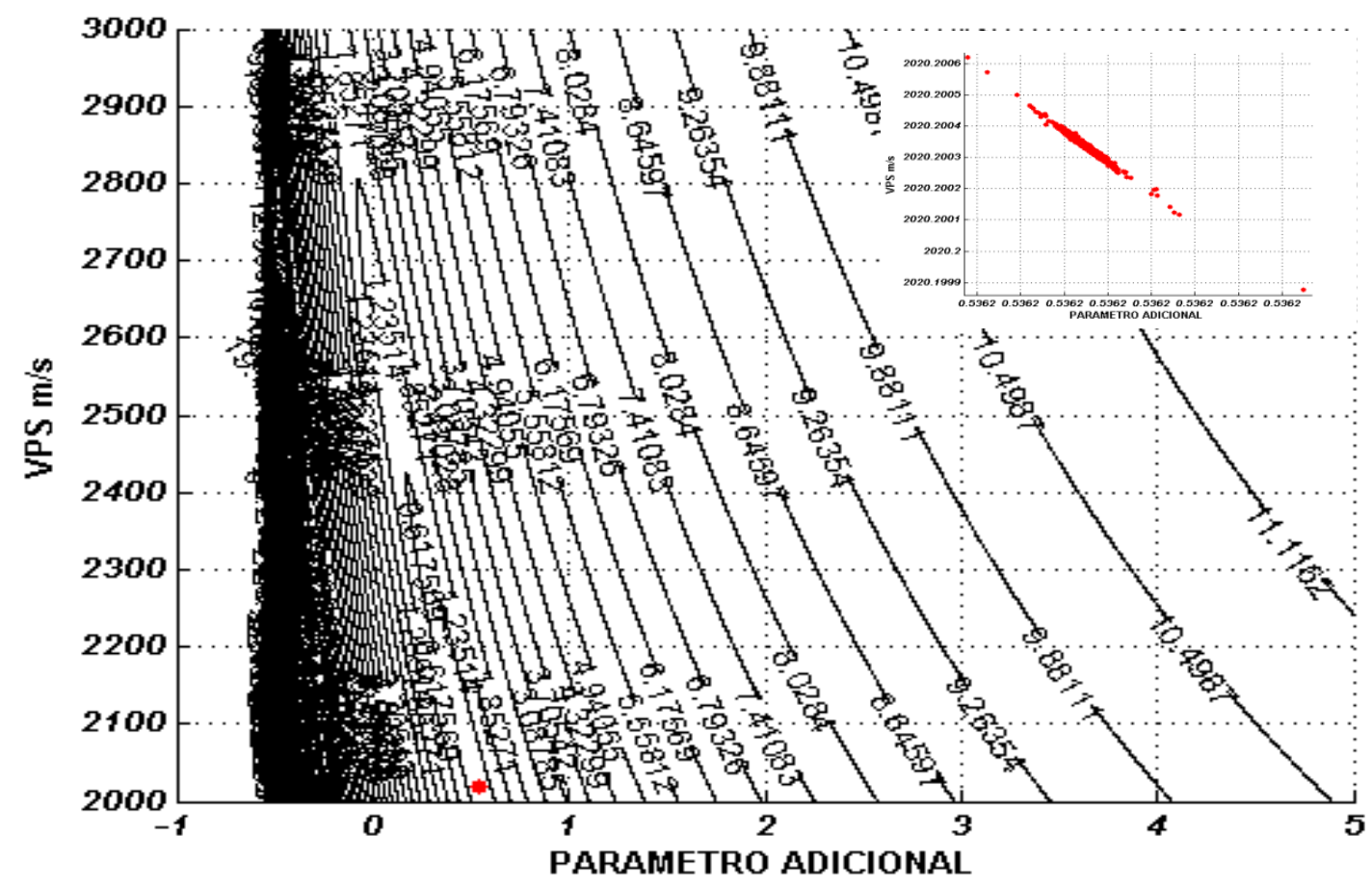

Figura 59: Mapas de dispersão sobrepostos ao mapa residual de função objetivo mostrando a complexidade da aproximação multiparamétrica de Alkhalifah e Tsvankin (1995) para um evento de reflexão de onda PS do Modelo 3. As dispersões em vermelho representam a região de mínimo global da função. 


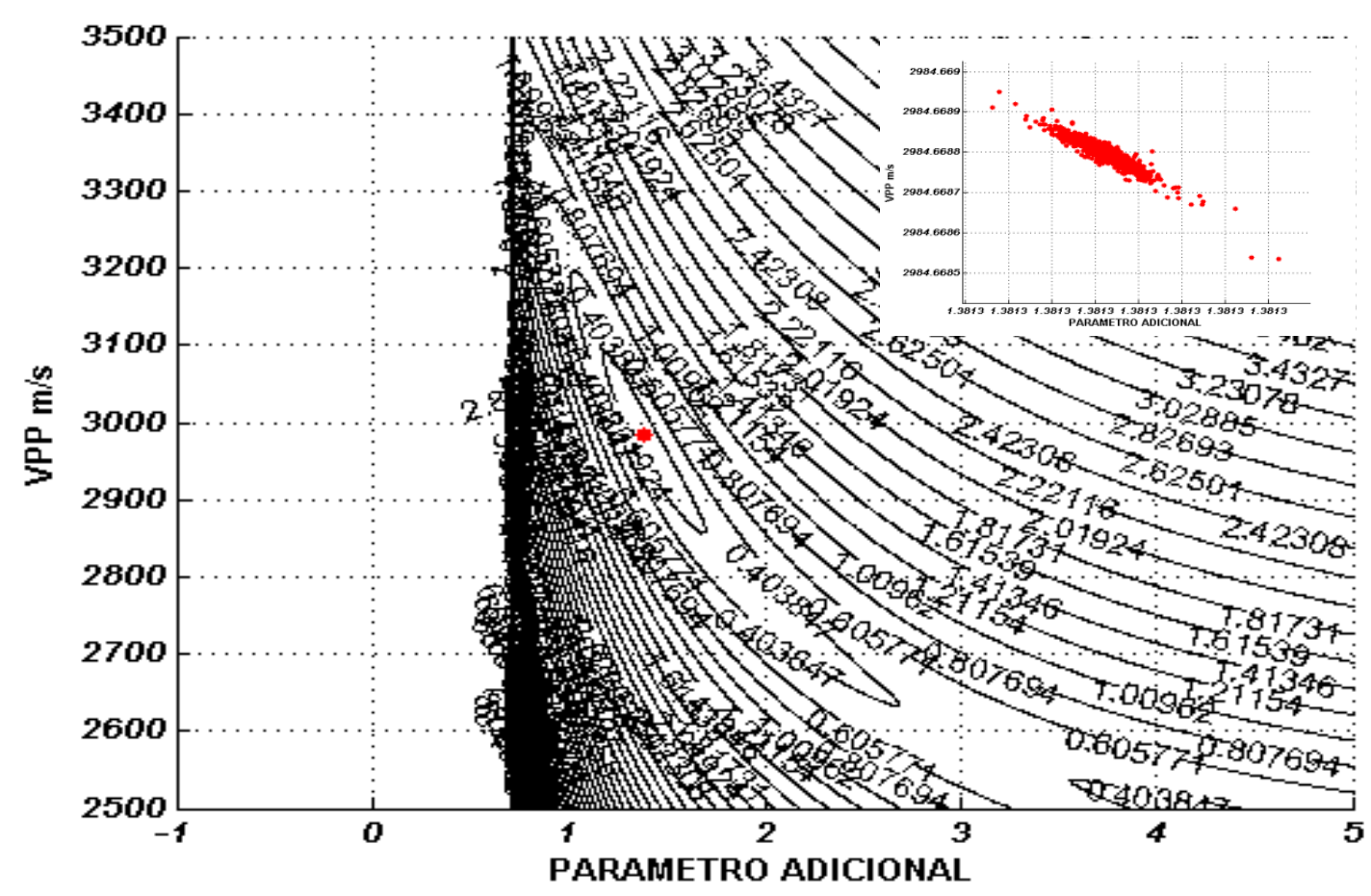

Figura 60: Mapas de dispersão sobrepostos ao mapa residual de função objetivo mostrando a complexidade da aproximação multiparamétrica de Ursin e Stovas (2006) para um evento de reflexão de onda PP do Modelo 3. As dispersões em vermelho representam a região de mínimo global da função.

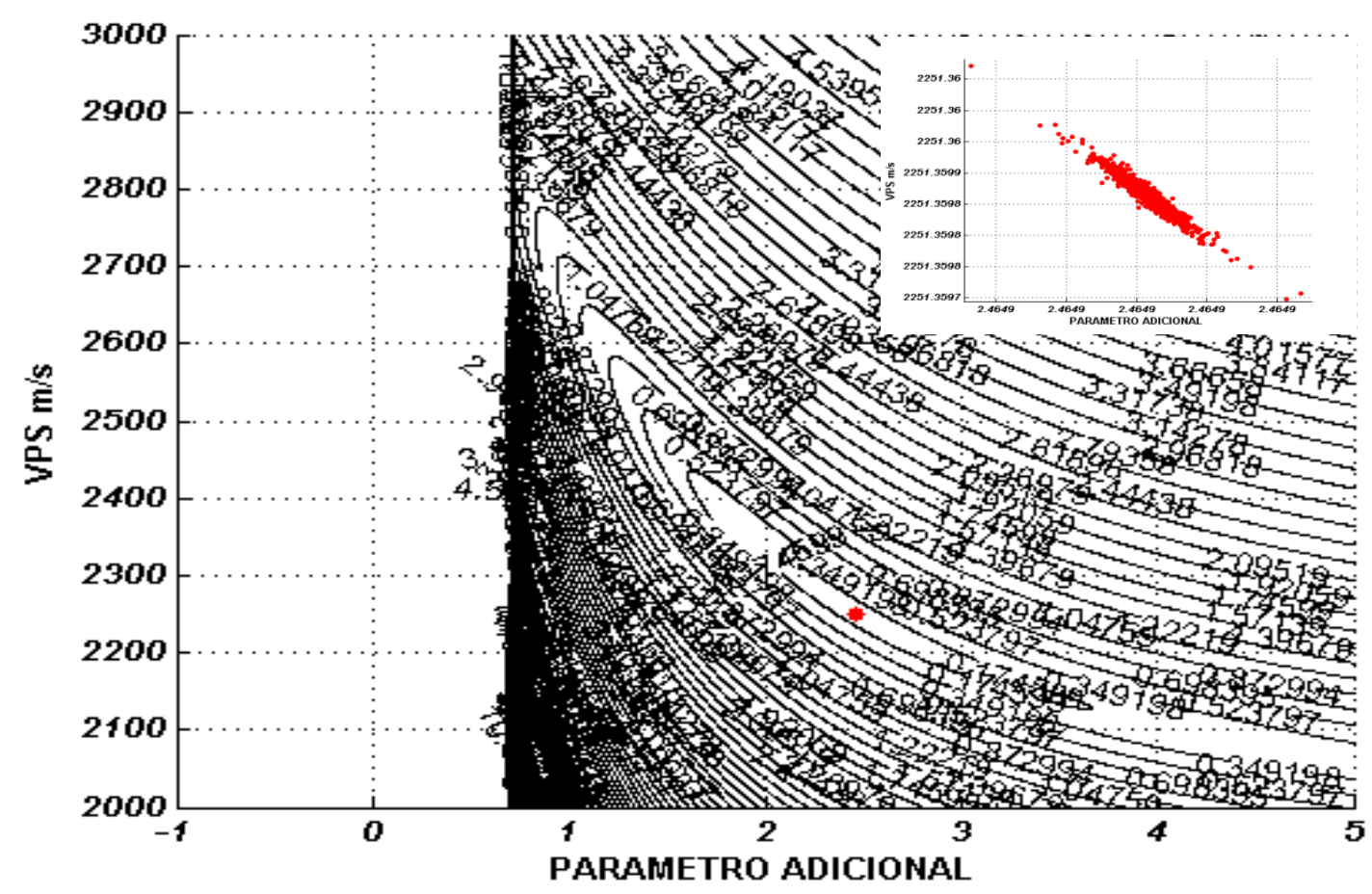

Figura 61: Mapas de dispersão sobrepostos ao mapa residual de função objetivo mostrando a complexidade da aproximação multiparamétrica de Ursin e Stovas (2006) para um evento de reflexão de onda PS do Modelo 3. As dispersões em vermelho representam a região de mínimo global da função. 


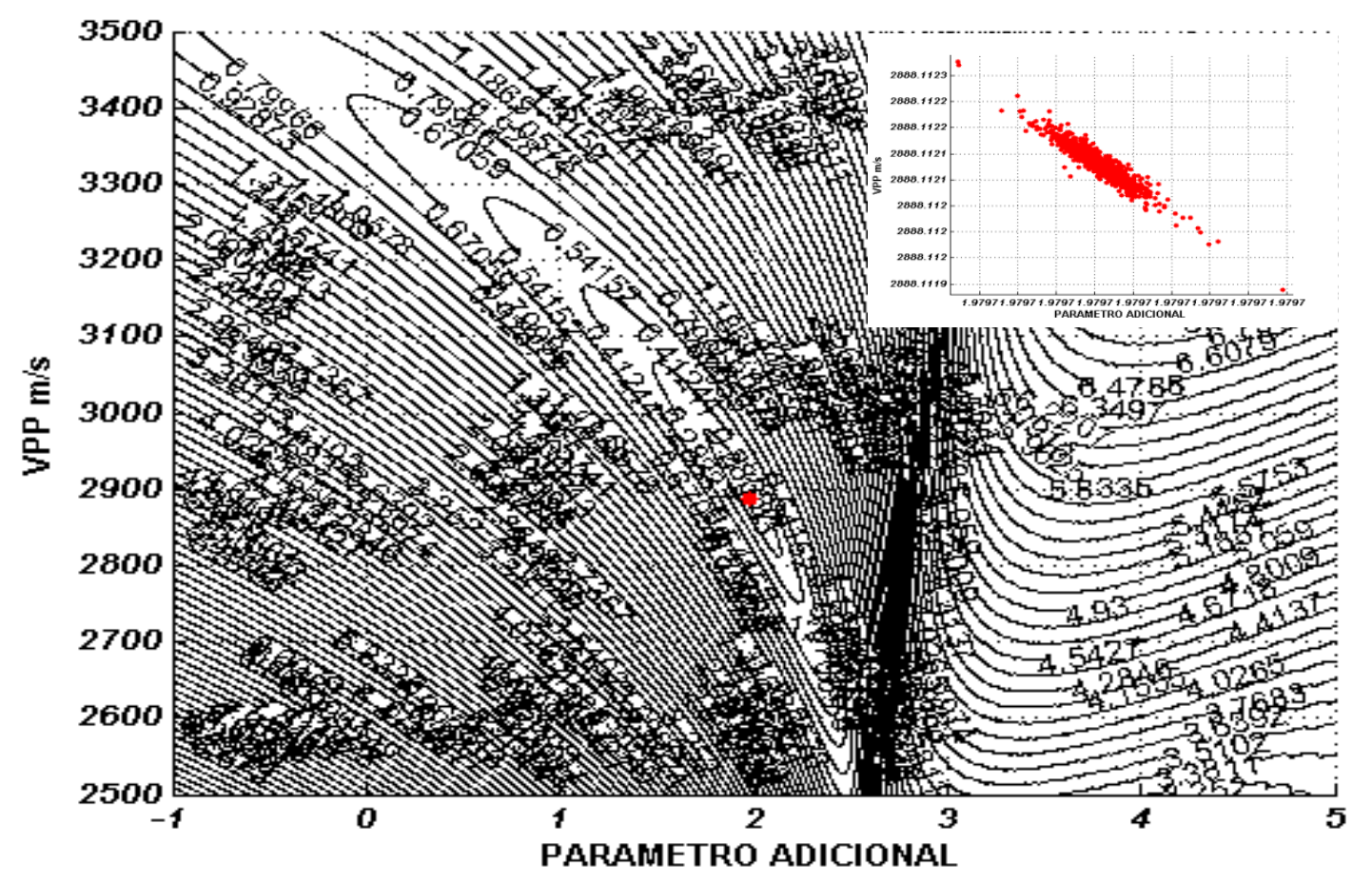

Figura 62: Mapas de dispersão sobrepostos ao mapa residual de função objetivo mostrando a complexidade da aproximação multiparamétrica de Blias (2009) para um evento de reflexão de onda PP do Modelo 3. As dispersões em vermelho representam a região de mínimo global da função.

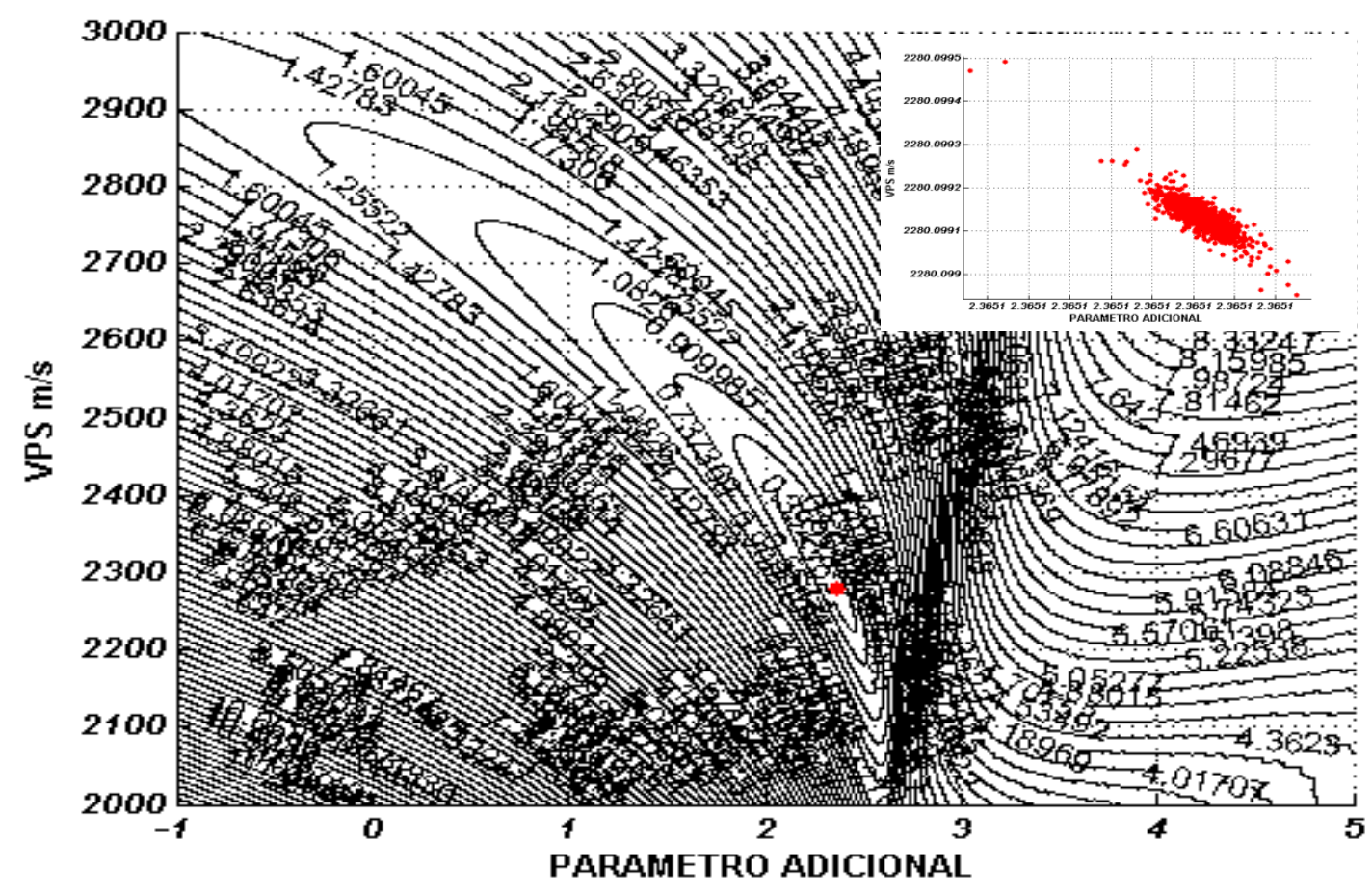

Figura 63: Mapas de dispersão sobrepostos ao mapa residual de função objetivo mostrando a complexidade da aproximação multiparamétrica de Blias (2009) para um evento de reflexão de onda PS do Modelo 3. As dispersões em vermelho representam a região de mínimo global da função. 


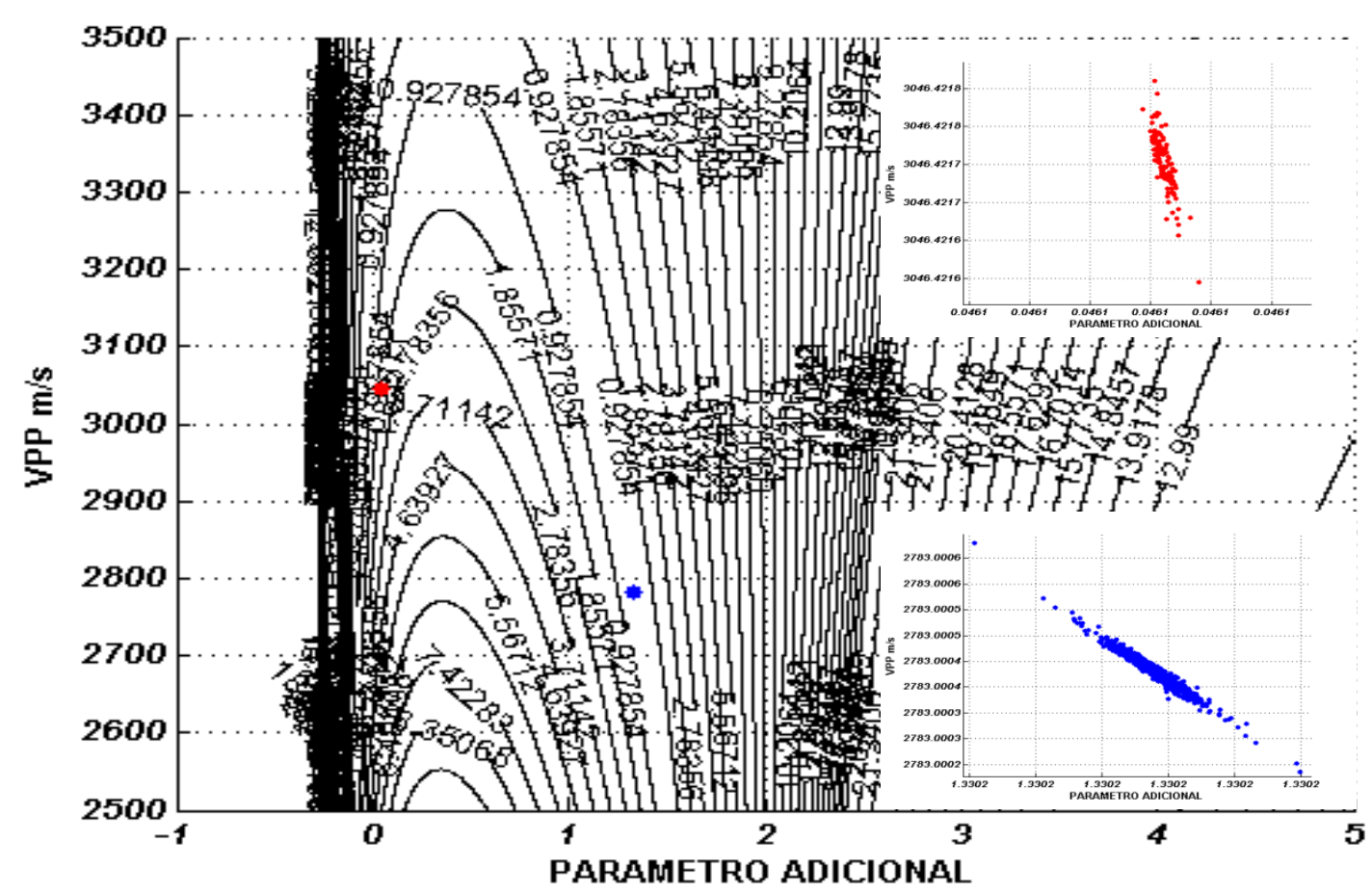

Figura 64: Mapas de dispersão sobrepostos ao mapa residual de função objetivo mostrando a complexidade da aproximação multiparamétrica de Muir e Dellinger (1985) para um evento de reflexão de onda PP do Modelo 3. As dispersões em vermelho representam a região de mínimo global da função e as dispersões em azul representam a região de mínimo local.

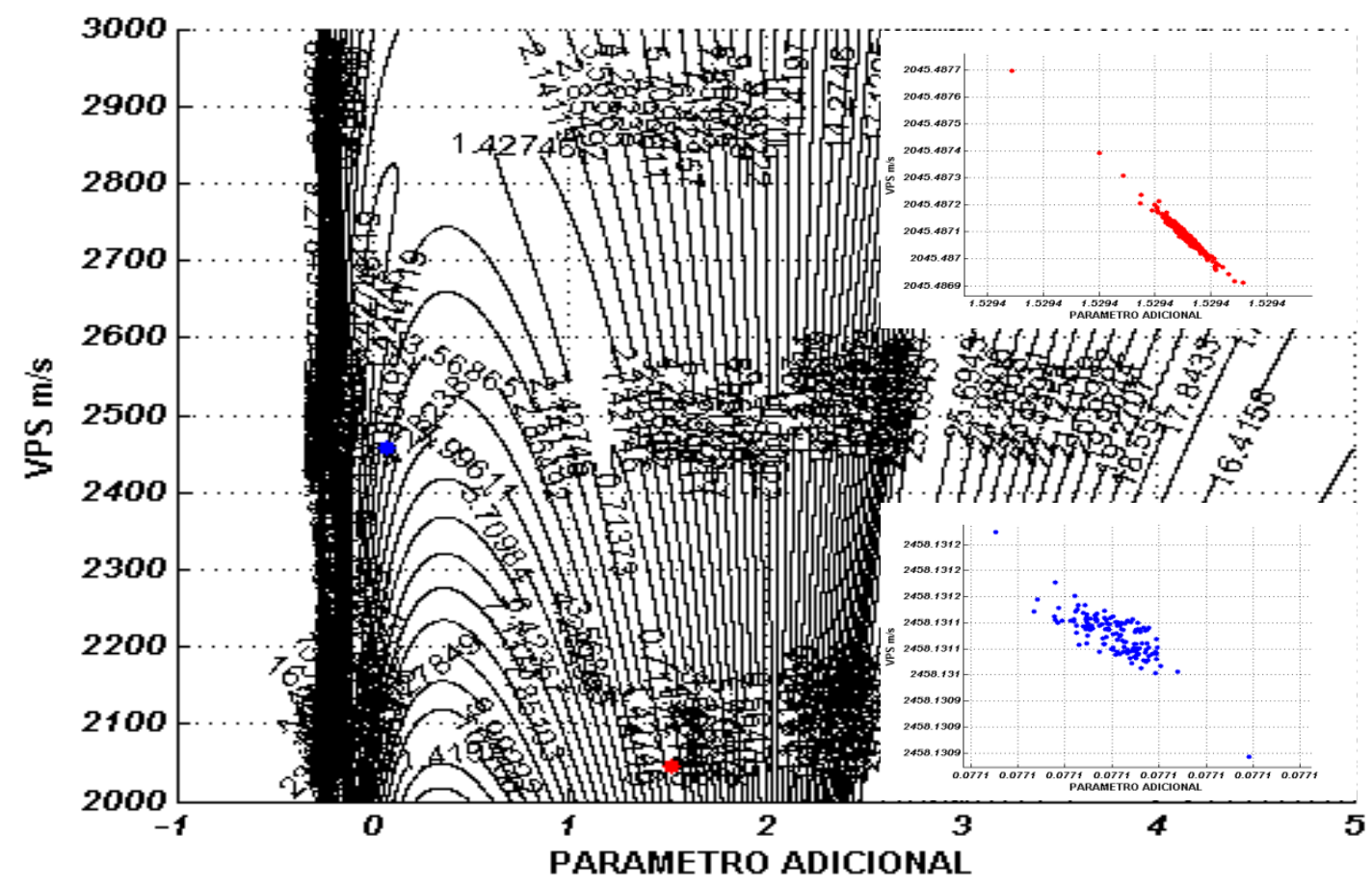

Figura 65: Mapas de dispersão sobrepostos ao mapa residual de função objetivo mostrando a complexidade da aproximação multiparamétrica de Muir e Dellinger (1985) para um evento de reflexão de onda PS do Modelo 3. As dispersões em vermelho representam a região de mínimo global da função e as dispersões em azul representam a região de mínimo local. 


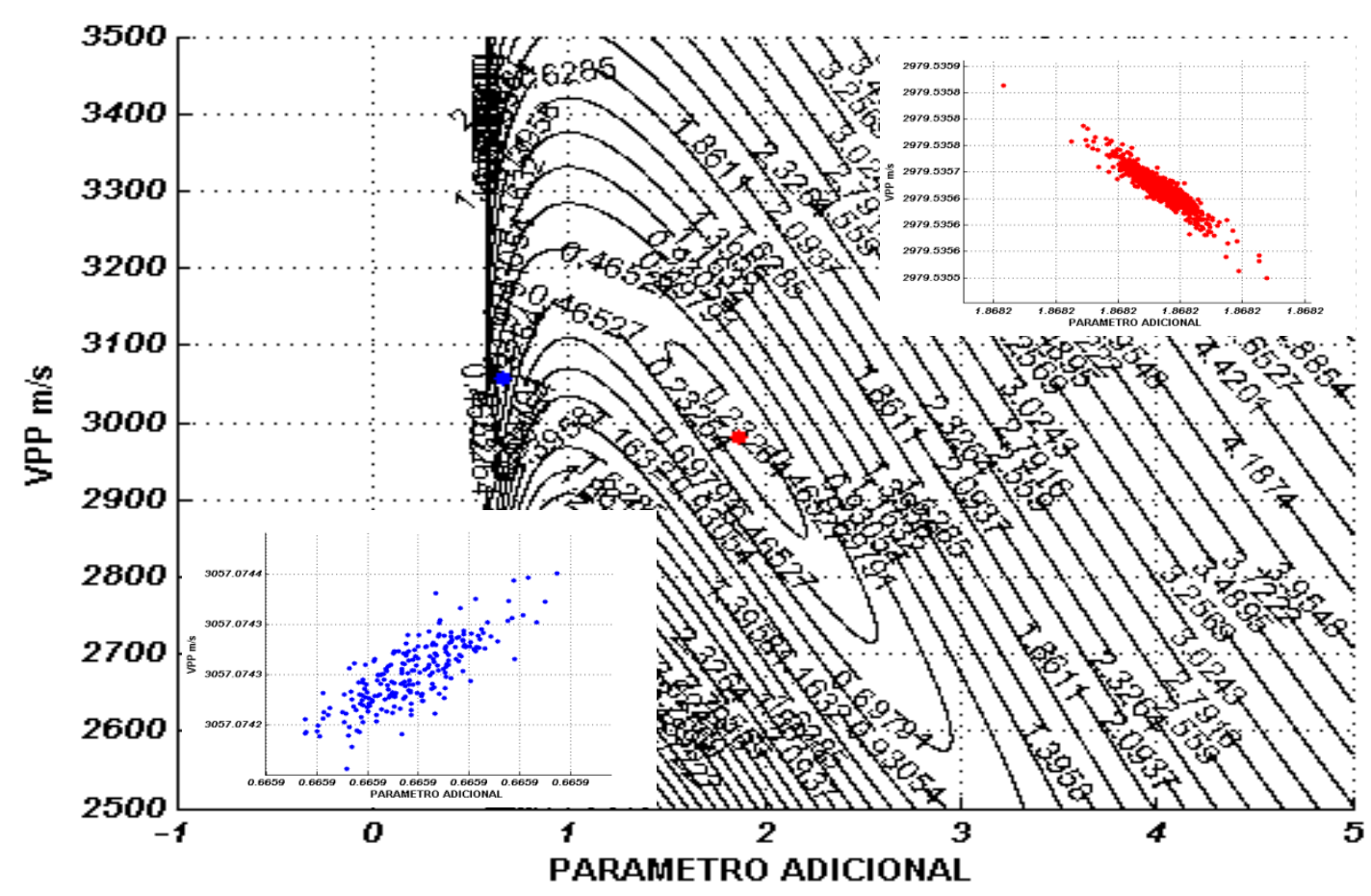

Figura 66: Mapas de dispersão sobrepostos ao mapa residual de função objetivo mostrando a complexidade da aproximação multiparamétrica de Li (2001) para um evento de reflexão de onda PP do Modelo 3. As dispersões em vermelho representam a região de mínimo global da função e as dispersões em azul representam a região de mínimo local.

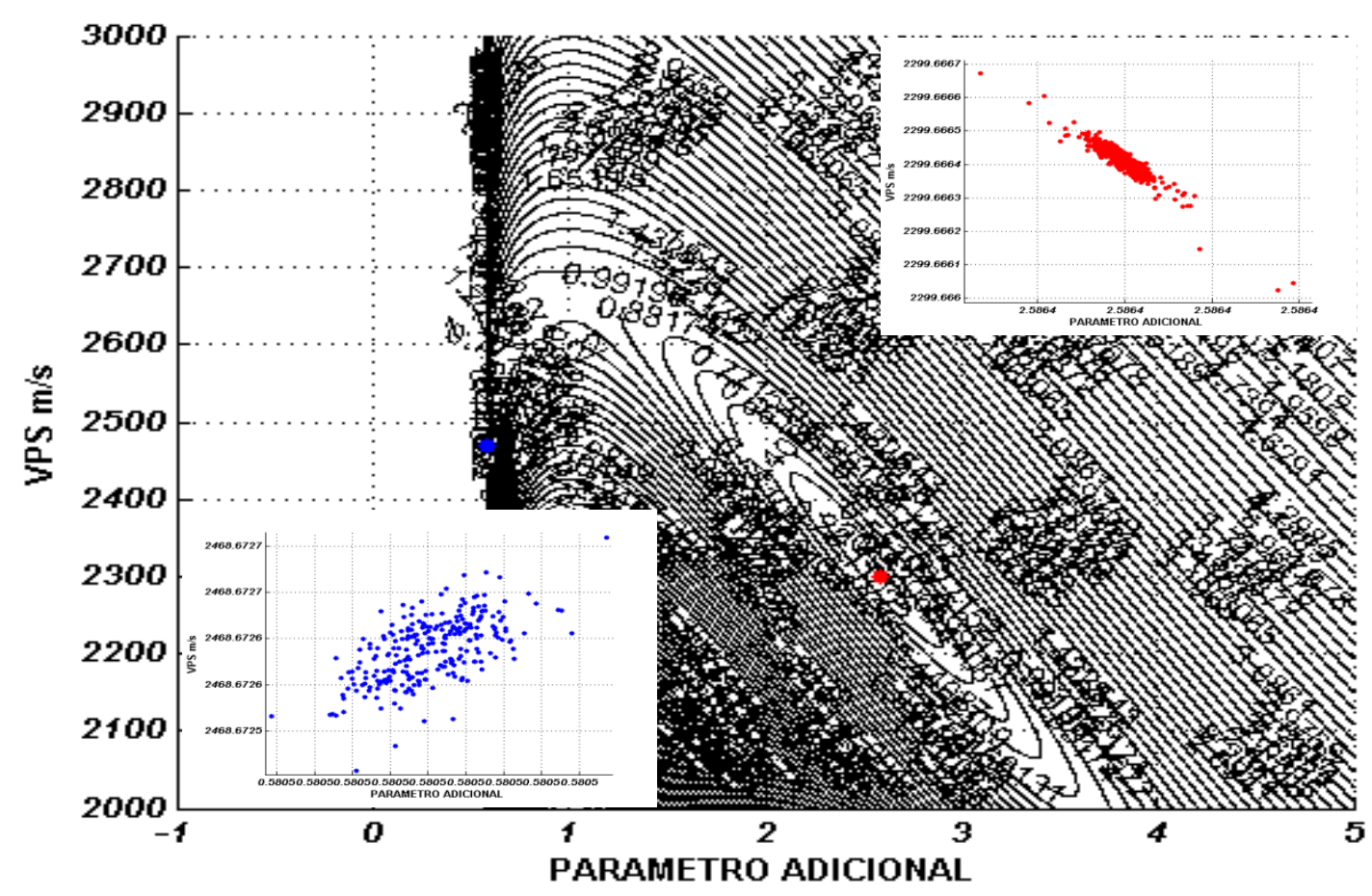

Figura 67: Mapas de dispersão sobrepostos ao mapa residual de função objetivo mostrando a complexidade da aproximação multiparamétrica de Li (2001) para um evento de reflexão de onda PS do Modelo 3. As dispersões em vermelho representam a região de mínimo global da função e as dispersões em azul representam a região de mínimo local. 


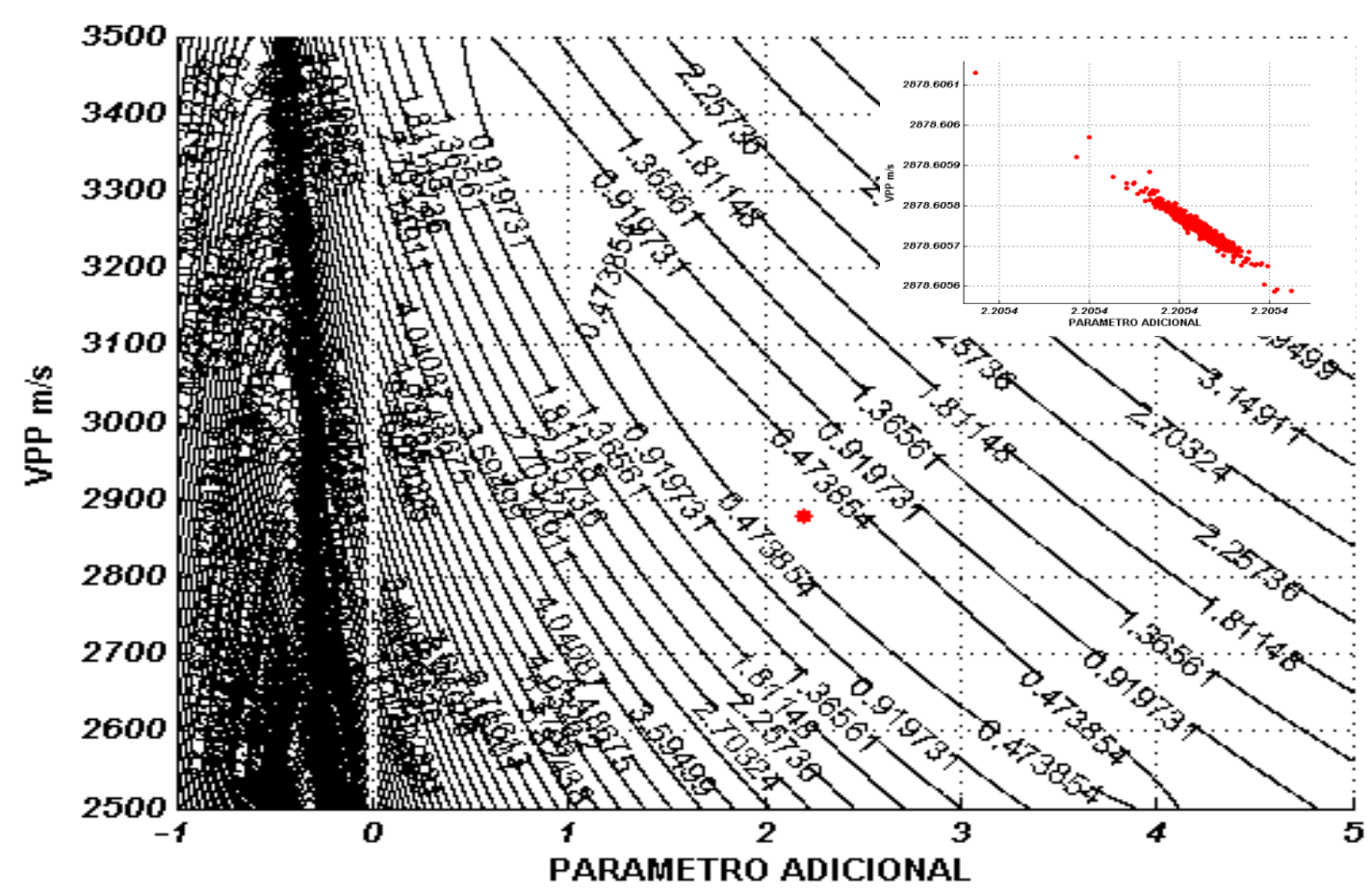

Figura 68: Mapas de dispersão sobrepostos ao mapa residual de função objetivo mostrando a complexidade da aproximação multiparamétrica de Malovichko (1978) para um evento de reflexão de onda PP do Modelo 4. As dispersões em vermelho representam a região de mínimo global da função.

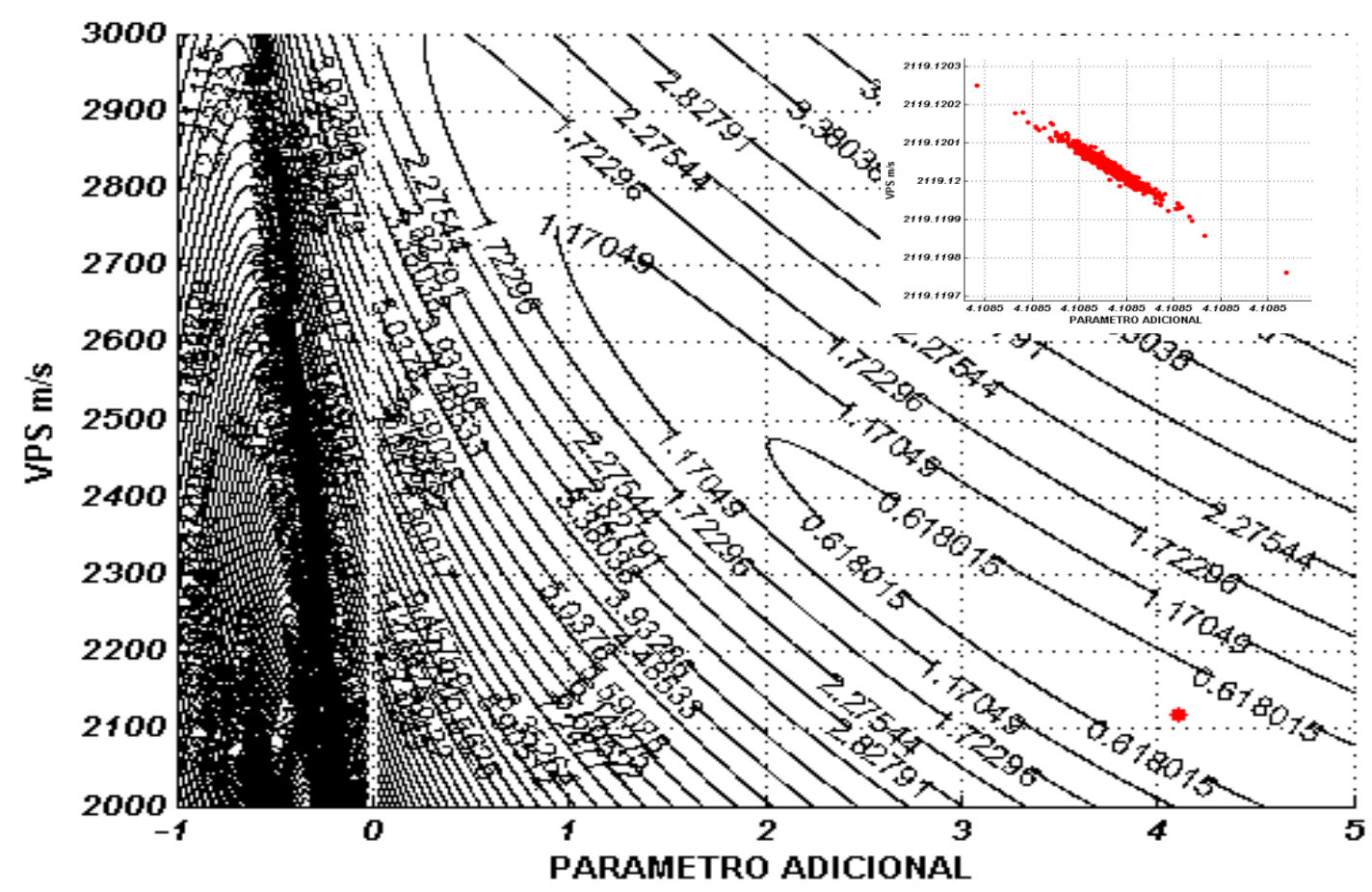

Figura 69: Mapas de dispersão sobrepostos ao mapa residual de função objetivo mostrando a complexidade da aproximação multiparamétrica de Malovichko (1978) para um evento de reflexão de onda PS do Modelo 4. As dispersões em vermelho representam a região de mínimo global da função. 


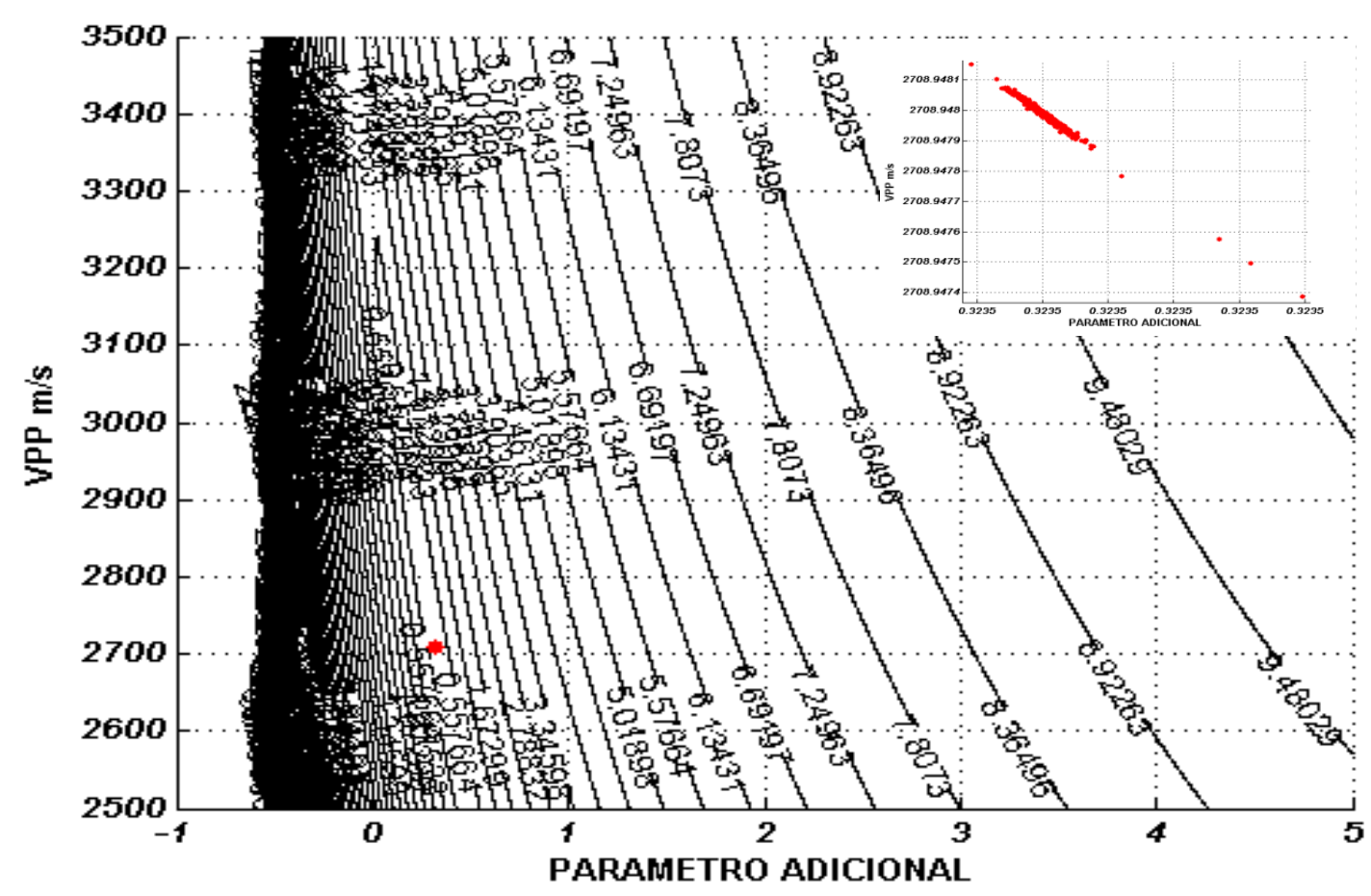

Figura 70: Mapas de dispersão sobrepostos ao mapa residual de função objetivo mostrando a complexidade da aproximação multiparamétrica de Alkhalifah e Tsvankin (1995) para um evento de reflexão de onda PP do Modelo 4. As dispersões em vermelho representam a região de mínimo global da função.

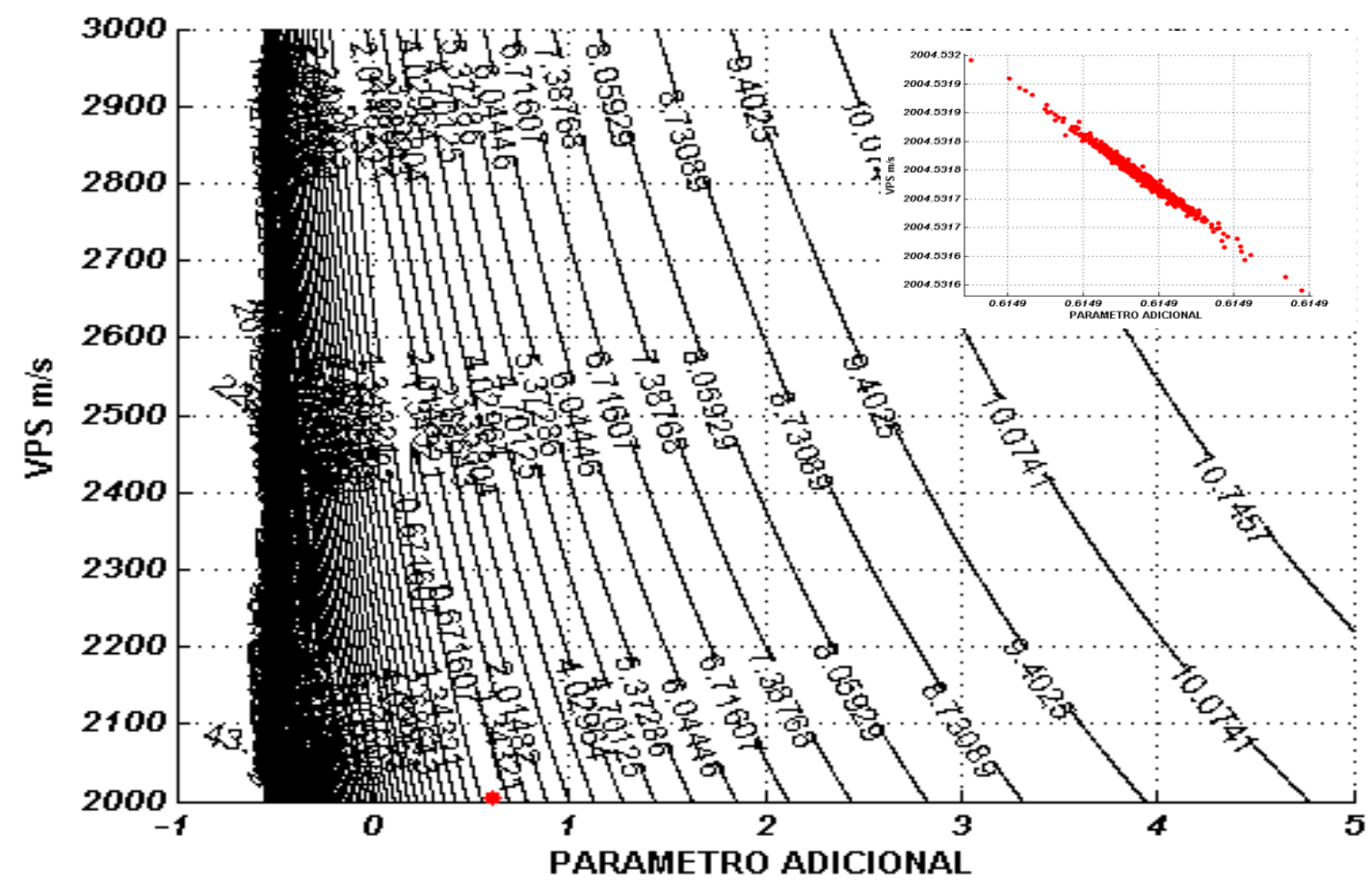

Figura 71: Mapas de dispersão sobrepostos ao mapa residual de função objetivo mostrando a complexidade da aproximação multiparamétrica de Alkhalifah e Tsvankin (1995) para um evento de reflexão de onda PS do Modelo 4. As dispersões em vermelho representam a região de mínimo global da função. 


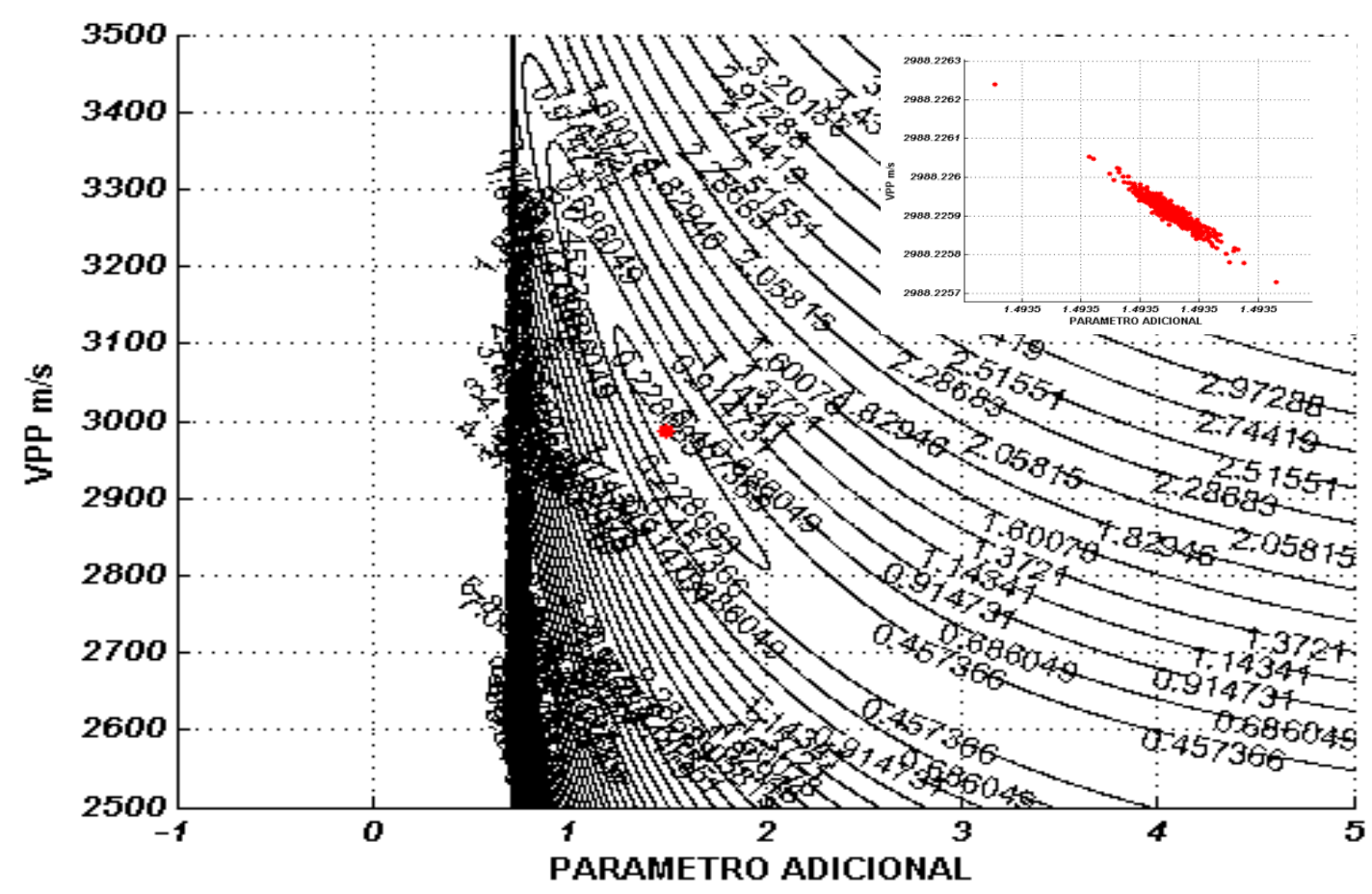

Figura 72: Mapas de dispersão sobrepostos ao mapa residual de função objetivo mostrando a complexidade da aproximação multiparamétrica de Ursin e Stovas (2006) para um evento de reflexão de onda PP do Modelo 4. As dispersões em vermelho representam a região de mínimo global da função.

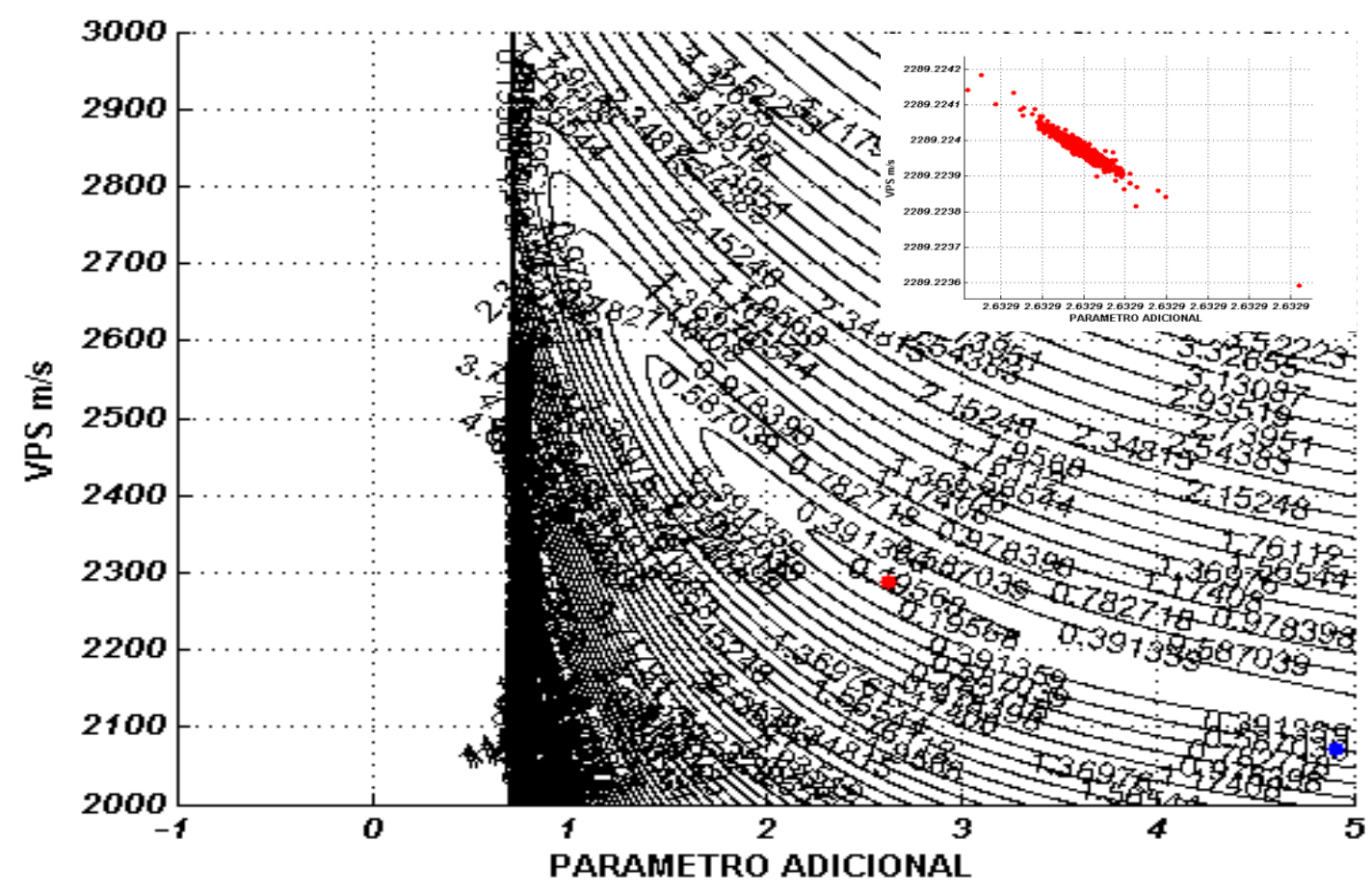

Figura 73: Mapas de dispersão sobrepostos ao mapa residual de função objetivo mostrando a complexidade da aproximação multiparamétrica de Ursin e Stovas (2006) para um evento de reflexão de onda PS do Modelo 4. As dispersões em vermelho representam a região de mínimo global da função. 


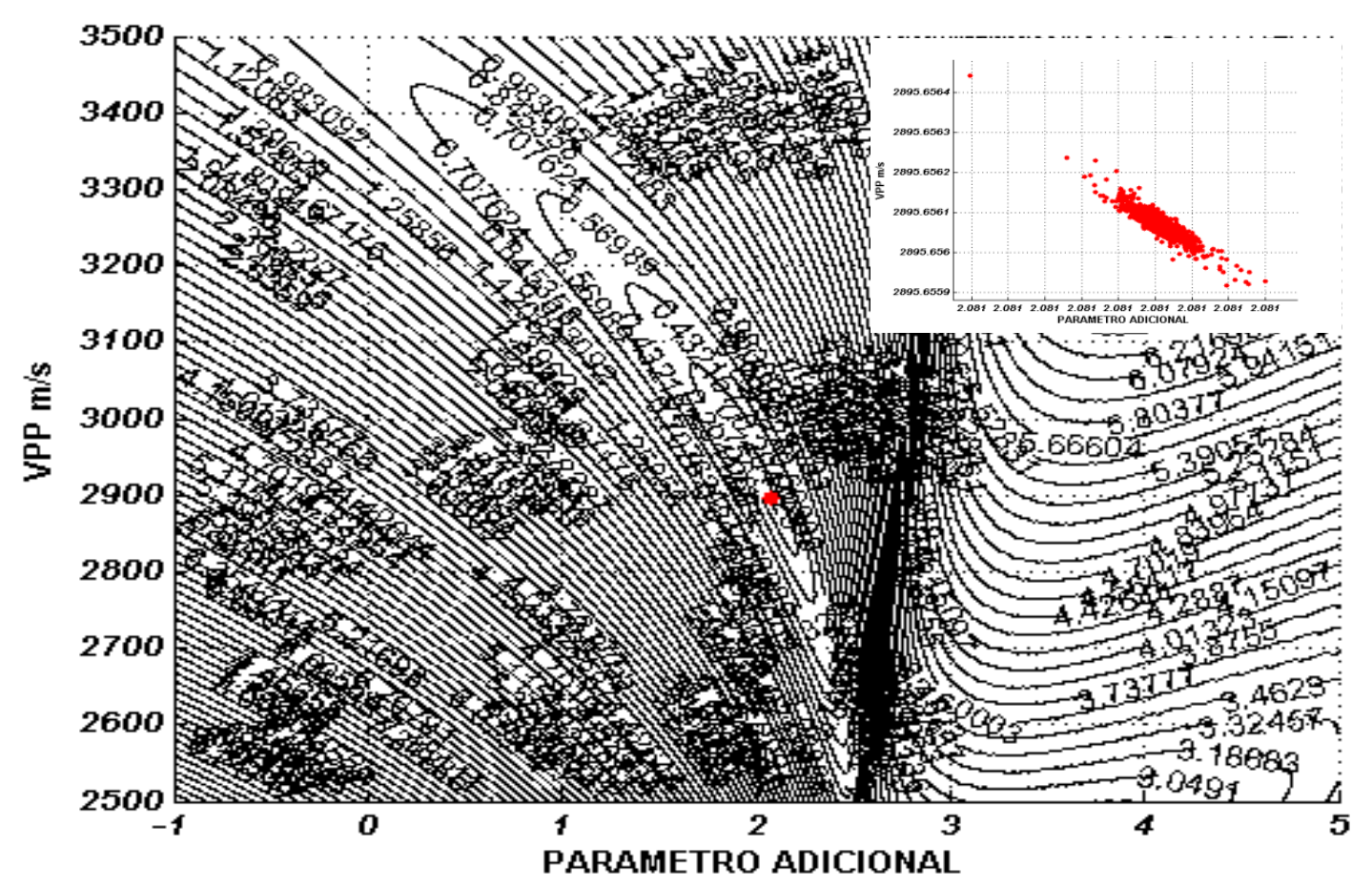

Figura 74: Mapas de dispersão sobrepostos ao mapa residual de função objetivo mostrando a complexidade da aproximação multiparamétrica de Blias (2009) para um evento de reflexão de onda PP do Modelo 4. As dispersões em vermelho representam a região de mínimo global da função.

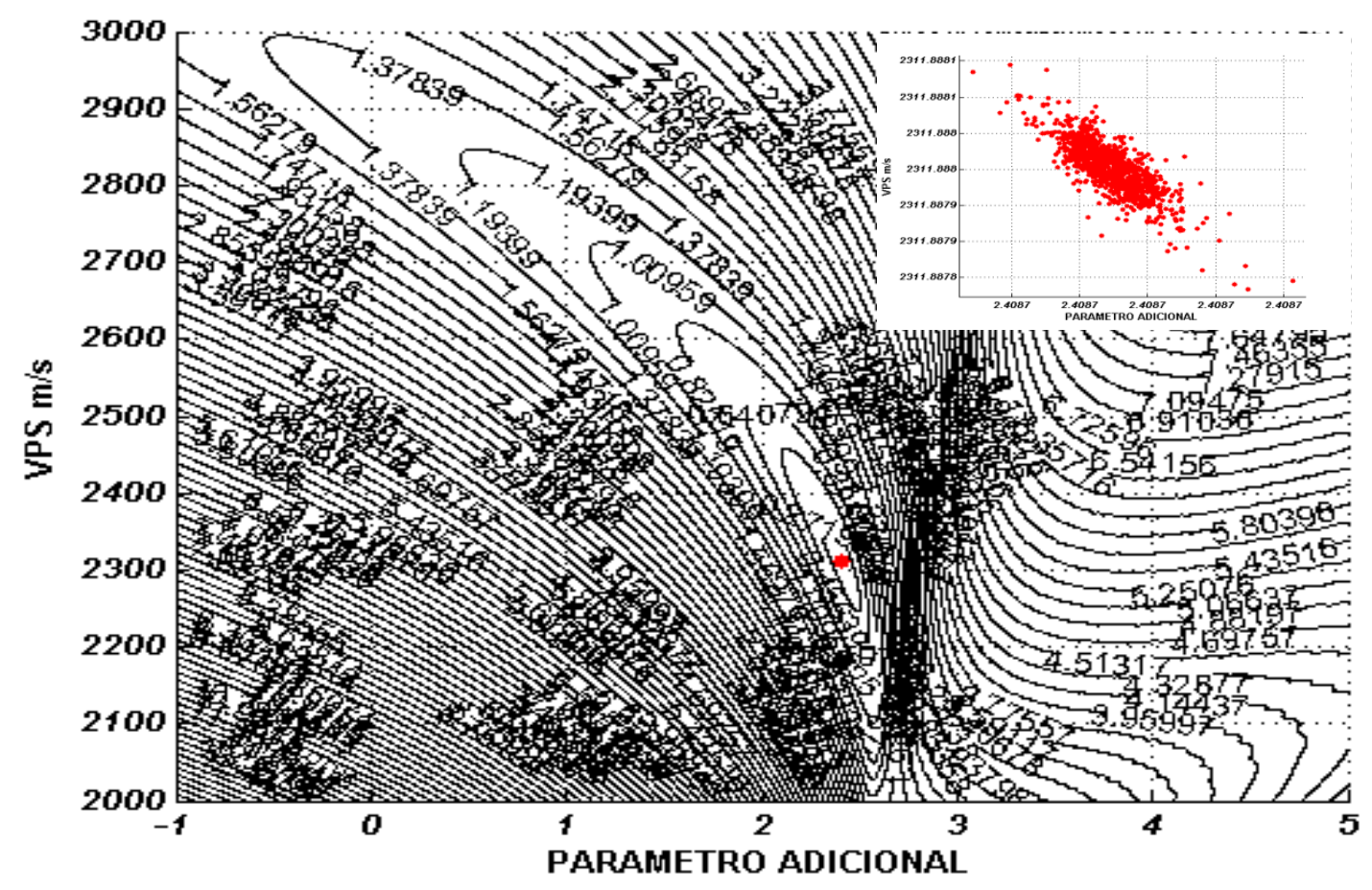

Figura 75: Mapas de dispersão sobrepostos ao mapa residual de função objetivo mostrando a complexidade da aproximação multiparamétrica de Blias (2009) para um evento de reflexão de onda PS do Modelo 4. As dispersões em vermelho representam a região de mínimo global da função. 


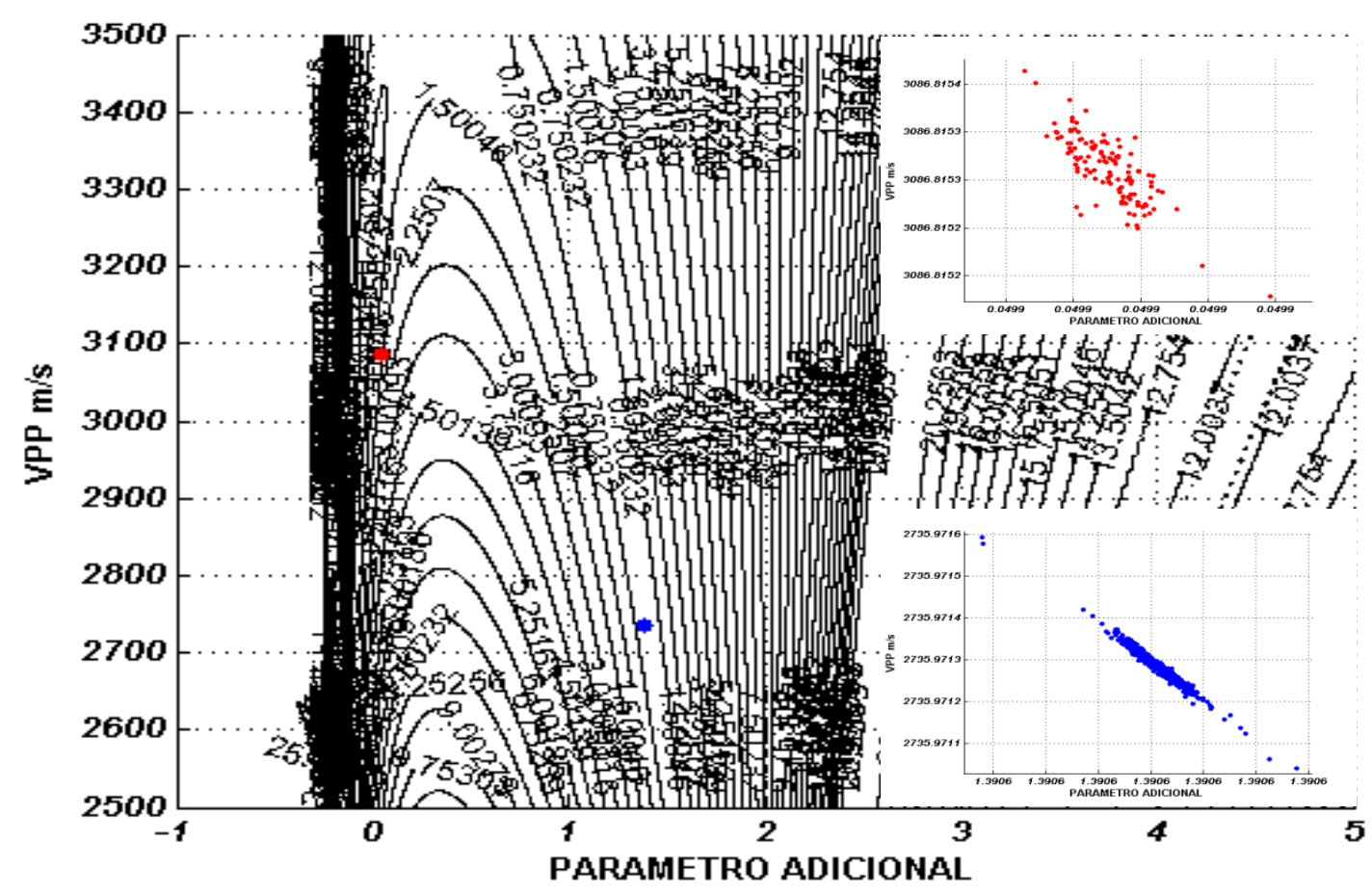

Figura 76: Mapas de dispersão sobrepostos ao mapa residual de função objetivo mostrando a complexidade da aproximação multiparamétrica de Muir e Dellinger (1985) para um evento de reflexão de onda PP do Modelo 4. As dispersões em vermelho representam a região de mínimo global da função e as dispersões em azul representam a região de mínimo local.

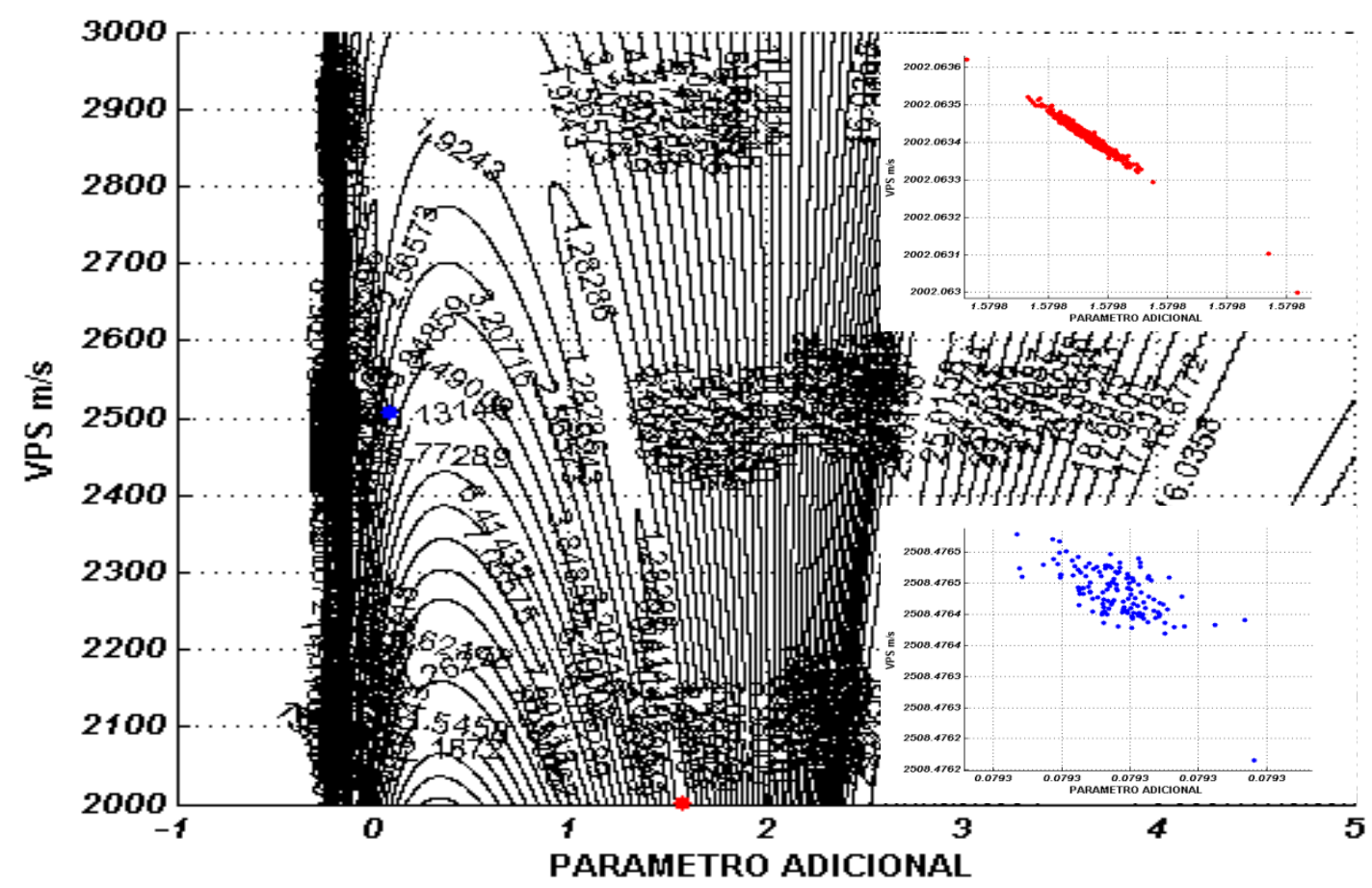

Figura 77: Mapas de dispersão sobrepostos ao mapa residual de função objetivo mostrando a complexidade da aproximação multiparamétrica de Muir e Dellinger (1985) para um evento de reflexão de onda PS do Modelo 4. As dispersões em vermelho representam a região de mínimo global da função e as dispersões em azul representam a região de mínimo local. 


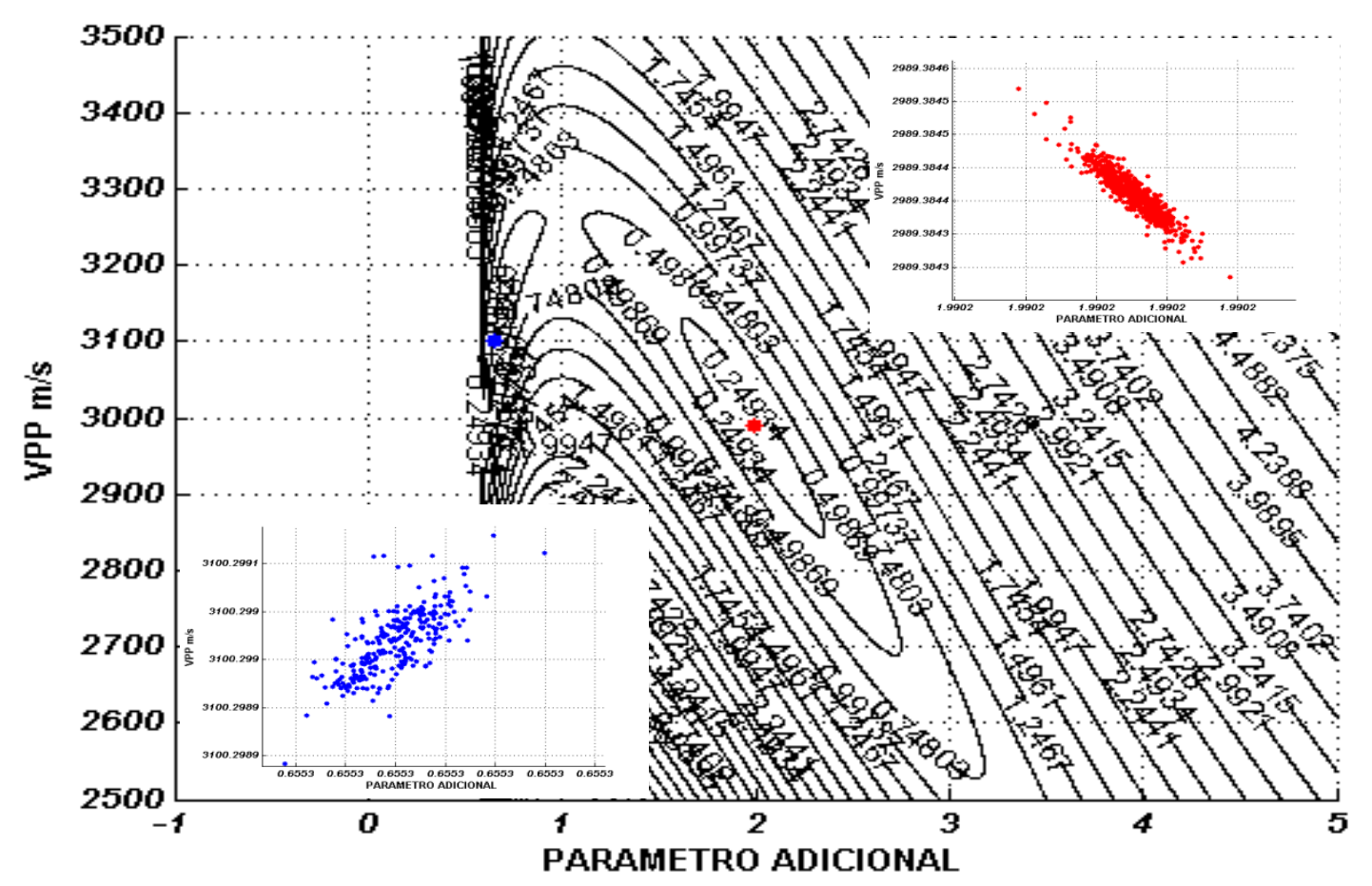

Figura 78: Mapas de dispersão sobrepostos ao mapa residual de função objetivo mostrando a complexidade da aproximação multiparamétrica de Li (2001) para um evento de reflexão de onda PP do Modelo 4. As dispersões em vermelho representam a região de mínimo global da função e as dispersões em azul representam a região de mínimo local.

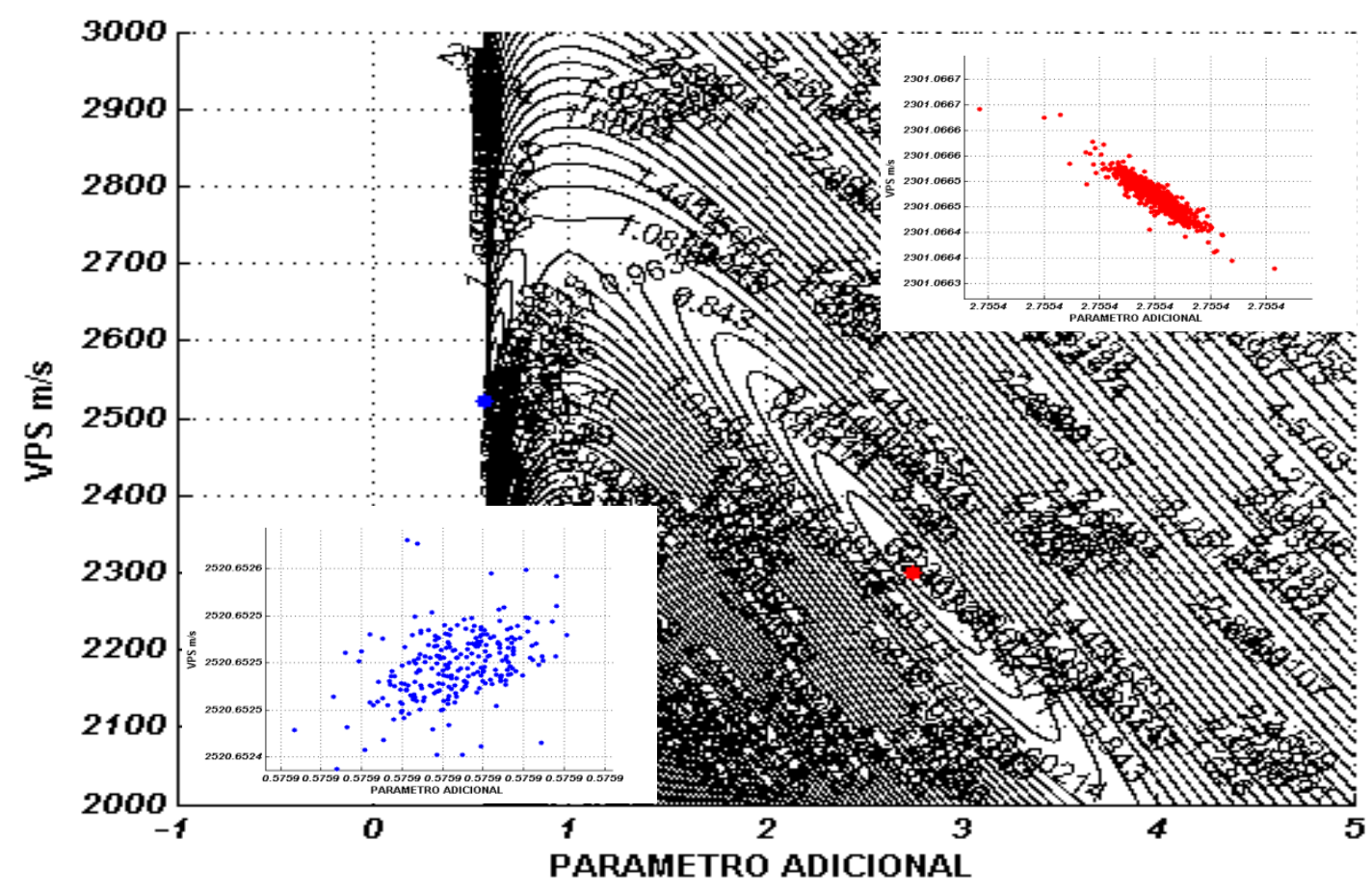

Figura 79: Mapas de dispersão sobrepostos ao mapa residual de função objetivo mostrando a complexidade da aproximação multiparamétrica de Li (2001) para um evento de reflexão de onda PS do Modelo 4. As dispersões em vermelho representam a região de mínimo global da função e as dispersões em azul representam a região de mínimo local. 


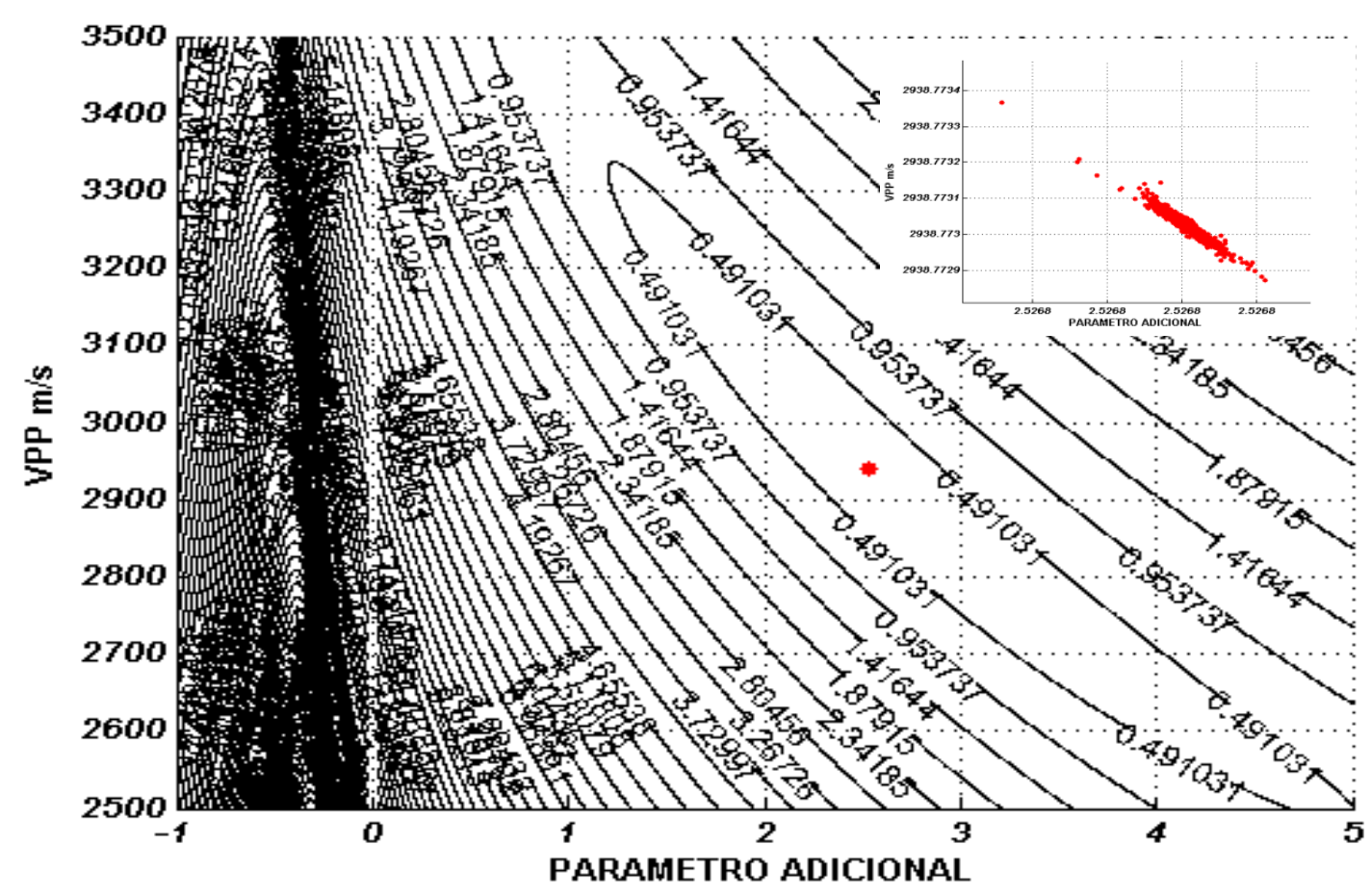

Figura 80: Mapas de dispersão sobrepostos ao mapa residual de função objetivo mostrando a complexidade da aproximação multiparamétrica de Malovichko (1978) para um evento de reflexão de onda PP do Modelo 5. As dispersões em vermelho representam a região de mínimo global da função.

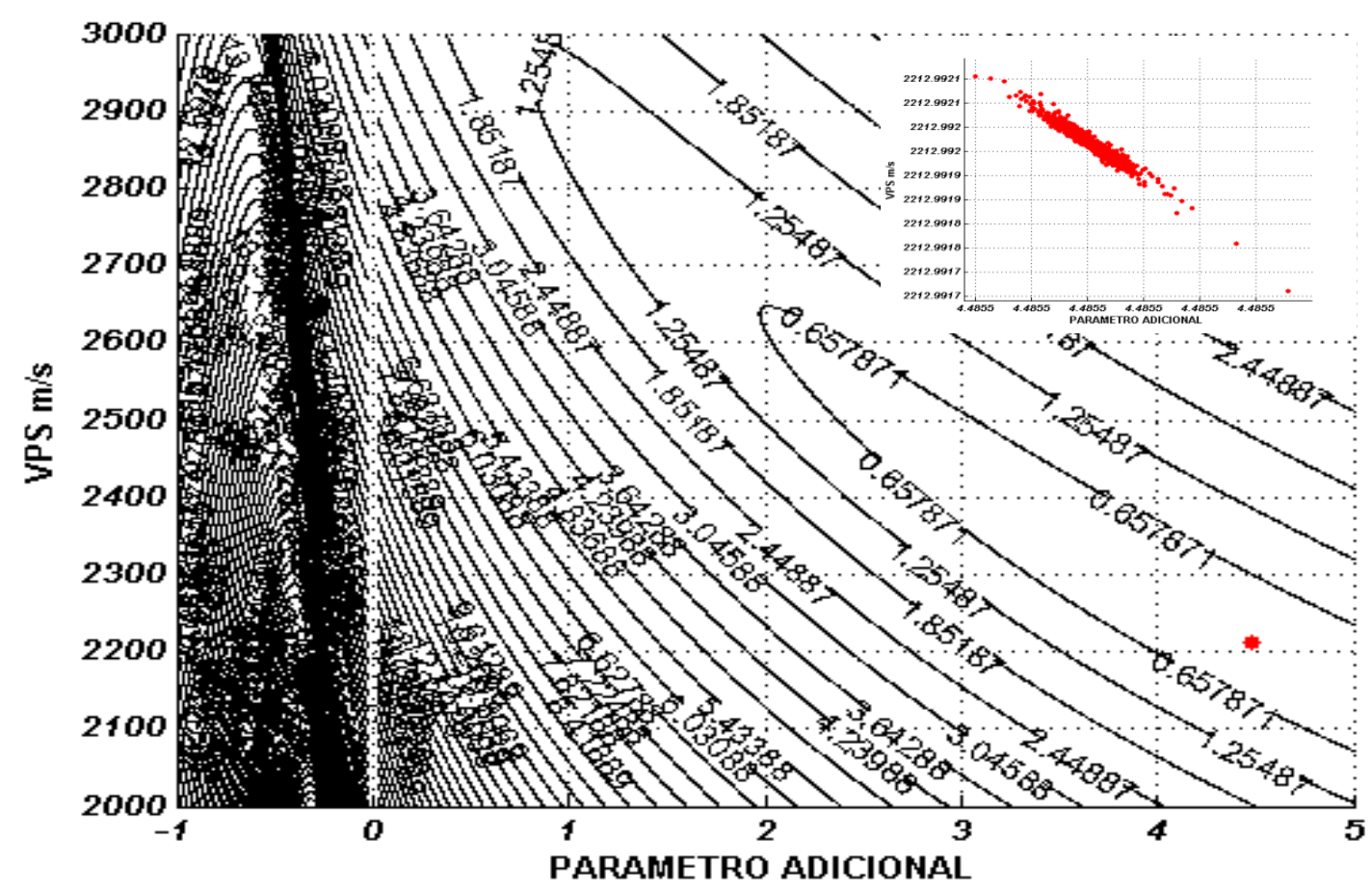

Figura 81: Mapas de dispersão sobrepostos ao mapa residual de função objetivo mostrando a complexidade da aproximação multiparamétrica de Malovichko (1978) para um evento de reflexão de onda PS do Modelo 5. As dispersões em vermelho representam a região de mínimo global da função. 


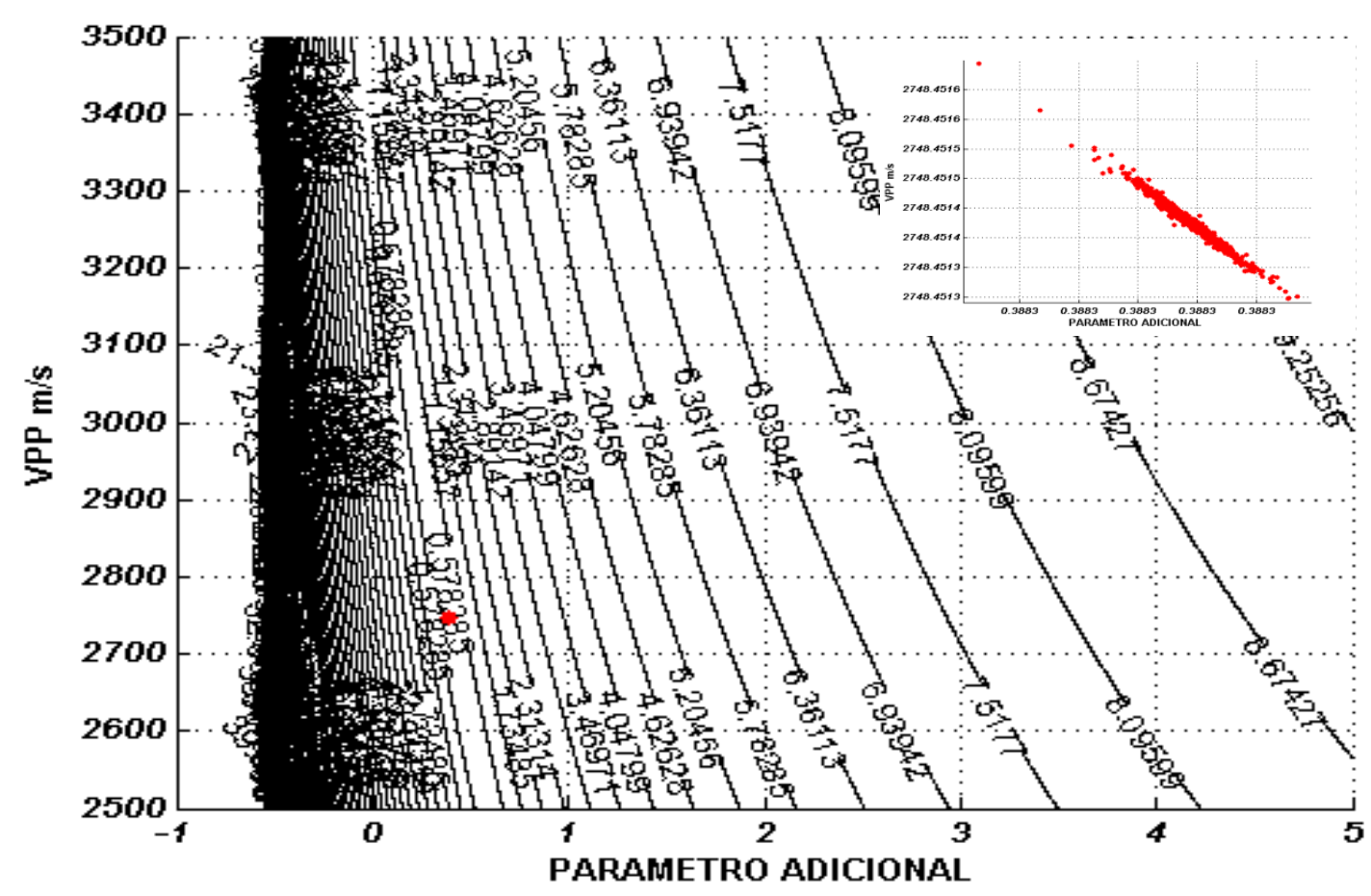

Figura 82: Mapas de dispersão sobrepostos ao mapa residual de função objetivo mostrando a complexidade da aproximação multiparamétrica de Alkhalifah e Tsvankin (1995) para um evento de reflexão de onda PP do Modelo 5. As dispersões em vermelho representam a região de mínimo global da função.

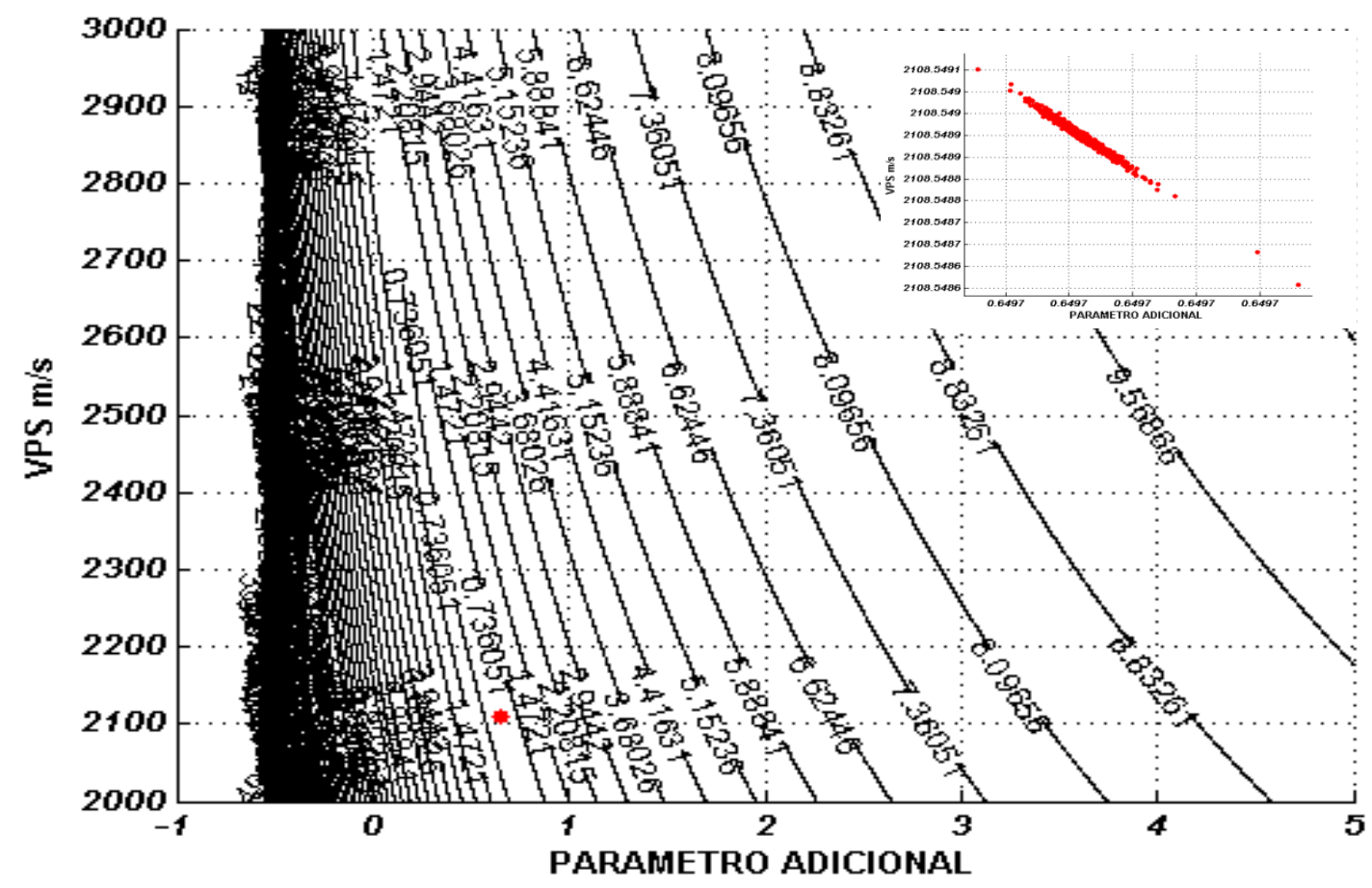

Figura 83: Mapas de dispersão sobrepostos ao mapa residual de função objetivo mostrando a complexidade da aproximação multiparamétrica de Alkhalifah e Tsvankin (1995) para um evento de reflexão de onda PS do Modelo 5. As dispersões em vermelho representam a região de mínimo global da função. 


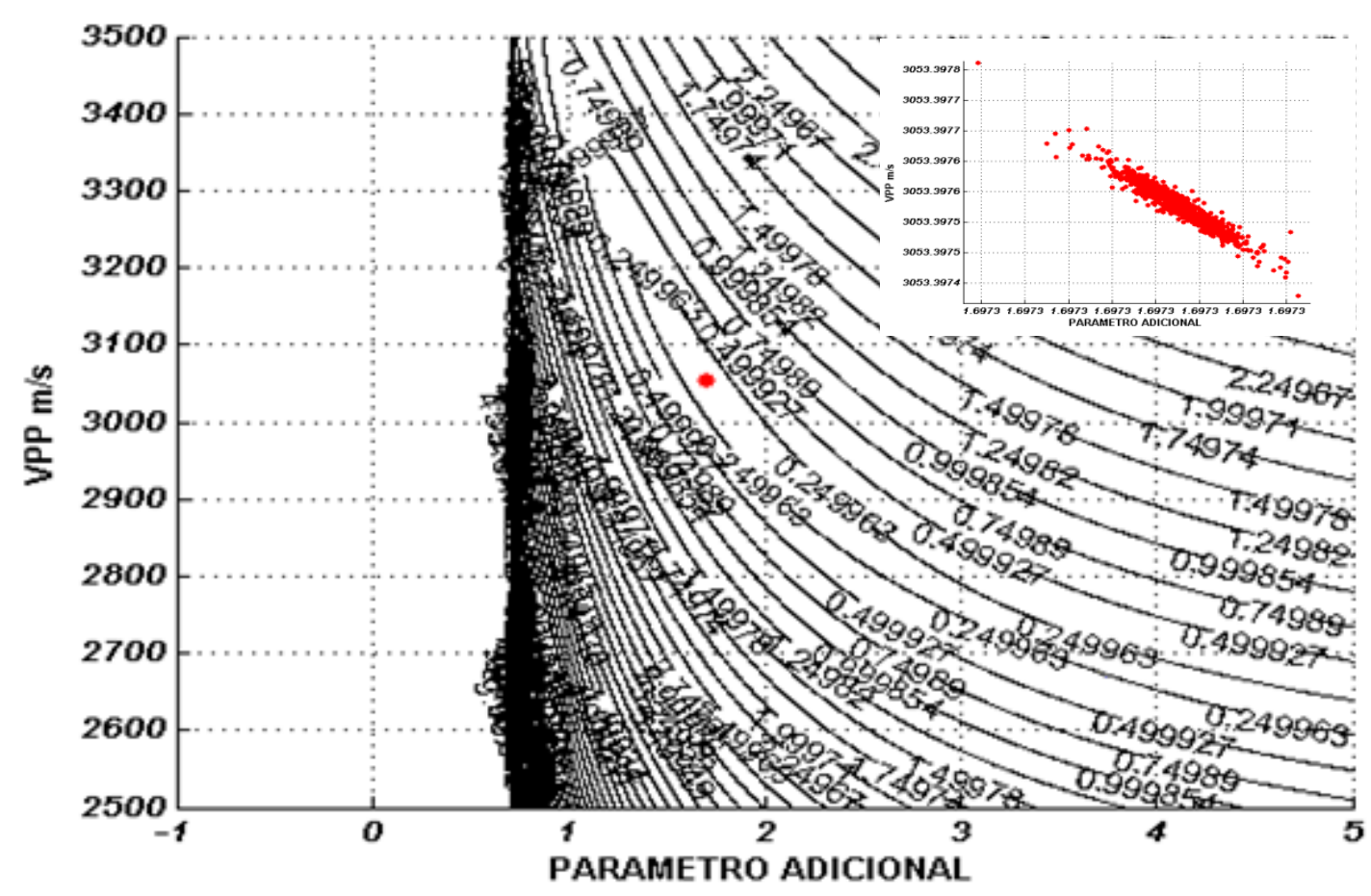

Figura 84: Mapas de dispersão sobrepostos ao mapa residual de função objetivo mostrando a complexidade da aproximação multiparamétrica de Ursin e Stovas (2006) para um evento de reflexão de onda PP do Modelo 5. As dispersões em vermelho representam a região de mínimo global da função.

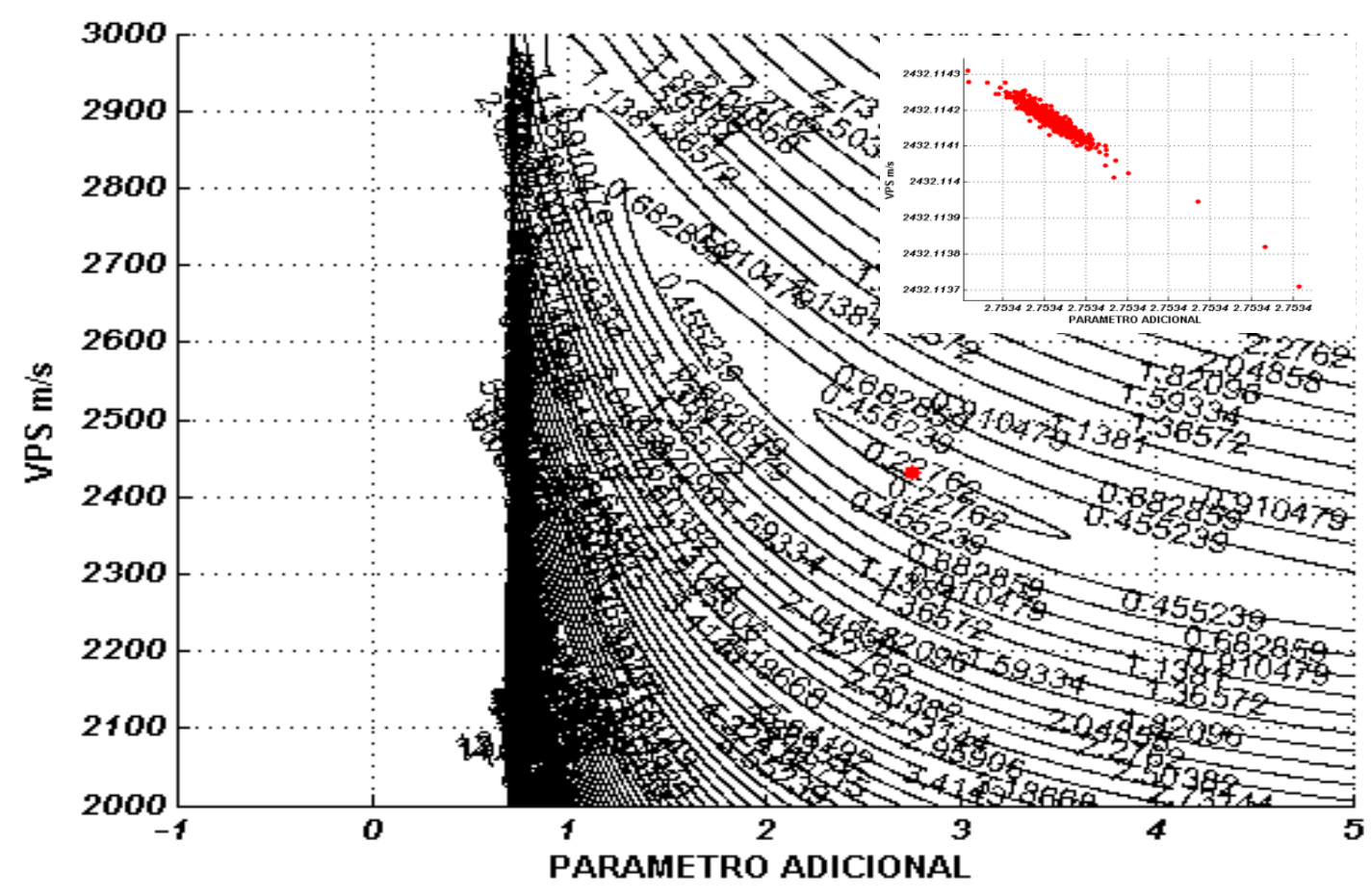

Figura 85: Mapas de dispersão sobrepostos ao mapa residual de função objetivo mostrando a complexidade da aproximação multiparamétrica de Ursin e Stovas (2006) para um evento de reflexão de onda PS do Modelo 5. As dispersões em vermelho representam a região de mínimo global da função. 


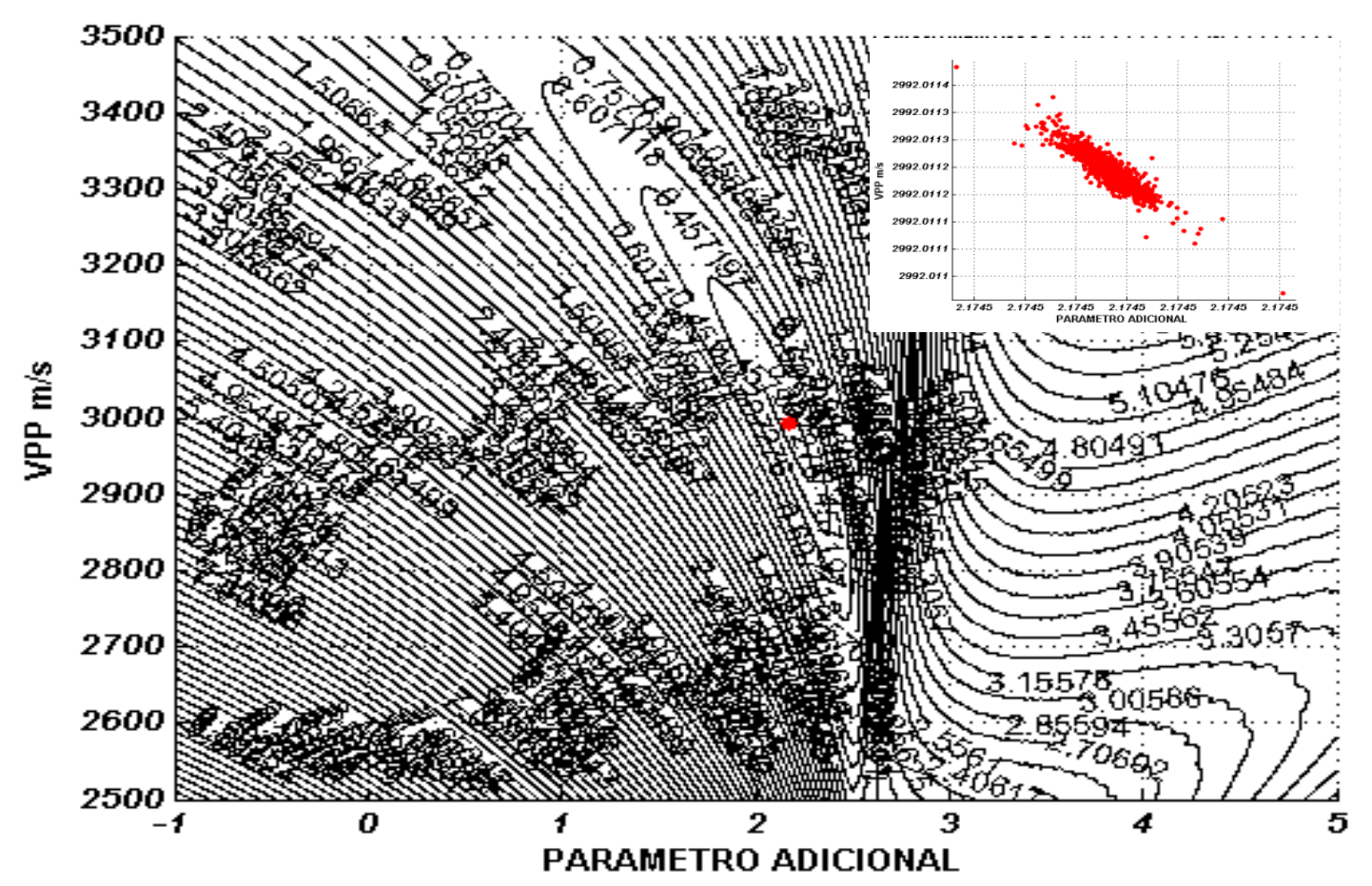

Figura 86: Mapas de dispersão sobrepostos ao mapa residual de função objetivo mostrando a complexidade da aproximação multiparamétrica de Blias (2009) para um evento de reflexão de onda PP do Modelo 5. As dispersões em vermelho representam a região de mínimo global da função.

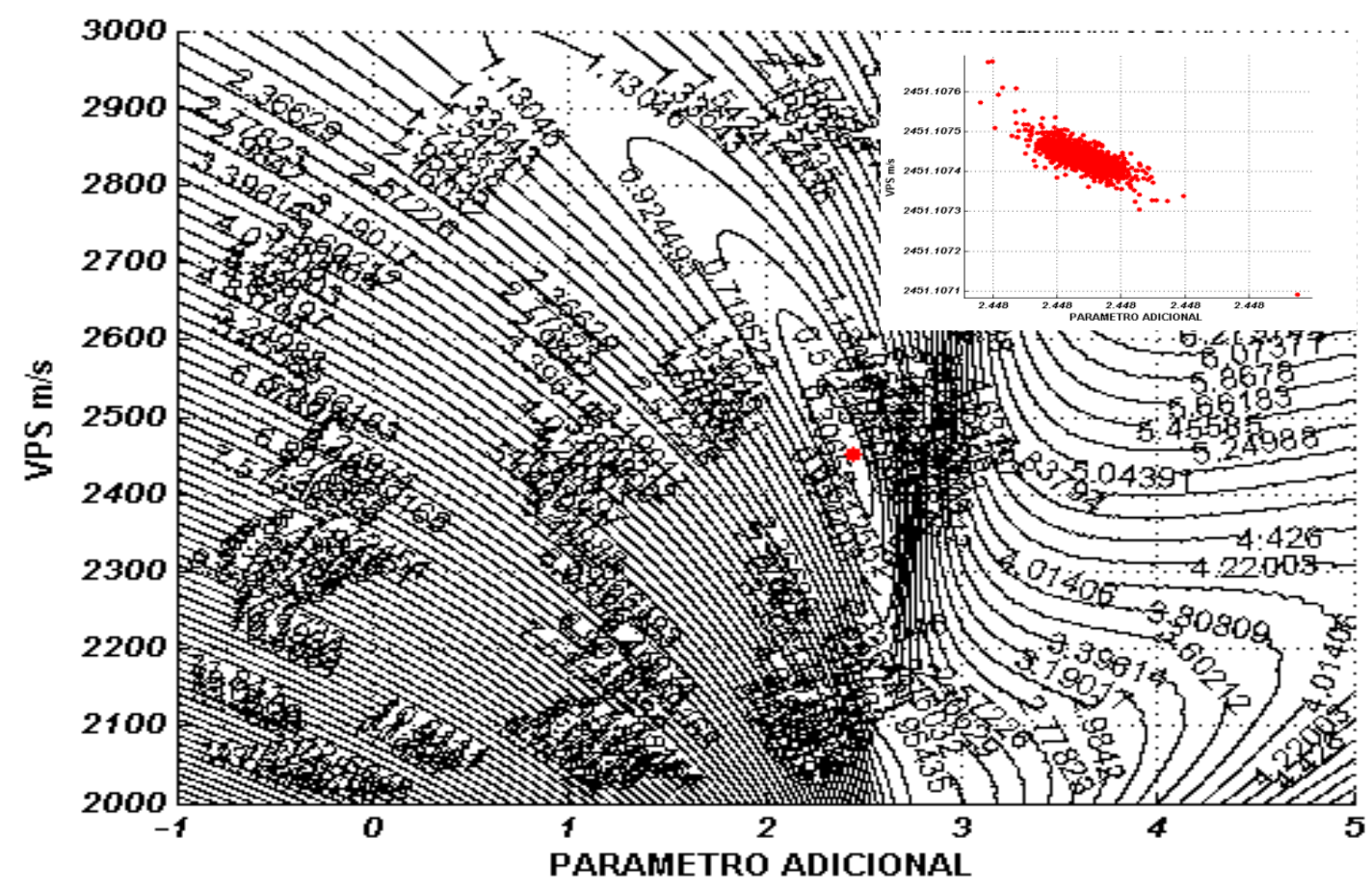

Figura 87: Mapas de dispersão sobrepostos ao mapa residual de função objetivo mostrando a complexidade da aproximação multiparamétrica de Blias (2009) para um evento de reflexão de onda PS do Modelo 5. As dispersões em vermelho representam a região de mínimo global da função. 


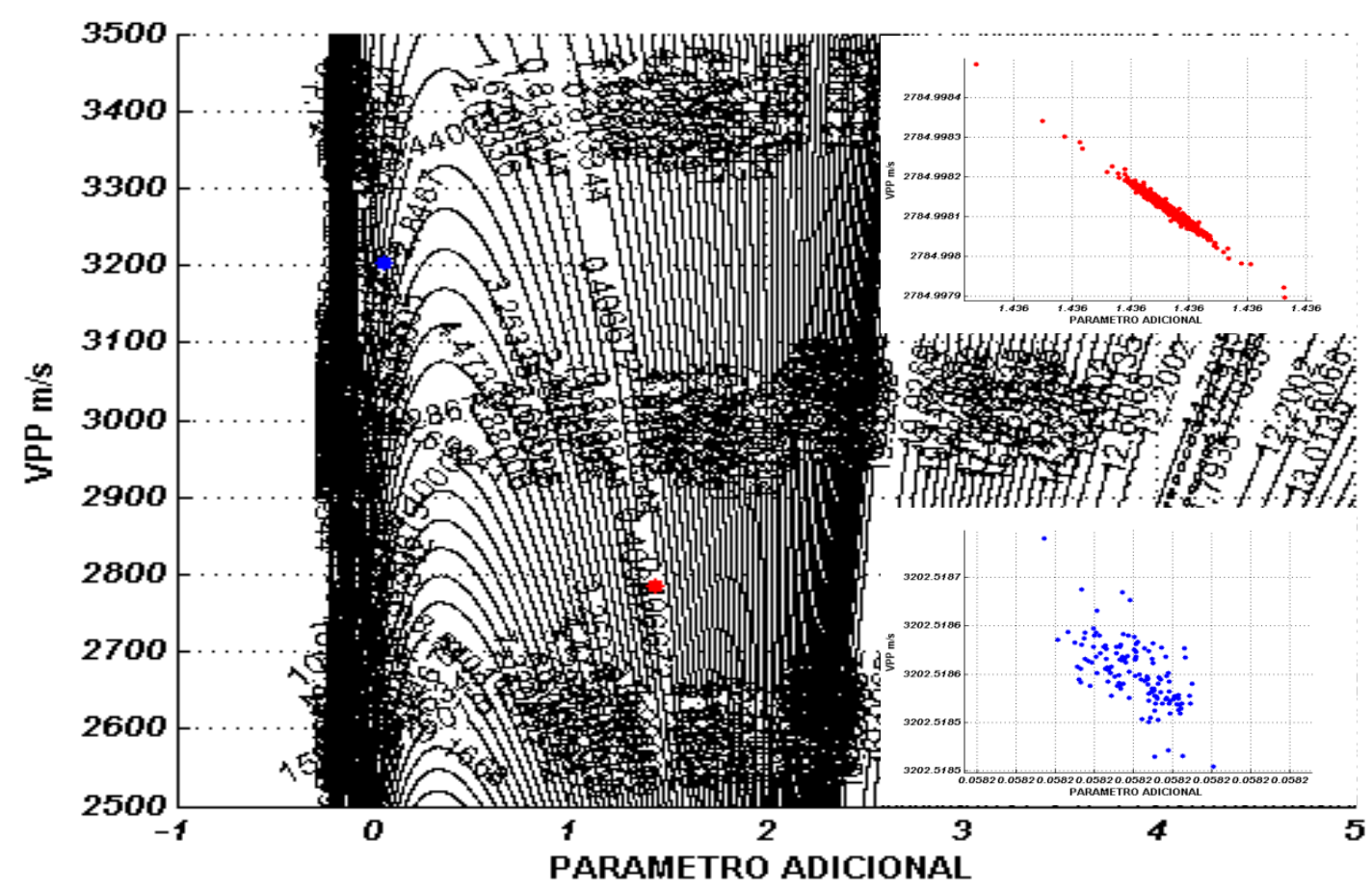

Figura 88: Mapas de dispersão sobrepostos ao mapa residual de função objetivo mostrando a complexidade da aproximação multiparamétrica de Muir e Dellinger (1985) para um evento de reflexão de onda PP do Modelo 5. As dispersões em vermelho representam a região de mínimo global da função e as dispersões em azul representam a região de mínimo local.

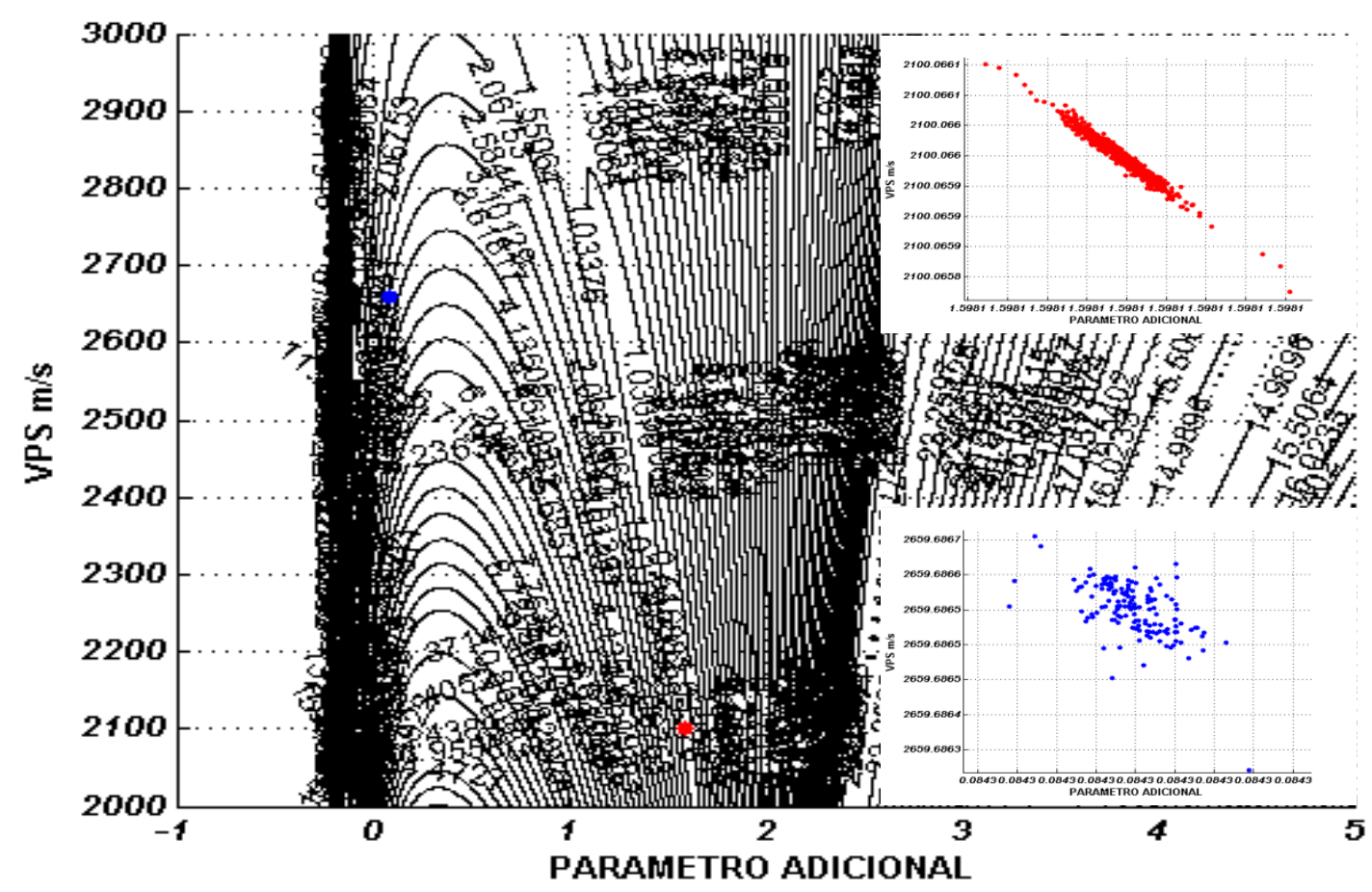

Figura 89: Mapas de dispersão sobrepostos ao mapa residual de função objetivo mostrando a complexidade da aproximação multiparamétrica de Muir e Dellinger (1985) para um evento de reflexão de onda PS do Modelo 5. As dispersões em vermelho representam a região de mínimo global da função e as dispersões em azul representam a região de mínimo local. 


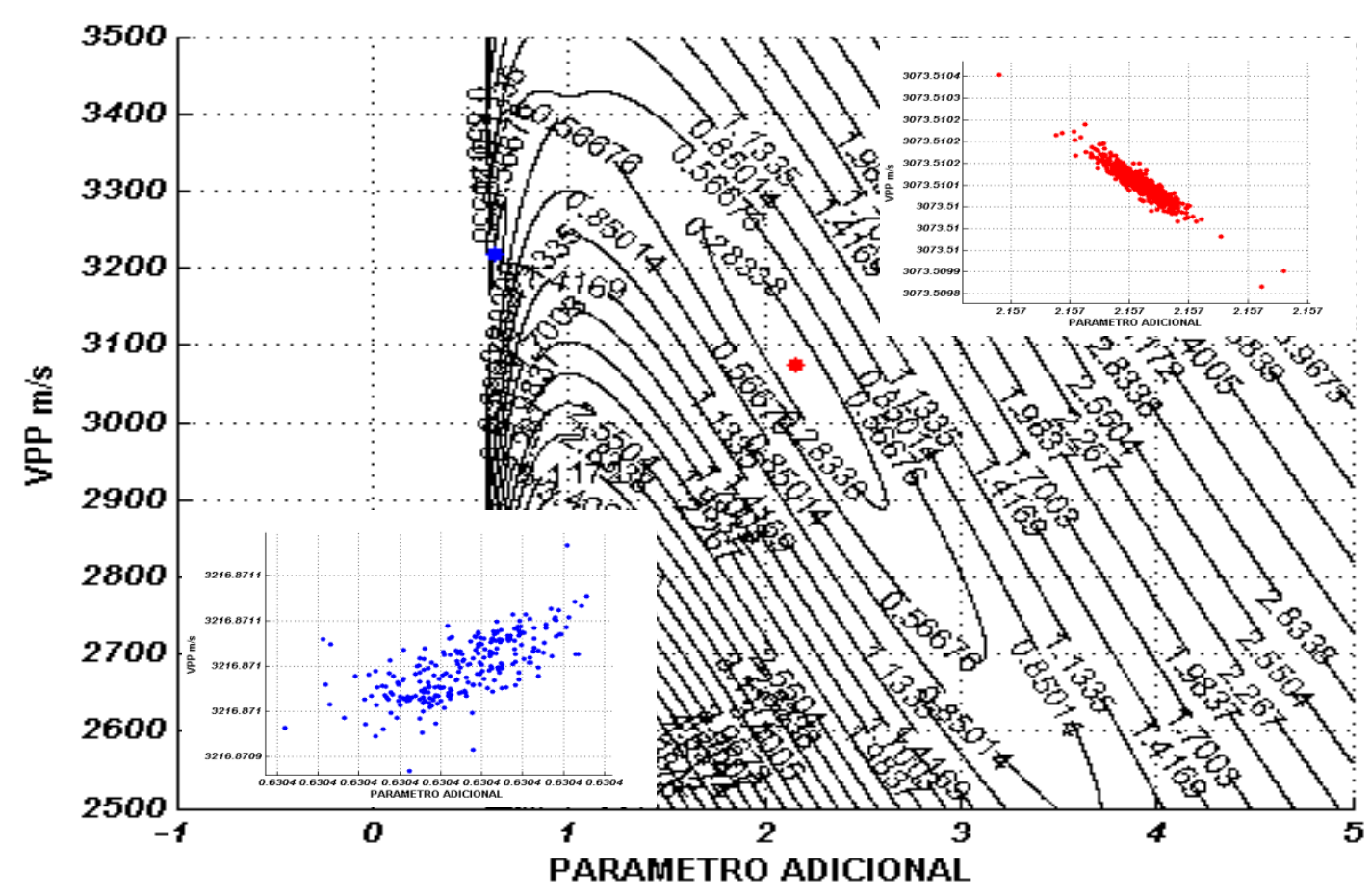

Figura 90: Mapas de dispersão sobrepostos ao mapa residual de função objetivo mostrando a complexidade da aproximação multiparamétrica de Li (2001) para um evento de reflexão de onda PP do Modelo 5. As dispersões em vermelho representam a região de mínimo global da função e as dispersões em azul representam a região de mínimo local.

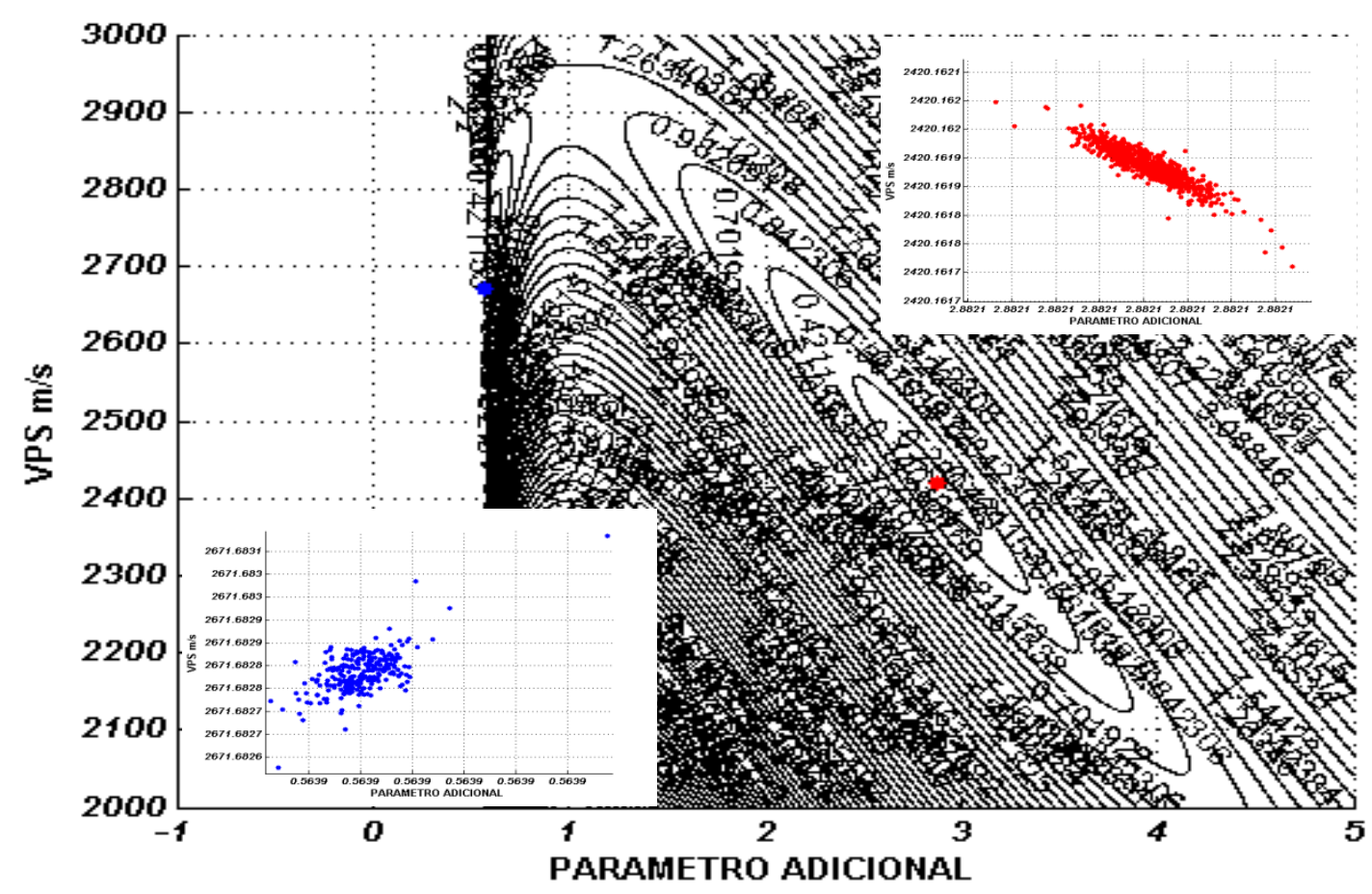

Figura 91: Mapas de dispersão sobrepostos ao mapa residual de função objetivo mostrando a complexidade da aproximação multiparamétrica de Li (2001) para um evento de reflexão de onda PS do Modelo 5. As dispersões em vermelho representam a região de mínimo global da função e as dispersões em azul representam a região de mínimo local. 
Os parâmetros associados ao valor de mínimo global obtidos foram substituídos em suas respectivas equações para comparar a qualidade do ajuste para cada evento de reflexão de cada modelo.

Analisando de uma forma geral o comportamento das equações testadas, a equação de Dix (1955) apresentou o pior ajuste em todos os eventos de reflexão no presente trabalho, o que de certa forma já era esperado devido à sua simplicidade. Algo semelhante era esperado, e também foi observado com relação à equação de Slotboom et al. (1990), que apresentou o segundo pior ajuste em todos os eventos de reflexão estudados.

Analisando as equações compostas por três parâmetros, foi possível observar que a equação de Alkhalifah e Tsvankin (1995), que é muito popular na indústria de exploração de petróleo e gás, apresentou o pior resultado em todos os eventos se comparada com as demais equações multiparamétricas, dessa maneira, ficando com resultados melhores do que as equações de dois parâmetros apenas. Algo muito similar foi constatado com relação à equação de Muir e Dellinger (1985) que, dentre as equações de três parâmetros, apresentou o segundo pior ajuste nos eventos de reflexão em quase todos os modelos. A exceção fica para o evento de reflexão PS do Modelo 2, em que a equação de Muir e Dellinger (1985) apresentou resultados compatíveis com o terceiro melhor ajuste.

Tendo essas informações iniciais, é importante focar o estudo nas quatro equações que apresentaram os melhores resultados: Malovichko (1978), Ursin e Stovas (2006), Blias (2009) e $\operatorname{Li}(2001)$.

Sendo assim, o evento de reflexão PP do Modelo 1 teve como equação que melhor se ajustou a de Li (2001), seguida pela equação de Ursin e Stovas (2006), Blias (2009) e Malovichko (1978) respectivamente (Figura 92). Para o mesmo modelo, no evento de reflexão PS, a equação de Li (2001) também apresenta o melhor resultado, porém dessa vez é seguida pela equação proposta por Blias (2009), deixando respectivamente Malovichko (1978) e Ursin e Stovas (2006) como terceiro e quarto melhores ajustes (Figura 93).

No Modelo 2, a equação de Li (2001) apresenta o melhor resultado para ambos os eventos de reflexão (Figura 94). O segundo melhor ajuste no evento PP fica por conta da equação de Blias (2009), enquanto Malovichko (1978) apresenta o segundo melhor resultado para o evento PS. Como terceiro e quarto melhores ajustes do evento PP, temos respectivamente Malovichko (1978) e Ursin e Stovas (2006). O resultado diferenciado reside no evento de reflexão PS deste segundo modelo, no qual a equação de Muir e Dellinger 
(1985), que apresentou alguns dos piores resultados de forma geral, apresentou o terceiro melhor ajuste para este caso, deixando a equação de Blias (2009), que proporcionou alguns dos melhores ajustes, como quarto melhor resultado (Figura 95).

No evento de reflexão PP do terceiro modelo (Figura 96), vemos novamente a equação de Li (2001) apresentando o melhor ajuste, seguida respectivamente pelas equações de Ursin e Stovas (2006), Malovichko (1978) e Blias (2009). No evento de reflexão PS, vemos curiosamente um resultado semelhante com o evento de reflexão PP do Modelo 2 (Figura 97), no qual os melhores resultados são dados respectivamente pelas equações de Li (2001), Blias (2009), Malovichko (1978) e Ursin e Stovas (2006).

Para o evento PP do Modelo 4, vemos um fenômeno no qual a equação de Li (2001) apresenta certas dificuldades para ajustar-se a um evento proveniente de um modelo em que há inversão de velocidades. Dessa maneira, esta equação apresenta, neste caso o segundo melhor ajuste, deixando a equação de Ursin e Stovas (2006) com o melhor resultado (Figura 98). Complementarmente observa-se a equação de Blias (2009) como terceiro e a de Malovichko (1978) como quarto melhor ajuste. Com relação ao evento de reflexão PS, também temos uma inversão de velocidades, por se tratar do mesmo modelo (Modelo 4). Entretanto neste caso, tem-se a equação de Li (2001) como melhor resultado devido ao fato das outras equações apresentarem mais dificuldades para lidar com a conversão de onda do que a equação de Li (2001) para lidar com uma inversão de velocidades do modelo. A equação de Malovichko (1978) apresentou o segundo melhor resultado, pouco à frente de Blias (2009), deixando assim Ursin e Stovas (2006) com o quarto melhor ajuste para este evento (Figura 99).

Similarmente ao quarto modelo, o Modelo 5 apresenta inversão de velocidades, porém de uma maneira mais complexa, com uma intercalação abrupta de diferenças de velocidades. Em consequência disso já era esperado que para o evento PP (Figura 100), a equação de Li (2001) apresentasse algumas dificuldades para efetuar o ajuste, ficando então com o segundo melhor resultado, apenas atrás da equação de Ursin e Stovas (2006). Com isso, Blias (2006) e Malovichko (1978) apresentam o terceiro e quarto melhores ajustes respectivamente. Para o evento PS deste mesmo modelo (Figura 101), novamente as dificuldades apresentadas por um evento convertido interferem de maneira significativa para as demais equações que não a de Li (2001) que apresentou o melhor resultado neste evento PS. As equações de Blias (2009) e 
Malovichko (1978) apresentaram resultados muito semelhantes, caracterizando o segundo melhor ajuste, superando a equação de Ursin e Stovas (2006).

Analisando por um panorama mais amplo, a equação de Li (2001) apresentou os melhores resultados para o Modelo 1 como um todo (considerando ambos os eventos de reflexão), e o mesmo pode se dizer para os demais modelos, mesmo onde há inversão de velocidades, pois decaimento da qualidade do ajuste desta equação é muito inferior ao das outras equações testadas. De forma similar, esta equação apresentou o melhor conjunto de ajustes para os eventos de onda PP como um todo, resultados semelhantes aos obtidos para ondas convertidas se comparados com esta mesma análise.

De uma forma geral pôde ser observado que a equação de Li (2001) lida melhor com diversas variações dos modelos, podendo ser aplicada para diversos casos diferentes, mesmo havendo equações como a de Blias (2009) (segunda mais genérica), e de Ursin e Stovas (2006) e Malovichko (1978) (terceiras mais genéricas), que apresentam excelentes resultados.

Devido à alta capacidade da equação proposta por Li (2001) conseguir controlar diferentes características que geram não-hiperbolicidade, ela demonstra ser claramente versátil e consideravelmente estável. 


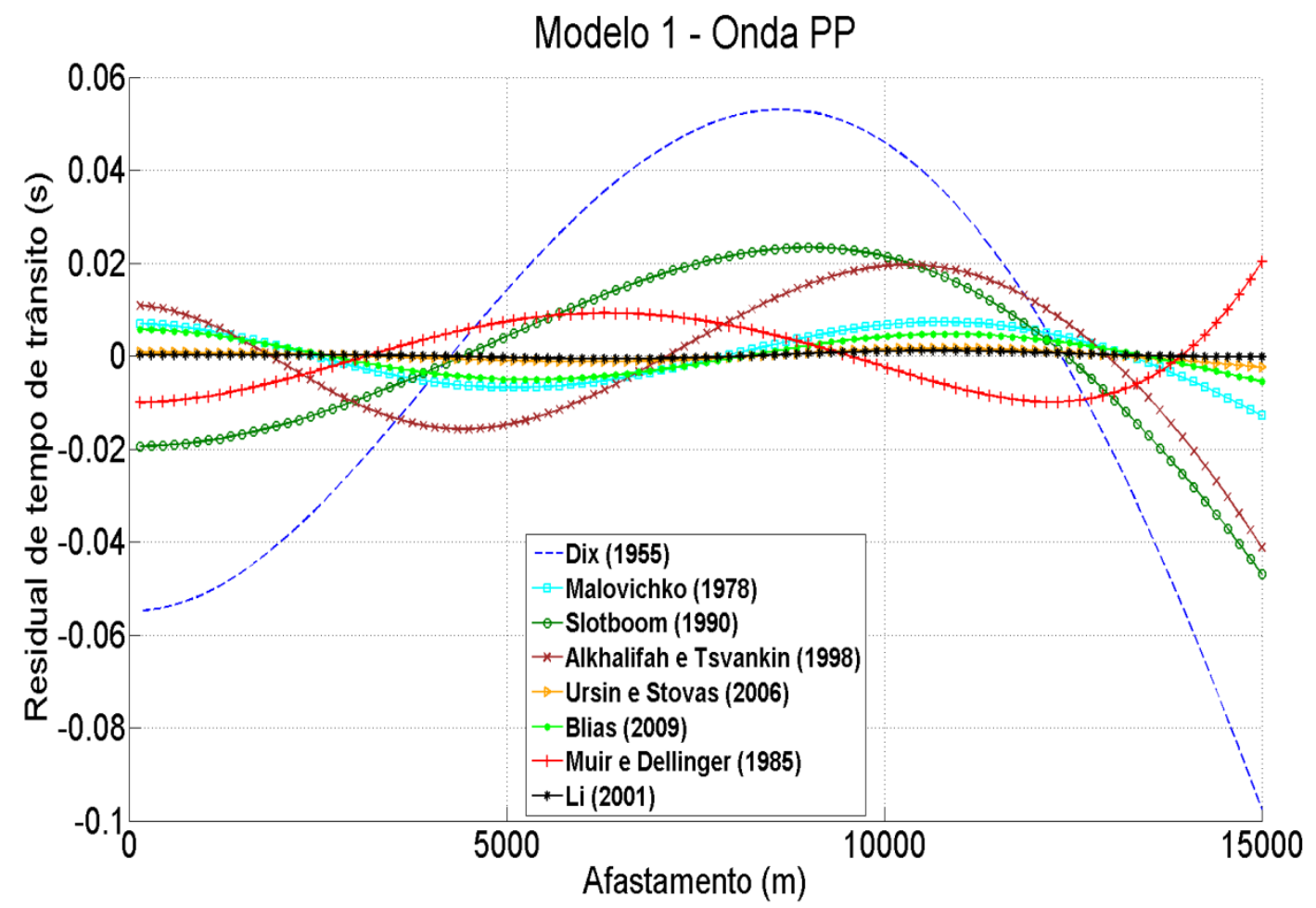

Figura 92: Diferença dos tempos de trânsito exatos e calculados pelas expressões utilizando os parâmetros que resultam da inversão dos tempos de trânsito de onda PP para o Modelo 1.

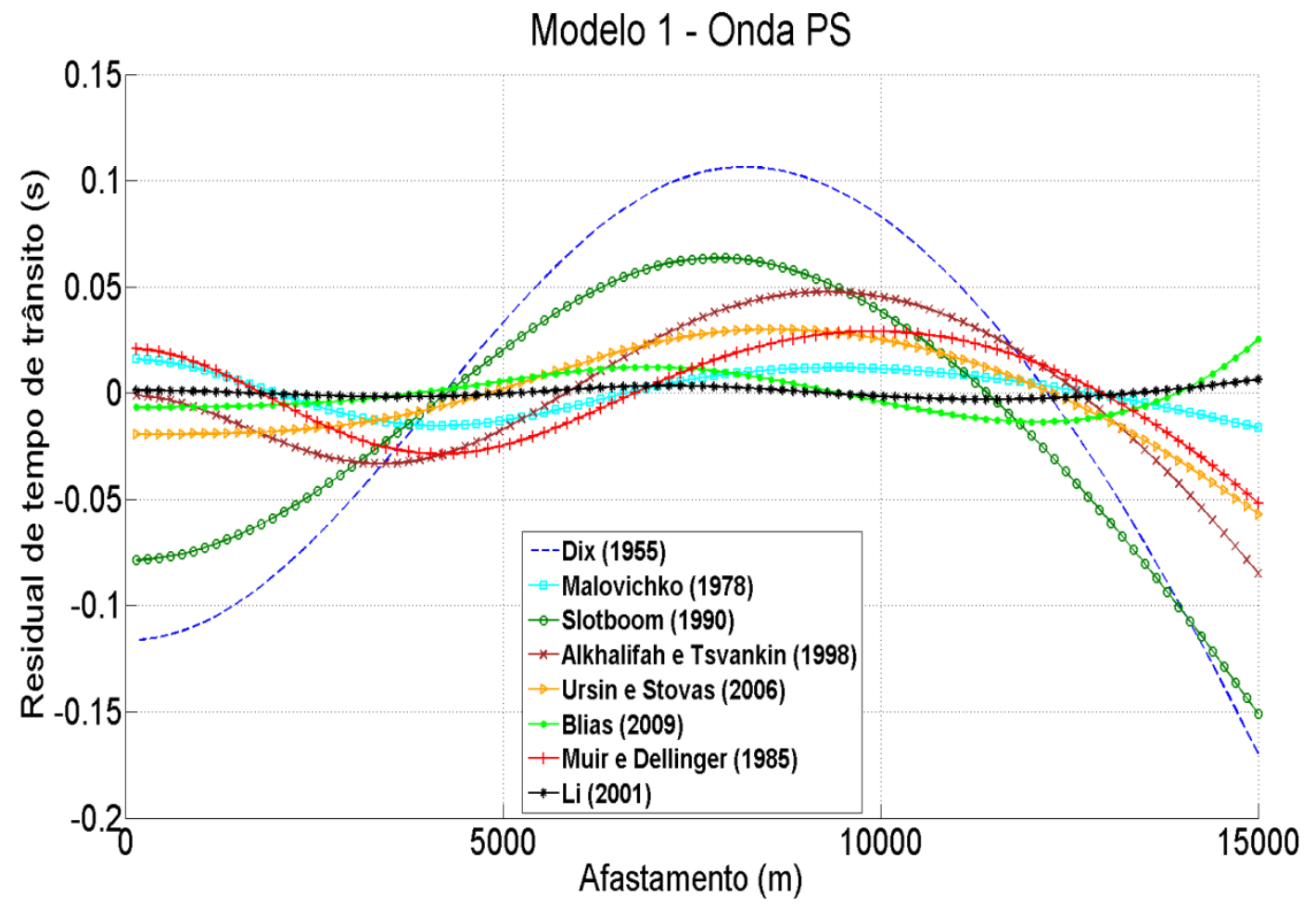

Figura 93: Diferença dos tempos de trânsito exatos e calculados pelas expressões utilizando os parâmetros que resultam da inversão dos tempos de trânsito de onda PS para o Modelo 1. 


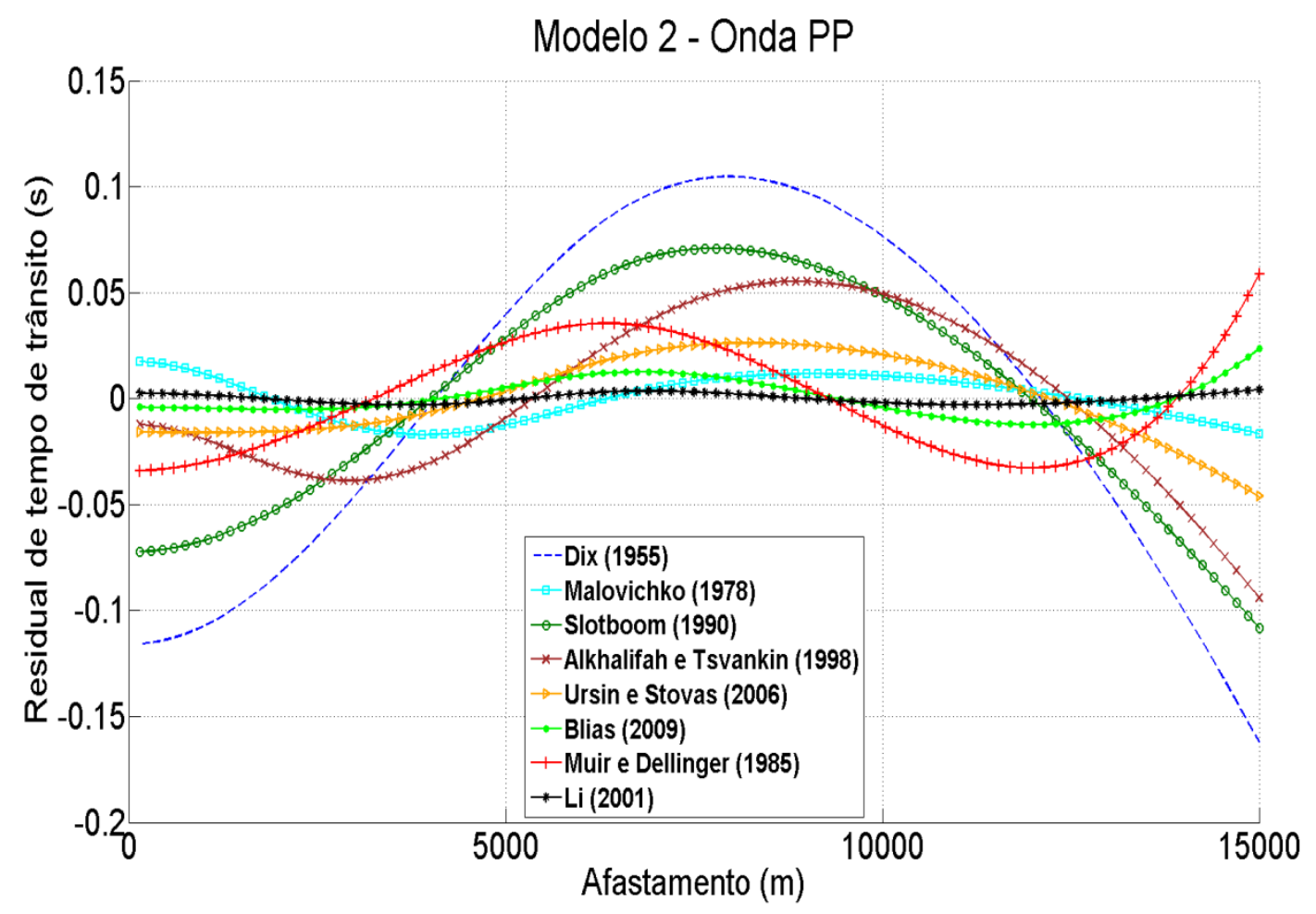

Figura 94: Diferença dos tempos de trânsito exatos e calculados pelas expressões utilizando os parâmetros que resultam da inversão dos tempos de trânsito de onda PP para o Modelo 2.

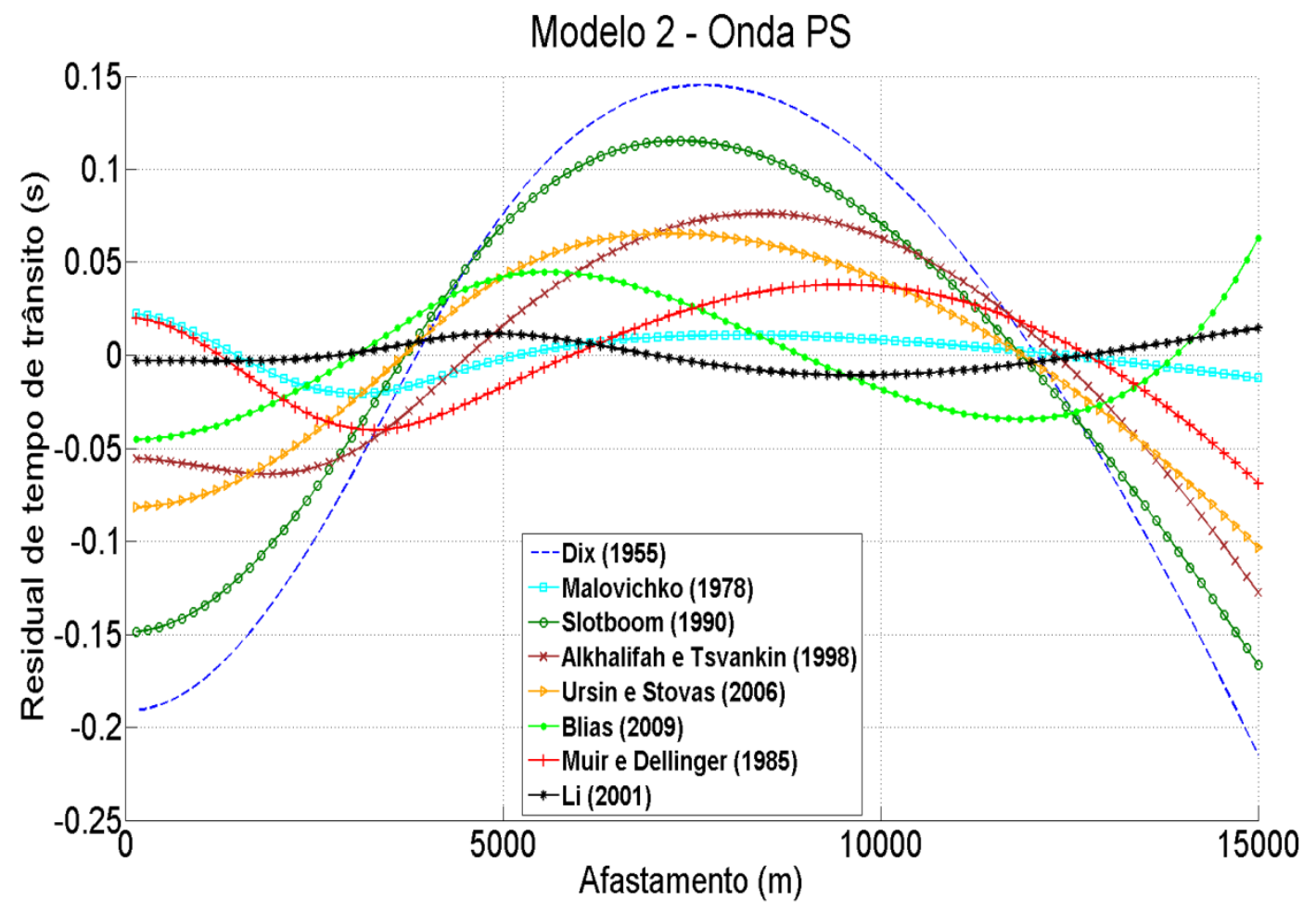

Figura 95: Diferença dos tempos de trânsito exatos e calculados pelas expressões utilizando os parâmetros que resultam da inversão dos tempos de trânsito de onda PS para o Modelo 2. 


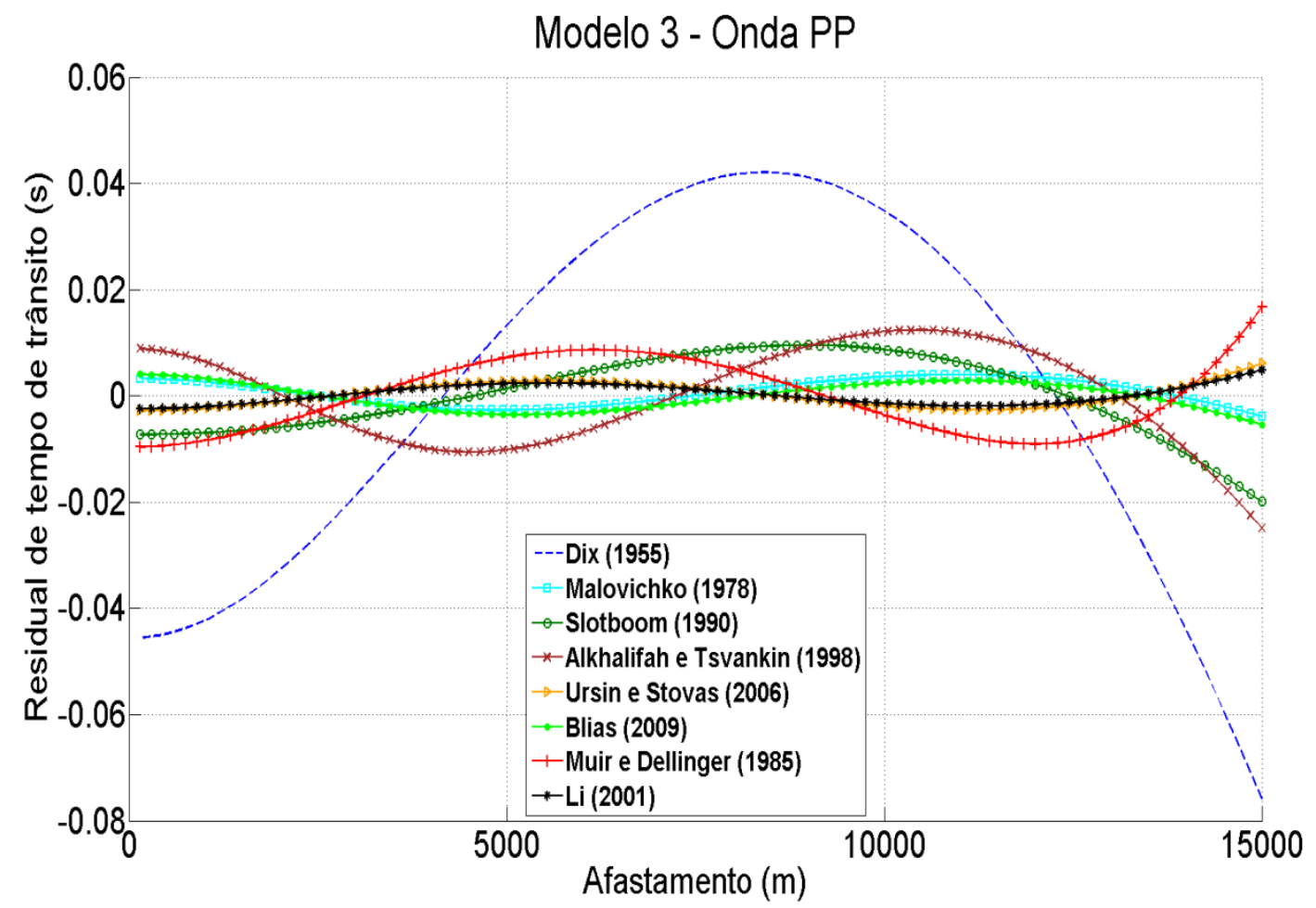

Figura 96: Diferença dos tempos de trânsito exatos e calculados pelas expressões utilizando os parâmetros que resultam da inversão dos tempos de trânsito de onda PP para o Modelo 3.

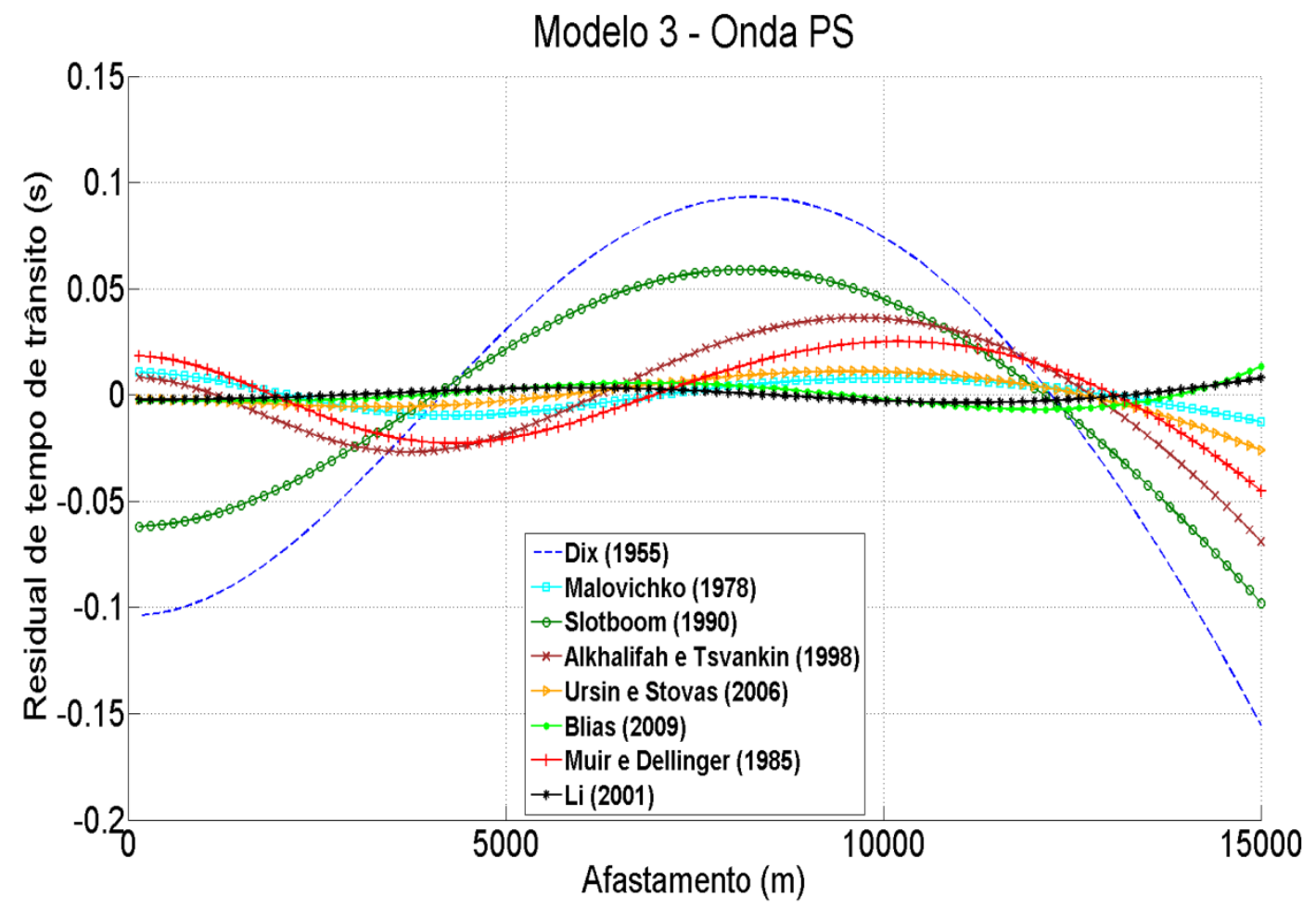

Figura 97: Diferença dos tempos de trânsito exatos e calculados pelas expressões utilizando os parâmetros que resultam da inversão dos tempos de trânsito de onda PS para o Modelo 3. 


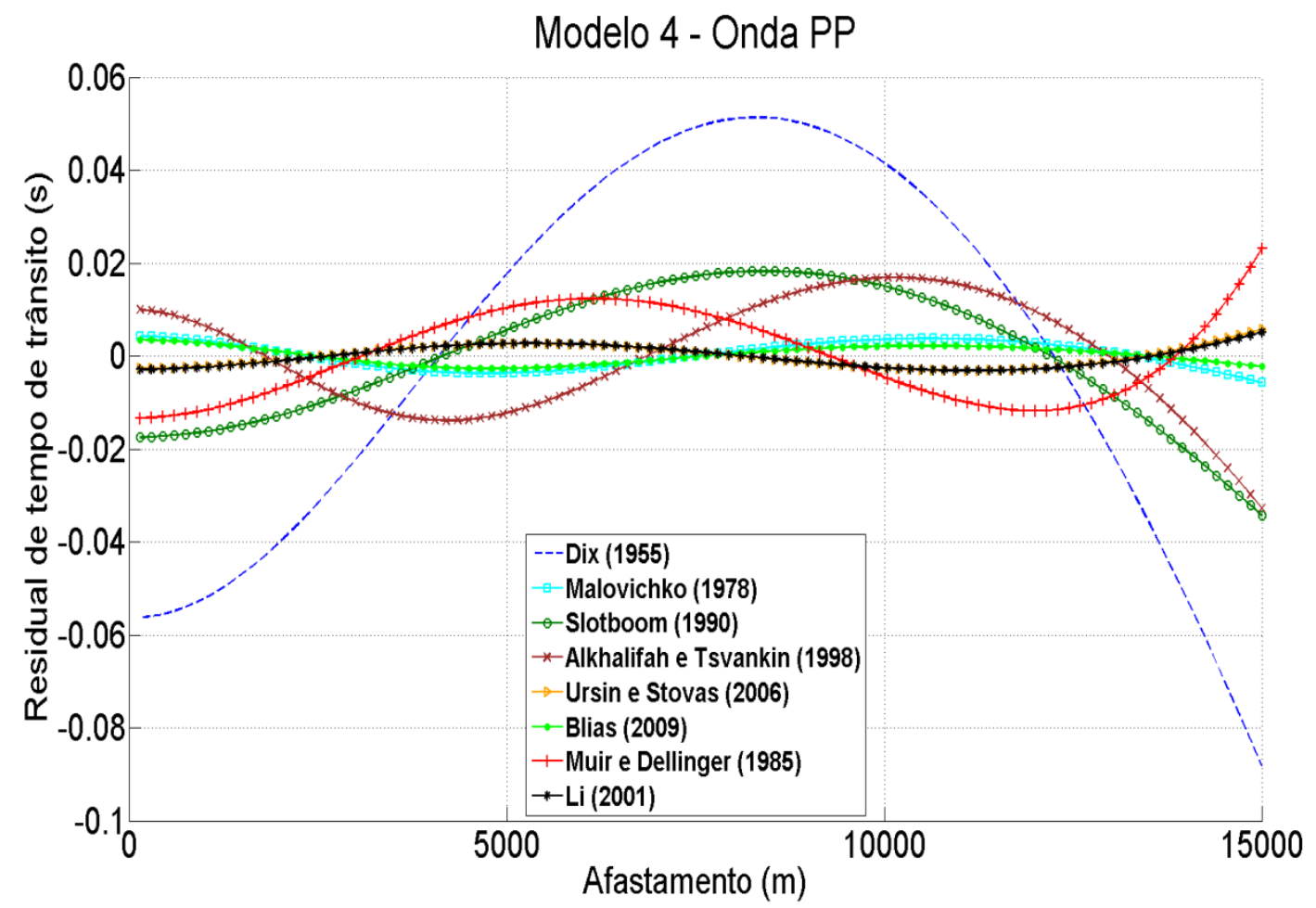

Figura 98: Diferença dos tempos de trânsito exatos e calculados pelas expressões utilizando os parâmetros que resultam da inversão dos tempos de trânsito de onda PP para o Modelo 4.

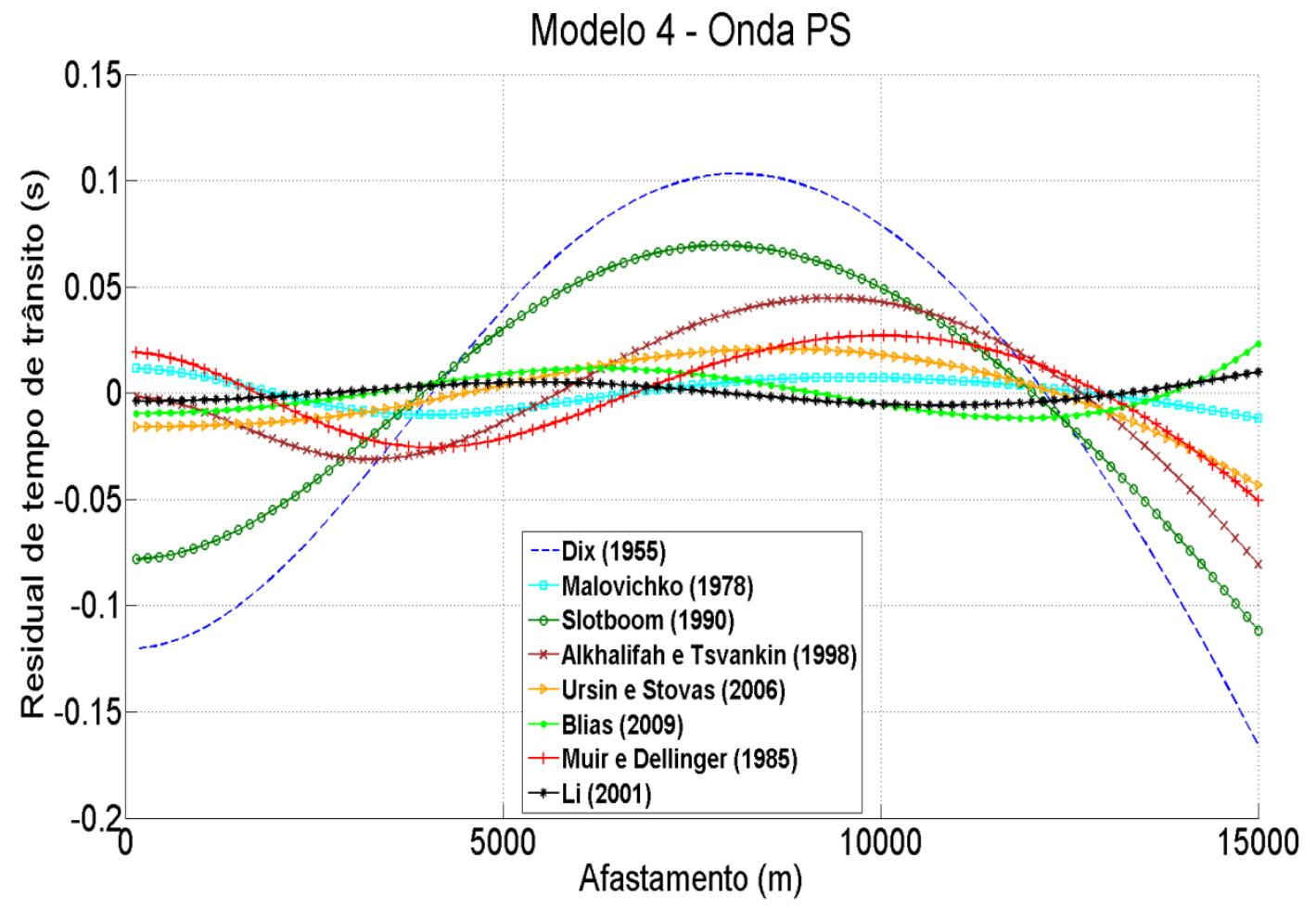

Figura 99: Diferença dos tempos de trânsito exatos e calculados pelas expressões utilizando os parâmetros que resultam da inversão dos tempos de trânsito de onda PS para o Modelo 4. 


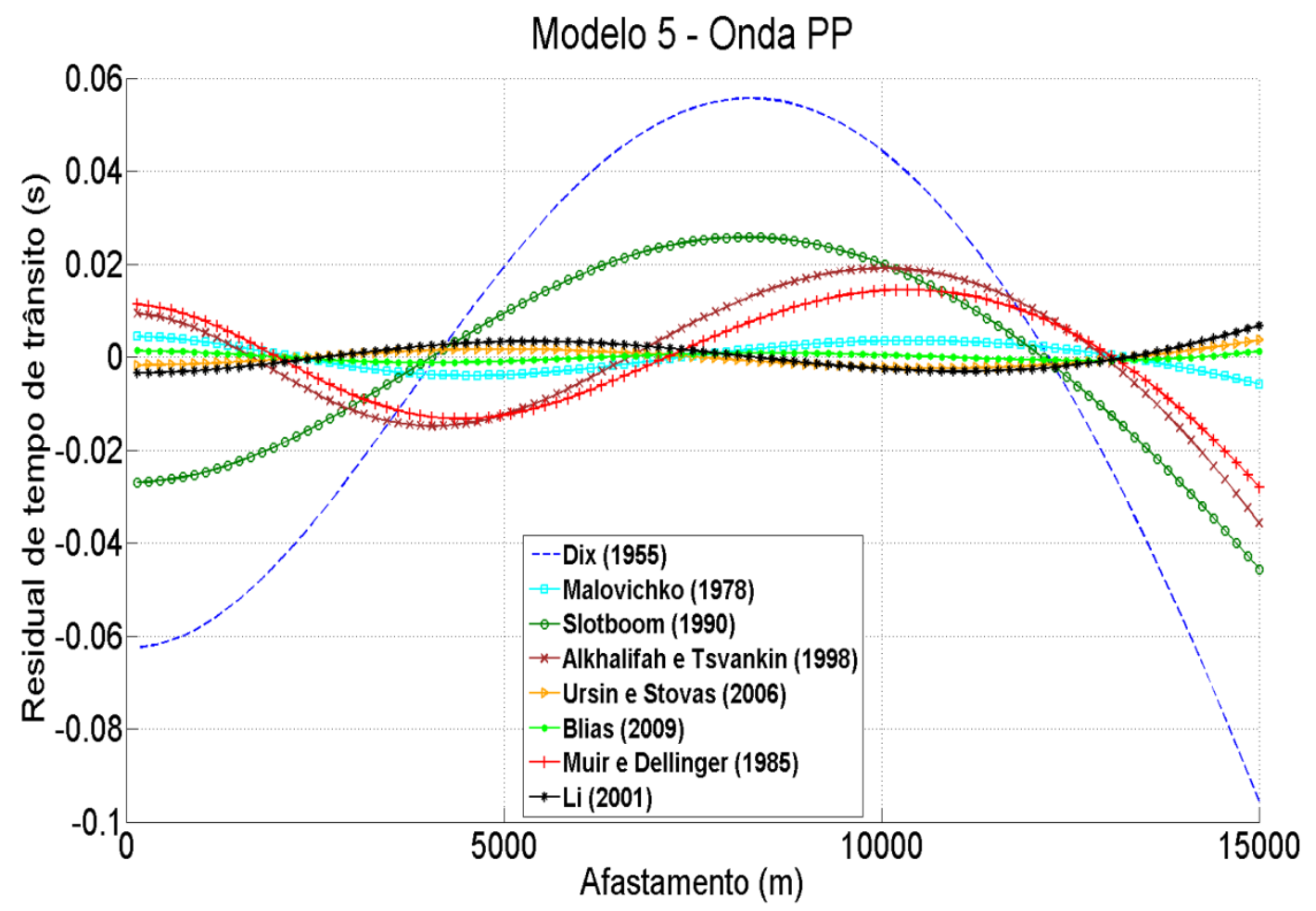

Figura 100: Diferença dos tempos de trânsito exatos e calculados pelas expressões utilizando os parâmetros que resultam da inversão dos tempos de trânsito de onda PP para o Modelo 5.

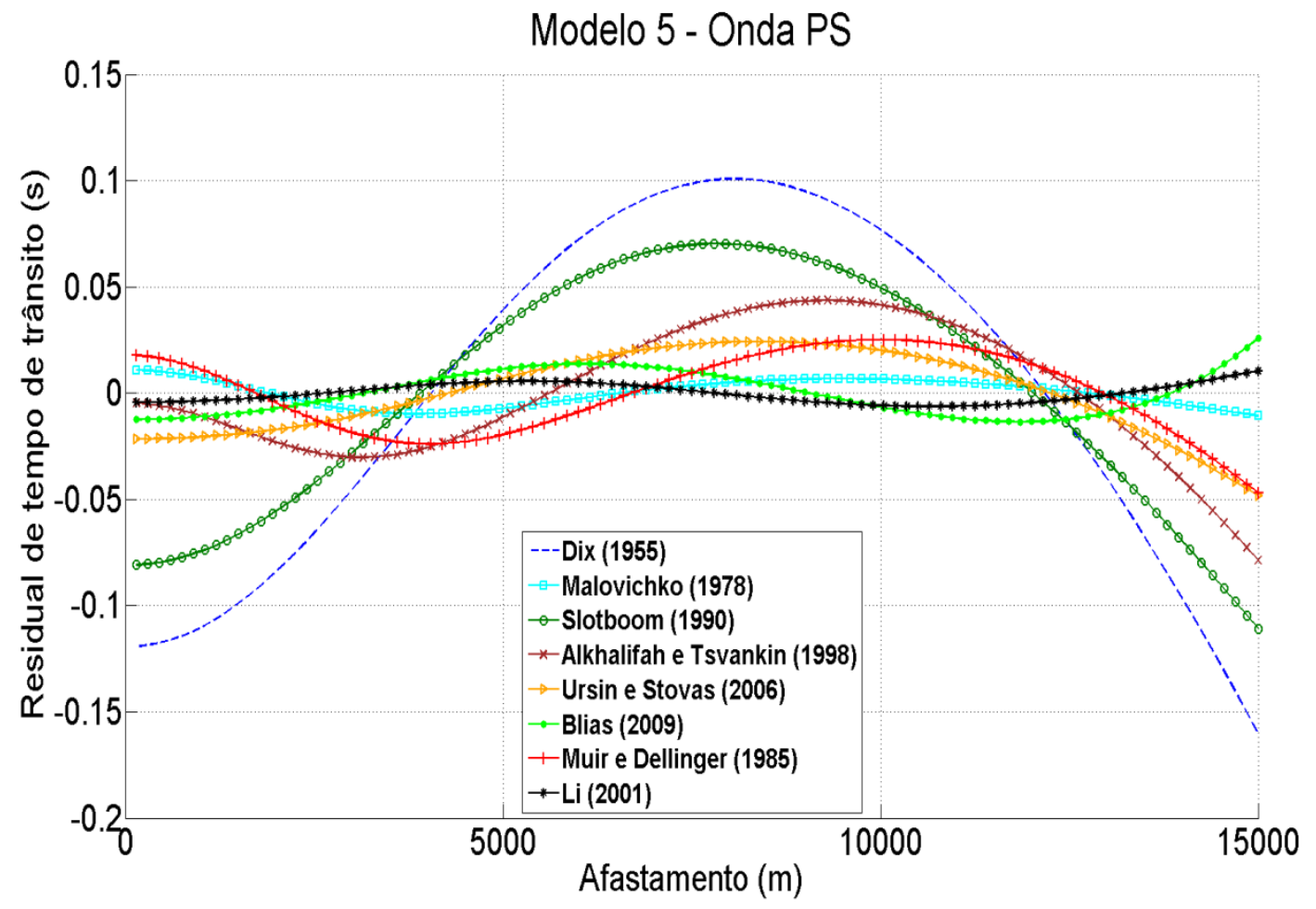

Figura 101: Diferença dos tempos de trânsito exatos e calculados pelas expressões utilizando os parâmetros que resultam da inversão dos tempos de trânsito de onda PS para o Modelo 5. 
Analisando o tempo de processamento, é notório que as equações que apresentam apenas dois parâmetros (Dix, 1955; Slotboom et al., 1990) tomam um tempo menor para executar a rotina de inversão (Tabela 1), entretanto apresentam muito menos qualidade em seus resultados (Tabelas 2 e 3), como já era previsto.

No caso das equações com três parâmetros apresentam tempos de processamento maiores e naturalmente maior qualidade no ajuste.

As equações de Malovichko (1978) e Alkhalifah e Tsvankin (1995) são de fato unimodais, e por isso não há a necessidade de executar uma rotina de inversão, e sim apenas uma inversão. Assim, mesmo estas equações apresentando tempos de processamento comparativamente não muito bons (Tabela 1), ainda sim são capazes de fornecer os resultados rapidamente quando executada apenas uma inversão. No caso da equação de Alkhalifah e Tsvankin (1995), há uma baixa qualidade nos ajustes (Tabelas 2 e 3); dessa maneira, mesmo sendo rápida para fornecer resultados, é pouco confiável. Com relação à equação de Malovichko (1978), os resultados apresentam-se mais confiáveis (Tabelas 2 e 3), o que permite concluir que essa equação é muito eficiente.

Com relação às equações de Ursin e Stovas (2006) e Blias (2009), já foi comentado que há um risco considerável em utilizá-las considerando-as unimodais, e por medidas de segurança elas devem ser consideradas equações multimodais, a não ser que se conheça suficientemente o modelo estudado. Sendo assim a equação de Ursin e Stovas (2006) apresentou altos tempos de processamento, diferentemente da equação de Blias (2009) que apresentou baixos tempos para a execução da rotina de inversão (Tabela 1). Apesar disso é possível observar nas tabelas 2 e 3 que ambas apresentaram bons resultados com relação à qualidade do ajuste.

A equação de Muir e Dellinger (1985) apresentou bons resultados em alguns dos casos (Tabelas 2 e 3), entretanto também apresentou tempos relativamente altos para executar a rotina de inversão (Tabela 1). Diferentemente, a equação de Li (2001) teve um desempenho consideravelmente superior às demais com relação ao tempo de execução da rotina de inversão (Tabela 1). Além disso, esta equação apresentou os melhores resultados trazendo os melhores ajustes em quase todos os eventos de reflexão dos modelos estudados no presente trabalho, e mesmo nos casos em que não foram a que melhor ajustou os dados, ainda sim apresentou resultados muito bons (Tabelas 2 e 3 ). 
De uma forma geral, a proposta de análise conjunta que conciliou do tempo necessário para executar a rotina de inversão e a qualidade do ajuste representada pelo mínimo global de cada uma das equações apresentou resultados mais específicos do que a análise qualitativa do residual das curvas de tempos de trânsito. Apesar disso, a aproximação proposta por Li (2001) apresentou resultados tão superiores aos das demais equações que essa análise se torna redundante. Dessa maneira foi possível observar que equações com desempenhos similares, que foram propostas para modelos mais simples, são claramente mais adequadas para este tipo de análise, pois estas apresentam tempos de processamento e qualidade do ajuste mais próximos entre si, o que gera a necessidade de uma análise quantitativa mais refinada para determinar a aproximação mais adequada para a execução da análise de velocidades. Com isso, é possível aplicar este tipo de análise tendo resultados mais proveitosos em modelos mais simples, nos quais não há a necessidade de usar equações tão complexas quanto às trabalhadas aqui.

\begin{tabular}{|c|c|c|c|c|c|c|c|c|c|c|}
\hline & \multicolumn{2}{|c|}{ Modelo 1} & \multicolumn{2}{|c|}{ Modelo 2} & \multicolumn{2}{|c|}{ Modelo 3} & \multicolumn{2}{|c|}{ Modelo 4} & \multicolumn{2}{|c|}{ Modelo 5} \\
\hline & PP & PS & PP & PS & PP & PS & PP & PS & PP & PS \\
\hline Eq. 1 & 313,5 & 338,5 & 319,8 & 344,8 & 322,9 & 341,6 & 316,6 & 357,3 & 321,3 & 357,3 \\
\hline Eq. 2 & 705,1 & 744,2 & 747,9 & 839,0 & 681,6 & 730,2 & 685,2 & 757,9 & 695,5 & 786,4 \\
\hline Eq. 3 & 329,2 & 326,1 & 344,8 & 341,6 & 340,1 & 324,5 & 346,4 & 332,3 & 344,8 & 340,1 \\
\hline Eq. 4 & 837,9 & 736,6 & 846,6 & 761,8 & 905,6 & 781,0 & 884,8 & 768,8 & 866,3 & 783,1 \\
\hline Eq. 5 & 778,9 & 878,6 & 771,0 & 866,7 & 796,6 & 932,1 & 800,9 & 926,6 & 816,0 & 942,2 \\
\hline Eq. 6 & 683,3 & 737,7 & 720,7 & 805,9 & 708,4 & 780,0 & 704,2 & 772,4 & 712,6 & 771,1 \\
\hline Eq. 7 & 786,4 & 819,9 & 833,7 & 877,0 & 811,4 & 845,7 & 818,9 & 861,1 & 813,4 & 854,7 \\
\hline Eq. 8 & 679,1 & 735,6 & 720,1 & 805,6 & 665,2 & 716,3 & 651,0 & 709,6 & 650,5 & 722,2 \\
\hline
\end{tabular}

Tabela 1: Tempos absolutos necessários (em segundos) para executar as rotinas de inversão considerando as diferentes aproximações, eventos e modelos. Equação 1 - Dix (1955), Equação 2 - Malovichko (1978), Equação 3 - Slotboom et al. (1990), Equação 4 - Alkhalifah e Tsvankin (1995), Equação 5 - Ursin e Stovas (2006), Equação 6 - Blias (2009), Equação 7 - Muir e Dellinger (1985) e Equação 8 - Li (2001). 


\begin{tabular}{|c|c|c|c|c|c|c|c|c|c|c|}
\hline & \multicolumn{2}{|c|}{ Modelo 1} & \multicolumn{2}{|c|}{ Modelo 2} & \multicolumn{2}{|c|}{ Modelo 3} & \multicolumn{2}{|c|}{ Modelo 4} & \multicolumn{2}{|c|}{ Modelo 5} \\
\hline & PP & PS & PP & PS & PP & PS & PP & PS & PP & PS \\
\hline Eq. 1 & 0,4174 & 0,8181 & 0,8028 & 1,1658 & 0,3334 & 0,7288 & 0,4029 & 0,8101 & 0,4395 & 0,7925 \\
\hline Eq. 2 & 0,0534 & 0,0980 & 0,1025 & 0,1048 & 0,0229 & 0,0655 & 0,0279 & 0,0655 & 0,0283 & 0,0608 \\
\hline Eq. 3 & 0,1803 & 0,5773 & 0,5313 & 0,9144 & 0,0738 & 0,4546 & 0,1431 & 0,5417 & 0,2023 & 0,5486 \\
\hline Eq. 4 & 0,1423 & 0,3315 & 0,3897 & 0,5780 & 0,0903 & 0,2556 & 0,1209 & ,3126 & 0,1333 & 0,3067 \\
\hline Eq. 5 & 0,0100 & 0,2221 & 0,1900 & 0,5283 & 0,0215 & 0,0833 & 0,0118 & 0,1634 & 0,0073 & 0,1922 \\
\hline Eq. 6 & 0,0355 & 0,0879 & 0,0829 & 0,2992 & 0,0250 & 0,0432 & 0,0222 & 0,0856 & 0,0258 & 0,1005 \\
\hline Eq. 7 & 0,0729 & 0,2157 & 0,2502 & 0,2876 & 0,0670 & 0,1815 & 0,0923 & 0,2009 & 0,1070 & 0,1866 \\
\hline Eq. 8 & 0,0048 & 0,0216 & 0,0223 & 0,0724 & 0,0174 & 0,0264 & 0,0218 & 0,0399 & 0,0255 & 0,0434 \\
\hline
\end{tabular}

Tabela 2: Valores de mínimos globais obtidos considerando as diferentes aproximações, eventos e modelos. Equação 1 - Dix (1955), Equação 2 - Malovichko (1978), Equação 3 - Slotboom et al. (1990), Equação 4 Alkhalifah e Tsvankin (1995), Equação 5 - Ursin e Stovas (2006), Equação 6 - Blias (2009), Equação 7 - Muir e Dellinger (1985) e Equação 8 - Li (2001).

\begin{tabular}{|c|c|c|c|c|c|c|c|c|c|c|}
\hline & \multicolumn{2}{|c|}{ Modelo 1} & \multicolumn{2}{|c|}{ Modelo 2} & \multicolumn{2}{|c|}{ Modelo 3} & \multicolumn{2}{|c|}{ Modelo 4} & \multicolumn{2}{|c|}{ Modelo 5} \\
\hline & PP & PS & PP & PS & PP & PS & PP & PS & PP & PS \\
\hline Eq. 1 & 0,0584 & 0,3152 & 0,3033 & 0,4533 & 0,1186 & 0,2671 & 0,0516 & 0,3124 & 0,1630 & 0,3005 \\
\hline Eq. 2 & 0,0449 & 0,0830 & 0,0906 & 0,0992 & 0,0172 & 0,0513 & 0,0216 & 0,0536 & 0,0227 & 0,0508 \\
\hline Eq. 3 & 0,0708 & 0,2143 & 0,2164 & 0,3523 & 0,0277 & 0,1583 & 0,0560 & 0,1943 & 0,0805 & 0,1980 \\
\hline Eq. 4 & 0,1423 & 0,2779 & 0,3856 & 0,4966 & 0,0903 & 0,2142 & 0,1209 & 0,2594 & 0,1333 & 0,2549 \\
\hline Eq. 5 & 0,0093 & 0,2221 & 0,1730 & 0,5283 & 0,0189 & 0,0833 & 0,0143 & 0,1634 & 0,0060 & 0,1922 \\
\hline Eq. 6 & 0,0290 & 0,0738 & 0,0706 & 0,2719 & 0,0196 & 0,0362 & 0,0201 & 0,0714 & 0,0194 & 0,0823 \\
\hline Eq. 7 & 0,0684 & 0,2013 & 0,2502 & 0,2845 & 0,0600 & 0,1647 & 0,0854 & 0,1867 & 0,1005 & 0,1693 \\
\hline Eq. 8 & 0,0039 & 0,0181 & 0,0190 & 0,0658 & 0,0128 & 0,0203 & 0,0160 & 0,0306 & 0,0192 & 0,0333 \\
\hline
\end{tabular}

Tabela 3: Números de eficiência (adimensional) obtidos considerando as diferentes aproximações, eventos e modelos. Equação 1 - Dix (1955), Equação 2 - Malovichko (1978), Equação 3 - Slotboom et al. (1990), Equação 4 - Alkhalifah e Tsvankin (1995), Equação 5 - Ursin e Stovas (2006), Equação 6 - Blias (2009), Equação 7 - Muir e Dellinger (1985) e Equação 8 - Li (2001). 


\section{CONCLUSÕES}

Dentre as equações testadas, as propostas por Malovichko (1978) e Alkhalifah e Tsvankin (1995) demostraram, de forma evidente, serem unimodais; sendo assim, essas equações podem ser usadas executando-se apenas uma inversão, proporcionando um tempo bem menor de processamento. Por outro lado, equações mais complexas, como as propostas por Muir e Dellinger (1985) e por Li (2001), apresentaram características de multimodalidade em todos os testes observados. Diferentemente, equações como as propostas por Ursin e Stovas (2006) e Blias (2009) apresentam ambas as características. O fato de essas equações serem unimodais ou multimodais é dependente essencialmente do modelo geológico estudado, o que torna o seu uso arriscado em modelos pouco conhecidos.

A análise quantitativa proposta apresentou alguns dados complicados de serem analisados em decorrência da complexidade de algumas equações utilizadas que apresentaram resultados superiores. Apesar disso, ao efetuar a análise desconsiderando as equações mais complexas, é possível extrair resultados proveitosos. Por isso esta análise é fortemente recomendada para modelos em que se utilizam apenas equações que apresentam resultados mais próximos entre si.

As equações propostas por Dix (1955) e Slotboom et al. (1990) não apresentaram bons ajustes e mostraram os piores resultados observados no presente trabalho, algo que era esperado devido à simplicidade dessas equações. Com relação à equação de Alkhalifah e Tsvankin (1995), mesmo sendo uma equação muito utilizada na indústria, foi observado o pior conjunto de resultados se comparados com as equações de três parâmetros, trazendo melhores resultados apenas do que as equações de Dix (1955) e Slotboom et al. (1990). A equação de Muir e Dellinger (1985), além de apresentar um tempo relativamente alto para executar a rotina de inversão, apresentou o segundo pior conjunto de resultados dentre as equações com três parâmetros.

Em virtude das complicações observadas com relação à complexidade da função objetivo das equações propostas por Ursin e Stovas (2006) e Blias (2009), torna-se arriscado utilizá-las em modelos pouco conhecidos. Entretanto, para modelos com mais informações disponíveis, estas equações seriam de grande valia devido aos bons resultados obtidos no 
presente trabalho. Mesmo com um tempo de processamento comparativamente um pouco elevado, elas apresentaram os conjuntos de segundo e terceiro melhores resultados.

A equação de Malovichko (1978) apresentou bons resultados, tendo desempenho semelhante ao da equação de Ursin e Stovas (2006). Ambas tiveram o terceiro melhor conjunto de resultados. Além disso, o fato dessa equação ser unimodal faz com que ela necessite de apenas uma inversão, o que proporciona um ótimo desempenho com relação ao tempo de processamento. Dessa maneira ela é uma equação fortemente recomendada para modelos mais simples.

Apesar de algumas dificuldades encontradas pela equação proposta por Li (2001) em modelos com inversão de velocidades, esta apresentou o melhor conjunto de resultados, não só obtendo os melhores ajustes, como também apresentando um tempo de processamento comparativamente mais baixo dentre as equações com três parâmetros. Desta forma, a equação caracteriza-se como a mais genérica dentre as testadas, lidando muito bem tanto com modelos mais simples como com modelos mais complexos propostos para a Bacia de Santos no presente trabalho. 


\section{REFERÊNCIAS}

AGUDELO, W; PINEDA, E; GOMEZ, R; GUERRERO, J; ROJAS, N; STEWART, R. Using converted- wave seismic data for lithology discrimination in a complex fluvial setting: Tenerife oil field, Middle Magdalena Valley, Colombia. The Leading Edge, v. 32, p. 72-78, 2013.

ALEIXO, R.; SCHLEICHER, J. Traveltime approximations for q-P waves in vertical transversely isotropic media. Geophys. Prospect.Vol. 58, p. 191-201, 2010.

ALIFANOV, O. M. Inverse Heat Transfer Problems. Berlin: Springer, p. 348. 1995.

ALKHALIFAH, T.; TSVANKIN, I. Velocity analysis for transversely isotropic Media. Geophysics, v. 60, p. 1550-1566, 1995.

ASTER, R. C; BORCHERS, B; THURBER, C.H. Parameter estimation and inverse problems. $2^{\text {a }}$ ed. Oxford: Elsevier Science \& Tecnology, 2012.

BLANGY, J. P. Integrated seismic lithology interpretation: The petrophysical basis. Ph.D. Dissertation, Stanford University, 1992.

BLIAS, E. Reflected waves travel-time curve in flat-bedded medium with transverse layers and their interpretation: Soviet Geology and Geophysics, N2, p. 91-95, 1983.

BLIAS, E. Long-offset NMO approximations for a layered VTI model: Model study. In: 79th Annual International Meeting: Society of Exploration Geophysics, 2009. Expanded Abstract..., 2009.

BOKHONOK, O. Sísmica de reflexão rasa multicomponente: Aquisição e inversão de tempos de trânsito e amplitudes. Ph. D. Dissertation, Universidade de São Paulo, 2010.

CADORET, T. Effet de la saturation eau/gaz sur les proprie'te's acoustiques des roches. Ph.D. Dissertation, University of Paris, 1993.

CASTLE, R.J. Shifted hyperbolas and normal moveout. In: 58 th Annual International Meeting: Society of Exploration Geophysics, 1988. Expanded Abstracts..., p. 894-896. 1988.

CASTLE, R. A theory of normal moveout. Geophysics, v. 59, p. 983-999, 1994.

CAUSSE, E.; HAUGEN, G. U.; ROMMEL. B. E. Large-offset approximation to seismic reflection traveltimes. Geophysical Prospecting, v. 48, p. 763-778, 2000.

CHERET, T.; BALE, R.; LEANEY, S. Parameterization of polar anisotropic moveout for converted wave. In: 70th Annual Internat. Mtg., Soc. Expl. Expanded Abstract, p.1181$1184,2000$.

COXETER, H. S. M. Regular Polytopes. London: Methuen, p. 321, 1948. 
DIX, C. H. Seismic velocities from surface measurements: Geophysics, 20, p.68-86, 1955.

DAVIS, T. L. Multicomponent Seismology - The next wave. Geophysics, v. 66, p. 49, 2001.

DUARTE, O. O.Dicionário enciclopédico inglês-português de geofísica e geologia. 4th ed. Rio de Janeiro: Sociedade Brasileira de Geofísica-SBGf, 2010.

FOMEL, S.; GRECHKA, V. On nonhyperbolic reflection moveout in anisotropic media. Standford Exploration Project, p.617-640, 2000.

FOMEL, S.; GRECHKA, V. Nonhyperbolic reflection moveout of $P$ waves. An overview and comparison of reason: Colorado School of Report CWP-372, 2001.

GOLIKOV, P.; STOVAS, A. Accuracy comparison of nonhyperbolic moveout approximations for qP-waves in VTI media. Journal of Geophysics and Engineering. Vol. 9, 428-432, 2012.

GRANLI, J. R; ARNTSEN, B; SOLLID, A; HILDE, E. Imaging through gas-filled sediments with marine S-wave data. Expanded Abstract. 65 ${ }^{\text {th }}$ Ann. Intl. Mtg., SEG, 1995.

GEERTSMA, J. Velocity-log interpretation: The effect of rock bulk compressibility. Soc. Pet.Eng, v. 1, p. 235-248, 1961.

HAN, D. H. Effects of porosity and clay content on acoustic properties of sandstones and unconsolidated sediments. Ph.D. Dissertation. Stanford University, 1986.

HARDAGE, B. A; MURRAY, P. E; ANGELO, M; SAVA, D; ROBERTS, H. H; SHEDD, W; HURT, J. Multicomponent Seismic Technology. Tulsa, Oklahoma: Society of Exploration Geophysicists, 2011.

HORST, R.; PARDALOS, P. M.; THOAI, N. V. Introduction to global optimization. 2nd ed. Dordrecht: Kluwer Academic Publusher, 2000.

JIZBA, D.L. Mechanical and acoustical properties of sandstones and shales. Ph.D. Dissertation, Stanford University, 1991.

KAN, H. A. H. G.; TIMMER, G. T. Stochastic global optimization method part I: Clustering methods. Mathematical Programing, v. 39, p. 27-56, 1987a.

KAN, H. A. H. G.; TIMMER, G. T. Stochastic global optimization method part II: Multi level methods. Mathematical Programing, v. 39, p. 57-78, $1987 \mathrm{~b}$.

KENDALL, R. Advances in Land Multicomponent Seismic Acquisition, Processing and Interpretation. CSEG Recorder - Special Edition, p. 65-75, 2006.

KEAREY, P.; BROOKS, M.; HILL, I. An introduction to geophysical exploration. 3rd ed. Blackwell Science, 2002.

KURT, H. Joint inversion of AVA data for elastic parameters by bootstrapping. Computers \& Geosciences, v. 33, n. 3, p. 367-382, 2007.

LARSEN, J. A. AVO Inversion by Simultaneous P-P and P-S Inversion. 1999. M.Sc. Dissertation, University of Calgary, 1999. 
LEIDERMAN, R; ARTOLA, F. A. V; SILVA, M. B. C; FONTOURA, S. A. B. Exemplo de modelagem sísmica dos modos PP e PS a partir de dados de poço e perfil litológico. $2^{\circ}$ Congresso Brasileiro de P\&D em Petróleo \& Gás, Resumo Expandido, 2003.

LEWIS, R. M.; TORCZON, V.; TROSSET, M. W. Direct search methods: Then and now. ICASE Report, 2000.

LI, X. Y.; Converted-wave moveout analysis revisited: The search for a standard approach. 73rd Annual internat. Mtg. Soc. Expl. Geophysics, Expanded Abstract, p. 805-808, 2003.

LI, X. Y.; YUAN, J. Converted-waves moveout and parameter estimation for transverse isotropy. 61st EAGE Conference, Expanded Abstract, v. 1, p. 4-35, 1999.

LI, X.Y.; YUAN, J. Converted wave imaging in inhomogeneous, anisotropic media: Part I. Parameter estimation. In: 63rdEAGE conference, Expanded Abstract, v. 1, p. 109, 2001.

LI, X. Y.; YUAN, J. Converted-wave moveout and conversion-point equations in layered VTI media: theory and applications. Journal of Applied Geophysics, v. 54, n. 3, 297-318, 2003.

LUCET, N. Vitesse et Attenuation des ondes e'lastiques soniques et ultrasoniques dans les roches sous pression de confinement. Ph.D. Dissertation, University of Paris, 1989.

MALOVICHKO, A. A. A new representation of the traveltime curve of reflected waves in horizontally layered media. Applied Geophysics (in Russian), v. 91, n. 1, p. 47-53, 1978.

MARGRAVE, G. F.; New seismic modellingfacilities in Matlab. CREWES Research Report, v. 12, 2000.

MARGRAVE, G. F.; Numerical methods exploration seismology with algorithms in MATLAB. CREWES Research Report, 2003.

MAVKO, G.; MUKERJI, T.; DVORKIN, J. The rock physics handbook: Tools for seismic analysis of porous media. 2nd ed. Cambridge: Cambridge University Press, 2009.

MEIER, M. A.; LEE, P. J. Converted-wave resolution. Geophysics, v. 74, n. 2, Q1-Q16, 2009.

MUIR, F.; DELLINGER, J. A practical anisotropic system, in SEP-44. Stanford Exploration Project, p. 55-58, 1985.

NELDER, J. A; MEAD, R. A simplex method for function minimization. The Computer Journal, v. 7, p. 308-313, 1965.

PICKETT, G. R. Acoustic character logs and their application in formation evaluation. Journal of Petroleum technology, v. 15, p. 659-667, 1963.

PURNELL, M. A. Conodonts of the Lower Border Group and equivalent strata (Lower Carboniferous) in northern Cumbria and the Scottish Borders. Royal Ontario Museum, Life Science Contributions, Vol. 156, p. 1-79, 1992. 
QIAN, Z; CHAPMAN, M; LI, X. A; DAI, H. C; LIU, E; ZHANG, Y; WANG, Y. Use of multicomponent seismic data for oil-water discrimination in fractures reservoirs. The Leading Edge. Vol. 26, p 1176-1184, 2007.

SHERIFF, R. E.; GELDART, L. P. Exploration seismology. 2nd ed. Cambridge: Cambridge University Press. p. 628, 1995.

SILVA, M. B. C; FILHO, O. K; GUIMARÃES, M. A. G; WINDELS, R; LEIDERMAN, R; ARTOLA, F. A. V; FONTOURA, S. A. B; SOBREIRA, J. F. F. 4-C seismic data processing experience in Brazil. 8th International Congress of the Brazilian Geophysical Society, Expanded Abstract, 2003.

SLOTBOOM, R.T. Converted wave moveout estimation. In: 60 th Annual International Meeting: Society of Exploration Geophysics, 1990. Expanded Abstracts..., 1990. p. 11041106.

SPENDLEY, W.; HEXT, G. R.; HIMSWORTH, F. R. Sequential Application of Simplex Designs in Optimazation and Evolutionary Operation. Technometrics, v. 4, n. 4, p. 441-461, 1962.

SPITZ, S; GRATACOS, B; HAGGARD, W; VUILLERMOZ, C. Reservoir monitoring using multicomponent seismic: Processing the Teal South 4D-4C. SEG/EAGE Summer Research Workshop, 2000.

STEWART, R. R; GAISER, J. E; BROWN, R. J; LAWTON, D. C. Converted-wave seismic exploration: Methods. Geophysics, v. 67, n. 5, p.1348-1363, 2002.

STEWART, R. R; GAISER, J. E; BROWN, R. J; LAWTON, D. C. Converted-wave seismic exploration: Applications. Geophysics, v. 68, n. 1, p. 40-57, 2003.

STIGLER, S. M. Gauss and the invention of least squares. Ann Statist, Vol. 9, p. 465-474, 1981.

STRANDENES, S. Rock physics analysis of the Brent Group reservoir in the Oseberg field. Stanford Rockphysics and Borehole Geophysics Project, special volume. 1991.

TARANTOLA, A. Inverse problem theory and methods for model parameters estimation. 1st ed. Paris: Society for Industrial and Applied Mathematics, 2005.

TERLAKY, T; SOTIROV, R. Multi-start approach to global conic optimization.ISE Archives of Working Papers, 2010.

TERLAKY, T; SOTIROV, R. Multi-start approach for an integer determinant maximization problem. Optimization, v. 61, p. 101-114, 2013.

THOMSEN, L. Weak elastic anisotropy. Geophysics, v. 51, n. 10, p. 1954-1966, 1986.

THORBECKE, J. W; DRAGANOV, D. Finite-difference modeling experiments for seismic interferometry. Geophysics, v. 76, n. 6, p. H1-H18, 2012.

TSVANKIN, I. Seismic Signatures and analysis of reaction data in anisotropic media. Elsevier, 2001. 
TSVANKIN, I.; GRECHKA, V. Dip moveout of converted waves and parameter estimation in transversely isotropic media. Geophysics, v. 48, p. 257-292, 2000a.

TSVANKIN, I.; GRECHKA, V. Two approaches to anisotropic velocity analysis of converted waves. In: 70th Annual Internat. Mtg., Soc. Expl. Expanded Abstrdact, p. 11931196, $2000 b$.

TSVANKIN, I.; THOMSEN, L. Nonhyperbolic reflection moveout in anisotropic media. Geophysics, v. 59, p. 1290-1304, 1994.

URSENBACH, C.; CARY, P.; PERZ, M. Limits on resolution enhancement for PS data mapped to PP time. The Leading Edge, v. 32, n. 1, p. 64-71, 2013.

URSIN, B.; STOVAS, A. Traveltime approximations for a layered transversely isotropic medium. Geophysics, v. 71, p. 23-33, 2006.

WANG, P. L.; JUNFENG, C. Y.; HU, T. Converted-wave imaging technology and application for complex structures. Exploration Geophysics, 2014.

YALE, D. P.; JAMEISON, W.H., Jr. Static and dynamic rock mechanical properties in the Hugoton and Panoma fields. In: Society of Petroleum Engineers Mid-Continent Gas Symposium, Expanded Abstract, 1994.

YILMAZ, O. Seismic data analysis: Processing, inversion, and interpretation of seismic data. 2nd ed. Tulsa: Society of Exploration Geophysicists. Vol. 1, 2001.

YUAN, J. Analysis of four-component seaoor seismic data for seismic anisotropy. Ph.D. Dissertation, University of Edinburgh, 2002.

YUAN, J.; LI, X. Y. Converted wave anisotropic parameter estimation from conversion point. In: 64rd EAGE conference, Expanded Abstract, v. 2, p. 253, 2002. 